CENTRO UNIVERSITÁRIO FEI

WELLINA MISSASSI FANTIM

APLICAÇÃO DE ÓXIDOS MISTOS DE MOLIBDÊNIO, VANÁDIO, TUNGSTÊNIO

E COBRE COMO CATALISADORES NA PRODUÇÃO DO ÁCIDO ACRÍLICO

São Bernardo do Campo 
WELLINA MISSASSI FANTIM

\title{
APLICAÇÃO DE ÓXIDOS MISTOS DE MOLIBDÊNIO, VANÁDIO, TUNGSTÊNIO E COBRE COMO CATALISADORES NA PRODUÇÃO DO ÁCIDO ACRÍLICO
}

\begin{abstract}
Dissertação apresentada ao Centro Universitário FEI, como parte dos requisitos necessários para obtenção do título de Mestre em Engenharia Química. Orientado pelo Prof. Dr. João Guilherme Rocha Poço.
\end{abstract}

São Bernardo do Campo 
Missassi Fantim, Wellina.

Aplicação de óxidos mistos de molibdênio, vanádio, tungstênio e cobre como catalisadores na produção do ácido acrílico / Wellina Missassi

Fantim. São Bernardo do Campo, 2020.

119 f. : il.

Dissertação - Centro Universitário FEI.

Orientador: Prof. Dr. João Guilherme Rocha Poço.

1. Ácido Acrílico. 2. Catalisadores. 3. Tratamento Hidrotérmico. I. Rocha Poço, João Guilherme, orient. II. Título.

Elaborada pelo sistema de geração automática de ficha catalográfica da FEI com os dados fornecidos pelo(a) autor(a). 
Aluno: Wellina Missassi Fantim

Matrícula: 418114-5

Título do Trabalho: Aplicação de óxidos mistos de molibdênio, vanádio, tungstênio e cobre como catalisadores na produção de ácido acrílico.

Área de Concentração: Engenharia Química

Orientador: Prof. Dr. João Guilherme Rocha Poço

Data da realização da defesa: $18 / 02 / 2020$

\section{ORIGINAL ASSINADA}

Avaliação da Banca Examinadora:

São Bernardo do Campo,

\section{MEMBROS DA BANCA EXAMINADORA}

Prof. Dr. João Guilherme Rocha Poço

Prof. Dr. Ronaldo Gonçalves dos Santos

Prof. Dr. Reinaldo Giudici
Ass.:

Ass.:

Ass. :

A Banca Julgadora acima-assinada atribuiu ao aluno o seguinte resultado:
REPROVADO

\section{VERSÃO FINAL DA \\ DISSERTAÇÃO}

APROVO A VERSÃO FINAL DA DISSERTAÇÃO EM QUE FORAM INCLUÍDAS AS RECOMENDAÇÕES DA BANCA EXAMINADORA
Aprovação do Coordenador do Programa de Pós-graduação

Prof. Dr. Ricardo Belchior Torres 
Dedico este trabalho aos meus pais, irmãs e toda a minha família que me deram todo o apoio e não mediram esforços para que chegasse até esta etapa da minha vida 


\section{AGRADECIMENTOS}

Aos meus pais, irmãs e a toda a minha família que me deram todo o apoio nos momentos em que mais precisei;

Ao meu orientador, Prof. Dr. João Guilherme Rocha Poço, que esteve ao meu lado durante todo o desenvolvimento do projeto e não mediu esforços para que pudéssemos concluir essa etapa juntos;

Aos meus amigos que me apoiaram na realização dessa etapa da minha vida;

Ao Centro Universitário da FEI pela oportunidade de participar do programa de mestrado em Engenharia Química e todos os professores e técnicos de laboratório que me deram toda a ajuda necessária para que eu pudesse concluir esse projeto;

Ao IPT (Instituto de Pesquisas Tecnológicas de São Paulo) e todos os seus funcionários que me deram todo o suporte para a realização dos testes catalíticos;

Ao LMA-IQ pela disponibilidade de utilização do microscópio eletrônico de varredura de alta resolução utilizado no presente trabalho;

À CAPES pela concessão da bolsa que tornou possível meu ingresso ao programa de mestrado da FEI - O presente trabalho foi realizado com o apoio do Coordenação de Aperfeiçoamento de Pessoal de Nível Superior Brasil (CAPES) - Código de Financiamento 001 . 
“Talvez não tenha conseguido fazer o melhor, mas lutei para que o melhor fosse feito. Não sou o que deveria ser, mas graças a Deus, não sou o que era antes". (Marthin Luther King). 


\section{RESUMO}

O ácido acrílico é um produto com diversas aplicações na indústria química, sendo uma das principais a produção do poliacrilato de sódio, um material superabsorvente utilizado na fabricação de artigos de higiene pessoal. Atualmente o ácido acrílico é obtido a partir da oxidação do propeno empregando catalisadores heterogenêos baseados em óxidos de $\mathrm{Mo} / \mathrm{Bi}$ e Mo/V. Nesse processo, primeiramente o propeno é oxidado a acroleína, que em seguida é oxidada formando o ácido acrílico. Apesar deste já ser um processo consolidado, o propeno é proveniente de fontes petroquímicas e assim há a preocupação em se buscar por rotas alternativas ao uso desta matéria-prima e uma das possibilidades é sintetizar a acroleína a partir da desidratação do glicerol utilizando catalisadores específicos. Durante o desenvolvimento do projeto foram preparados catalisadores heterogenêos para a obtenção do ácido acrílico, primeiramente avaliados na oxidação da acroleína e posteriormente na oxidesidratação do glicerol. Foram sintetizados três tipos de amostras com composições diferentes (B1$\mathrm{Mo}_{12} \mathrm{~V}_{4,8} \mathrm{~W}_{2,4} \mathrm{Cu}_{2,2} \mathrm{Si}_{8,4} ; \quad \mathrm{B} 2-\mathrm{Mo}_{12} \mathrm{~V}_{2} \mathrm{~W}_{0,5} \mathrm{Si}_{6,2}$ e $\left.\mathrm{B} 3-\mathrm{Mo}_{12} \mathrm{~V}_{2,7} \mathrm{Si}_{6,2}\right)$ por quatro métodos de preparo, sendo eles por evaporação, evaporação seguido de tratamento hidrotérmico, tratamento hidrotérmico $(\mathrm{TH})$ e utilizando um copolímero de blocos. Para os dois últimos métodos foi realizado um estudo mais detalhado para a determinação das melhores condições de síntese (Etapa I), e foi verificado que a dissolução total dos reagentes na mistura antes do TH resultou em amostras com maior cristalinidade e menor perda de fase ativa no líquido mãe e a utilização de um copolímero de blocos dissolvido a frio contribuiu para um aumento no volume de poros. $\mathrm{Na}$ segunda etapa, os materiais sintetizados pelos quatro métodos propostos foram caracterizados e avaliados em reator na produção do ácido acrílico. As amostras B1 apresentaram formação de fases cristalinas diferentes dependendo do método de preparo utilizado, e nas amostras B2 e B3 foi identificada como fase principal o $\alpha-\mathrm{MoO}_{3}$, independentemente do método utilizado. As amostras sintetizadas por evaporação seguida por TH foram as que apresentaram maiores seletividades para a formação do ácido acrílico a partir da acroleína para uma mesma composição de catalisador, o que pode estar relacionada ao maior teor de óxido de vanádio presente nas amostras identificadas por FRX e a formação da fase cristalina $\mathrm{V}_{0,35} \mathrm{Mo}_{4,65} \mathrm{O}_{14}$. O melhor desempenho foi observado na amostra $\mathrm{B} 1-\mathrm{EV}+\mathrm{TH}$ com seletividade de 50,59\% e 3,61\% para o ácido acrílico nos processos a partir da acroleína e glicerol, respectivamente.

Palavras-chave: Ácido acrílico. Catalisadores heterogêneos. Tratamento hidrotérmico. 


\begin{abstract}
Acrylic acid is a product with several applications in the chemical industry, the main one is the production of sodium polyacrylate, a superabsorbent material used in the toiletries manufacture. Currently acrylic acid is obtained from propene oxidation using heterogeneous $\mathrm{Mo} / \mathrm{Bi}$ and $\mathrm{Mo} / \mathrm{V}$ oxide-based catalysts. In this process, propene is first oxidized to acrolein, which is then oxidized to acrylic acid. Although this is already a consolidated process, propylene comes from petrochemical sources and thus there is a concern to search for alternative routes to the use of this raw material and one of the possibilities is to synthesize acrolein from glycerol dehydration using specific catalysts. For the project, heterogeneous catalysts were prepared to obtain the acrylic acid, first evaluated in the oxidation of acrolein and later in the glycerol oxideshydration. Three types of samples were synthesized with different compositions B1- $\mathrm{Mo}_{12} \mathrm{~V}_{4,8} \mathrm{~W}_{2,4} \mathrm{Cu}_{2,2} \mathrm{Si}_{8,4} ; \mathrm{B} 2-\mathrm{Mo}_{12} \mathrm{~V}_{2} \mathrm{~W}_{0,5} \mathrm{Si}_{6,2}$ and $\left.\mathrm{B} 3-\mathrm{Mo}_{12} \mathrm{~V}_{2,7} \mathrm{Si}_{6,2}\right)$ by four preparation methods, namely by evaporation, evaporation followed by hydrothermal treatment, hydrothermal treatment $(\mathrm{TH})$ and using a block copolymer. For the last two methods a more detailed study was performed to determine the best synthesis conditions (Phase I), and it was found that the total dissolution of the reagents in the mixture before TH resulted in samples with higher crystallinity and less active phase loss in the liquid and the use of a cold dissolved block copolymer contributed to an increase in pore volume. In the second stage, the materials synthesized by the four proposed methods were characterized and evaluated in reactor in acrylic acid production. The samples B1 showed different crystalline phase formation depending on the preparation method used, and in samples B2 and B3 the main phase was identified as $\alpha-\mathrm{MoO}_{3}$, regardless of the method used. The samples synthesized by evaporation followed by TH showed the highest selectivity for acrylic acid formation from acrolein for the same catalyst composition, which may be related to the higher vanadium oxide content present in samples identified by FRX and the formation of the crystalline phase $\mathrm{V}_{0.35} \mathrm{Mo}_{4,65} \mathrm{O}_{14}$. The best performance was observed in sample B1-EV+TH with selectivity of $50.59 \%$ and $3.61 \%$ for acrylic acid in the processes from acrolein and glycerol, respectively.
\end{abstract}

Keywords: Acrylic Acid. Heterogeneous catalysts. Hydrothermal treatment. 


\section{LISTA DE ILUSTRAÇÕES}

Figura 1 - Fórmula estrutural do ácido acrílico

Figura 2 - Principais países consumidores de ácido acrílico em 2016

Figura 3 - Representação do processo de obtenção de ácido acrílico da Sohio (hoje BP America) -Nippon-Kayaku .

Figura 4 - Esquematização da reação de oxidação seletiva da acroleína e a reoxidação do catalisador

Figura 5 - Esquema da migração de oxigênio ativo num catalisador multicomponente 30

Figura 6 - Mecanismo de oxidação de propeno a acroleína sobre catalisadores baseados em óxidos de Bi e Mo

Figura 7 - Mecanismo de oxidação de acroleína a ácido acrílico sobre catalisadores baseados em óxidos de $\mathrm{V}$, Mo e $\mathrm{P}$

Figura 8 - Modelo de célula unitária na projeção [001] de $\mathrm{Mo}_{7.5} \mathrm{~V}_{2.2} \mathrm{Nb}_{1.5} \mathrm{Te}_{0.9} \mathrm{O}_{\mathrm{x}}$ mostrando quatro sítios catalíticos em isolamento

Figura 9 - Mistura obrigatória de biodiesel de 2005 a 2019. .35

Figura 10 - Cronograma do aumento da mistura de biodiesel nos próximos anos...................36

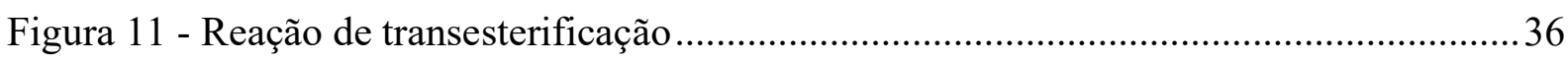

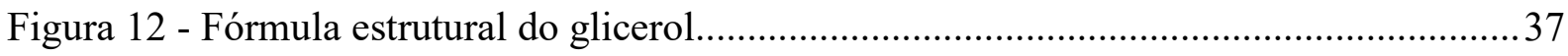

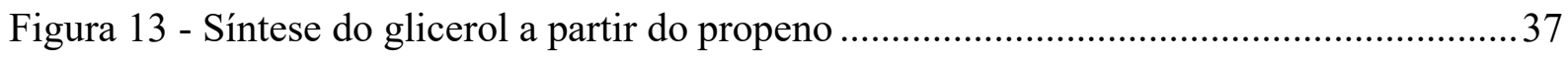

Figura 14 - Aplicações do glicerol e seus derivados ............................................................... 38

Figura 15 - Reação de eterificação entre o glicerol e o etanol................................................39

Figura 16 - Representação da reação do glicerol com ácido graxo para a síntese do

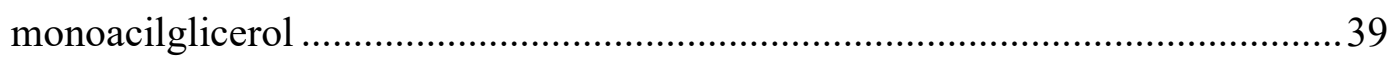

Figura 17 - Produtos de oxidação do glicerol ........................................................................ 40

Figura 18 - Reações de desidratação do glicerol ................................................................... 41

Figura 19 - Processo em uma e duas etapas para obtenção do ácido acrílico a partir do glicerol

Figura 20 - Fórmula estrutural do copolímero blocos Pluronic ${ }^{\circledR}$ P123 ….............................44

Figura 21 - Amostras B sintetizadas para caracterizações preliminares ...................................45

Figura 22 - Fluxograma base para a preparação da amostra B1 ...........................................46

Figura 23 - Fluxograma base para a preparação da amostra B2 ...........................................47

Figura 24 - Fluxograma base para a preparação da amostra B3 .............................................48

Figura 25 - Autoclave de Teflon para a realização do TH ......................................................50 
Figura 26 - Resumo das amostras testadas em reator

Figura 27 - Processo catalítico para a obtenção do ácido acrílico .54

Figura 28 - Esquematização do reator utilizado no processo e corte lateral .............................56

Figura 29 - Esquematização do tubo do reator onde é inserido o catalisador ..........................56

Figura 30 - Misturas iniciais antes de seguir para o tratamento hidrotérmico. A figura (a.) corresponde a amostra B1, (b.) a amostra B2 e (c.) a amostra B3

Figura 31 - Espectrogramas na região do infravermelho das amostras B1 (a.), B2 (b.) e B3 (c.) das amostras preparadas na etapa 1

Figura 32 - Comparação dos espectrogramas obtidos para as amostras B1 e B2 da etapa 1 com padrões de $\mathrm{MoO}_{3}, \mathrm{~V}_{2} \mathrm{O}_{5}$ e $\mathrm{WO}_{3}$ na faixa espectral de $400-4000 \mathrm{~cm}^{-1}$ (a) e de 400 $1900 \mathrm{~cm}^{-1}(\mathrm{~b})$.

Figura 33 - Difração de raios-X das amostras B1 (a.), B2 (b.) e B3 (c.) preparadas na etapa 1 e comparação com padrões (d.)

Figura 34 - Isotermas de adsorção-dessorção de nitrogênio das amostras B2. (•)-Curva obtida durante a adsorção do $\mathrm{N}_{2}$ e ( $\left.\boldsymbol{\Delta}\right)$-Curva obtida durante a dessorção

Figura 35 - Imagens obtidas por MEV das amostras (a.) B2 preparadas por TH-ET, (b.) com polímero a frio e (c.) polímero a quente com ampliação de x15.000 e x50.000 ...70

Figura 36 - Espectrogramas na região do infravermelho das amostras B1 (a.), B2 (b.) e B3 (c.) e variações da amostra B1 (d.) testadas em reator..............................................77

Figura 37 - Análise de difração de raios-X das amostras B1 (a.), B2 (b.) e B3 (c.) e variações da amostra B1 (d.) testadas em reator.

Figura 38 - Comportamento da reação de oxidação da acroleína em função do tempo acompanhando parâmetros de temperatura, conversão de $\mathrm{O} 2$ e massa de produto recolhido

Figura 39 - Resultados de conversão e seletividade para as amostras B1 preparadas por EV, TH e EV+TH avaliadas na oxidação da acroleína .83

Figura 40 - Resultados de conversão e seletividade para as amostras B2 preparadas TH e EV+TH avaliadas na oxidação da acroleína . .84

Figura 41 - Resultados de conversão e seletividade para as amostras B3 preparadas TH e EV+TH avaliadas na oxidação da acroleína .....

Figura 42 - Resultados catalíticos para as variações do catalisador B1 (B1.2 e B1.3) avaliados na oxidação da acroleína em fase gasosa..... 86

Figura 43 - Resultados Catalíticos para a amostra sintetizada na presença de Pluronic P123.87 
Figura 44 - Seletividade da reação de oxirredução do glicerol em fase gasosa na presença dos catalisadores propostos no trabalho.

Figura 45 - Cromatógrafo utilizado para análise dos produtos formados ..............................99

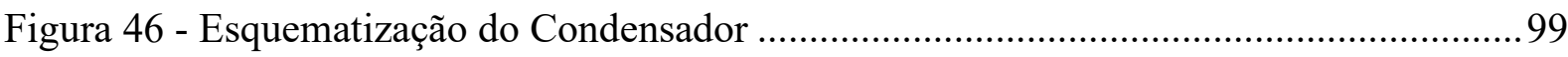

Figura 47 - Curva para calibração do controlador para o ar sintético ..................................... 100

Figura 48 - Curva para calibração do controlador para o nitrogênio....................................... 100

Figura 49 - Curva dos padrões para quantificação dos componentes condensáveis na saída do processo por CG no detector FID.

Figura 50 - Cromatograma obtido na injeção de uma amostra padrão contendo os principais componentes dos produtos de saída do processo.............................................. 103

Figura 51 - Cromatograma obtido na injeção do gás da saída do processo............................ 104

Figura 52 - Curva de calibração para a quantificação da acroleína residual no gás na saída do processo 104

Figura 53 - Curva dos padrões para a quantificação dos gases na saída do processo por CG no detector TCD. 106

Figura 54 - Exemplo de cromatograma obtido nas análises no TCD 107

Figura 55 - Bandas características de diferentes molibdatos metálicos 118

Figura 56 - Bandas características de diferentes tungstatos metálicos 118 


\section{LISTA DE TABELAS}

Tabela 1 - Condições de reação nos processos de obtenção de ácido acrílico em uma e duas etapas

Tabela 2 - Conteúdo dos catalisadores multifásicos baseados em molibdato de bismuto .......25

Tabela 3 - Catalisadores para oxidação de acroleína a ácido acrílico ...................................27

Tabela 4 - Volumes de água utilizados nas preparações das variações da amostra B1 ............46

Tabela 5 - Volumes de água utilizados nas preparações das variações da amostra B2 ...........47

Tabela 6 - Volumes de água utilizados nas preparações das variações da amostra B3 ............48

Tabela 7 - Condições de alimentação do processo para a obtenção de ácido acrílico .............57

Tabela 8 - Rendimentos de sólidos na produção dos catalisadores ........................................60

Tabela 9 - Resultados de área específica e porosidade obtidos por fisissorção com $\mathrm{N}_{2}$ para as amostras preliminares B1, B2 e B3 sintetizadas por tratamento hidrotérmico ........68

Tabela 10 - Composições em \%massa das amostras B1 ........................................................73

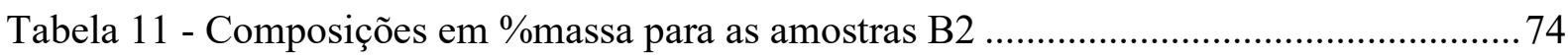

Tabela 12 - Composições em \%massa para as amostras B3 .................................................74

Tabela 13 - Composições em \%massa para as amostras B1.2 …......................................... 75

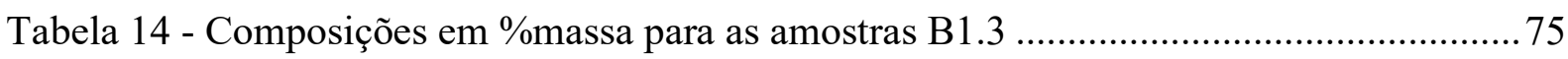

Tabela 15 - Composições em \%massa para a amostra B1 com P123 …................................76

Tabela 16 - Resultados de área específica e porosidade obtidos por fisissorção com $\mathrm{N}_{2}$ para as

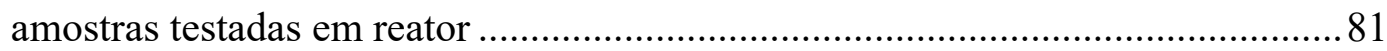

Tabela 17 - Resultados da literatura para a reação de desidratação oxidativa do glicerol .......89

Tabela 18 - Resultados de conversão e seletividades para os ensaios sem catalisador .............90

Tabela 19 - Erros no balanço de carbono (\%) para testes com o glicerol ...............................90

Tabela 20 - Dados para a calibração do controlador para o ar sintético................................. 100

Tabela 21 - Dados para a calibração do controlador de gás nitrogênio .................................... 100

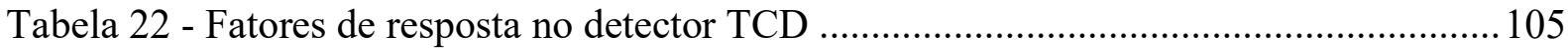

Tabela 23 - Determinação do fator de resposta para análises no TCD................................... 106

Tabela 24 - Cálculos de conversão e seletividade amostrar B1-EV e B1-TH........................ 108

Tabela 25 - Cálculos de conversão e seletividade para as amostras B2-TH e B3-TH ........... 109

Tabela 26 - Cálculos de conversão e seletividade para as amostras B1-EV+TH e B2-EV+TH

Tabela 27 - Cálculos de conversão e seletividade para as amostras B3-EV+TH e B1-P123-F 
Tabela 28 - Cálculos de conversão e seletividade para as amostras B1.2-EV e B1.2-EV+TH 112

Tabela 29 - Cálculos de conversão e seletividade para as amostras B1.3-EV+TH.................113

Tabela 30 - Cálculos de conversão e seletividade para as reações com glicerol (1) ...............114

Tabela 31 - Cálculos de conversão e seletividade para as reações com glicerol (2) ...............115

Tabela 32 - Dados de conversão e seletividade para os testes com acroleína sem catalisador 116

Tabela 33 - Dados de conversão e seletividade para os testes com glicerol sem catalisador.117 


\section{LISTA DE SÍMBOLOS}

$\mathrm{M}^{\mathrm{I}} \quad$ Símbolo genérico que pode representar os $\mathrm{Co}, \mathrm{Ni}, \mathrm{Fe}, \mathrm{Mg}, \mathrm{Mn}$ na fórmula molecular dos catalisadores

$\mathrm{M}^{\mathrm{II}} \quad$ Símbolo genérico que pode representar os $\mathrm{Fe}, \mathrm{Cr}, \mathrm{Al}$ (especialmente o $\mathrm{Fe}$ ) na fórmula molecular dos catalisadores

$\mathrm{M}^{\mathrm{III}} \quad$ Símbolo genérico que pode representar os $\mathrm{K}, \mathrm{Na}, \mathrm{Cs}$, Tl na fórmula molecular dos catalisadores

X Símbolo genérico que pode representar os $\mathrm{Sb}, \mathrm{Nb}, \mathrm{V}, \mathrm{W}, \mathrm{Te}$ na fórmula molecular dos catalisadores

Y Símbolo genérico que pode representar os $\mathrm{P}, \mathrm{B}$ na fórmula molecular dos catalisadores

B2 - B15 Nomenclatura dada ao teor da mistura de biodiesel ao diesel de petróleo, variando entre $2 \%$ e $15 \%$.

B1 Amostra de catalisador sintetizada com composição $\mathrm{Mo}_{12} \mathrm{~V}_{4,8} \mathrm{~W}_{2,4} \mathrm{Cu}_{2,2} \mathrm{Si}_{8,4}$

B2 Amostra de catalisador sintetizada com composição $\mathrm{Mo}_{12} \mathrm{~V}_{2} \mathrm{~W}_{0,5} \mathrm{Si}_{6,2}$

B3 Amostra de catalisador sintetizada com composição $\mathrm{Mo}_{12} \mathrm{~V}_{2,7} \mathrm{Si}_{6,2}$

(B) Marca registrada

P123 Copolímero blocos poly(ethylene glycol)-block-poly(propylene glycol)block-poly(ethylene glycol)

TH Tratamento hidrotérmico

E0 Nomenclatura da amostra sintetizada com copolímero e evaporação do solvente

EP Amostra sintetizada com o copolímero e evaporação parcial do solvente

ET Amostra sintetizada com o copolímero e evaporação total do solvente

$\mathrm{X}_{\text {reagente } \quad \text { Conversão do reagente na reação }}$

Si Seletividade para os produtos da reação

Ri Rendimento da reação

Z Representação dos elementos $\mathrm{C}, \mathrm{O}, \mathrm{H}, \mathrm{N}$ no balanço da reação 


\section{SUMÁRIO}

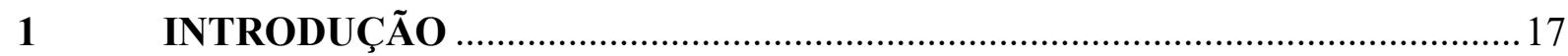

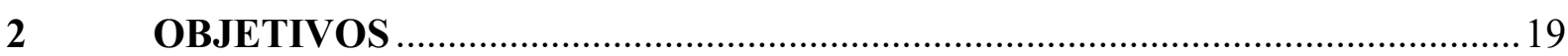

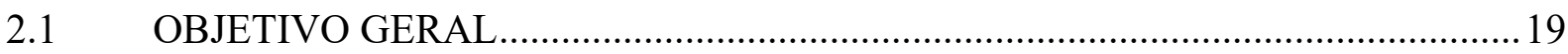

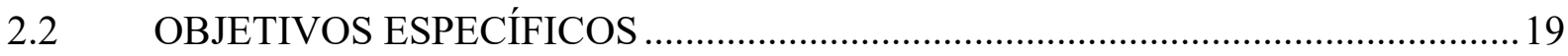

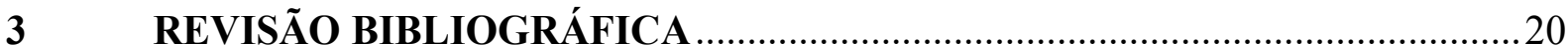

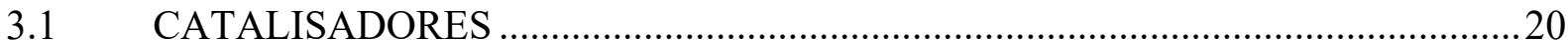

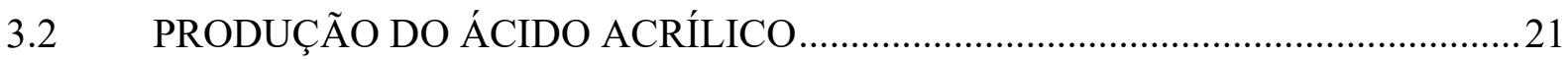

3.3 OBTENÇÃO DO ÁCIDO ACRÍLICO A PARTIR DO PROPENO .........................23

3.3.1 Catalisadores para a produção de acroleína a partir do propeno ......................25

3.3.2 Catalisadores para a produção de ácido acrílico a partir da acroleína .............26

3.4 CATALISADORES PARA OXIDAÇÃO SELETIVA …..........................................28

3.4.1 Arranjamento espacial dos átomos de oxigênio...............................................29

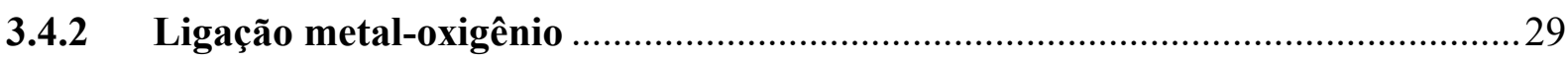

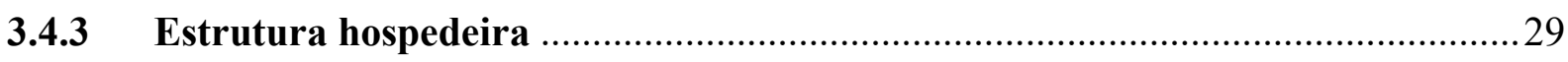

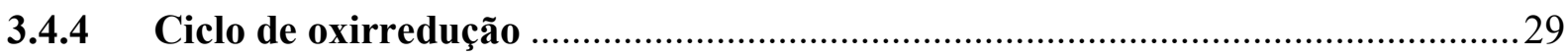

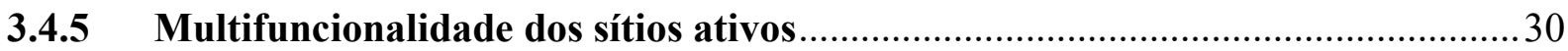

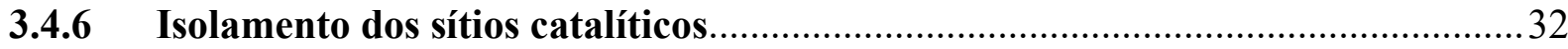

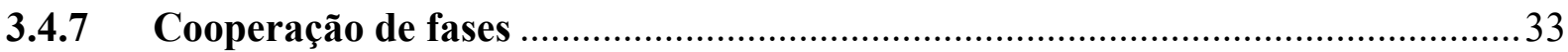

3.5 PRODUÇÃO DE BIODIESEL E MOTIVAÇÃO PARA O USO DO GLICEROL 34

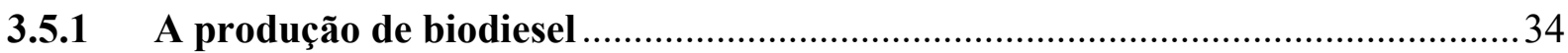

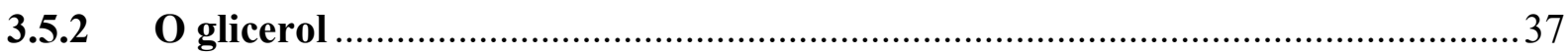

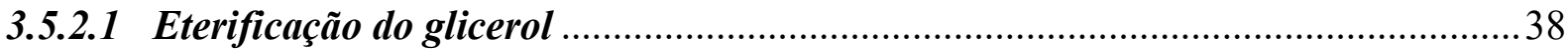

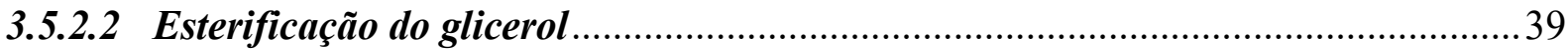

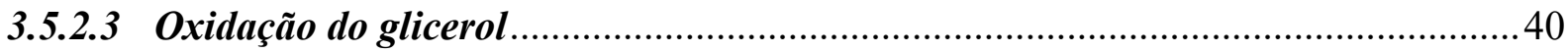

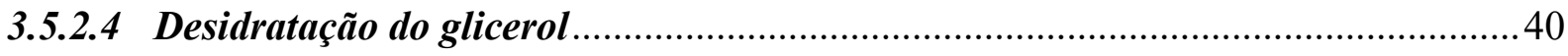

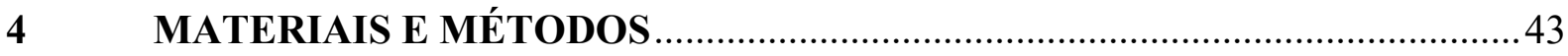

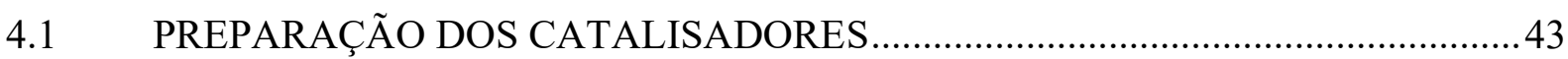


4.1.1 Etapa I - Estudo da metodologia de síntese via tratamento hidrotérmico 44

4.1.2 Etapa II - Preparação das amostras pelos diferentes métodos de síntese para os testes em reator 50

4.2 CARACTERIZAÇÕES FÍSICO-QUÍMICAS DOS CATALISADORES ...............52

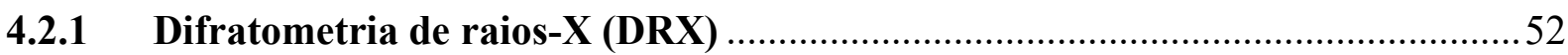

4.2.2 Espectroscopia na região do infravermelho (FTIR) …......................................52

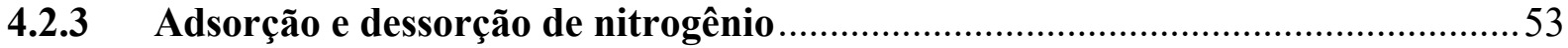

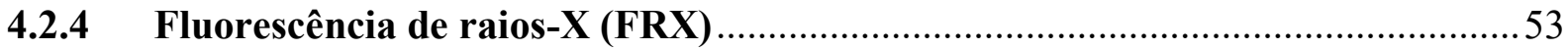

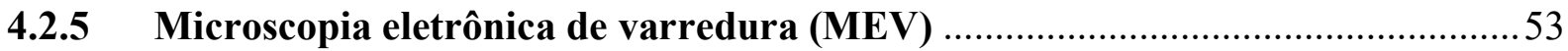

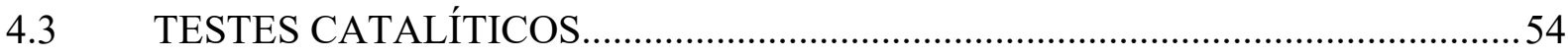

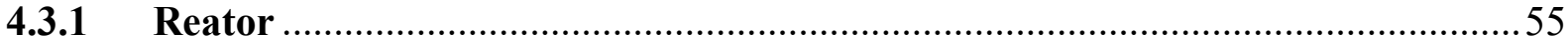

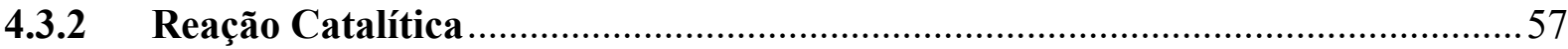

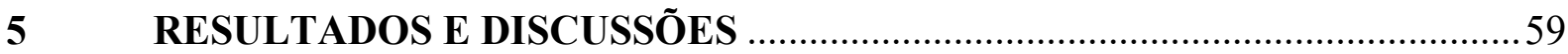

5.1 ETAPA I - ESTUDO DA METODOLOGIA DE SÍNTESES VIA TRATAMENTO

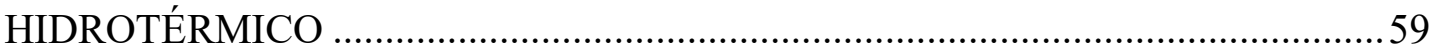

5.1.1 Análises por transformada de Fourier na região da infravermelho (FTIR) ......62

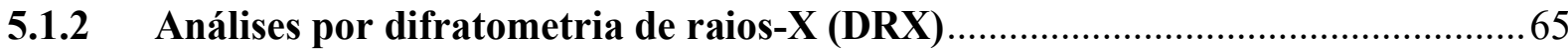

5.1.3 Análise de fisissorção de $\mathrm{N}_{2}$ para determinação de área específica e porosidade ..

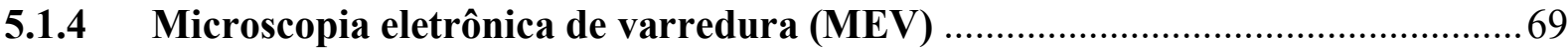

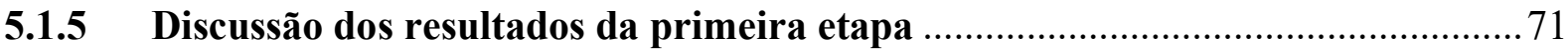

5.2 ETAPA II - AMOSTRAS SINTETIZADAS PELOS DIFERENTES MÉTODOS DE PREPARO PARA A AVALIAÇÃO CATALÍTICA...............................................72

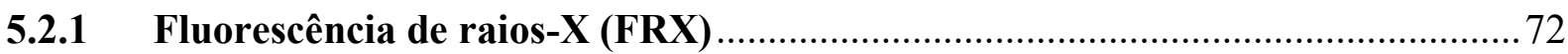

5.2.2 Análises por transformada de Fourier na região da infravermelho (FTIR) ......76

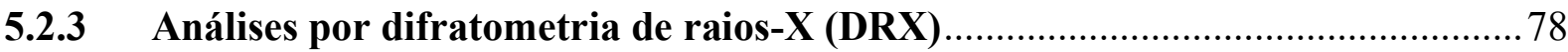

5.2.4 Análise de fisissorção de N2 para determinação de área específica e porosidade.. 80

5.2.5 Avaliação catalítica dos materiais na obtenção do ácido acrílico 81 


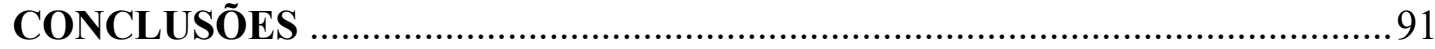

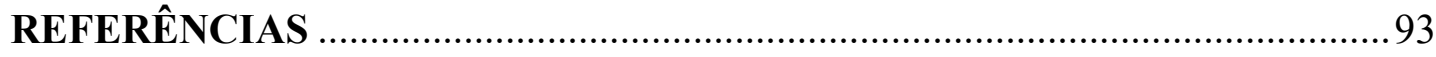

APÊNDICE A- EQUIPAMENTOS UTILIZADOS NO TESTE CATALÍTICO

.99

APÊNDICE B- DADOS AUXILIARES PARA A CROMATOGRAFIA GASOSA 101

APÊNDICE C- CÁLCULOS DE CONVERSÃO E SELETIVIDADE 108 ANEXO A - REFERÊNCIAS DE APOIO PARA ANALISES DE FTIR E DRX 


\section{INTRODUÇÃO}

O ácido acrílico é um produto com diversas aplicações na indústria química, sendo uma das principais a produção do poliacrilato de sódio, um material superabsorvente utilizado na fabricação de artigos de higiene pessoal, como fraldas e absorventes íntimos (LIN, 2001).

Atualmente, o processo mais viável comercialmente para a produção do ácido acrílico é a partir da oxidação do propeno. Nesse processo, primeiramente o propeno é oxidado a acroleína utilizando catalisadores contendo como fase ativa os óxidos de molibdênio e bismuto. Em seguida a acroleína é oxidada, levando a formação do ácido acrílico, na presença de óxidos de molibdênio e vanádio (GRASSELLI, TRIFIRO, 2017).

Apesar deste já ser um processo consolidado aplicado industrialmente, o propeno é uma matéria-prima proveniente de fontes petroquímicas e, de maneira geral, a sociedade contemporânea ainda é muito dependente dos derivados de origem fóssil. Nesse contexto surge todo o interesse em se buscar por rotas alternativas ao uso de matérias-primas não renováveis, e uma das possibilidades é a utilização da biomassa.

Estudos voltados para a utilização do glicerol como matéria prima para a produção de ácido acrílico tem ganhado atenção nos últimos anos devido a grande disponibilidade do glicerol no mercado mundial, um subproduto gerado durante a produção do biodiesel. Estimase que $1 \mathrm{~kg}$ do produto seja formado a cada $10 \mathrm{~kg}$ de biodiesel produzido, e por isso é imprescindível sua utilização para a obtenção de produtos com maior valor agregado (BEZERRA, ALTINO, SPARES, 2019; STOSIC, 2014).

Catalisadores heterogêneos contendo como fase ativa os óxidos de molibdênio e vanádio se mostraram eficientes na conversão do glicerol a ácido acrílico em estudos anteriores. Tais catalisadores apresentam tanto sítios ácidos que permitem a desidradação do glicerol em acroleína, quanto sítios redox nos quais ocorre a oxidação da acroleína a ácido acrílico, o que permite que a reação ocorra em uma único etapa, garantindo uma maior eficiência econômica e energética do processo (POSSATO et al., 2017; FANTIM et al., 2017).

No presente trabalho, foram sintetizados catalisadores baseados em metodologias decritas em patentes em domínio público que mostraram bons resultados de conversão e seletividade para o ácido acrílico em trabalho anterior (FANTIM et al., 2017). Esses catalisadores continham como fase principal os óxidos de molibdênio, vanádio e também outros metais como tungstênio, cobre e estanho adicionados para melhorar o desemenho dos materiais. Os catalisadores contendo molibdênio, vanádio, tungstênio e cobre suportados em sílica foram sintetizados via tratamento hidrotérmico e coprecipitação para avaliar como tais técnicas de 
preparo influenciam nas propriedades físico-químicas e morfológicas dos materiais e também na seletidade para a obtenção do ácido acrílico. Por fim, foi utilizado também um copolímero blocos Pluronic ${ }^{\circledR}$ P-123 durante a preparação para a obtenção de materiais com poros de maior dimensão. 


\section{OBJETIVOS}

Nos itens 2.1 e 2.2 estão descritos os objetivos gerais e específicos propostos no presente trabalho.

\subsection{OBJETIVO GERAL}

O projeto de pesquisa tem como objetivo principal a síntese de catalisadores heterogêneos que apresentam como fase ativa compostos como molibdênio, vanádio e outros metais, para reações de oxidação seletiva para obtenção do ácido acrílico.

\subsection{OBJETIVOS ESPECÍFICOS}

A fim de se atingir o objetivo geral proposto, verifica-se a necessidade de:

- Sintetizar catalisadores que se mostraram promissores na reação de formação do ácido acrílico por três diferentes métodos de preparação, sendo eles por evaporação, via tratamento hidrotérmico e por evaporação seguida por tratamento hidrotérmico;

- Determinar as melhores condições de síntese via tratamento hidrotérmico, na presença ou não de um copolímero blocos;

- Realizar as caracterizações físico-química dos catalisadores produzidos (composição, morfologia, área específica, entre outros);

- Avaliar como os diferentes métodos de preparação influenciam nas propriedades físicoquímicas e morfológica dos materiais;

- Avaliar a atividade catalítica dos materiais em reator no processo de obtenção do ácido acrílico a partir da oxidação da acroleína e oxidesidratação do glicerol. 


\section{REVISÃO BIBLIOGRÁFICA}

Fundamentos teóricos para o desenvolvimento do trabalho.

\subsection{CATALISADORES}

Catalisadores são substâncias que possibilitam e facilitam a conversão dos reagentes em produtos desejáveis, e sempre são regenerados ao seu estado inicial ao final de cada ciclo, até a sua desativação. Eles não participam do balanço material de uma reação química, apenas alteram sua cinética, não influenciando em sua termodinâmica e equilíbrio químico (SCHMAL, 2011; DUMESIC, HUBER, BOUDART, 2008).

A principal função dos catalisadores é a diminuição da energia de ativação de uma reação. Para que uma reação ocorra, é necessário que o sistema chegue a um alto estado de energia capaz de quebrar as ligações químicas do reagente, permitindo assim a formação dos produtos. Os catalisadores facilitam essas quebras de ligações devido a sua interação com as moléculas de reagente, e assim é necessário o fornecimento de uma menor quantidade de energia para a ocorrência da reação (FOGLER, 2009).

Os catalisadores podem ser classificados como homogêneos, quando estão no mesmo estado físico que os reagentes e produtos, ou heterogêneos, quando em fases diferentes. Nesse caso, a separação e reutilização do catalisador são facilitadas. Os catalisadores heterogêneos geralmente são sólidos porosos que possuem elevada área superficial, na qual estão distribuídos seus centros ativos, locais onde ocorrem as reações químicas (SCHMAL, 2011; DUMESIC, HUBER, BOUDART, 2008).

Os catalisadores heterogêneos mais comuns são os suportados, que apresentam uma fase ativa suportada em um material inerte utilizado para aumentar a área superficial do catalisador e distanciar os sítios ativos. As fases ativas geralmente são formadas por óxidos metálicos ou sítios ácidos, e os suportes mais empregados são carvão ativado, alumina ou óxido de silício $\left(\mathrm{SiO}_{2}\right)$. As principais variáveis que influenciam no desempenho de um catalisador são o tamanho de poro e área superficial, interação da fase ativa com o suporte, a localização dos sítios ativos, o tamanho das partículas e suas propriedades mecânicas e estabilidade térmica (SCHMAL, 2011).

Um bom catalisador deve ter alta seletividade para os produtos desejados e baixa para os subprodutos, deve atingir taxas de reações adequadas para as condições desejadas, ter um desempenho estável por longos períodos de tempo, e ter boa acessibilidade dos reagentes e 
produtos para os locais ativos de tal modo a se obter altas taxas por volume do reator. E o mais importante, devem ter uma boa interação entre sua superfície catalítica e os reagentes, intermediários e produtos. Se a interação for fraca, há a necessidade de uma energia de ativação maior, o que leva a uma baixa atividade catalítica. E se for muito forte, há um bloqueio excessivo o que novamente leva a baixa atividade catalítica (DUMESIC, HUBER, BOUDART, 2008).

\subsection{A PRODUÇÃO DO ÁCIDO ACRÍLICO}

O ácido acrílico ou ácido 2-propanóico é um composto pertencente à família dos ácidos carboxílicos $\alpha-\beta$ insaturados, formado por um grupo vinílico ligado a uma carboxila, cuja estrutura está representada na Figura 1. A temperatura ambiente o ácido acrílico é líquido e incolor, apresenta odor irritante e é solúvel em água, álcool, ésteres e outros solventes orgânicos. Em contato com ácidos, sais de ferro ou exposto a altas temperaturas, o ácido acrílico pode polimerizar liberando grande quantidade de energia (CETESB, 2018).

Figura 1 - Fórmula estrutural do ácido acrílico

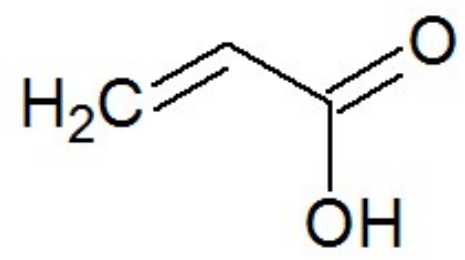

Fonte: Autor

O ácido acrílico é um precursor para diversos produtos nas indústrias químicas devido as características de sua estrutura molecular. Elas permitem que o ácido acrílico se comporte e reaja tanto como um composto insaturado, quanto como um ácido carboxílico. Uma de suas principais aplicações é na produção de polímeros, dentre eles o poliacrilato de sódio, um material superabsorvente utilizado na fabricação de artigos de higiene pessoal. Mas também existem outras aplicações importantes como a produção de ésteres que são utilizados como matérias-primas para a fabricação de resinas diversas utilizadas como tintas e adesivos (MOTA, PINTO, 2017; POSSATO et al., 2017).

Do ácido acrílico bruto total produzido no mundo, 55\% é destinado para a fabricação dos ésteres de acrilato e os $45 \%$ restantes para a produção de polímeros superabsorvenetes. Até o ano de 2021 preve-se um aumento de produção de 4,5\% ao ano, estimulado pelo aumento de 
demanda ao uso de fraldas descartáveis pela população mundial. Atualmente, os principais consumidores de ácido acrílico são a China, Estados Unidos e Europa, conforme mostrado na Figura 2. E os principais produtores de ácido acrílico mundiais são a BASF SE, China Petroleum\&Chemical Corporation, Arkema, Mitsubishi Chemical Corporation e a Dow (IHS MARKIT, 2017).

Figura 2 - Principais países consumidores de ácido acrílico em 2016

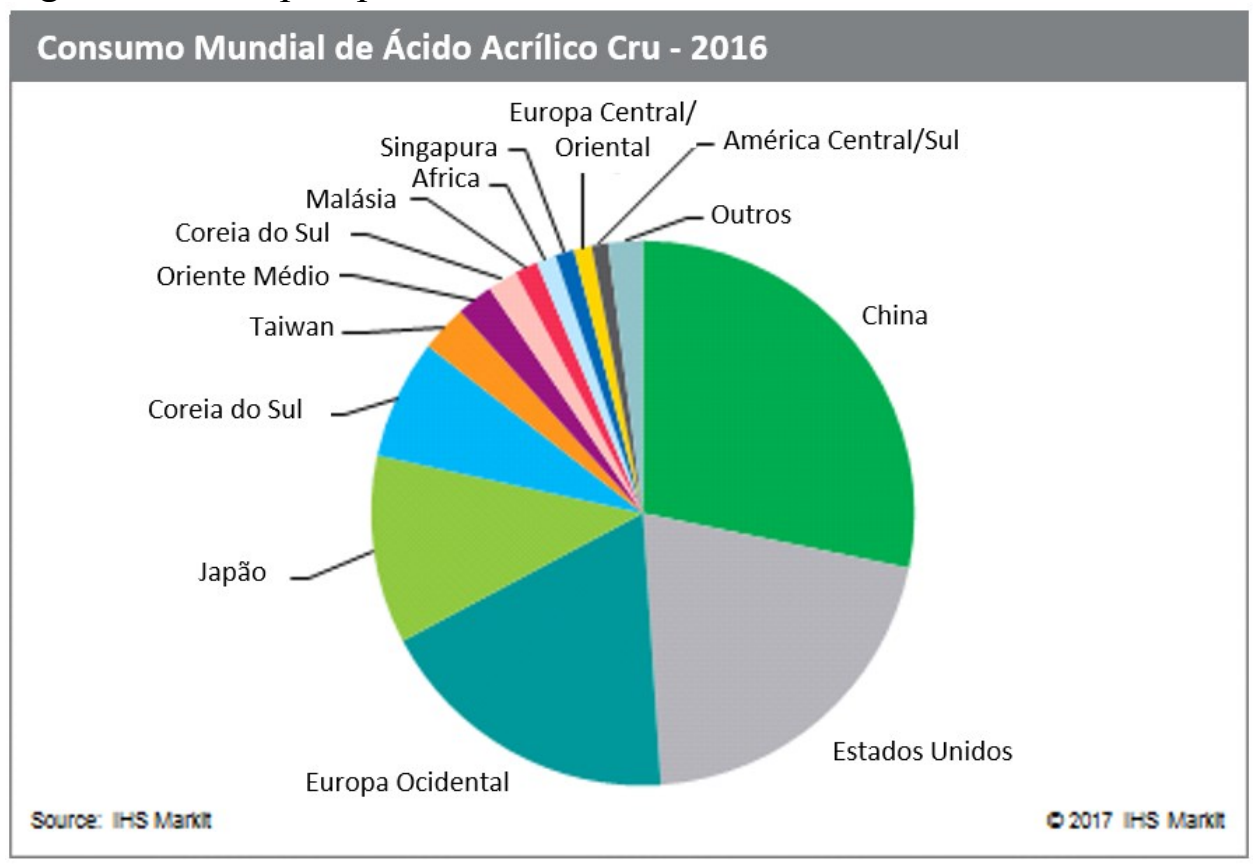

Fonte: Autor “adaptado de" IHS MARKIT, 2017

Atualmente o principal processo empregado industrialmente para a produção do ácido acrílico é a partir da oxidação do propeno. Primeiramente o propeno é oxidado a acroleína utilizando catalisadores contendo como fase ativa os óxidos de molibdênio e bismuto. Em seguida, a acroleína é oxidada, formando o ácido acrílico na presença de óxidos de molibdênio e vanádio como catalisadores. Nesse caso as reações ocorrem em reatores e condições reacionais distintas (GRASSELLI, BURRINGTON, 2008).

Apesar desse já ser um processo consolidado aplicado industrialmente, o propeno é uma matéria-prima proveniente de fontes petroquímicas e por isso surge o interesse em se buscar por rotas alternativas e uma das possibilidades é a utilização do glicerol, que é um subproduto na produção do biodiesel e aparecesse em excesso no mercado global (BEATRIZ, ARAUJO, LIMA, 2011). 


\subsection{OBTENÇÃO DO ÁCIDO ACRÍLICO A PARTIR DO PROPENO}

A principal rota utilizada industrialmente para a produção do ácido acrílico é pela oxidação do propeno obtido durante o craqueamento do petróleo. Nesse caso, primeiramente o propeno é oxidado formando a acroleína, que em seguida é oxidada formando o ácido acrílico. Esse processo pode ocorrer em um ou dois estágios, a Tabela 1 apresenta uma comparação entre as condições reacionais utilizadas em cada um.

O sucesso da rota de obtenção do ácido acrílico a partir do propeno se deve aos catalisadores de oxidação seletiva, os quais tem sido aperfeiçoado desde o final da década de 50 (OHARA et al., 1998).

No processo em etapa única o propeno é oxidado diretamente a ácido acrílico ("monooxidação"), seguindo a reação descrita na Equação 1, utilizando catalisadores contendo os óxidos de molibdênio e telúrio e a uma temperatura entre $280-370{ }^{\circ} \mathrm{C}$. Algumas desvantagens apresentadas nesse caso são os baixos rendimentos obtidos para o ácido acrílico (50 - 60\%) e curto tempo de vida do catalisador, por esses motivos os processos com etapa única têm sido substituídos pelos processos com duas etapas (OHARA, 1977; OHARA et al., 1998).

$\mathrm{C}_{3} \mathrm{H}_{6}+3 / 2 \mathrm{O}_{2} \rightarrow \mathrm{C}_{3} \mathrm{H}_{4} \mathrm{O}_{2}+\mathrm{H}_{2} \mathrm{O} \quad \Delta \mathrm{H}=-598,68 \frac{\mathrm{kJ}}{\mathrm{mol}}$

Tabela 1 - Condições de reação nos processos de obtenção de ácido acrílico em uma e duas etapas

\begin{tabular}{c|c|c|c}
\hline & Processo em uma & \multicolumn{2}{|c}{ Processo em duas etapas } \\
\cline { 3 - 4 } & etapa & Acroleína & Ácido Acrílico \\
\hline Propeno (\%vol.) & $5-8$ & $6-10$ & $\mathrm{n} / \mathrm{a}$ \\
$\mathrm{H}_{2} \mathrm{O}$ vapor (\%vol.) & $6-10$ & $5-40$ & $\mathrm{n} / \mathrm{a}$ \\
$\mathrm{O}_{2}$ /Propeno (molar) & $1,6-2,5$ & $1,2-1,8$ & $\mathrm{n} / \mathrm{a}$ \\
Temperatura $\left({ }^{\circ} \mathrm{C}\right)$ & $280-370$ & $280-350$ & $200-300$ \\
Tempo de contato $(\mathrm{s})$ & $1,8-3,6$ & $1,8-3,6$ & $1,4-2,4$ \\
\hline
\end{tabular}

Fonte: Ohara, 1977

Legenda: dados da Nippon Shokubai Co. Ltda

Já no processo em duas etapas ocorre a bi-oxidação do propeno em duas reações sequenciais distintas, que acontecem em reatores com condições diferentes e cada uma utilizando um tipo de catalisador. Isso possibilita uma otimização de cada fase da reação e, assim, o rendimento global do processo é maior. Nesse caso, primeiramente o propeno é oxidado a acroleína utilizando catalisadores do tipo A que são formados principalmente por 
óxido de molibdênio e bismuto (Equação 2) a uma temperatura entre $330-370{ }^{\circ} \mathrm{C}$. E, em seguida, a acroleína é oxidada a ácido acrílico na presença de catalisadores do tipo $\mathrm{B}$, que contém como fase ativa os óxidos de molibdênio e vanádio (Equação 3) a uma temperatura entre $200-300{ }^{\circ} \mathrm{C}$ (GRASSELLI, TENHOVER, 2008).

$$
\begin{array}{ll}
\mathrm{C}_{3} \mathrm{H}_{6}+\mathrm{O}_{2} \stackrel{\text { Catalisador } \mathrm{A}}{\longrightarrow} \mathrm{C}_{3} \mathrm{H}_{4} \mathrm{O}+\mathrm{H}_{2} \mathrm{O} & \Delta \mathrm{H}=-333,15 \frac{\mathrm{kJ}}{\mathrm{mol}} \\
\mathrm{C}_{3} \mathrm{H}_{4} \mathrm{O}+1 / 2 \mathrm{O}_{2} \stackrel{\text { Catalisador B }}{\longrightarrow} \mathrm{C}_{3} \mathrm{H}_{4} \mathrm{O}_{2} & \Delta \mathrm{H}=-265,53 \frac{\mathrm{kJ}}{\mathrm{mol}}
\end{array}
$$

Uma representação do processo em duas etapas de obtenção de ácido acrílico a partir de propeno é apresentada na Figura 3. Os reatores são do tipo casco-tubo leito-fixo e contém mais de 10000 tubos por reator com aproximadamente 2 a $2,5 \mathrm{~cm}$ de diâmetro e 3 a $5 \mathrm{~m}$ de comprimento (GRASSELLI, BURRINGTON, 2008).

Figura 3 - Representação do processo de obtenção de ácido acrílico da Sohio (hoje BP America) -Nippon-Kayaku
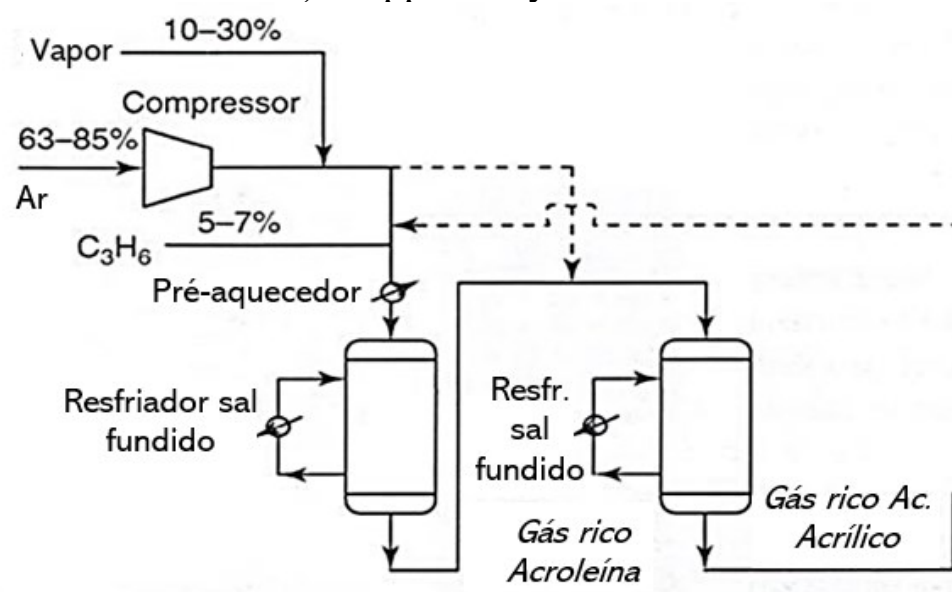

Incinerator

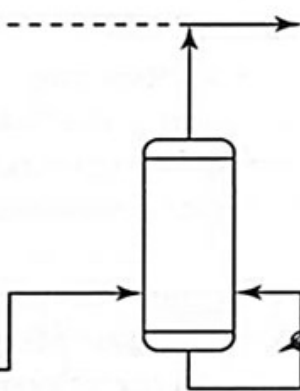

Resfriador

de fundo

Ácido acrílico

aquoso

\begin{tabular}{|lccc|}
\hline Unid: & Casco\&Tubos Reator 1 & Casco\&Tubos Reator 2 & Absorvedor \\
Temp: & $320-430^{\circ} \mathrm{C}$ & $280-360^{\circ} \mathrm{C}$ & $60-70^{\circ} \mathrm{C}$ \\
Processo: & $\mathrm{C}_{3} \mathrm{H}_{6}+\mathrm{O}_{2} \rightarrow \mathrm{CH}_{2}=\mathrm{CH}_{2} \mathrm{CHO}+\mathrm{H}_{2} \mathrm{OCH}_{2}=\mathrm{CH}_{2} \mathrm{CHO}+1 / 2 \mathrm{O}_{2} \rightarrow \mathrm{CH}_{2}=\mathrm{CH}_{2} \mathrm{CO}_{2} \mathrm{H}$ & Recup. de prod. \\
\hline
\end{tabular}

Fonte: Autor "adaptado de" Grasselli e Burrington, 2008, pg. 3481 


\subsubsection{Catalisadores para a produção de acroleína a partir do propeno}

O primeiro processo para oxidação de propeno a acroleína utilizava catalisador de óxido e selenito de cobre desenvolvidos na década de 40 , porém a conversão era baixa $(<15 \%)$ implicando em reciclo do propeno (KAMER, VOGT, THYBAUT, 2017).

No final de década de 50, foi descoberto que o molibdato de bismuto fazia a reação com conversões de propeno superiores a $90 \%$ a baixas pressões. A partir de então, esforços de pesquisa nessa área foram voltados na melhoria desses catalisadores. Os catalisadores atuais são misturas de óxidos de bismuto ( $\mathrm{Bi})$, molibdênio (Mo), ferro $(\mathrm{Fe})$, níquel $(\mathrm{Ni})$ e/ou cobre $(\mathrm{Cu})$, entre outros. Uma característica comum aos metais selecionados é a existência de mais de um estado de valência, que permitem a ocorrências das reações de oxirredução (GRASSELLI, TENHOVER, 2008; OHARA, 1977; CALLAHAN et al., 1960).

A Tabela 2 apresenta a composição básica dos catalisadores para a oxidação do propeno. Os quatro primeiros componentes ( $\mathrm{Mo}, \mathrm{Bi}, \mathrm{M}^{\mathrm{I}}$ e $\mathrm{M}^{\mathrm{II}}$ ) são os elementos essenciais que fazem parte da estrutura fundamental do catalisador. Os demais componentes ( $\mathrm{M}^{\mathrm{III}}, \mathrm{X}$ e $\left.\mathrm{Y}\right)$ são acrescentados para aprimorar a vida do catalisador e a resistência mecânica, melhorar a atividade e aumentar a seletividade à acroleína (MORO-OKA, UEDA 1994; OHARA, 1977).

Tabela 2 - Conteúdo dos catalisadores multifásicos baseados em molibdato de bismuto

\begin{tabular}{ccc}
\hline Componentes & Composição atômica (\%) & Elementos usados \\
\hline Mo & $50-55$ & $\mathrm{Mo}$ \\
$\mathrm{Bi}$ & $3-7$ & $\mathrm{Bi}$ \\
$\mathrm{M}^{\mathrm{I}}$ & $30-35$ & $\mathrm{Co}, \mathrm{Ni}, \mathrm{Fe}, \mathrm{Mg}, \mathrm{Mn}$ \\
$\mathrm{M}^{\mathrm{II}}$ & $8-15$ & $\mathrm{Fe}, \mathrm{Cr}, \mathrm{Al}(\mathrm{especialmente} \mathrm{o} \mathrm{Fe)}$ \\
$\mathrm{M}^{\mathrm{III}}$ & pequeno teor & $\mathrm{K}, \mathrm{Na}, \mathrm{Cs}, \mathrm{Tl}$ \\
$\mathrm{X}$ & & $\mathrm{Sb}, \mathrm{Nb}, \mathrm{V}, \mathrm{W}, \mathrm{Te}$ \\
$\mathrm{Y}$ & & $\mathrm{P}, \mathrm{B}$ \\
\hline
\end{tabular}

Fonte: Moro-Oka e Ueda, 1994

A reação de oxidação para a obtenção da acroleína a partir do propeno ocorre em pressões próximas a atmosférica e temperaturas de $350{ }^{\circ} \mathrm{C}$, utilizando ar (mistura $\mathrm{O}_{2} / \mathrm{N}_{2}$ ) como oxidante e vapor d'água para controlar a flamabilidade da mistura (OHARA, 1977).

Catalisadores contendo excesso de molibdênio e operando em temperaturas elevadas têm parte do molibdênio sublimado na zona de reação e condensado nas partes frias do reator ocasionando um aumento da perda de carga. Por isso os catalisadores devem ser ativos em 
baixas temperaturas. Porém, o excesso de $\mathrm{MoO}_{3}$ é necessário para a longa duração dos sistemas multicomponentes baseados em molibdatos, funcionando como uma reserva de molibdênio a ser usada para restaurar algum eventual dano à estrutura. Outro parâmetro importante a ser controlado é a acidez do catalisador responsável pela adsorção do propeno (GRASSELLI, TENHOVER, 2008; OHARA, 1977).

Os catalisadores operam com ciclos de redução que dão origem ao produto desejado de maneira seletiva, seguidos de ciclos de reoxidação por oxigênio oriundo da estrutura cristalina do catalisador. Os subprodutos, produzidos pelas principais reações paralelas, são o ácido acrílico, monóxido e dióxido de carbono e componentes em pequena concentração (acetaldeído, ácido acético, formaldeído, etileno, óxido de propeno, propionaldeído, 1,5-hexadiene e poliacroleína (GRASSELLI, TENHOVER, 2008).

\subsubsection{Catalisadores para a produção de ácido acrílico a partir da acroleína}

Dentre os catalisadores empregados atualmente para a produção de ácido acrílico a partir da acroleína, predominam aqueles que contém os elementos vanádio e molibdênio em sua composição com relação atômica $\mathrm{Mo} / \mathrm{V}$ elevada. Também podem ser encontrados outros metais, que são adicionados com a função de melhorar o desempenho do catalisador, dentre eles podem ser citados o As, U, Al, W, Ag, Mn, Ge, Au, Ba, Cu, Mg, Ca, Sr, B, Sn, Co, Fe, Ni e Ce. O catalisador é do tipo suportado e a função do suporte é remover calor, aumentar a área específica dos elementos ativos e prevenir a queda de atividade ao longo do tempo (OHARA, 1977). Outro objetivo do suporte é aumentar a resistência mecânica das partículas de catalisador assim como sua área superficial (GRASSELLI, TENHOVER, 2008).

A ativação do catalisador é a principal etapa do processo de produção e é conduzida em temperaturas elevadas $\left(400{ }^{\circ} \mathrm{C}\right)$, usando um fluxo de gás composto por acroleína, vapor d'água e oxigênio em relações de $\mathrm{O}_{2}$ /acroleína > 2,0 (ANDRUSHKEVICH, 1993). Dessa maneira a superfície fica parcialmente reduzida e muito mais ativa. Entretanto, durante a operação, esses catalisadores perdem a atividade, sendo necessária a realização da oxidação de propeno ou propano para reativá-los. Dessa forma, uma maneira de manter a atividade e seletividade elevadas seria o estabelecimento de condições nas quais a superfície do catalisador fique com um dado grau de redução. Muitas das patentes existentes descrevem formas de como inibir essa desativação, e uma delas é a adição de promotores ao catalisador, como o $\mathrm{Li}_{2} \mathrm{SO}_{4}, \mathrm{Mn}, \mathrm{Cu}, \mathrm{W}$, Cr e um suporte inerte de propriedades especiais (OHARA,1977). 
Na Tabela 3 encontra-se uma relação de patentes contendo a composição atômica aproximada dos catalisadores de oxidação de acroleína a ácido acrílico, dados de conversão e seletividade, bem como o nome da empresa proprietária da tecnologia e o número das patentes depositadas. É possível verificar que a relação atômica $\mathrm{Mo} / \mathrm{V}$ varia de 2,5 a 6,3, e que uma grande maioria dos catalisadores possui tungstênio e cobre em sua composição.

Tabela 3 - Catalisadores para oxidação de acroleína a ácido acrílico

\begin{tabular}{|c|c|c|c|c|}
\hline $\begin{array}{l}\text { Catalisador } \\
\text { (Referência) }\end{array}$ & $\begin{array}{l}\text { Temp. } \\
\left({ }^{\circ} \mathrm{C}\right)\end{array}$ & $\begin{array}{c}\text { Conv. } \\
(\%)\end{array}$ & $\begin{array}{l}\text { Seletividade } \\
(\text { mol \%) } \\
\text { Ac. Acrílico }\end{array}$ & $\begin{array}{l}\text { Rendimento } \\
\text { (mol\%) } \\
\text { Ac. Acrílico }\end{array}$ \\
\hline $\begin{array}{c}\text { Mo12 }_{\mathbf{1 . 9}} \mathbf{A l}_{\mathbf{1 0}} \mathbf{C u}_{2.2} \\
\text { (US 3567772, YANAGITA,KITAHARA,1971) }\end{array}$ & 300 & 100 & 97,5 & 97,5 \\
\hline $\begin{array}{c}\mathbf{M o}_{12} \mathbf{V}_{\mathbf{3}} \mathbf{W}_{1.2}\left(\mathbf{S i O}_{2}\right) \\
\text { (US 3567773, YAMAGUCHI, TAKENAKA, 1971) }\end{array}$ & 240 & 97,8 & 89 & 87 \\
\hline $\begin{array}{c}\mathbf{M o}_{12} \mathbf{V}_{\mathbf{3}} \mathbf{W}_{\mathbf{1}} \mathbf{N a}_{1} \\
\text { (US 3857796, OGAWA, TAKENAKA, SHIMIZU, 1974) }\end{array}$ & 270 & 96,1 & 88,4 & 85 \\
\hline $\begin{array}{l}\mathbf{M o 1 2}_{\mathbf{1 2}} \mathbf{V}_{3} \mathbf{W}_{1.2} \mathbf{M n}_{3} \\
\text { (US 3644509, ALLEN, 1972) }\end{array}$ & 255 & 99 & 94 & 93 \\
\hline $\begin{array}{c}\qquad \mathbf{M o}_{12} \mathbf{V}_{2} \mathbf{W}_{2} \mathbf{F e}_{3} \\
\text { (US 3845120, KRABETZ, ENGELBACH, 1974) }\end{array}$ & 230 & 99 & 92 & 91 \\
\hline $\begin{array}{c}\mathbf{M o}_{12} \mathbf{V}_{\mathbf{3}} \mathbf{W}_{\mathbf{1}, \mathbf{2}} \mathbf{C u}_{\mathbf{1}} \mathbf{S b}_{\mathbf{6}} \\
\text { (US 3773692, HENSEL et al., 1973) }\end{array}$ & 272 & 99 & 91,9 & 91 \\
\hline $\begin{array}{l}\mathbf{M o}_{12} \mathbf{V}_{\mathbf{4 . 8}} \mathbf{W}_{2.4} \mathbf{C u}_{2.2} \mathbf{S r}_{0,5}\left(\mathbf{A l}_{\mathbf{2}} \mathbf{O}_{\mathbf{3}}\right) \\
\text { (US3954855, WADA et al., 1976) }\end{array}$ & 255 & 100 & 97,5 & 97,5 \\
\hline $\begin{array}{l}\mathbf{M o}_{12} \mathbf{V}_{\mathbf{4 . 6}} \mathbf{W}_{2.4} \mathbf{C u}_{2.2} \mathbf{C r}_{\mathbf{0}, \mathbf{6}}\left(\mathbf{A l}_{\mathbf{2}} \mathbf{O}_{3}\right) \\
\text { (US 3833649, WADA et al., 1974) }\end{array}$ & 220 & 100 & 98 & 98 \\
\hline $\begin{array}{c}\mathbf{M o}_{\mathbf{1 2}} \mathbf{V}_{\mathbf{2}, \mathbf{4}} \mathbf{C u}_{\mathbf{0}, 24}(\mathbf{S i C}) \\
\text { (US 3773828, KADOWAKI, KOSHIKAWA, 1973) }\end{array}$ & 290 & 99,5 & 95,3 & 94,8 \\
\hline $\begin{array}{c}\text { Mo12 }_{\mathbf{1}} \mathbf{V}_{\mathbf{3}} \mathbf{W}_{\mathbf{1}, \mathbf{2}} \mathbf{C e}_{3} \\
\text { (GB 1477029, DOLHYJ, MILBERGER, 1977) }\end{array}$ & 288 & 100 & 96,1 & 96,1 \\
\hline $\begin{array}{c}\mathbf{M o}_{\mathbf{1 2}} \mathbf{V}_{\mathbf{3}} \mathbf{W}_{\mathbf{1}, \mathbf{2}} \mathbf{S b}_{\mathbf{3}} \mathbf{S b}_{\mathbf{3}} \\
\text { (US 3840595, GRASSELLI, SURESH, 1974) }\end{array}$ & 330 & 97,8 & 86 & 84 \\
\hline $\begin{array}{c}\mathbf{M o}_{12} \mathbf{V}_{\mathbf{2}}\left(\mathbf{L i}_{2} \mathbf{S O}_{4}\right)_{2} \\
\text { (US 3766265, SHIRAISHI et al. 1973) }\end{array}$ & 300 & 99,8 & 92,6 & 92,4 \\
\hline $\begin{array}{c}\text { Mo12 }_{\mathbf{4}} \mathbf{V}_{\mathbf{4}} \mathbf{W}_{\mathbf{1}, \mathbf{1}} \mathbf{C u}_{\mathbf{6}, \mathbf{3}} \\
\text { (US 3997600, FERLAZZO, BUZZI, GHIRGA, 1976) }\end{array}$ & 260 & 99 & 97 & 96 \\
\hline
\end{tabular}

Fonte: Autor

Os catalisadores baseados em óxidos de vanádio e molibdênio podem ser preparados tanto como óxidos mássicos, quanto como óxidos suportados contendo $30 \%$ de material ativo. A fase mais ativa e seletiva é o composto $\mathrm{VMo}_{3} \mathrm{O}_{11}$ que possui alta mobilidade para o oxigênio estrutural e são estáveis em relações $\mathrm{O}_{2} /$ acroleína $>2,0$. A fase é obtida em catalisadores contendo 7 a 14,5 mol\% de $\mathrm{V}_{2} \mathrm{O}_{4}$ e 85,5 a 93 mol\% de $\mathrm{MoO}_{3}$. Nesse composto, a relação entre as quantidades de acroleína ou ácido acrílico adsorvidos forte ou fracamente é pequena e esta 
relação foi inversamente correlacionada com a seletividade ao ácido acrílico. Elementos adicionados ao catalisador mudam essas relações de forma positiva ou negativa dependendo da quantidade adicionada. O cobre é um dos poucos elementos que atua positivamente em toda faixa de concentração adicionada em estudos apresentados na literatura (ANDRUSHKEVICH, 1993).

\subsection{CATALISADORES PARA OXIDAÇÃO SELETIVA}

Uma ampla gama de estudos tem sido voltada para o desenvolvimento de óxidos metálicos para utilização nas reações de oxidação seletiva. A maioria dos casos de oxidação são associadas ao mecanismo de Mars-Van Krevelen, que consiste na oxidação do hidrocarboneto pelo oxigênio superficial do catalisador. Dessa maneira uma vacância de oxigênio é liberada na superfície do material e é necessário a movimentação dos ânions de oxigênio da estrutura do catalisador para preencher novamente o vazio da superfície do catalisador. Uma representação do esquema é mostrada na Figura 4 (VEDRINE, 2017).

Durante seus estudos, Mars e Van Krevelen descobriram que a reação de oxidação é dividida em três etapas. Primeiramente as moléculas dos reagentes são adsorvidas pela superfície do catalisador onde são oxidadas pelos oxigênios ali presentes e em seguida ocorre a dessorção dos produtos formados. Na segunda etapa ocorre a migração das vacâncias de oxigênio para o interior da estrutura do catalisador devido ao preenchimento da vacância da superfície por um oxigênio estrutural e por fim o oxigênio da fase gasosa reoxida o catalisador.

Figura 4 - Esquematização da reação de oxidação seletiva da acroleína e a reoxidação do catalisador

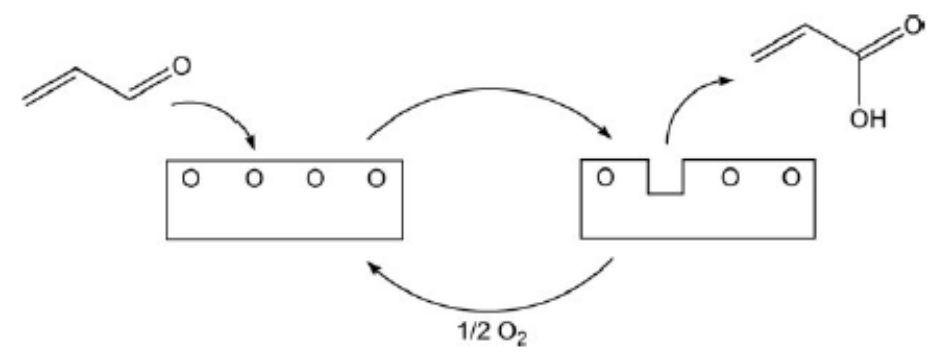

Fonte: Drochner et al., 2014

Segundo Grasselli \& Tenhover (2008), os catalisadores de oxidação seletiva são multifuncionais e possuem propriedades que são essenciais para seu bom desempenho. Sete dessas propriedades foram nomeadas como os "princípios fundamentais" ou "sete pilares" que abrangem o funcionamento dos catalisadores heterogêneos seletivos e são elas: Arranjamento 
espacial dos átomos de oxigênio, força da ligação metal-oxigênio, estrutura do hospedeiro, mecanismo de oxirredução ou redox, multifuncionalidade dos sítios ativos, isolamento dos sítios e cooperação de fases. Esses princípios são úteis no entendimento do comportamento dos catalisadores baseados em óxidos metálicos e são descritos a seguir (GRASSELI, 2002).

\subsubsection{Arranjamento espacial dos átomos de oxigênio}

Foi postulado na década de 50 que os átomos de oxigênio de óxidos metálicos redutíveis seriam agentes oxidantes mais versáteis e seletivos que oxigênio molecular. As vacâncias criadas pela saída do oxigênio seriam completadas por átomos de oxigênio vindo de átomos estruturais vizinhos criando novas vacâncias que seriam posteriormente preenchidas pelo oxigênio molecular.

\subsubsection{Ligação metal-oxigênio}

Tendo sido verificado o papel ativo da estrutura de oxigênio, foi postulado posteriormente que a força de ligação entre os átomos de oxigênio ativos e os do metal deveria ser de intermediária nas condições de reação. A explicação é que se a ligação for muito forte, nenhuma reação ocorreria, ou seja o rendimento seria muito baixo, ao passo que se a ligação for muito fraca, poderia ocorrer superoxidação levando a produtos indesejados. Essa suposição levou a definição do uso de óxidos metálicos que são covalentes e de caráter anfótero tais como molibdatos, antimoniatos e vanadatos.

\subsubsection{Estrutura hospedeira}

A estrutura hospedeira que contém o óxido metálico com a estrutura desejada precisa ser maleável de forma que ela possa acomodar as vacâncias criadas pela saída do oxigênio sem que a estrutura cristalina se colapse. Ela também deve ser capaz de realizar rápida transferência de elétrons, vacâncias e difusão de oxigênio estrutural.

\subsubsection{Ciclo de oxirredução}

Óxidos metálicos contendo oxigênios estruturais removíveis, ligações metal-oxigênio apropriadas e estrutura hospedeira adequada, precisa também exibir propriedades redox 
utilizáveis no processo cíclico oxidante ou no processo de oxidação catalítica. Em outras palavras o óxido catalisador precisa perder o oxigênio para oxidar o hidrocarboneto, mas depois esse oxigênio precisa ser reabastecido pelo oxigênio molecular de uma forma direta ou indireta (mais frequente), completando o ciclo de oxirredução. Nos catalisadores mais eficientes, o sítio de dissociação do oxigênio molecular é diferente do sítio catalítico ativo de oxidação e para ser realmente eficiente, a regeneração do óxido metálico deve ser mais rápida que a oxidação do reagente. A Figura 5 apresenta um diagrama de como o catalisador funciona na transferência de oxigênio (GRASSELI, 2002).

Figura 5 - Esquema da migração de oxigênio ativo num catalisador multicomponente

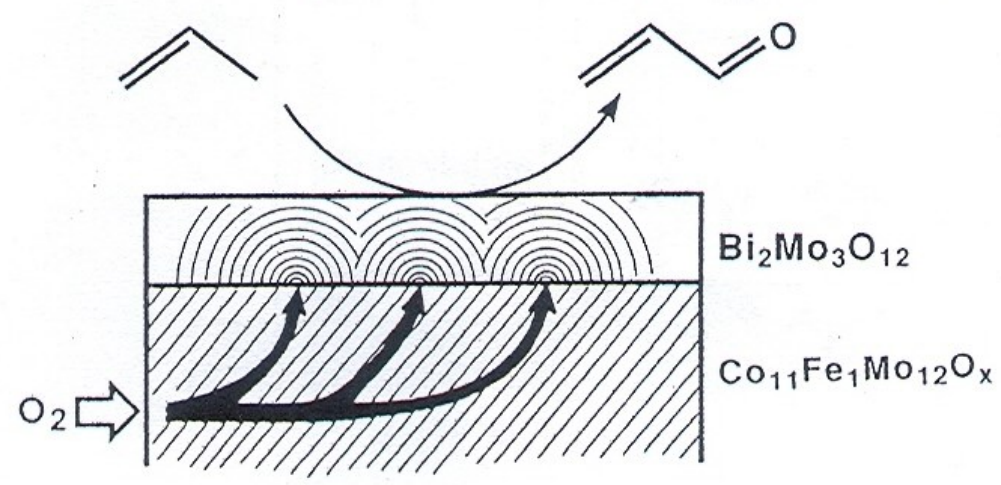

Fonte: Ueda, 2003

Um dos mecanismos disponíveis na literatura para representar esse fenômeno de maneira global é o mecanismo de Mars-Van Krevelen que pode ser escrito nas Equações (4) e (5) a seguir (MARS, VAN KREVELEN, 1954).

propeno + catalisador oxidado $=>$ acroleína + catalisador-reduzido

(Equação 4)

catalisador reduzido $+\mathrm{O}_{2}=>$ catalisador oxidado

(Equação 5)

\subsubsection{Multifuncionalidade dos sítios ativos}

Os sítios ativos de catalisadores seletivos baseados em óxidos metálicos são geralmente multifuncionais e multimetálicos, usualmente bimetálicos e bifuncionais. Eles desempenham várias funções no ciclo catalítico tais como quimissorção do substrato, abstração do oxigênio do substrato, inserção de oxigênio no substrato ativado adsorvido e finalmente dessorção do produto. As Figura 6 e Figura 7 representam o mecanismo de reação de oxidação de propeno a 
acroleína e o de oxidação de acroleína a ácido acrílico, respectivamente, onde são incluídos os sítios catalíticos multifuncionais dos catalisadores baseados em óxidos de Mo, Bi, V e P. Como pode ser verificado, o processo de oxidação do propeno envolve quatro elétrons enquanto o processo de oxidação da acroleína envolve apenas dois elétrons.

Figura 6 - Mecanismo de oxidação de propeno a acroleína sobre catalisadores baseados em óxidos de Bi e Mo

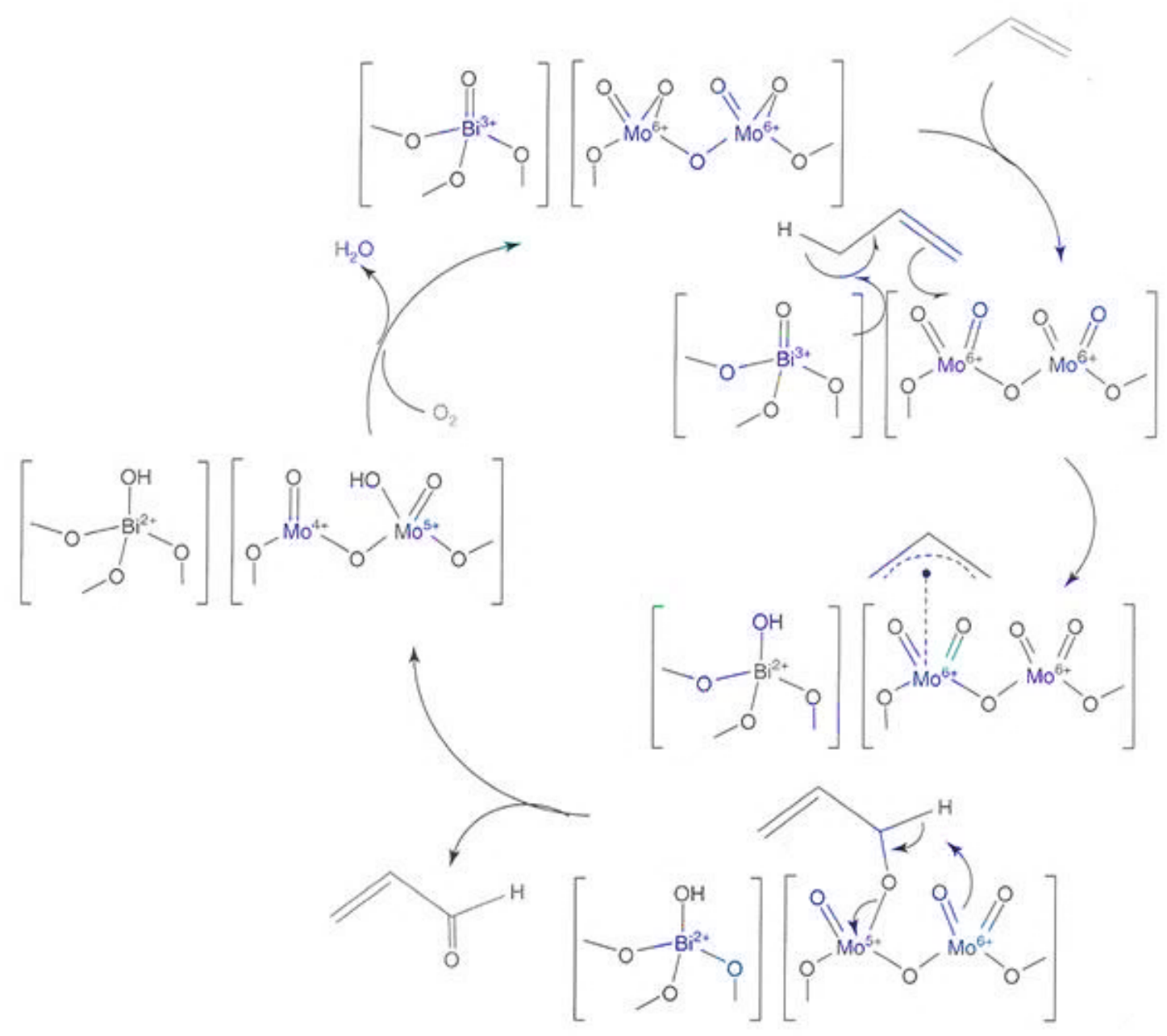

Fonte: Grasselli e Burrington, 2008 
Figura 7 - Mecanismo de oxidação de acroleína a ácido acrílico sobre catalisadores baseados em óxidos de $\mathrm{V}$, Mo e $\mathrm{P}$

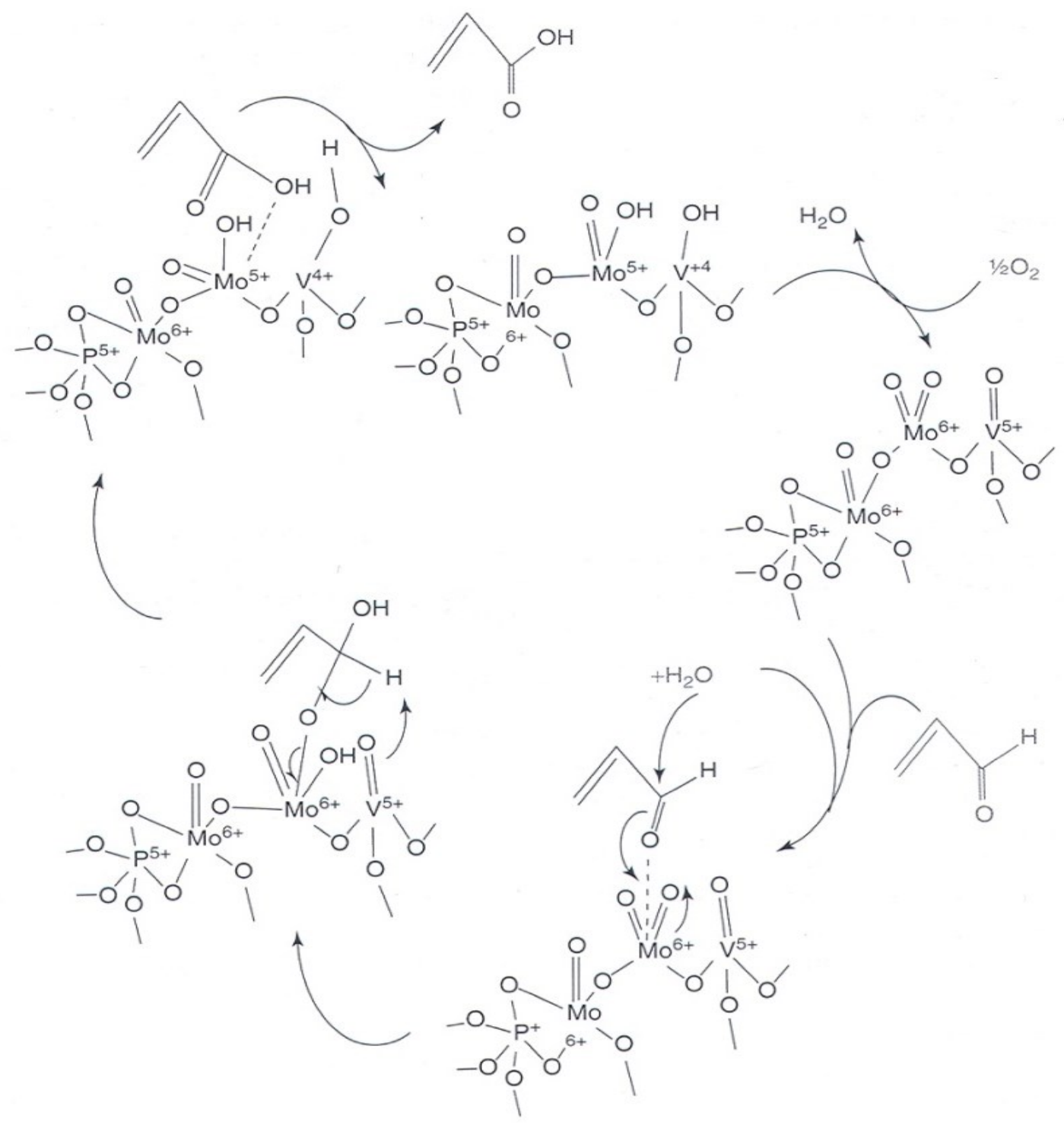

Fonte: Grasselli e Burrington, 2008

\subsubsection{Isolamento dos sítios catalíticos}

Outro princípio a ser considerado no projeto e preparação de catalisadores de oxidação seletiva é o do isolamento ou separação dos sítios catalíticos. Isso foi demonstrado primeiro por Callahan et al. (1963) e se baseia no postulado de que se o sítio catalítico desejado para oxidação catalítica de propeno a acroleína necessita de dois a cinco átomos de oxigênio. Se o sítio tem mais que cinco átomos de oxigênio ele se torna não seletivo. Então os sítios têm que estar bastante espaçados, o que é conseguido com a adição de determinados elementos químicos tais 
como o nióbio. A Figura 8 exemplifica o isolamento dos sítios em um catalisador complexo usado para amoxidação seletiva de propano.

Figura 8 - Modelo de célula unitária na projeção [001] de $\mathrm{Mo}_{7.5} \mathrm{~V}_{2.2} \mathrm{Nb}_{1.5} \mathrm{Te}_{0.9} \mathrm{O}_{\mathrm{x}}$ mostrando quatro sítios catalíticos em isolamento

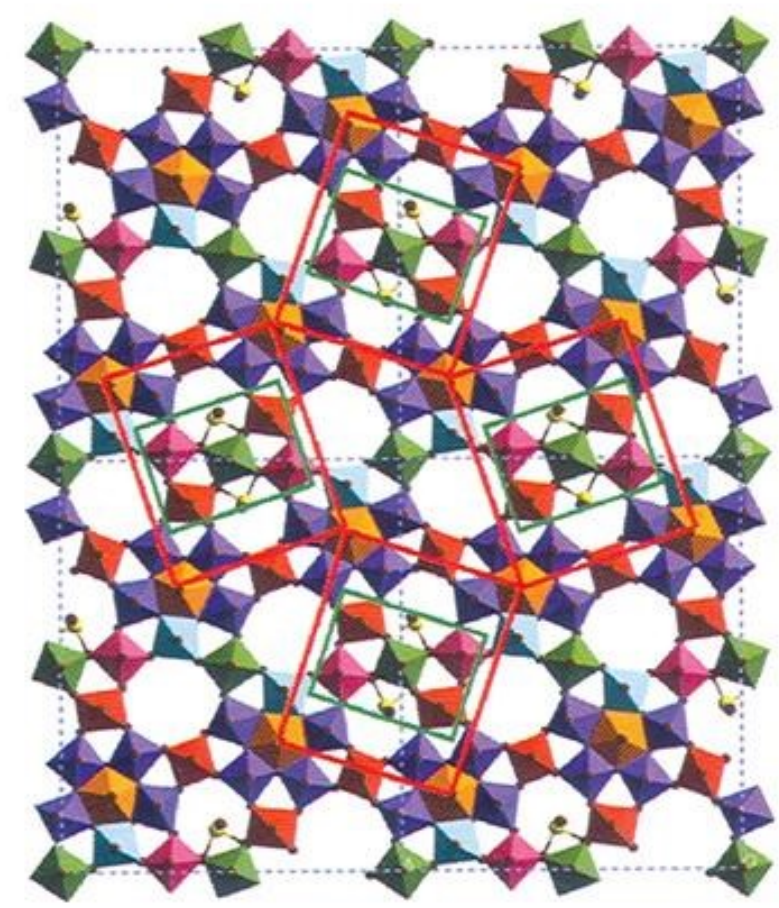

Fonte: Grasselli e Tenhover, 2008

\subsubsection{Cooperação de fases}

Quando uma estrutura hospedeira não reunir todas as funções catalíticas fundamentais, a melhor aproximação possível é encontrar duas ou mais fases que tenham separadamente as funções necessárias e colocá-las em contato íntimo (ex: epitaxialmente) de forma que elas possam se comunicar entre si e cooperar no processo catalítico.

Esta cooperação foi observada primeiro para as fases $\alpha-\mathrm{Bi}_{2} \mathrm{Mo}_{3} \mathrm{O}_{12}$ e $\gamma-\mathrm{Bi}_{2} \mathrm{MoO}_{6}$ onde a primeira fase mais ativa, realizava a oxidação seletiva catalítica e a segunda a função de reoxidação do catalisador.

O catalisador mais eficiente para cada uma das reações será aquele que é capaz de reunir todas as características relacionadas neste capítulo. 


\subsection{PRODUÇÃO DE BIODIESEL E MOTIVAÇÃO PARA O USO DO GLICEROL}

A busca por fontes de energia renováveis que possam substituir, ao menos parcialmente, os combustíveis de origem fóssil vêm se tornando imprescindível no cenário mundial atual. $\mathrm{O}$ intenso desenvolvimento socioeconômico de muitos países vem exigindo maior quantidade de energia, e atualmente elas são em sua maioria provenientes de fontes petroquímicas, e causam grandes prejuízos ao meio ambiente durante sua queima, principalmente quando relacionado à emissão de gases poluentes (GRASSELLI, TRIFINO, 2017).

Nesse contexto, uma medida encontrada por alguns países, inclusive o Brasil, para tentar diminuir o uso dos combustíveis de origem fóssil, foi a implementação dos biocombustíveis. Em 2008, o governo brasileiro tornou obrigatória a adição do biodiesel ao diesel de petróleo, desde então sua produção aumentou consideravelmente e junto a ela a coprodução do glicerol, um subproduto proveniente da transesterificação dos triglicerídeos que passou a ser ofertado em excesso no mercado mundial. Assim, é de suma importância o estudo e desenvolvimento de novas rotas para o uso e valorização do glicerol, tornando-o uma grande commodity da indústria química (POSSATO et al., 2017).

\subsubsection{A produção de biodiesel}

Biodiesel é um biocombustível obtido pela transesterificação de triglicerídeos provenientes dos óleos vegetais com um álcool primário, geralmente o metanol ou etanol. Neste processo são obtidos ésteres alquílicos de ácidos graxos e glicerol, que só podem ser utilizados como biodiesel após um processo de purificação para atender as especificações de qualidade supervisionadas pela ANP (AGÊNCIA NACIONAL DO PETRÓLEO, GÁS NATURAL E BIOCOMBUSTÍVEIS, 2017).

O biodiesel tem sido utilizado como um possível substituto ao diesel do petróleo devido às suas propriedades físico-químicas e térmicas que se assemelham muito as do óleo diesel, sem que tenham havido grandes modificações nos motores para sua utilização. Além disso o biocombustível é biodegradável, isento de enxofre e aromáticos, o que auxilia na redução emissões dos gases tóxicos de exaustão, apresenta excelente lubricidade, é miscível ao diesel de petróleo e principalmente, é produzido a partir de matérias-primas renováveis que são menos agressivas ao meio ambiente (OLIVEIRA, COELHO, 2017; DABDOUB, BRONZEL, 2009).

A primeira patente que cita a produção de biodiesel foi depositada em 1937 pelo pesquisador Charles George Chavanne da Universidade de Bruxelas. Nela é descrita a 
transformação de óleos vegetais em seus correspondentes ésteres de cadeia longa para sua utilização como combustível de motores de combustão interna. Nesse caso, o óleo utilizado na transesterificação foi o de palma africana (dendê) com metanol ou etanol utilizando o ácido sulfúrico como catalisador (DABDOUB, BRONZEL, 2009).

No Brasil, o biodiesel foi oficialmente introduzido na matriz energética brasileira em 2005, com a criação do PNPB (Programa Nacional de Produção e Uso de Biodiesel) pela Lei Federal n. 11097/2005. O programa visava estimular a utilização do biocombustível em substituição ao diesel do petróleo e colaborar para tornar o processo de síntese do biodiesel economicamente viável. Com essa possível substituição, além de diminuir os problemas ambientais relacionados à queima dos combustíveis de origem fóssil e tantos outros já discutidos anteriormente, o governo estaria colaborando e incentivando a agricultura familiar, principal responsável pelo cultivo dos grãos para produção de biodiesel (OLIVEIRA, COELHO, 2017; AGÊNCIA NACIONAL DO PETRÓLEO, GÁS NATURAL E BIOCOMBUSTÍVEIS, 2017).

Com o surgimento PNPB, começou-se a discutir a possibilidade da adição do biodiesel ao diesel do petróleo. Assim, entre os anos de 2005 e 2007, a ANP (Agência Nacional do Petróleo, Gás Natural e Biocombustíveis) tornou opcional a comercialização do diesel contendo 2\% de biodiesel em sua composição (B2), mistura que passou a ser obrigatória em 2008, com o artigo 2 da Lei 11.097/2005. Com o desenvolvimento das indústrias de biodiesel e adaptação do mercado brasileiro, o governo vem ampliando esse percentual até atingir os $15 \%$ (B15) em 2023, conforme descrito nas Figura 9 e 10 (OLIVEIRA, COELHO, 2017; AGÊNCIA NACIONAL DO PETRÓLEO, GÁS NATURAL E BIOCOMBUSTÍVEIS, 2017).

Figura 9 - Mistura obrigatória de biodiesel de 2005 a 2019

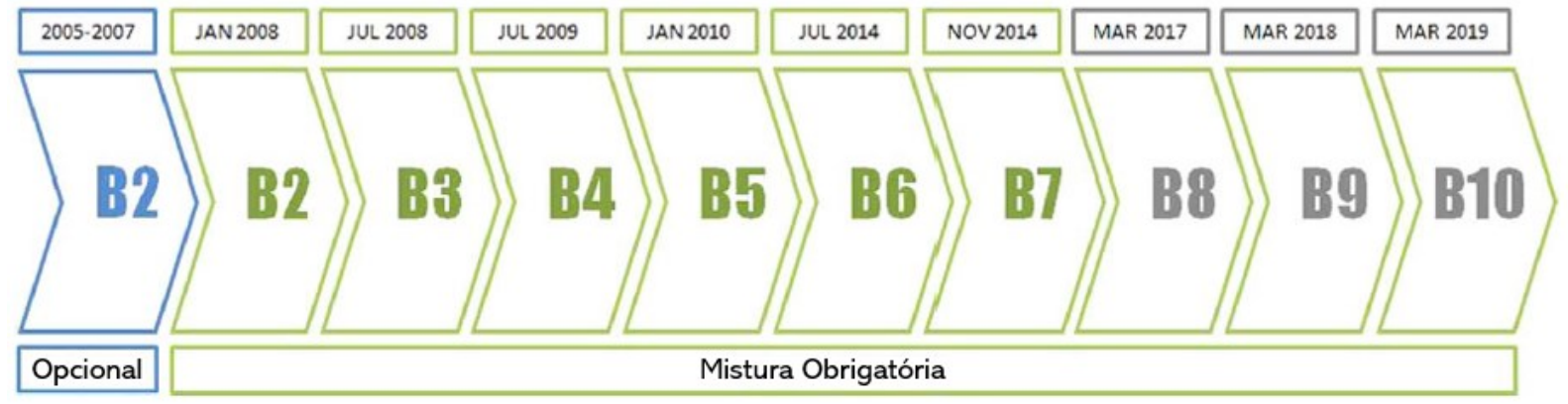

Fonte: Oliveira e Coelho, 2017 
Figura 10 - Cronograma do aumento da mistura de biodiesel nos próximos anos

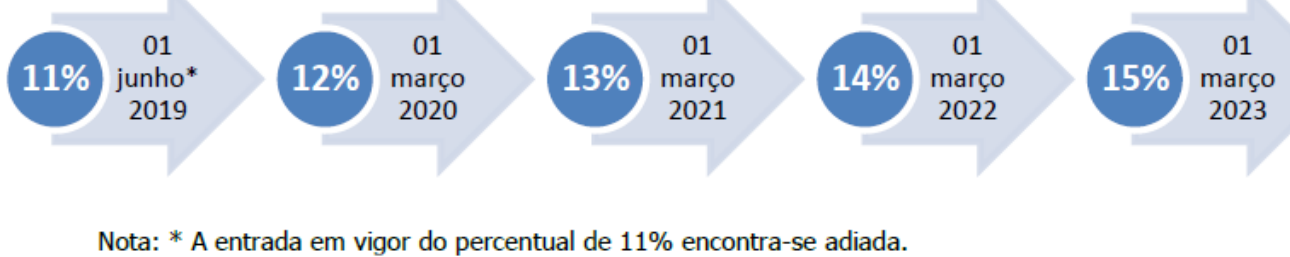

Fonte: Empresa de Pesquisa Energética, 2019

Devido ao aumento da demanda pelo biocombustível causado pelo teor de biodiesel obrigatório atual, em 2018 foram produzidos cerca de 5,4 bilhões de litros de biodiesel, um aumento de $24,7 \%$ em relação ao ano anterior, o que gerou uma quantidade significativa de glicerol, já que a cada $10 \mathrm{~kg}$ de biodiesel produzido há a geração de $1 \mathrm{~kg}$ de glicerol (GRASSELLI, TRIFIRO, 2017; EMPRESA DE PESQUISA ENERGETICA, 2019).

O glicerol é um subproduto gerado durante a transesterificação dos triglicerídeos com um álcool. Durante a reação, as moléculas dos triglicerídeos se quebram em moléculas menores formando os ésteres de ácidos graxos e glicerol, conforme esquematizado na Figura 11.

Figura 11 - Reação de transesterificação

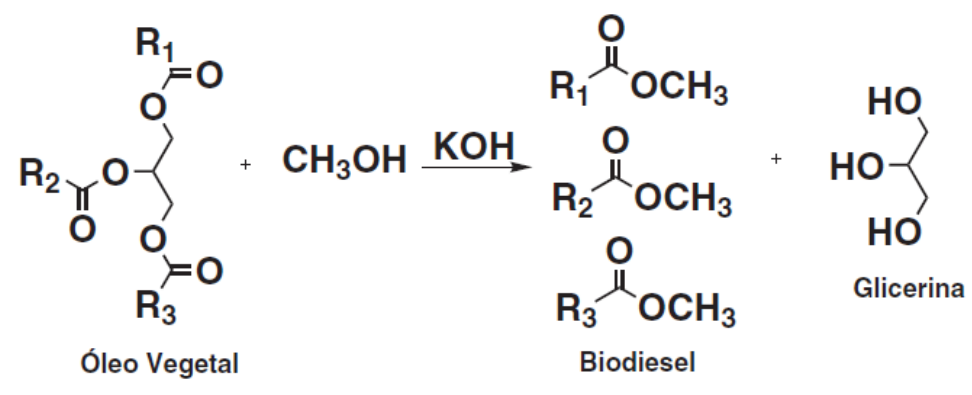

Fonte: Mota, Silva e Gonçalves, 2009

Devido à grande oferta de glicerol no mercado mundial, causada pelo aumento da produção de biodiesel, o glicerol passou a ter menos valor agregado, o que fez com que muitas empresas que a sintetizavam a partir do propeno fossem desativadas (MOTA, SILVA, GONÇALVES., 2009). Por esse motivo, é de suma importância o estudo e desenvolvimento de novas rotas para a valorização do glicerol, utilizando-a como matéria-prima para outros produtos com maior valor agregado. O item 3.5.2 apresenta algumas dessas alternativas, como os processos de oxidação, desidratação, eterificação e esterificação do glicerol. 


\subsubsection{O glicerol}

O glicerol (1,2,3-propanotriol) é um composto pertencente à família dos álcoois, formado por três átomos de carbono e três hidroxilas, conforme a fórmula estrutural representada na Figura 12. À temperatura ambiente ele se apresenta como um líquido incolor viscoso (com ponto de ebulição de $290{ }^{\circ} \mathrm{C}$ e viscosidade de 1,5 Pa.s a $20{ }^{\circ} \mathrm{C}$ ), com sabor adocicado e sem cheiro. Devido a presença das hidroxilas, o glicerol é solúvel em água e tem características higroscópicas, que correspondem a capacidade do material em absorver água (BEATRIZ, ARAUJO, LIMA, 2011; MOTA, PINTO, 2017).

Figura 12 - Fórmula estrutural do glicerol

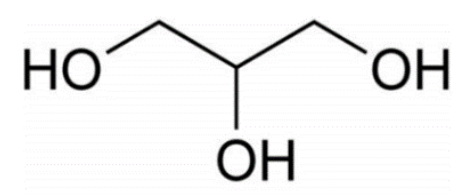

Fonte: Autor

Em 1779, o químico sueco Carl Wilhelm Scheele conseguiu isolar o glicerol quando submeteu uma mistura de letargo (óxido de chumbo) e azeite de oliva a aquecimento. Naturalmente, o glicerol só é encontrado em suas formas combinadas, como é o caso dos triglicerídeos, e pode ser separado com a adição de hidróxido de sódio pela reação de saponificação. O mesmo pode ser sintetizado a partir do propeno conforme a reação descrita na Figura 13. Primeiramente, o propeno passa por uma etapa de cloração a altas temperaturas formando o cloreto de etila. Em seguida, é adicionado ácido hipocloroso para a formação da haloidrina, que em presença de excesso de base leva à formação do glicerol (MOTA, SILVA, GONCALVES, 2009; BEATRIZ, ARAUJO, LIMA, 2011).

Figura 13 - Síntese do glicerol a partir do propeno

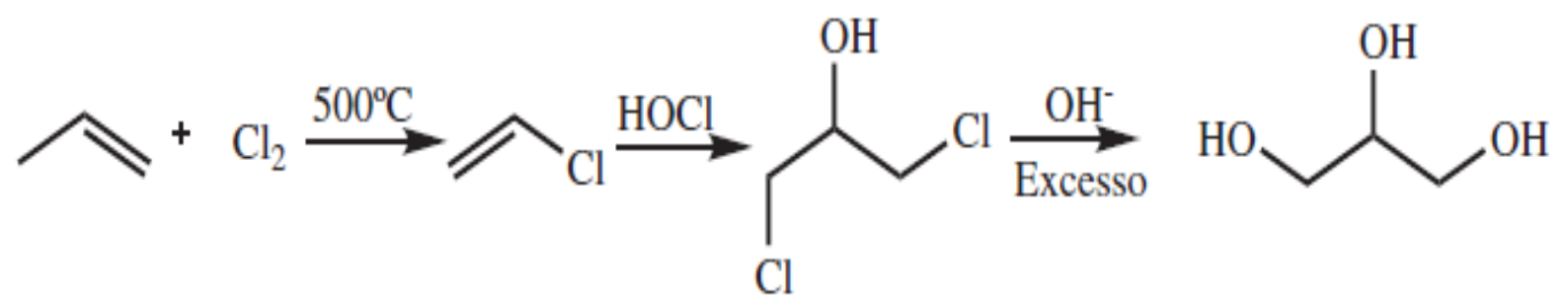

Fonte: Mota, Silva e Gonçalves, 2009 
O glicerol quando purificado pode ser utilizado na fabricação de cosméticos, artigos de higiene pessoal, medicamentos, alimentos e explosivos (nitroglicerina). A Figura 14 apresenta um gráfico indicando as principais aplicações na indústria atualmente (MOTA, SILVA, ARAUJO, 2009).

O glicerol obtido na transesterificação dos óleos vegetais é chamado de glicerina loira, contém cerca de $80 \%$ de glicerol e apresenta outros compostos como água, resíduos de metanol e sais dissolvidos. Antes de ser utilizada, ele passa por um tratamento ácido para neutralização do catalisador básico utilizado na transesterificação e é necessário remover os ácidos graxos que podem ser formados nesse processo (MOTA, SILVA, ARAUJO, 2009).

A seguir são apresentadas algumas rotas químicas que possibilitam o uso do glicerol como matéria-prima para a produção de outros compostos importantes para a indústria química.

Figura 14 - Aplicações do glicerol e seus derivados

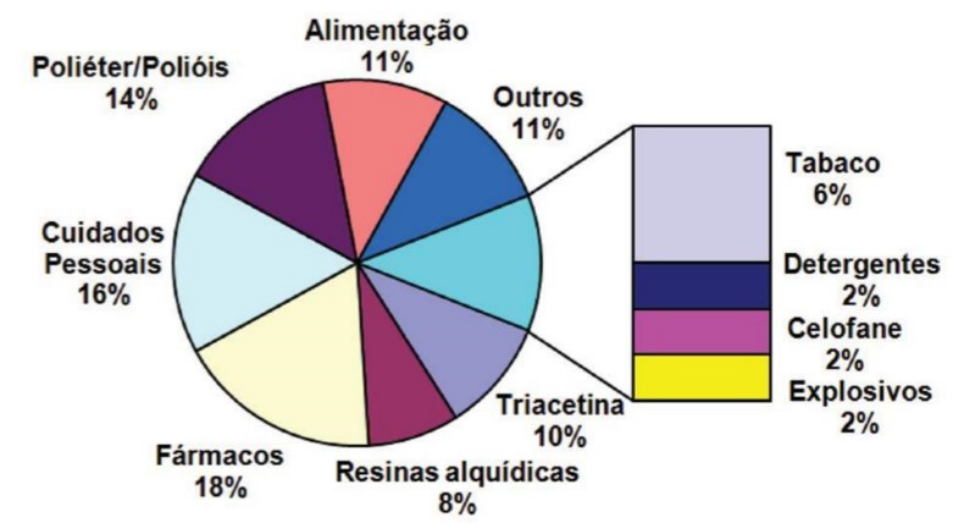

Fonte: Beatriz, Araújo e Lima, 2011

\subsubsection{Eterificação do glicerol}

Assim como a maioria das aplicações dos produtos derivados do glicerol, sua reação de eterificação com um álcool também gera produtos muito utilizados na produção de solventes e aditivos para combustíveis. Em sua maioria, apresentam características como menor viscosidade e polaridade que o glicerol. Isso se deve provavelmente pela proteção das hidroxilas que diminuem as interações por pontes de hidrogênio. A eterificação com o etanol pode ser feita utilizando como catalisador sólidos ácidos como as zeólitas e resinas sulfônicas. Nesses casos, podem ser produzidos mono, di e tri-glicerol-éteres conforme as reações representadas na Figura 15, que são utilizados como aditivos para o biodiesel para melhorar suas propriedades de fluxo a frio (PINTO et al., 2016). 
Figura 15 - Reação de eterificação entre o glicerol e o etanol<smiles>CCOCC(O)CO</smiles><smiles>CCOC(CO)CO</smiles><smiles>C#CC(O)CO</smiles><smiles>CCOCC(O)COCC</smiles><smiles>CCOCC(CO)OCC</smiles><smiles>CCOCC(COCC)OCC</smiles>

Fonte: Mota e Pinto, 2017

\subsubsection{Esterificação do glicerol}

Os ésteres de glicerol são naturalmente encontrados em gorduras animais e óleos vegetais e podem ser sintetizados pela esterificação do glicerol com ácidos graxos. Dentre os ésteres produzidos, há grande interesse para a obtenção do mono e diacilglicerois, pois são muito utilizados como surfactantes. Nesta reação, primeiramente é necessário proteger as hidroxilas do glicerol utilizando uma acetona para a formação de um cetal. Em seguida, ocorre a transesterificação da hidroxila livre do glicerol com um ácido graxo e por fim o produto é hidrolisado para a formação do monoacilglicerol, conforme representado na Figura 16.

Figura 16 - Representação da reação do glicerol com ácido graxo para a síntese do monoacilglicerol<smiles>CC(=O)[18OH]</smiles>

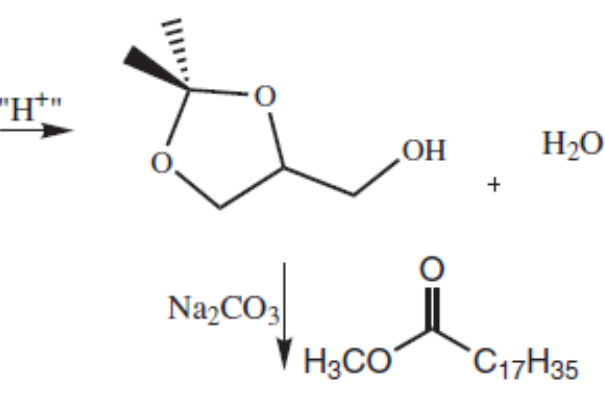

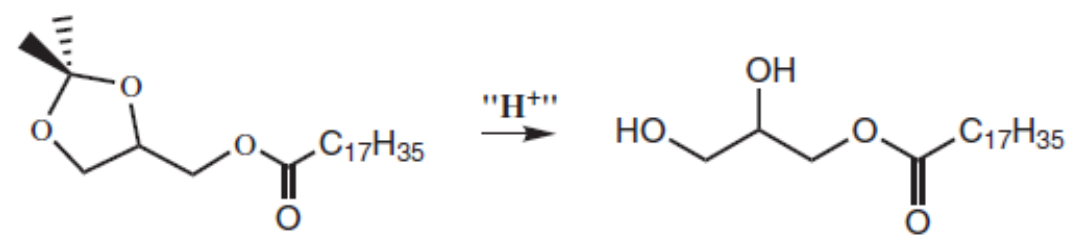




\subsubsection{Oxidação do glicerol}

A oxidação do glicerol pode levar a produção de diversos compostos, dentre eles a 1,3-dihidroxicetona, o gliceraldeído e outros que estão representados na Figura 17.

A 1,3-dihidroxiacetona (DHA) é utilizada na produção de polímeros e bronzeadores e é sintetizada a partir oxidação eletrocatalítica do glicerol. A seletividade da DHA está relacionada ao tempo de reação, em curtos períodos sua seletividade é maior, se a reação se estender por longos períodos pode levar a formação do ácido hidroxipirúvico. Já o gliceraldeído é um intermediário no metabolismo de carboidratos. Ele é obtido na presença de catalisadores contendo platina, pois facilitam o ataque a hidroxila primária (ALABA et al., 2019; MOTA, SILVA, GONÇALVES, 2009).

Figura 17 - Produtos de oxidação do glicerol

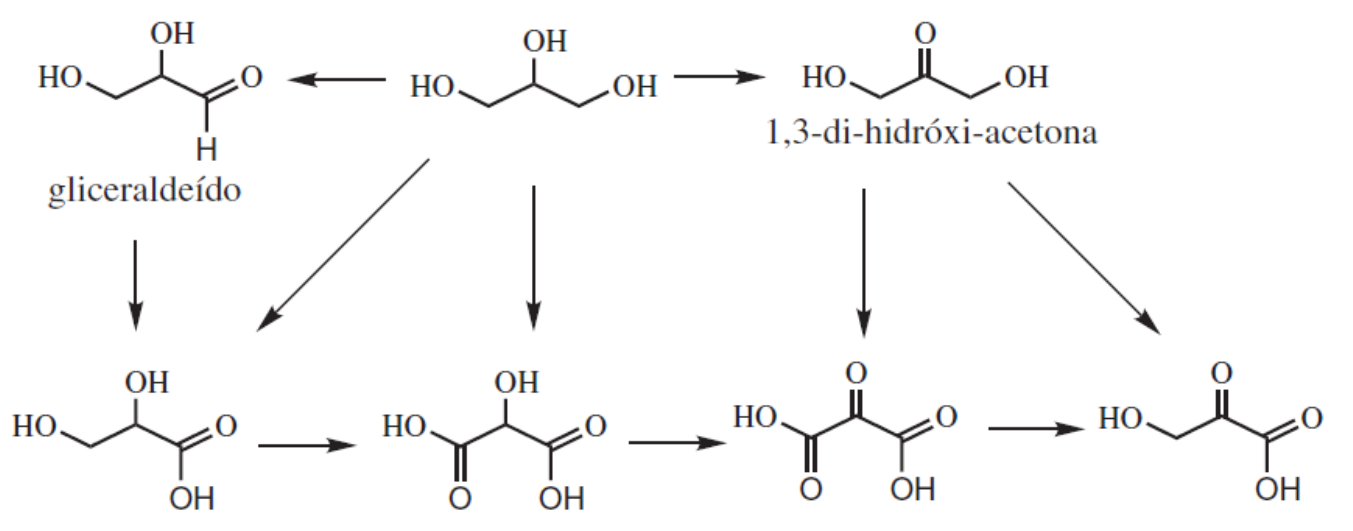

ácido glicérico

ácido tartrônico

ácido mesoxálico

ácido hidróxi-pirúvico

Fonte: Mota, Silva e Pinto, 2009

\subsubsection{Desidratação do glicerol}

Os catalisadores utilizados para a desidratação do glicerol são ácidos, e este é um dos parâmetros com maior influência na atividade catalítica e seletividade do catalisador. Segundo o trabalho desenvolvido por Chai et al., 2007, catalisadores com acidez de Hammett entre -8 e -3 $\left(\mathrm{Nb}_{2} \mathrm{O}_{5}, \mathrm{WO}_{3}, \mathrm{HSM}-5\right.$, entre outros) apresentam bom desempenho para obtenção da acroleína, com seletividade próxima a 70\%, mas se a acidez for muito elevada, pode levar a formação de coque e $\mathrm{CO}_{\text {x. }}$ o que diminui a seletividade da reação.

Além da acidez do catalisador, o tipo de sítio ácido presente também afeta nos produtos obtidos. Aqueles que possuem maior quantidade de sítios ácidos de Lewis, apresentam maior 
seletividade para o acetol, nesse caso ocorre a desidratação da hidroxila primária do glicerol. Já os que possuem sítios ácidos de Brønsted apresentam maior seletividade para a formação da acroleína, na qual ocorre a desidratação da hidroxila secundária, as reações são mostradas na Figura 18 (CHAI et al., 2007; TALEBIAN-KIAKALAIEH, AMIN, HEZAVEH, 2014; MA et al., 2017).

Figura 18 - Reações de desidratação do glicerol

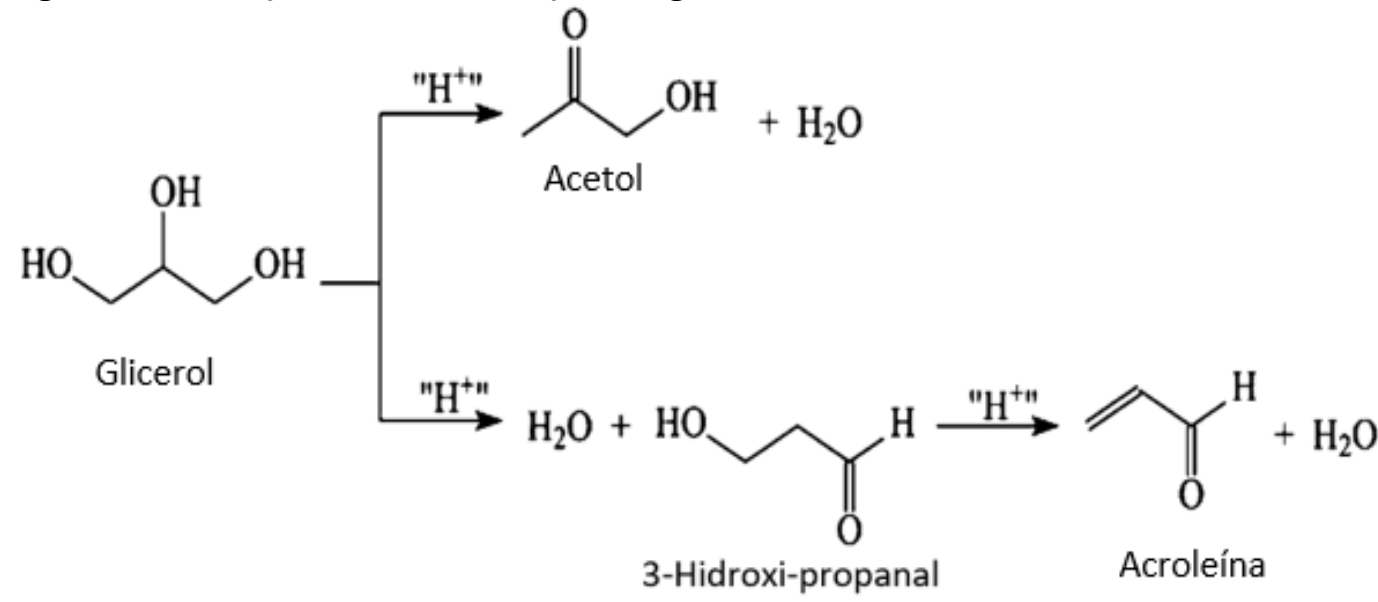

Fonte: Autor “adaptado de" Grasselli e Trifiro, 2017, pg S51

O processo para a obtenção do ácido acrílico a partir do glicerol é semelhante à rota partir do propeno já comentada anteriormente. Primeiramente o glicerol é desidratado utilizando catalisadores ácidos para a formação da acroleína, que na sequência é oxidada para ácido acrílico. Esse processo pode ocorrer em duas etapas distintas, utilizando catalisadores e condições reacionais diferentes o que possibilita a otimização de cada etapa e assim aumentar a seletividade para o ácido acrílico. Liu e colaboradores estudaram o processo utilizando dois reatores em série, o primeiro, contendo um catalisador ácido formado por $\mathrm{Cs}, \mathrm{P}$ e W suportado em $\mathrm{Nb}_{2} \mathrm{O}_{5}$ apresentou conversões de $100 \%$ para o glicerol e uma seletividade de $84 \%$ para acroleína. E o segundo, operando na presença de um catalisador formado por óxidos mistos de Mo-V suportados, apresentou um rendimento de 75\% para o ácido acrílico (LIU, WANG, JIN, 2014).

Apesar do processo em duas etapas apresentar altos rendimentos para a produção do ácido acrílico, é possível converter o glicerol diretamente a ácido acrílico por meio do processo de oxidesidratação, a Figura 19 mostra uma esquematização das reações em uma e duas etapas. Nesse caso, são utilizados catalisadores bifuncionais contendo como fase ativa os óxidos de molibdênio e vanádio, e também outros compostos como os óxidos de tungstênio e nióbio, 
conforme descrito por Omata et al. (2015), o qual apresentou um rendimento de $46 \%$ para o ácido acrílico. Esses catalisadores contêm sítios ácidos que permitem a desidratação do glicerol a acroleína que logo em seguida é oxidada a ácido acrílico nos sítios redox. Uma das vantagens apresentada no processo em uma única etapa é a combinação das reações de desidratação e oxidação em um único reator, o que pode gerar um ganho energético no sistema se considerar que o calor gerado na reação de oxidação (exotérmica $-\Delta \mathrm{H}=-298,3 \mathrm{~kJ} / \mathrm{mol}$ ) pode ser usado na etapa de formação da acroleína (endotérmica $-\Delta \mathrm{H}=18 \mathrm{~kJ} / \mathrm{mol}$ ), além da simplificação do processo (POSSATO et al., 2017; RASTEIRO et al., 2017; OMATA et al., 2015).

Figura 19 - Processo em uma e duas etapas para obtenção do ácido acrílico a partir do glicerol

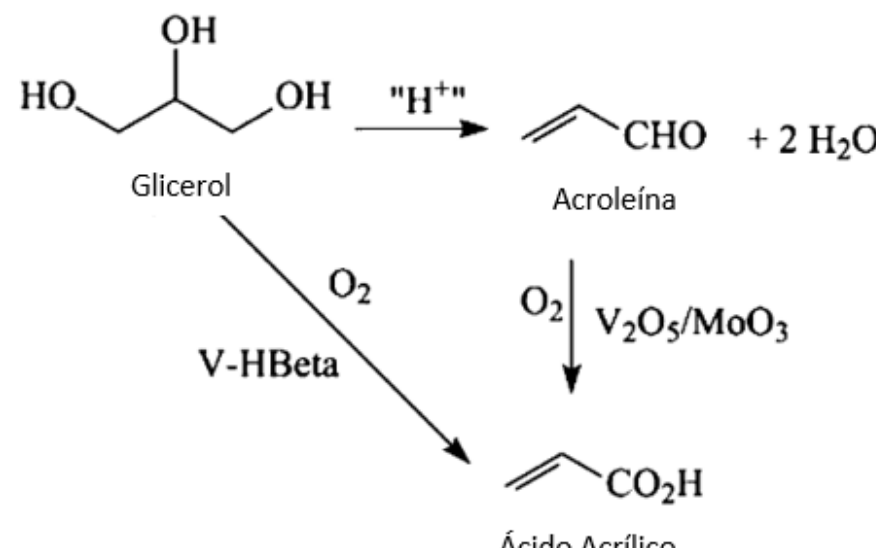

Fonte: Autor "adaptado de" Grasselli e Trifiro, 2017, pg 62 


\section{MATERIAIS E MÉTODOS}

Os procedimentos realizados para a síntese dos catalisadores, assim como os reagentes utilizados para os preparos e as análises necessárias para as caracterizações dos materiais estão descritas nos itens 4.1 e 4.2. Já o item 4.3 apresenta as condições utilizadas nos processos reacionais para os testes catalíticos.

\subsection{PREPARAÇÃO DOS CATALISADORES}

Para o desenvolvimento do trabalho foram sintetizados catalisadores contendo os óxidos de molibdênio, vanádio, tungstênio e cobre com composições B1- $\mathrm{Mo}_{12} \mathrm{~V}_{4,8} \mathrm{~W}_{2,4} \mathrm{Cu}_{2,2} \mathrm{Si}_{8,4}$, B2$\mathrm{Mo}_{12} \mathrm{~V}_{2} \mathrm{~W}_{0,5} \mathrm{Si}_{6,2}$ e B3- $\mathrm{Mo}_{12} \mathrm{~V}_{2,7} \mathrm{Si}_{6,2}$, seguindo metodologias adaptadas de patentes disponíveis em domínio público, descritas nos itens 4.1 .1 e 4.1.2 a seguir. Os catalisadores foram sintetizados por diferentes métodos de preparação, sendo eles por evaporação, evaporação seguido por tratamento hidrotérmico e tratamento hidrotérmico, baseando-se em estudos realizados anteriormente (FANTIM et al., 2019; FANTIM et al., 2017).

O trabalho foi divido em duas etapas: primeiramente foram preparadas amostras preliminares por tratamento hidrotérmico, exclusivas para caracterizações físico-químicas e morfológicas. Nessa etapa, os três catalisadores foram preparadas via tratamento hidrotérmico, na presença ou não de um copolímero de blocos, variando a relação sólido/água durante a preparação para verificar como esse parâmetro influenciou na estrutura e composição dos catalisadores, terminadas as caracterizações, um exemplar preparado por tratamento hidrotérmico e um com o copolímero, que mostraram melhores resultados, foram selecionados para os testes da Etapa II do projeto.

$\mathrm{Na}$ segunda e principal etapa do trabalho, as amostras selecionadas na primeira etapa foram preparadas novamente em maior escala para os testes em reator, e junto a elas foram preparadas também as amostras por evaporação, e evaporação seguida por tratamento. Por fim, os materiais foram avaliados nas reações para obtenção do ácido acrílico a partir da acroleína e glicerol. Os procedimentos mais detalhados de cada etapa estão apresentados nos itens $4.1 .1 \mathrm{e}$ 4.1.2.

Os reagentes utilizados no preparo, assim como a porcentagem de pureza e fabricante dos mesmos estão listados abaixo. 
- Heptamolibdato de amônio - $\left(\mathrm{NH}_{4}\right)_{6} \mathrm{Mo}_{7} \mathrm{O}_{24} \cdot 4 \mathrm{H}_{2} \mathrm{O}$ - 99,0\% de pureza $(1235,86 \mathrm{~g} / \mathrm{mol})$ - Sigma Aldrich;

- Metavanadato de amônio - $\mathrm{HNO}_{3} \mathrm{~V}$ - 99,0\% de pureza (116,98 g/mol) - Sigma-Aldrich;

- Tungstato de amônio - $\mathrm{H}_{42} \mathrm{~N}_{10} \mathrm{O}_{42} \mathrm{~W}_{12}$ - 99,9\% de pureza $(3060,46 \mathrm{~g} / \mathrm{mol})$ - SigmaAldrich

- Nitrato de cobre - $\mathrm{CuN}_{2} \mathrm{O}_{6} .3 \mathrm{H}_{2} \mathrm{O}-99 \%$ de pureza $(241,60 \mathrm{~g} / \mathrm{mol})$ - Sigma-Aldrich

- Ácido oxálico - Dinâmica

- Sílica Aerosil - $\mathrm{SiO}_{2}-\mathrm{Synth}$ do Brasil

- Pluronic ${ }^{\circledR}$ P-123 - PEG-PPG-PEG - Sigma Aldrich

\subsubsection{Etapa I - Estudo da metodologia de síntese via tratamento hidrotérmico}

$\mathrm{Na}$ primeira etapa do projeto, os catalisadores B1, B2 e B3 foram preparadas via tratamento hidrotérmico, variando a quantidade de água utilizada durante a dissolução dos reagentes, para avaliar como esse parâmetro influenciou no rendimento, cristalinidade, propriedades físico-químicas e morfológica das amostras obtidas. Além disso, foi avaliado também como as amostras se comportaram quando preparadas na presença de um copolímero de blocos, cuja a finalidade foi o aumento da dimensão e estruturação dos poros dos catalisadores para a formação de materiais mesoporosos. O copolímero utilizado foi o Pluronic ${ }^{\circledR}$ P123 cujo nome é poly(ethylene glycol)-block-poly(propylene glycol)-blockpoly(ethylene glycol) e sua estrutura é mostrada na Figura 20 (KRUK, 2012). Um esquema das preparações e a nomenclatura atribuída a cada amostra estão mostrados na Figura 21.

Figura 20 - Fórmula estrutural do copolímero blocos Pluronic ${ }^{8}$ P123<smiles>CCC(C)(C)OC(C)CC(C)(C)OCCC(C)(C)O</smiles> 
Figura 21 - Amostras B sintetizadas para caracterizações preliminares

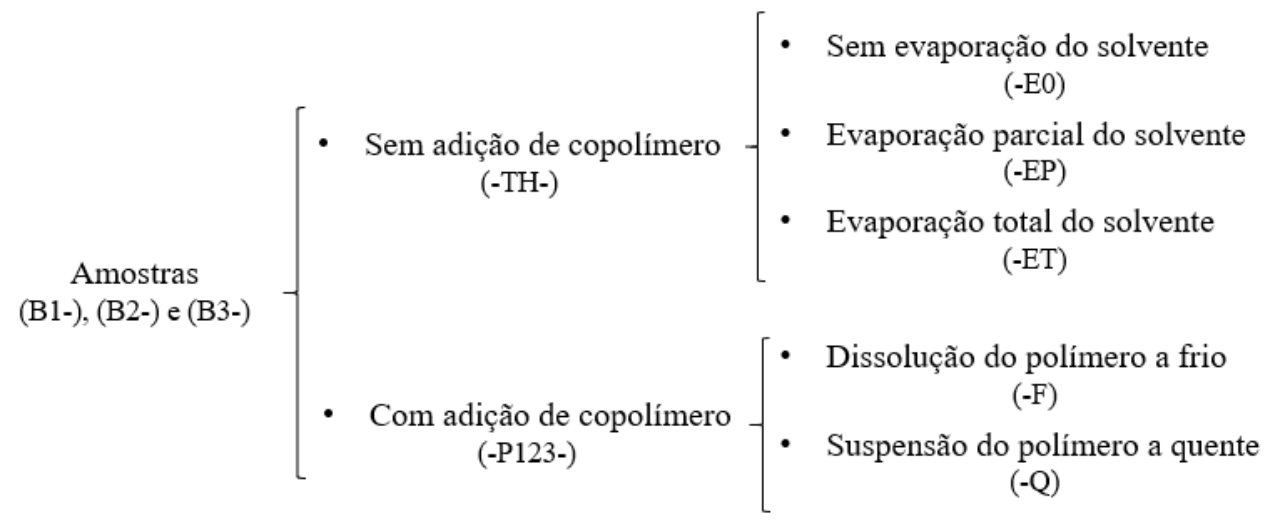

Fonte: Autor

As metodologias seguidas para a preparação das variações das amostras B1, B2 e B3 foram adaptadas de procedimentos descritos em patentes no domínio público, identificada nas metodologias abaixo, propondo algumas alterações e adaptações no método de preparo. Apesar dessas variações, o procedimento base seguido para todas foi semelhante e consistiu em (I), na preparação das soluções iniciais de reagentes variando a quantidade de água, (II) no tratamento hidrotérmico para a formação das amostras e (III) no tratamento térmico do material obtido para a formação dos óxidos metálicos. As Figuras 22, 23 e 24 apresentam um fluxograma base para a preparação das amostras B1, B2 e B3.

A primeira etapa (I) consistiu na preparação das misturas iniciais de reagentes que formaram os catalisadores com as composições desejadas. Como foi variada a quantidade de água usada na dissolução de cada reagente, o volume utilizado está com um valor variável no texto e determinado nas Tabelas 4, 5 e 6 . A seguir são descritas as metodologias gerais para a preparação das amostras B1, B2 e B3.

- $\quad B 1-\mathrm{Mo}_{12} \mathrm{~V}_{4,8} \mathrm{~W}_{2,4} \mathrm{Cu}_{2,2} \mathrm{Si}_{8,4}$

Em um béquer contando $\mathbf{V}_{1} \mathrm{~mL}$ de água destilada a $80^{\circ} \mathrm{C}$ foi adicionado sob agitação vigorosa, 0,80 $\mathrm{g}$ de tungstato de amônio. Após a dissolução adicionou-se $0,72 \mathrm{~g}$ de metavanadato de amônio e em seguida, 2,80 g de heptamolibdato de amônio. Separadamente, $0,73 \mathrm{~g}$ de nitrato de cobre foi dissolvido em $\mathbf{V}_{\mathbf{2}} \mathrm{mL}$ de água a $70{ }^{\circ} \mathrm{C}$ e adicionados a mistura principal. O sistema foi mantido sob agitação por 5 minutos. Após esse período foram adicionados 0,60 g de sílica Aerosil ${ }^{\circledR}$ e novamente o sistema permaneceu sob agitação a $80{ }^{\circ} \mathrm{C}$ (WADA et al., 1974). 
Tabela 4 - Volumes de água utilizados nas preparações das variações da amostra B1

\begin{tabular}{lccccc}
\hline & B1-TH-E0 & B1-TH-EP & B1-TH-ET & B1-P123-Q & B1-P123-F \\
\hline $\mathrm{V}_{1}(\mathrm{~mL})$ & 15 & 50 & 50 & 30 & 30 \\
$\mathrm{~V}_{2}(\mathrm{~mL})$ & 5 & 10 & 10 & 5 & 5 \\
\multirow{2}{*}{ Preparação } & Sem & $\begin{array}{c}\text { Evaporação } \\
\text { parcial do } \\
\text { solvente }\end{array}$ & $\begin{array}{c}\text { Evaporação } \\
\text { total do } \\
\text { solvente }\end{array}$ & $\begin{array}{c}\text { Polímero } \\
\text { suspenso em } \\
\text { água a quente }\end{array}$ & $\begin{array}{c}\text { dissolvímero } \\
\text { água a frio }\end{array}$ \\
\hline
\end{tabular}

Fonte: Autor

Figura 22 - Fluxograma base para a preparação da amostra B1

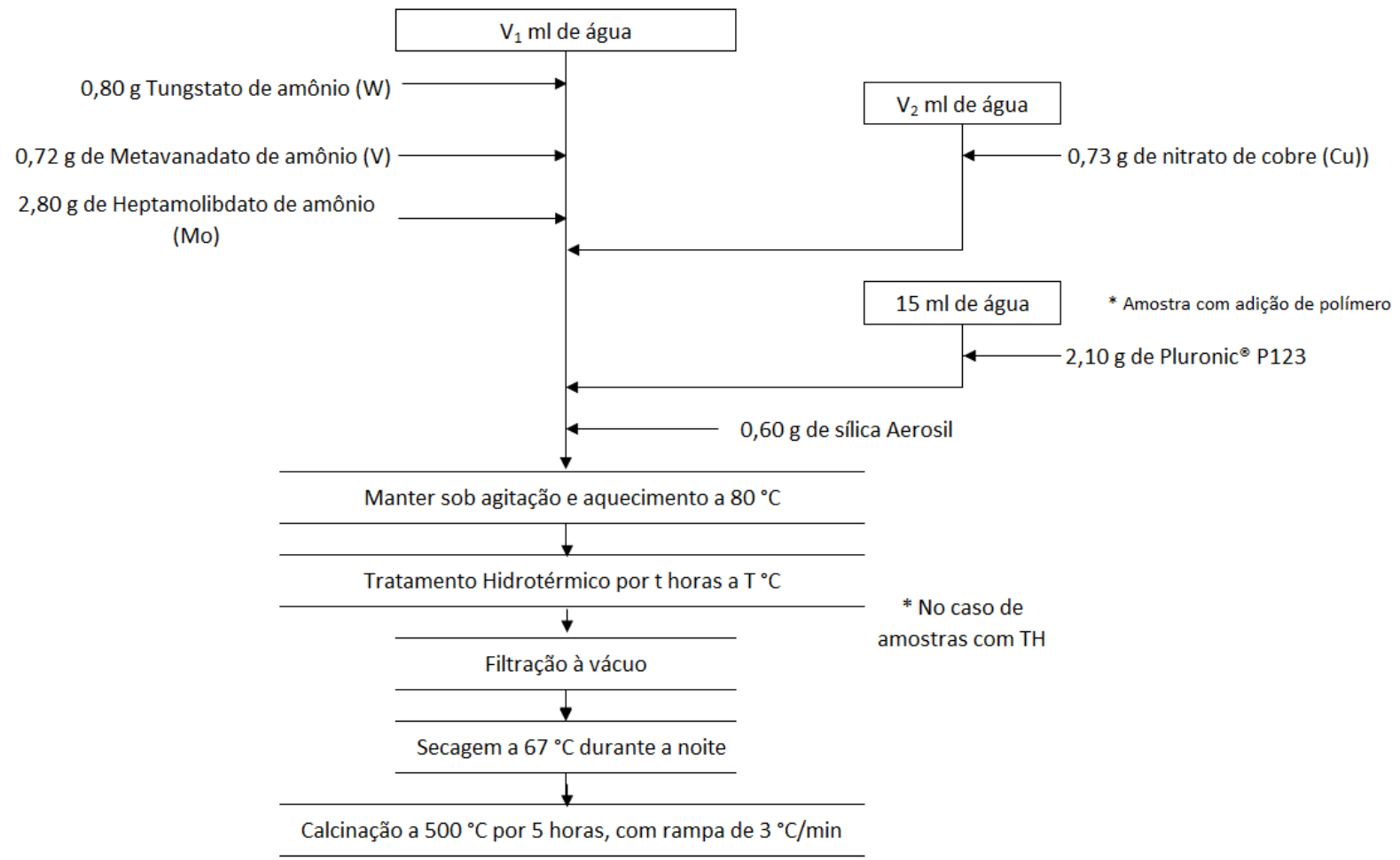

Fonte: Autor

- $\quad B 2-\mathrm{Mo}_{12} \mathrm{~V}_{2} \mathrm{~W}_{0,5} \mathrm{Si}_{6,2}$

Em béqueres diferentes, 4,20 $\mathrm{g}$ de heptamolibdato de amônio, 0,47 $\mathrm{g}$ de metavanadato de amônio e $0,28 \mathrm{~g}$ de tungstato de amônio foram dissolvidos em $\mathbf{V}_{\mathbf{3}}, \mathbf{V}_{\mathbf{4}}$ e $\mathbf{V}_{\mathbf{5}} \mathrm{mL}$ de água destilada a $70{ }^{\circ} \mathrm{C}$ sob agitação vigorosa, respectivamente. Em seguida, a solução de metavanadato foi adicionada à solução de heptamolibdato e depois a solução de tungstato foi adicionada à mistura principal. $\mathrm{O}$ sistema foi mantido sob agitação e aquecimento a $80{ }^{\circ} \mathrm{C}$ por 5 minutos e então foi adicionado $0,60 \mathrm{~g}$ de sílica Aerosil ${ }^{\circledR}$ e novamente o sistema permaneceu sob agitação e aquecimento (YAMAGUCHI, TAKENAKA, 1971). 
Tabela 5 - Volumes de água utilizados nas preparações das variações da amostra B2

\begin{tabular}{|c|c|c|c|c|c|}
\hline Amostra & B2-TH-E0 & B2-TH-EP & B2-TH-ET & B2-P123-Q & B2-P123-F \\
\hline $\mathrm{V}_{3}(\mathrm{~mL})$ & 5 & 20 & 20 & 10 & 10 \\
\hline $\mathrm{V}_{4}(\mathrm{~mL})$ & 5 & 20 & 20 & 10 & 10 \\
\hline $\mathrm{V}_{5}(\mathrm{~mL})$ & 15 & 15 & 15 & 10 & 10 \\
\hline Preparação & $\begin{array}{c}\text { Sem } \\
\text { evaporação }\end{array}$ & $\begin{array}{c}\text { Evaporação } \\
\text { parcial do } \\
\text { solvente }\end{array}$ & $\begin{array}{c}\text { Evaporação } \\
\text { total do } \\
\text { solvente }\end{array}$ & $\begin{array}{c}\text { Polímero } \\
\text { suspenso em } \\
\text { água a quente }\end{array}$ & $\begin{array}{c}\text { Polímero } \\
\text { dissolvido em } \\
\text { água a frio }\end{array}$ \\
\hline
\end{tabular}

Fonte: Autor

Figura 23 - Fluxograma base para a preparação da amostra B2

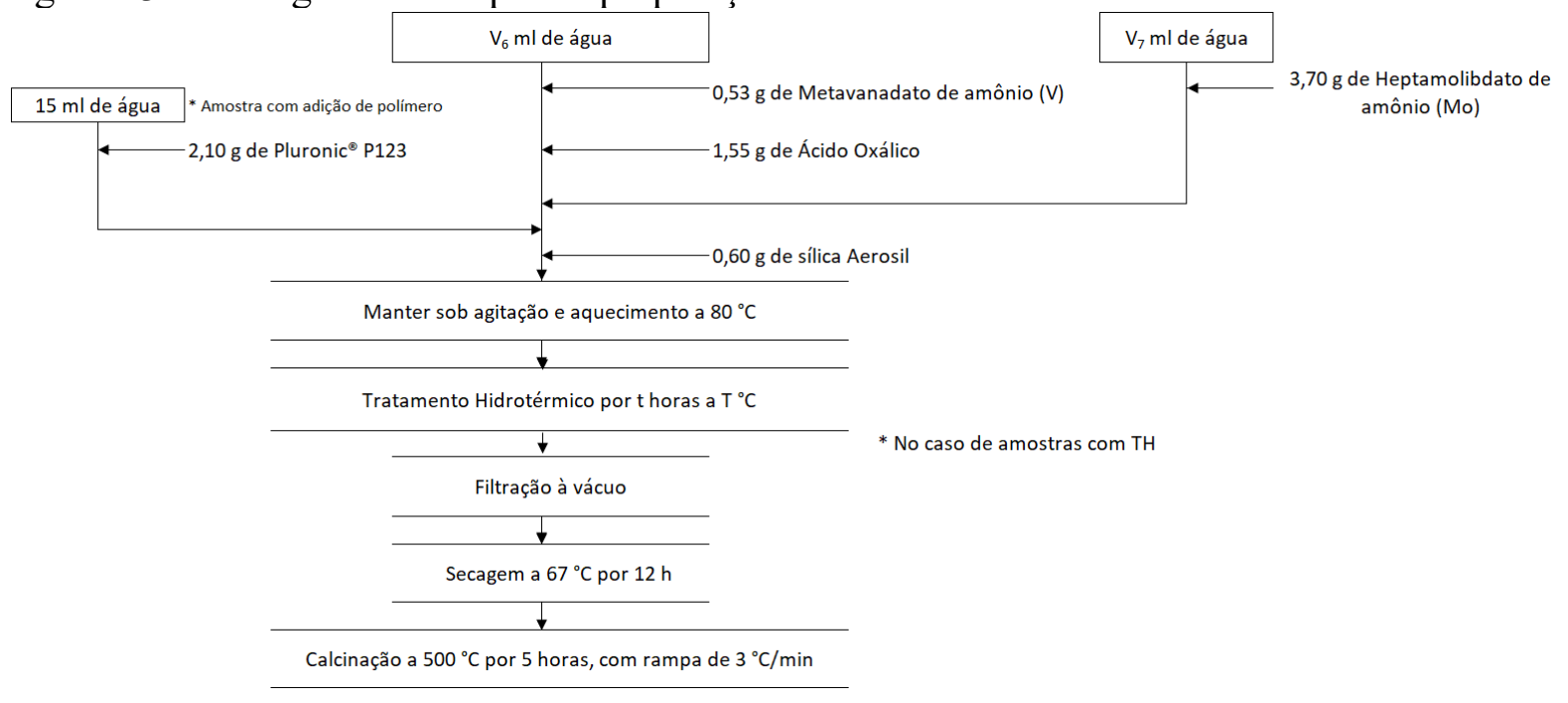

Fonte: Autor

- $\quad B 3-\mathrm{Mo}_{12} \mathrm{~V}_{2,7} \mathrm{Si}_{6,2}$

0,53 $\mathrm{g}$ de metavanadato de amônio foram dissolvidos em $\mathbf{V}_{6} \mathrm{~mL}$ de água destilada a $70{ }^{\circ} \mathrm{C}$ sob agitação vigorosa até completa dissolução. Em seguida foram adicionados 1,55 g de ácido oxálico e manteve-se a agitação do sistema até que todo o ácido tenha reagido. Depois disso, 3,70 g de heptamolibdato de amônio dissolvidos em $\mathbf{V}_{7} \mathrm{~mL}$ de água destilada a $70{ }^{\circ} \mathrm{C}$ foram adicionados a mistura principal. O sistema foi mantido sob agitação e aquecimento a $80{ }^{\circ} \mathrm{C}$ por 5 minutos e então foi adicionado $0,60 \mathrm{~g}$ de sílica Aerosil ${ }^{\circledR}$ e novamente o sistema permaneceu sob agitação e aquecimento (KADOWAKI, KOSHIKAWA, 1973). 
Figura 24 - Fluxograma base para a preparação da amostra B3

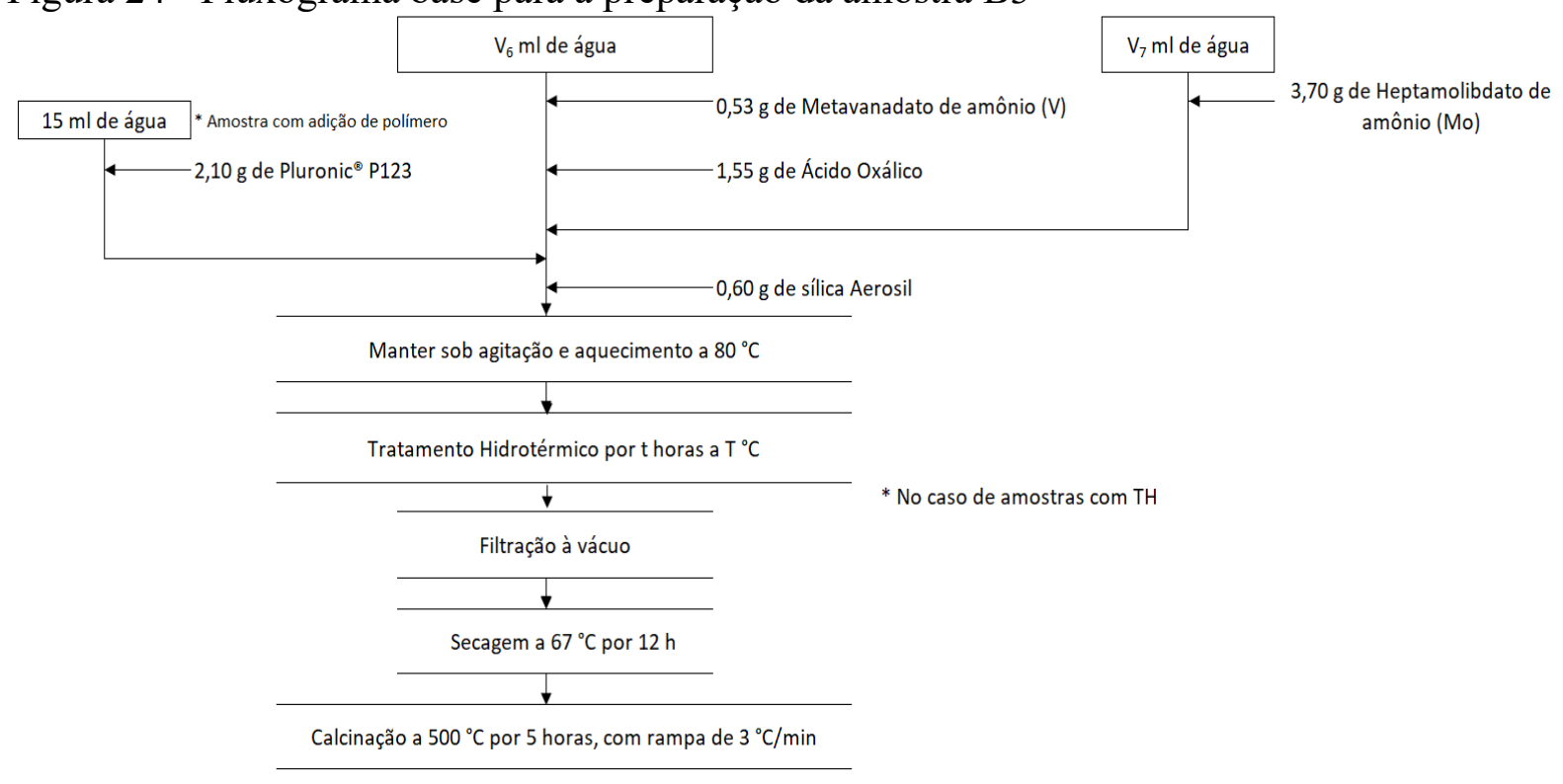

Fonte: Autor

Tabela 6 - Volumes de água utilizados nas preparações das variações da amostra B3

\begin{tabular}{|c|c|c|c|c|c|}
\hline & B3-TH-E0 & B3-TH-EP & B3-TH-ET & B3-P123-Q & B3-P123-F \\
\hline $\mathrm{V}_{6}(\mathrm{~mL})$ & 15 & 25 & 25 & 15 & 15 \\
\hline $\mathrm{V}_{7}(\mathrm{~mL})$ & 10 & 25 & 25 & 10 & 10 \\
\hline Preparação & $\begin{array}{c}\text { Sem } \\
\text { evaporação }\end{array}$ & $\begin{array}{c}\text { Evaporação } \\
\text { parcial do } \\
\text { solvente }\end{array}$ & $\begin{array}{c}\text { Evaporação } \\
\text { total do } \\
\text { solvente }\end{array}$ & $\begin{array}{c}\text { Polímero } \\
\text { suspenso em } \\
\text { água a quente }\end{array}$ & $\begin{array}{c}\text { Polímero } \\
\text { dissolvido em } \\
\text { água a frio }\end{array}$ \\
\hline
\end{tabular}

Fonte: Autor

A primeira modificação proposta na metodologia foi a preparação das amostras utilizando diferentes relações sólido/água, nesse caso foram feitas três adaptações no procedimento base no período de tempo que o sistema permaneceu sob agitação após a adição da sílica e são descritas a seguir.

\section{- Preparação sem evaporação (-E0)}

Nessa preparação, foi utilizada uma menor quantidade de água na dissolução dos reagentes, resultando assim em uma mistura principal com um volume próximo a $20 \mathrm{~mL}$. Assim, logo após a adição da sílica Aerosil ${ }^{\circledR}$ não foi necessário evaporar o excesso de solvente, a mistura permaneceu sob agitação e aquecimento a $80^{\circ} \mathrm{C}$ por 10 minutos e depois seguiu para o tratamento hidrotérmico. 


\section{- Evaporação parcial do solvente (-EP)}

Nesse tipo de preparação foi utilizado um maior volume de água para facilitar a dissolução dos reagentes. Por esse motivo, antes de seguir para o tratamento hidrotérmico, a amostra foi mantida sob agitação e aquecimento a $80^{\circ} \mathrm{C}$ para a evaporação do excesso do solvente, até que o volume final da mistura fosse próximo a $20 \mathrm{~mL}$.

\section{- Evaporação total do solvente (-ET)}

Procedimento semelhante ao anterior no qual ocorreu a evaporação parcial do solvente, porém nesse caso, a água foi evaporada totalmente até a formação de uma suspensão pastosa. Em seguida foram adicionados $20 \mathrm{~mL}$ de água destilada a temperatura ambiente, agitados até homogeneização e em seguida a mistura seguiu para o tratamento hidrotérmico.

Além das amostras preparadas com a variação da quantidade de água utilizada na dissolução dos reagentes, foram preparadas também amostras na presença do copolímero de blocos Pluronic ${ }^{\circledR}$ P123 para a formação de materiais mesoporosos, com maior dimensão de poros. O copolímero foi introduzido na mistura principal antes da adição da sílica e o sistema foi mantido sob agitação por 30 minutos e em seguida seguiu para o tratamento hidrotérmico. A preparação do polímero foi feita de duas maneiras diferentes, a primeira dissolvendo o polímero a frio, e a segunda realizando sua suspensão em água quente conforme descrito abaixo (SCHLOGL, TRUNSCHKE, 2006).

\section{- Polímero a frio}

Na preparação das amostras utilizando o Pluronic ${ }^{\circledR}$ P123 a frio, 2,10 g do copolímero foram adicionados a $15 \mathrm{~mL}$ de água sob intensa agitação em banho de gelo. Nesse caso ocorreu a solubilização total polímero, formando uma solução transparente. Essa solução foi adicionada a mistura principal das amostras B1, B2 e B3 logo antes da adição da sílica Aerosil@.

\section{- Polímero a quente}

O procedimento semelhante ao anterior, porém nesse caso o sistema se manteve sob agitação em um banho a $80^{\circ} \mathrm{C}$. Nesse caso ocorreu a suspensão do polímero por não ser solúvel a essa temperatura. Em seguida, a mistura de polímero foi adicionada a mistura principal logo antes da adição da sílica e o sistema seguiu para o tratamento hidrotérmico. 
Depois de preparadas as misturas principais para a formação dos catalisadores, elas foram transferidas para uma autoclave de Teflon ${ }^{\circledR}$ formada por sete cavidades com um volume aproximado de $40 \mathrm{~mL}$ cada, conforme mostrado na Figura 25, para a realização do tratamento hidrotérmico, denominado a etapa (II) da preparação.

O tratamento hidrotérmico consistiu em manter as amostras em sistema fechado em condições brandas de temperatura por um longo período de tempo. As amostras sintetizadas sem a adição de polímero (-TH-) foram tratadas a $160^{\circ} \mathrm{C}$ por 48 horas e as amostras sintetizadas na presença de copolímero (-P123-) permaneceram a $140{ }^{\circ} \mathrm{C}$ por 96 horas para conformação dos poros. Finalizado o tratamento, a autoclave foi resfriada a temperatura ambiente, as amostras filtradas à vácuo e secas em estufa a $67^{\circ} \mathrm{C}$ por 12 horas. Por último, as amostras foram quebradas em pedaços menores e calcinadas a $500{ }^{\circ} \mathrm{C}$ por 5 horas, com uma rampa de aquecimento de $3^{\circ} \mathrm{C}$ por minuto.

Figura 25 - Autoclave de Teflon para a realização do TH

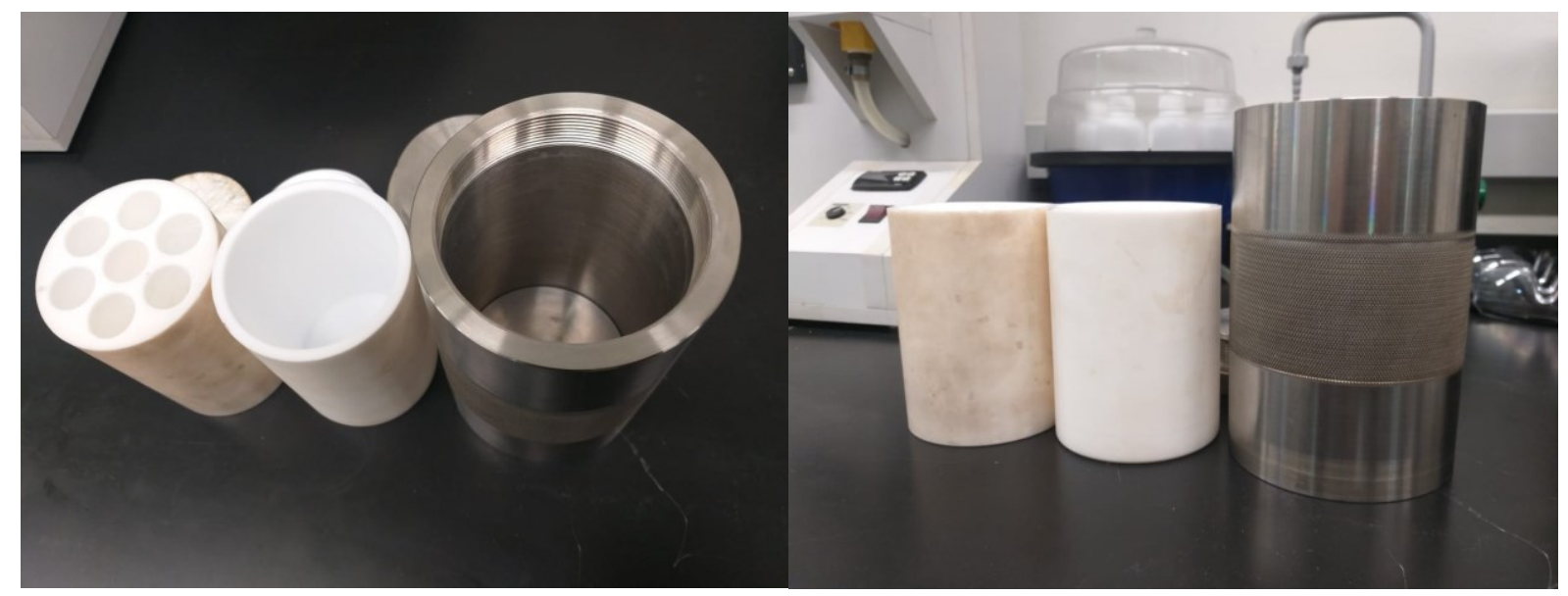

Fonte: Autor

\subsubsection{Etapa II - Preparação das amostras pelos diferentes métodos de síntese para os testes} em reator

Para a avaliação catalítica, as amostras B1, B2 e B3 foram preparadas por quatro métodos diferentes. O primeiro foi por tratamento hidrotérmico com evaporação parcial do solvente (- TH-EP), o segundo foi utilizando o copolímero P123 dissolvido a frio (-P123-F) (ambos escolhidos com base nos resultados obtidos na caracterização das amostras preliminares da primeira etapa, Item 5.1), por evaporação (-EV), e por último evaporação seguida por tratamento hidrotérmico $(-\mathrm{EV}+\mathrm{TH})$. 
As amostras escolhidas com base nos testes preliminares seguiram os mesmos procedimentos descritos no item 4.1.1 e foram preparadas em maior quantidade. As amostras sintetizadas por evaporação também seguiram a mesma metodologia para a mistura dos reagentes, porém não houve o tratamento hidrotérmico. Após a etapa de adição da sílica, as misturas foram mantidas sob agitação e aquecimento a $80^{\circ} \mathrm{C}$ até a evaporação total do solvente, em seguida foram secas em estufa a $67^{\circ} \mathrm{C}$ por 12 horas e calcinadas a $500{ }^{\circ} \mathrm{C}$ por 5 horas com rampa de aquecimento de $3{ }^{\circ} \mathrm{C} / \mathrm{min}$. A nomenclatura atribuída a essas amostras foram B1/B2/B3- EV.

Uma outra preparação proposta foi a realização de um tratamento hidrotérmico logo após a calcinação das amostras. Nesse caso, $6 \mathrm{~g}$ da amostra pronta e calcinada foram adicionados a $24 \mathrm{~mL}$ de água destilada a temperatura ambiente sob agitação, na qual permaneceram por 5 minutos. Em seguida a amostra foi transferida para a autoclave e permaneceu no tratamento hidrotérmico por 48 horas a $160{ }^{\circ} \mathrm{C}$. Por fim foram filtradas a vácuo e secas em estufa por 12 horas. Essas amostras foram identificadas como B1/B2/B3-EV+TH.

$\mathrm{O}$ último teste proposto foi a síntese da amostra B1 realizando variações em relação a composição do catalisador. A amostra B1 original apresentou em sua composição os elementos Mo, V, W e Cu. Na primeira alteração proposta, o nitrato de cobre foi excluído da preparação, mantendo os demais reagentes com a mesmas quantidades. E na segunda foram excluídos tanto o nitrato de cobre quanto o tungstato de amônio, obtendo-se assim as amostras B1.2 $\left(\mathrm{Mo}_{12} \mathrm{~V}_{4,66} \mathrm{~W}_{2,4} \mathrm{Si}_{8,4}\right)$ e $\mathrm{B} 1.3\left(\mathrm{Mo}_{12} \mathrm{~V}_{4,66} \mathrm{Si}_{8,4}\right)$. A Figura 26 mostra um resumo das amostras sintetizadas para o teste em reator e o método de preparo seguido para cada uma delas.

Figura 26 - Resumo das amostras testadas em reator

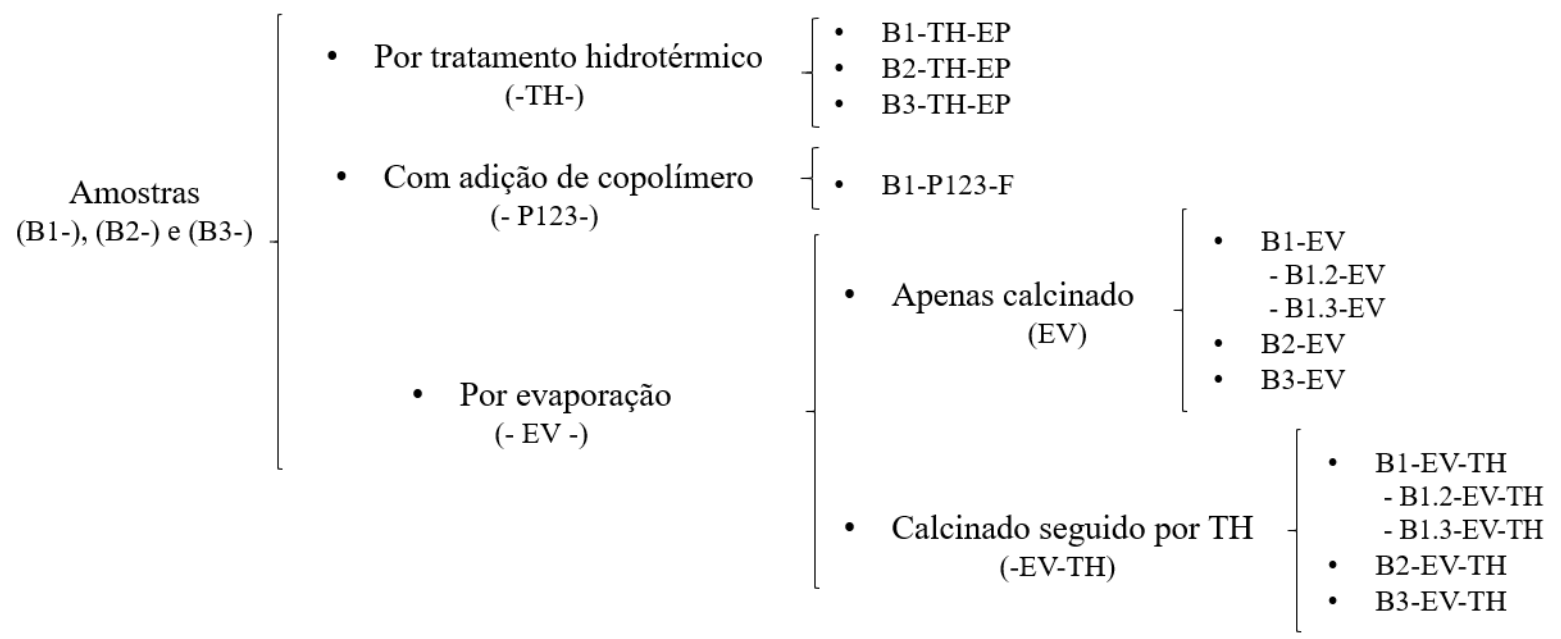




\subsection{CARACTERIZAÇÕES FÍSICO-QUÍMICAS DOS CATALISADORES}

A caracterização de catalisadores heterogêneos é essencial para determinação de propriedades físico-químicas, estrutura e morfologia. É por meio destas que se obtém informações referentes a superfície do material, as fases cristalinas formadas durante o processo de preparação, porosidade dos catalisadores, dentre outras inúmeras.

Os itens seguintes descrevem as técnicas utilizadas para as caracterizações das amostras sintetizadas no presente trabalho, e apresentam as condições dos experimentos e outros detalhes.

\subsubsection{Difratometria de raios-X (DRX)}

Os catalisadores obtidos foram caracterizados por difratometria de raios-X utilizando um difratômetro Shimadzu modelo XRD-7000, equipado com tubo de cobre e monocromador de grafite.

Para determinação das fases cristalinas presentes em cada catalisador sintetizado, as análises foram realizadas a temperatura ambiente, utilizando com fonte de radiação o cobre $(\mathrm{Cu}-\mathrm{K} \alpha, \lambda=1,5406 \AA)$, corrente de $30 \mathrm{~mA}$, tensão de $40 \mathrm{~V}$, abertura da janela de 1,0 e abertura do contador de 0,3 . Os difratogramas foram obtidos num intervalo de 10 a 56 em $2 \theta$, com velocidade de varredura de $1 \%$ min e tempo de contato de $3 \mathrm{~s}$.

\subsubsection{Espectroscopia na região do infravermelho (FTIR)}

Os catalisadores obtidos foram caracterizados via FTIR (espectrometria de infravermelho com transformada de Fourier) utilizando um espectrofotômetro Thermo Scientific, por meio de pastilhas de KBr. As pastilhas foram preparadas moendo-se $1 \mathrm{mg}$ de amostra em $400 \mathrm{mg}$ de $\mathrm{KBr}$ próprio para FTIR em almofariz de ágata, o sólido foi transferido para um molde que foi submetido a uma pressão de $9 \mathrm{kgf} / \mathrm{cm}^{2}$ por 1 minuto. Assim obtêm-se discos finos e transparente com partículas dispersas em seu interior, que são colocadas diretamente no suporte do equipamento. 


\subsubsection{Adsorção e dessorção de nitrogênio}

A determinação da área específica dos catalisadores, assim como o volume e diâmetro de poros, foi realizada por meio da construção de isotermas de adsorção-dessorção de nitrogênio a $-196{ }^{\circ} \mathrm{C}$ em um analisador de área superficial e porosidade Micromeritics Gemini VII.

Antes das análises, as amostras calcinadas foram submetidas a $200{ }^{\circ} \mathrm{C}$ e vácuo por algumas horas para eliminação dos resíduos que possa ter no interior de seus poros.

As isotermas de adsorção foram construídas com os volumes de $\mathrm{N}_{2}$ adsorvidosdessorvidos em diferentes pressões de equilíbrio $\left(\mathrm{P} / \mathrm{P}_{0}\right)$. $\mathrm{O}$ volume de $\mathrm{N}_{2}$ corresponde a quantidade do gás necessária para formar uma monocamada na superfície do material analisado.

O modelo matemático utilizado para o cálculo da área específica foi o BET proposto em 1938 por Brunauer, Emmet e Teller, e pode ser escrita pela Equação 6.

$\frac{\mathrm{P}}{\mathrm{V}\left(\mathrm{P}_{0}-\mathrm{P}\right)}=\frac{1}{\mathrm{~V}_{\mathrm{m}} \mathrm{C}}+\frac{(\mathrm{C}-1) \mathrm{P}}{\mathrm{V}_{\mathrm{m}} \mathrm{CP}_{0}}$

Na qual, V é o volume adsorvido na pressão $P, P_{0}$ é a pressão de saturação do $\mathrm{N}_{2}, \mathrm{~V}_{\mathrm{m}}$ é o volume de $\mathrm{N}_{2}$ necessário para formação da monocamada e $\mathrm{C}$ é a constante BET, dada pela Equação 7, onde q 1 é o calor de adsorção da primeira camada e qL é o calor de liquefação do gás adsorvente (BRUNEUER, S., EMMET, P. H., TELLER, E, 1938).

$C=e^{\frac{\left(q_{1}-q_{L}\right)}{R T}}$

(Equação 7)

\subsubsection{Fluorescência de raios-X (FRX)}

As análises de fluorescência de raios $\mathrm{X}$ foram realizadas no Instituto Oceanográfico da USP para a determinação quantitativa da composição das amostras sintetizadas. As análises foram realizadas nos catalisadores sólidos finais sintetizados obtidos e testados em reator e nos líquidos remanescentes do tratamento hidrotérmico, quando aplicável, para avaliar a quantidade de materiais ativos que foram solubilizados durante o tratamento hidrotérmico.

\subsubsection{Microscopia eletrônica de varredura (MEV)}

As imagens microscópicas para avaliação morfológica dos materiais sintetizadas foram obtidas por microscopia eletrônica de varredura $(\mathrm{MEV})$ realizadas no Microscópio Eletrônico 
de Varredura de Alta Resolução - MEV/FEG JSM-7500 (JEOL) na UNESP Araraquara. As imagens foram obtidas com ampliações de 15000x e 50000x.

\subsection{TESTES CATALÍTICOS}

A avaliação catalítica dos materiais estudados foi realizada no processo mostrado na Figura 27. O processo foi montado no laboratório de materiais particulados do Instituto de Pesquisas Tecnológicas de São Paulo - IPT, o qual cedeu todos os equipamentos e recursos necessários. Essa parceria foi possível graças ao programa "Novos Talentos do IPT", que apoia pesquisas conduzidas por alunos matriculados em programas de pós-graduação de instituições públicas ou privadas em temas de interesse.

Figura 27 - Processo catalítico para a obtenção do ácido acrílico

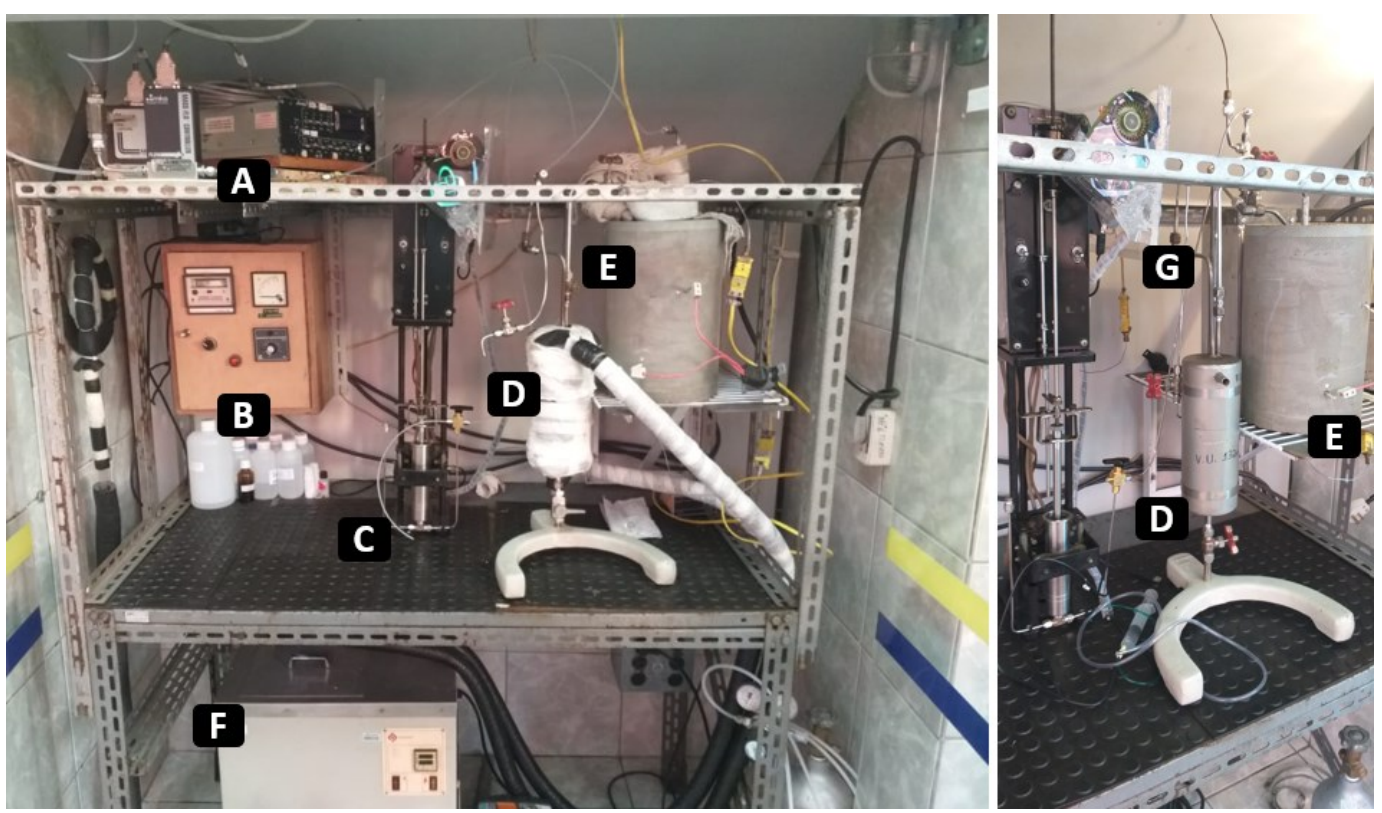

Fonte: Autor

Os equipamentos utilizados no processo foram nomeados de (A) a (H) e estão descritos nos itens a seguir. Mais detalhes, esquematizações e curvas de calibrações dos equipamentos então disponíveis no Apêndice A.

(A) - Controladores de fluxos MKS: dois controladores de fluxo MKS, o primeiro atuando com uma faixa de trabalho entre 0 e $1000 \mathrm{sccm}$, utilizado para controlar o fluxo de ar sintético e o segundo, entre 0 e $500 \mathrm{sccm}$, para o controle da vazão de $\mathrm{N}_{2}$;

(B) - Painel do controlador de temperatura do pré-aquecedor; 
(C) - Bomba Microfeeder MF-2 (Azumadenki Kogyo, Tóquio, Japão), equipada com uma seringa com capacidade para aproximadamente $100 \mathrm{~mL}$ de líquido. O controle do fluxo foi feito pela plataforma eletrônica Arduíno. Nesse sistema, uma placa composta por um microcontrolador foi acoplada ao motor micropasso da bomba, e conectada a um computador contendo o software instalado. Utilizando um programa em linguagem $\mathrm{C}++$ foi possível indicar uma vazão de operação.

(D) - Condensador em aço inox com volume de $132 \mathrm{~mL}$ (Figura 46 do Apêndice A)

(E) - Reator, maiores informações estão descritas no item 4.3.1 abaixo;

(F) - Banho Ultratermostático Microprocessado com Circulador Quimis;

(G) - Pré-aquecedor em U com diâmetro interno de 1/5 pol (12,7 mm) e comprimento de $600 \mathrm{~mm}$ recheado com esferas de quartzo de $0,4 \mathrm{~mm}$ de diâmetro;

(H) - Cromatógrafo gasoso HP 5890 series II equipado com detector FID e TCD, operando com as colunas cromatográficas DB-225 (30 m; 0,530 mm; 1,00 $\mu \mathrm{m})$ e CP7429 Select Permanent Gases $/ \mathrm{CO}_{2}$, respectivamente.

\subsubsection{Reator}

Para avaliação catalítica foi utilizado o reator em aço esquematizado na Figura 28. A imagem mostra a vista superior, lateral e corte transversal do equipamento completo (a.) e seus componentes separadamente: a parte externa por onde ocorre a entrada dos reagentes (b.) e tubo do reator onde é inserido o catalisador (c.).

Nesse sistema, o catalisador fica localizado no tubo da parte interna do reator (c.) ele tem $145 \mathrm{~mm}$ de comprimento, $15,36 \mathrm{~mm}$ de diâmetro interno e no seu centro há um poço para a inserção de um termopar com 4,95 mm o que o confere uma seção anular para o escoamento dos reagentes e produtos conforme mostrado na Figura 29. Acima da porção do catalisador foi colocado um suporte (indicado na cor azul) para evitar o excesso de fluidização do leito catalítico.

Os reagentes entram pela tubulação da camisa indicada pela seta azul, seguem para a parte inferior do reator, atravessam o leito catalítico, e saem pela parte superior do mesmo onde seguem para o condensador, indicado pela seta vermelha na Figura 28. Uma característica desse tipo de reator é que os produtos trocam calor com os reagentes na porção superior do reator.

A temperatura da reação no leito é acompanhada por um termopar inserido no tubo no centro do reator e controlada por outro termopar localizado no forno de aquecimento que envolve o mesmo. 
Figura 28 - Esquematização do reator utilizado no processo e corte lateral
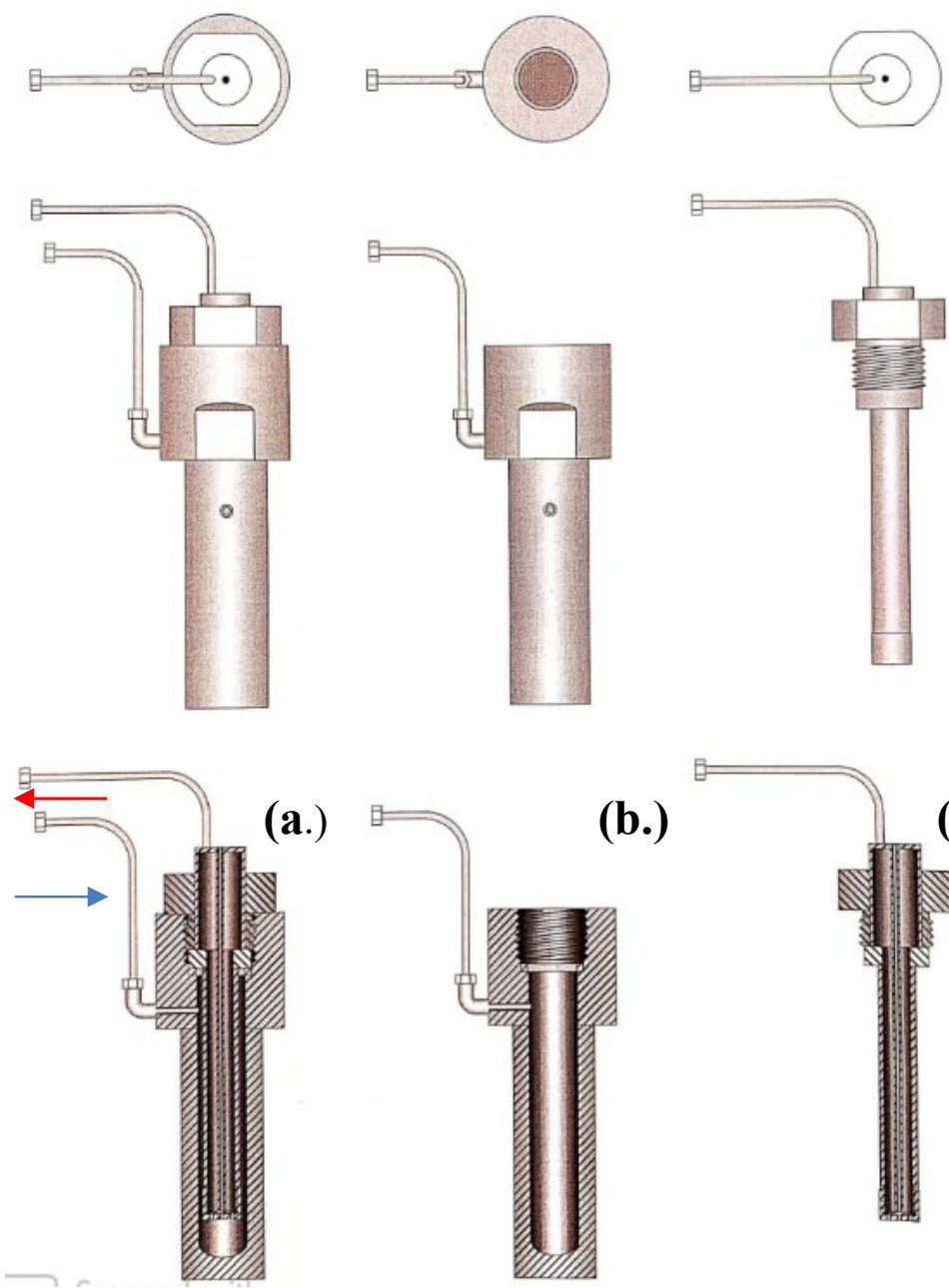

(b.)

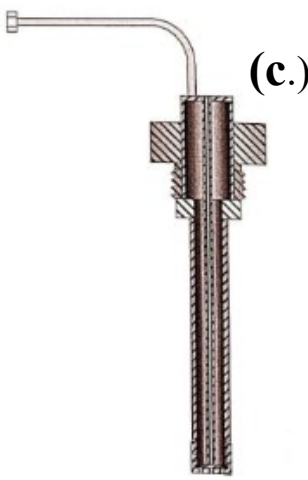

Fonte: Autor

Figura 29 - Esquematização do tubo do reator onde é inserido o catalisador
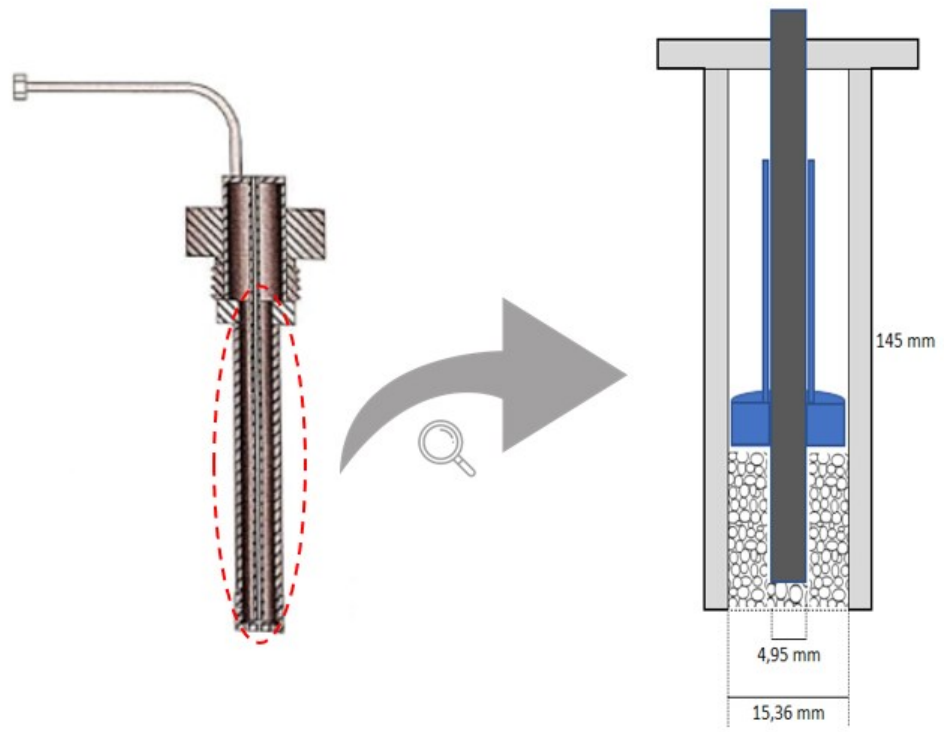

Fonte: Autor 


\subsubsection{Reação Catalítica}

Os materiais sintetizados foram avaliados na obtenção do ácido acrílico a partir de duas rotas distintas. A primeira foi pela oxidação direta da acroleína e a segunda a partir da oxidesidratação do glicerol em uma única etapa, como uma alternativa à primeira.

As reações ocorreram em fase gasosa a uma temperatura de $308+/-1{ }^{\circ} \mathrm{C}$ sob pressão atmosférica e fluxo contínuo em reator de leito fixo descrito no item 4.3.1. O reator foi alimentado com $1 \mathrm{~g}$ de catalisador com diâmetro de $0,5 \mathrm{~mm}$ (granulometria entre $0,6 \mathrm{~mm}$ e 0,5 $\mathrm{mm}-30$ e $35 \mathrm{mesh}$ ) dissolvido em $3 \mathrm{~g}$ de partículas de quartzo de mesmo diâmetro. O sistema foi previamente tratado a temperaturas superiores a $400{ }^{\circ} \mathrm{C}$ sob fluxo de nitrogênio de $40 \mathrm{~mL} / \mathrm{min}$ por 30 minutos antes do início da reação para a ativação do catalisador, e depois resfriado até a temperatura de trabalho na qual permaneceu por $10 \mathrm{~min}$ sob o fluxo de ar sintético até o início da injeção do reagente.

O processo foi alimentado com uma vazão gasosa de ar sintético (Linde- 20\% $\mathrm{O}_{2}$ e 80\% $\mathrm{N}_{2}$ ) de $140 \mathrm{~mL} / \mathrm{min}$ pré-aquecido a $300{ }^{\circ} \mathrm{C}$ e uma vazão de líquidos de $0,35 \mathrm{~mL} / \mathrm{min}$. As soluções utilizadas foram de 6,3\% em massa de acroleína em água (Fluka - 95\%) no caso do experimento 1 e de 10\% em massa de glicerol (Sigma-Aldrich 99,5\%) no experimento 2. A temperatura da reação foi controlada por um termopar localizado no forno de aquecimento do reator e acompanhada por outro inserido no tubo de termopar localizado no interior do reator. A Tabela 7 apresenta um resumo das condições de entrada do processo.

Tabela 7 - Condições de alimentação do processo para a obtenção de ácido acrílico

\begin{tabular}{|c|c|c|}
\hline Condições $\backslash$ Ensaio & Experimento 1 & Experimento 2 \\
\hline Reagente & Acroleína & Glicerol \\
\hline Concentração & $6,3 \%$ em massa & $10 \%$ em massa \\
\hline Temperatura Pré-Aquecedor & \multicolumn{2}{|c|}{$300^{\circ} \mathrm{C}$} \\
\hline Temperatura da Reação & \multicolumn{2}{|c|}{$308^{\circ} \mathrm{C}$} \\
\hline Vazão liquido & \multicolumn{2}{|c|}{$0,35 \mathrm{~mL} / \mathrm{min}$} \\
\hline Vazão gás & \multicolumn{2}{|c|}{$140 \mathrm{~mL} / \mathrm{min}\left(20 \% \mathrm{O}_{2} \mathrm{em} \mathrm{N}_{2}\right)$} \\
\hline Temperatura condensador & \multicolumn{2}{|c|}{$1{ }^{\circ} \mathrm{C}$} \\
\hline
\end{tabular}
Fonte: Autor

Os produtos condensáveis a $1{ }^{\circ} \mathrm{C}$ foram coletados no condensador/separador de gases a cada 30 minutos contendo $25 \mu \mathrm{L}$ de uma solução de terc-butil-hidroquinona em metanol a 50 ppm para evitar a polimerização dos produtos formados e a vazão de gases na saída foi 
quantificada com o auxílio de um integrador de gases e acompanhada por um medidor de vazão e indicador de $\mathrm{O}_{2}$ para estimar a conversão de $\mathrm{O}_{2}$.

Os produtos líquidos foram analisados por cromatografia gasosa em um cromatógrafo HP 5890 series II equipado com coluna DB-225 (30 m; 0,530 mm; 1,00 $\mu \mathrm{m}$ ) e detector FID. Antes de cada injeção, uma massa conhecida de etilenoglicol (aproximadamente $2 \%$ em massa) foi adicionada à amostra para quantificação dos produtos formados com base em comparações com as curvas padrões preparadas previamente. O tempo de retenção de cada produto foi comparado ao padrão puro.

O efluente gasoso foi analisado on-line no mesmo cromatógrafo equipado com uma válvula de seis vias para a injeção do gás, detector TCD e uma CP7429 Select Permanent Gases/CO para a quantificação do $\mathrm{O}_{2}, \mathrm{~N}_{2}, \mathrm{CO}_{2}$ e $\mathrm{CO}$. Os gases também foram analisados no FID para estimar a quantidade de acroleína não condensada. Mais detalhes sobre as curvas de calibrações e cálculos utilizados nas análises por cromatografia gasosa estão disponíveis no Apêndice B.

A atividade catalítica dos materiais obtidos foi avaliada de acordo com os dados de conversão do reagente (acroleína ou glicerol), seletividade e rendimento dos produtos calculados seguindo as Equações 8, 9 e 10, respectivamente. O balanço dos elementos da reação (C, H, O, N) calculado de acordo com Equação 11 (CHAI et al., 2014).

$$
\begin{aligned}
& X_{\text {reagente }}(\%)=\frac{n_{\text {reagentrada }}-n_{\text {reagsaída }}}{n_{\text {reagentrada }}} * 100 \\
& S_{i}(\%)=\frac{n_{i}}{n_{\text {reag }} \text { entrada }-n_{\text {reag }} \text { saída }} * \frac{y_{i}}{y_{\text {reag }}} * 100 \\
& R_{i}(\%)=X_{\text {reagente }}(\%) * S_{i}(\%)=\frac{n_{i}}{n_{\text {reag entrada }}} * \frac{y_{i}}{y_{\text {reag }}} * 100
\end{aligned}
$$

Balanço de $Z .=\frac{n^{\circ} \text { de mols do elemento } W \text { nos produtos }}{n^{\circ} \text { de mols do elemento } W \text { alimentado }}$

$n_{\text {reag }}$ entrada e $n_{\text {reag }}$ saída representam a quantidade molar (mol) que entra e que saem do reator no intervalo de tempo da amostra, $n_{i}$ representa a quantidade molar do produto i no intervalo da amostra. $y_{i}$ e $y_{\text {reag }}$ representam o número de átomos de carbono na molécula do produto e do reagente respectivamente. $\mathrm{E} Z$ representa os elementos $\mathrm{C}, \mathrm{O}, \mathrm{H}, \mathrm{N}$ para a realização do balanço. 


\section{RESULTADOS E DISCUSSÕES}

Neste capítulo são apresentados e discutidos os resultados dos testes propostos na metodologia do trabalho. No Item 5.1 são apresentados os resultados das caracterizações das amostras preliminares sintetizadas via tratamento hidrotérmico, na presença ou não de Pluronic ${ }^{\circledR}$ P123, para a seleção de duas representantes para os testes em reator, uma preparada apenas por tratamento hidrotérmico e outro na presença do copolímero. O Item 5.2 apresenta os resultados de caracterização e avaliação catalíticas das amostras B1, B2 e B3 preparadas seguindo diferentes metodologias, por evaporação, tratamento hidrotérmico, evaporação seguida por tratamento hidrotérmico e preparadas na presença de um copolímero de blocos.

\subsection{ETAPA I - ESTUDO DA METODOLOGIA DE SÍNTESES VIA TRATAMENTO HIDROTÉRMICO}

Analisando primeiramente as amostras sintetizadas via tratamento hidrotérmico sem a utilização do copolímero, as amostras com final (-EO) preparadas sem evaporação apresentaram maior dificuldade para a dissolução dos reagentes (precursores) devido a utilização de uma menor quantidade de água, assim as amostras seguiram para o tratamento hidrotérmico ainda com a presença de sais não dissolvidos o que pode ter levado a formação de sólidos com composição não homogênea em sua totalidade. As amostras com final (- EP) e (- ET) foram preparadas utilizando uma quantidade de água suficiente para garantir a completa dissolução dos precursores e assim avaliar se tal técnica foi capaz de aumentar a homogeneidade da amostra e formar óxidos mistos.

A Tabela 8 apresenta os resultados de rendimento, em massa, das amostras preparadas, relacionando a massa total de reagentes utilizada e a massa final de amostra após a calcinação e apresenta também a composição teórica esperada para as amostras B1, B2 e B3 considerando a formação dos óxidos simples de $\mathrm{MoO}_{3}, \mathrm{~V}_{2} \mathrm{O}_{5}, \mathrm{WO}_{3}$ e $\mathrm{CuO}$. Analisando as diferentes composições, as amostras do tipo B1 apresentam como diferencial a presença de cobre em sua estrutura e uma menor relação $\mathrm{Mo} / \mathrm{V}$. As amostras B2 e B3 apresentam uma relação $\mathrm{Mo} / \mathrm{V}$ semelhante, se diferenciando pelo acréscimo de tungstênio na amostra B2. Tais composições foram escolhidas para avaliar como a adição de diferentes metais refletem nas propriedades dos materiais obtidos. 
Tabela 8 - Rendimentos de sólidos na produção dos catalisadores

\begin{tabular}{ccccccc}
\hline \multirow{2}{*}{ Amostra } & $\mathrm{M}_{\text {amostra }} / \sum \mathrm{m}_{\text {reagente }}$ & \multicolumn{5}{c}{ Composição teórica (\%massa) } \\
\cline { 3 - 6 } & $(\%)$ & $\mathrm{MoO}_{3}$ & $\mathrm{~V}_{2} \mathrm{O}_{5}$ & $\mathrm{WO}_{3}$ & $\mathrm{CuO}$ & $\mathrm{SiO}_{2}$ \\
\hline B1-TH-ET & 23,78 & & & & & \\
B1-TH-EP & 26,33 & & & & & \\
B1-TH-E0 & 28,30 & 50,87 & 12,46 & 16,46 & 5,36 & 14,85 \\
B1-P123-Q & 18,97 & & & & & \\
B1-P123-F & 15,39 & & & & & \\
\hline B2-TH-ET & 17,33 & & & & & \\
B2-TH-EP & 21,44 & & & & & \\
B2-TH-E0 & 21,18 & 71,49 & 7,60 & 5,35 & & \\
B2-P123-Q & 14,47 & & & & & \\
B2-P123-F & 13,23 & & & & & \\
\hline B3-TH-ET & 16,07 & & & & & \\
B3-TH-EP & 18,90 & & & & & \\
B3-TH-E0 & 17,37 & & & & & \\
B3-P123-Q & 14,18 & & & & & \\
B3-P123-F & 16,08 & 73,20 & 10,30 & & & \\
\hline
\end{tabular}

Fonte: Autor

Analisando os resultados referentes aos rendimentos, foi possível observar que o máximo rendimento obtido na primeira etapa de preparação foi de $28,30 \%$ para a amostra B1 sintetizada via TH sem a evaporação de água, seguido das demais preparações também com composição B1. Uma das possíveis explicações para essa diferença em relação as amostras B2 e B3 foi a adição de nitrato de cobre no fim da mistura que possibilitou a coprecipitação dos produtos formados.

Entre as amostras preparadas via tratamento hidrotérmico, as preparações com evaporação total da água nas três composições (B1/B2/B3-TH-ET) foram as que apresentaram o menor rendimento. As demais preparações apresentaram rendimentos semelhantes, com destaque para as preparações com evaporação parcial (Bx-TH-EP), que apresentaram maior rendimento para as composições B2 e B3 (21,44 e 18,90\% respectivamente).

Quando analisadas as amostras preparadas na presença de copolímero, elas apresentaram um rendimento ainda menor que as amostras preparadas por tratamento 
hidrotérmico, isso se deve ao fato de que todo o copolímero foi eliminado durante a etapa de calcinação, diminuindo a massa final das amostras obtidas. Quando comparadas as preparações a quente e a frio, os rendimentos obtidos foram semelhantes nos três casos. Para as amostras B1 e B2, a preparação a quente (B1/B2-P123-Q) apresentou um rendimento maior em relação a preparação a frio (18,97 e 14,47\% em relação a 15,39 e 13,23\% a frio), já a amostra B3 apresentou o contrário, a preparação a frio (B3-P123-F) apresentou maior rendimento $(16,08 \%)$.

A Figura 30 apresenta uma foto das misturas B1, B2 e B3 antes de serem transferidas para a autoclave para a realização do tratamento hidrotérmico. A diferença de composição é notável quando analisada a coloração final de cada suspensão.

Quando o metavanadato de amônio é dissolvido em água há a formação dos íons $\mathrm{VO}_{2}{ }^{+}$ que confere ao vanádio um estado de oxidação 5+ que possui uma coloração amarelada, cor característica de todos as amostras B1, B2 e B3 durante a mistura das soluções de heptamolibdato de amônio e metavanadato de amônio.

Figura 30 - Misturas iniciais antes de seguir para o tratamento hidrotérmico. A figura

(a.) corresponde a amostra B1, (b.) a amostra B2 e (c.) a amostra B3.

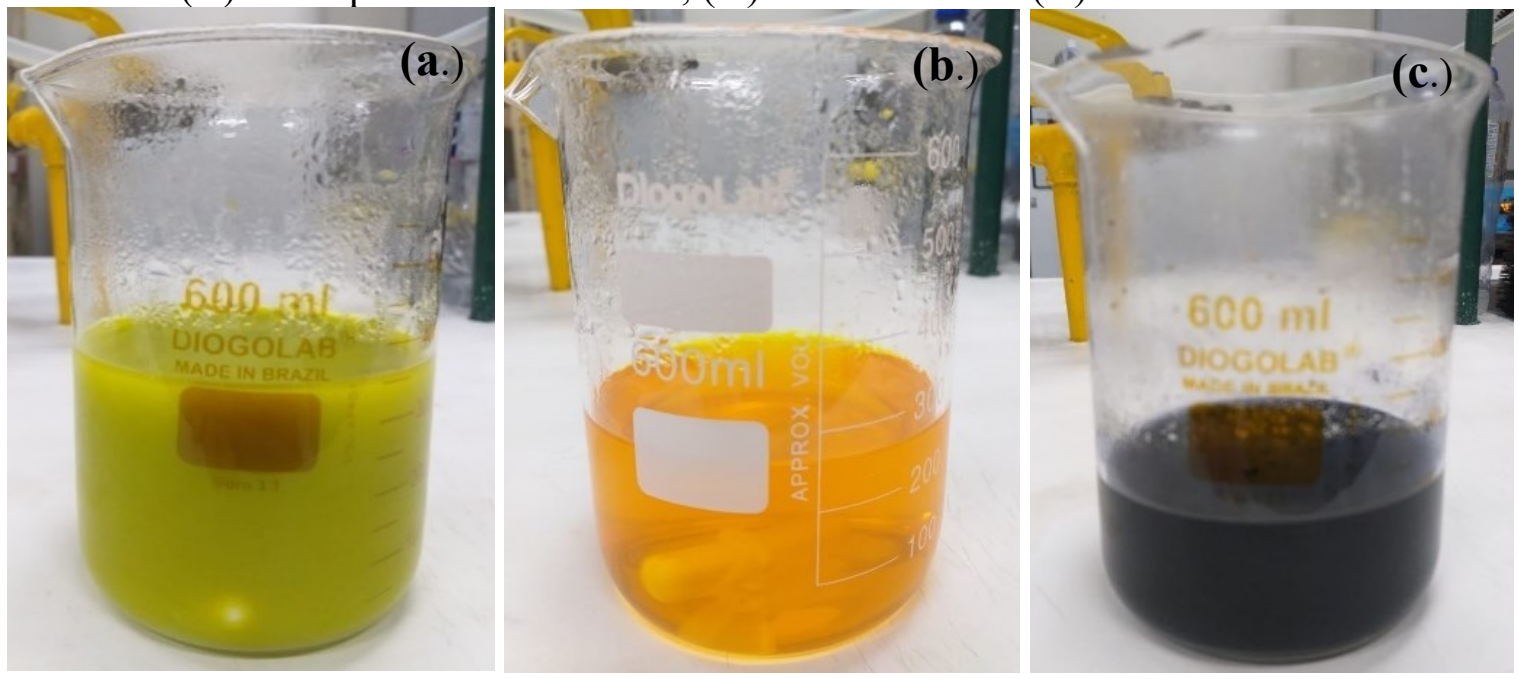

Fonte: Autor.

Durante a preparação da amostra B2, quando adicionada a solução de tungstato de amônio (incolor) à mistura principal, não há uma mudança de coloração, mantendo-se em um aspecto amarelado conforme é possível observar Figura 30 (b), indicando a presença do íon $\mathrm{VO}_{2}{ }^{+}$. Na preparação da amostra $\mathrm{B} 3$, foi adicionado ácido oxálico à solução de vanádio a fim de se obter o vanádio com estado de oxidação 4+, que confere a solução uma coloração azulada. Nesse caso, o metavanadato de amônio é reagido com o ácido oxálico, levando a formação do 
oxalato de vanadila $\left(\mathrm{VOC}_{2} \mathrm{O}_{4}\right)$ que quando calcinado, produz o pentóxido de vanádio, conforme equação descrita na Equação 12. Nessa situação, o ácido oxálico atua como um agente redutor levando a formação do V4+ (OYAMA et al., 1989).

$1 \mathrm{NH}_{4} \mathrm{VO}_{3}+(\mathrm{COOH})_{2} \cdot 2 \mathrm{H}_{2} \mathrm{O} \rightarrow 1 \mathrm{VOC}_{2} \mathrm{O}_{4} \rightarrow \frac{1}{2} \mathrm{~V}_{2} \mathrm{O}_{5}$

Já a amostra B1, quando a solução de nitrato de cobre (azulada) é adiciona a solução principal contendo Mo, V e W (amarelada) há a coprecipitação de produtos finais que conferem a coloração verde-clara a suspenção.

\subsubsection{Análises por transformada de Fourier na região da infravermelho (FTIR)}

Os espectros obtidos nas análises de FTIR para as amostras B1, B2 e B3 são apresentados a seguir. A Figura 31 apresenta os espectros na faixa espectral entre 400$1900 \mathrm{~cm}^{-1}$, para as amostras sintetizadas por TH na presença ou não do copolímero de blocos e a Figura 32 apresenta uma comparação entre os espectros das amostras B1 e B2 com os espectros de amostras padrões de $\mathrm{MoO}_{3}, \mathrm{~V}_{2} \mathrm{O}_{5}$ e $\mathrm{WO}_{3}$. Na Figura 32 (a) são apresentados os espectros na região entre 400-4000 cm $\mathrm{cm}^{-1}$ e em Figura 32 (b) são os mesmos espectros, porém com um detalhamento maior da região entre $400-1900 \mathrm{~cm}^{-1}$, região na qual foram identificadas as principais bandas características das amostras, referentes as vibrações de alongamento e flexão das ligações metal-oxigênio (ALAYAT et al., 2018; CHITHAMBARARAJ, BOSE, 2011).

As primeiras bandas identificadas nos espectros foram na região de 3400 e $1640 \mathrm{~cm}^{-1}$ referentes aos estiramentos H-O-H das ligações das moléculas de água, causadas pela umidade residual presente nas amostras após calcinação.

É possível identificar também uma banda larga e intensa comum a todas as amostras na região entre 1090-1100 cm-1, correspondente aos estiramentos assimétricos da ligação Si-O-Si, presente, devido a utilização sílica Aerosil $\left(\mathrm{SiO}_{2}\right)$ como suporte (MUSIC, FILIPOVICVINCEKOVIC, SEKOVANIC, 2011). 
Figura 31 - Espectrogramas na região do infravermelho das amostras B1 (a.), B2 (b.) e B3 (c.) das amostras preparadas na etapa 1
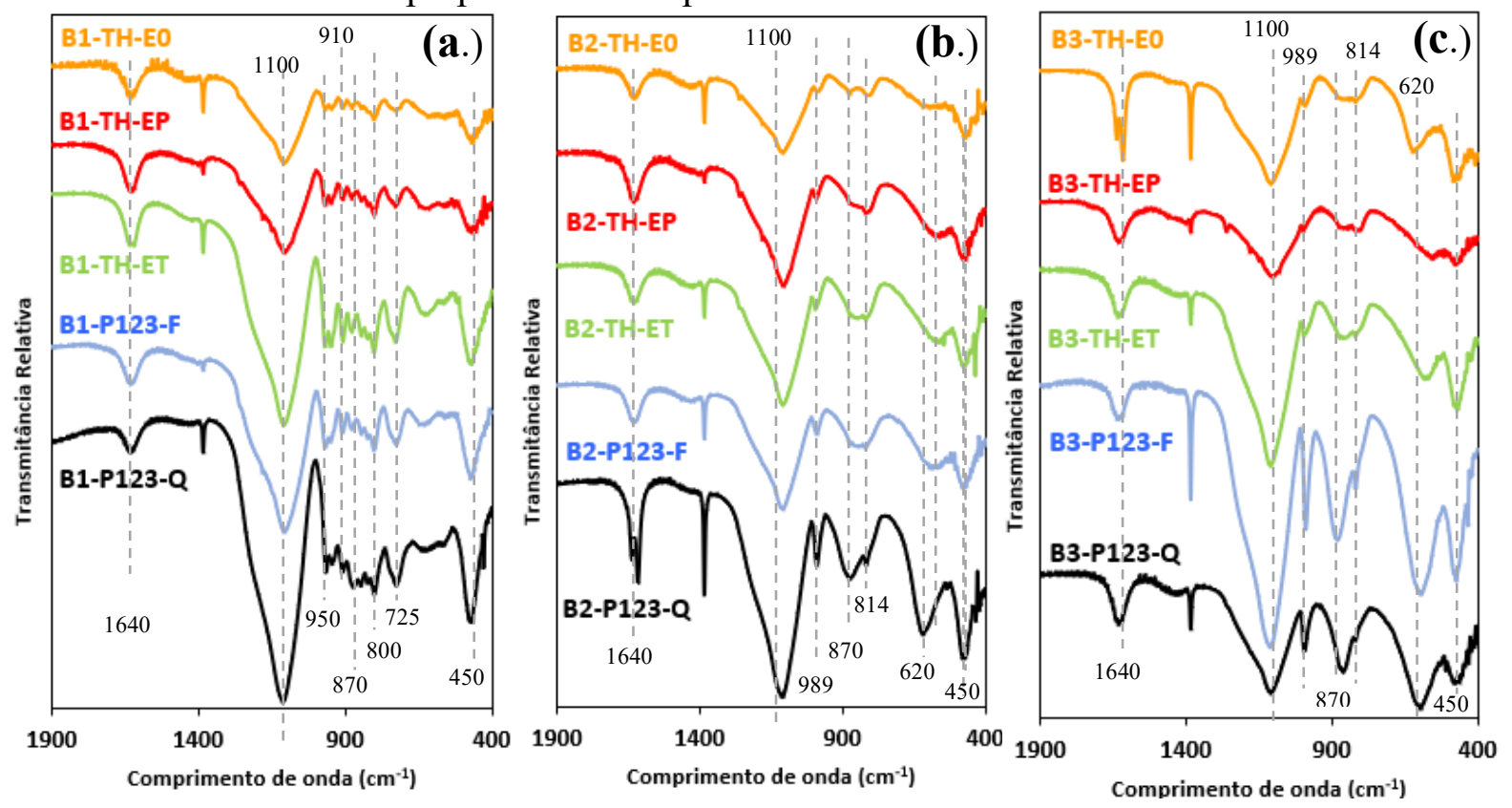

Fonte: Autor

Figura 32 - Comparação dos espectrogramas obtidos para as amostras B1 e B2 da etapa 1 com padrões de $\mathrm{MoO}_{3}, \mathrm{~V}_{2} \mathrm{O}_{5}$ e $\mathrm{WO}_{3}$ na faixa espectral de 400 $4000 \mathrm{~cm}^{-1}$ (a) e de $400-1900 \mathrm{~cm}^{-1}$ (b)
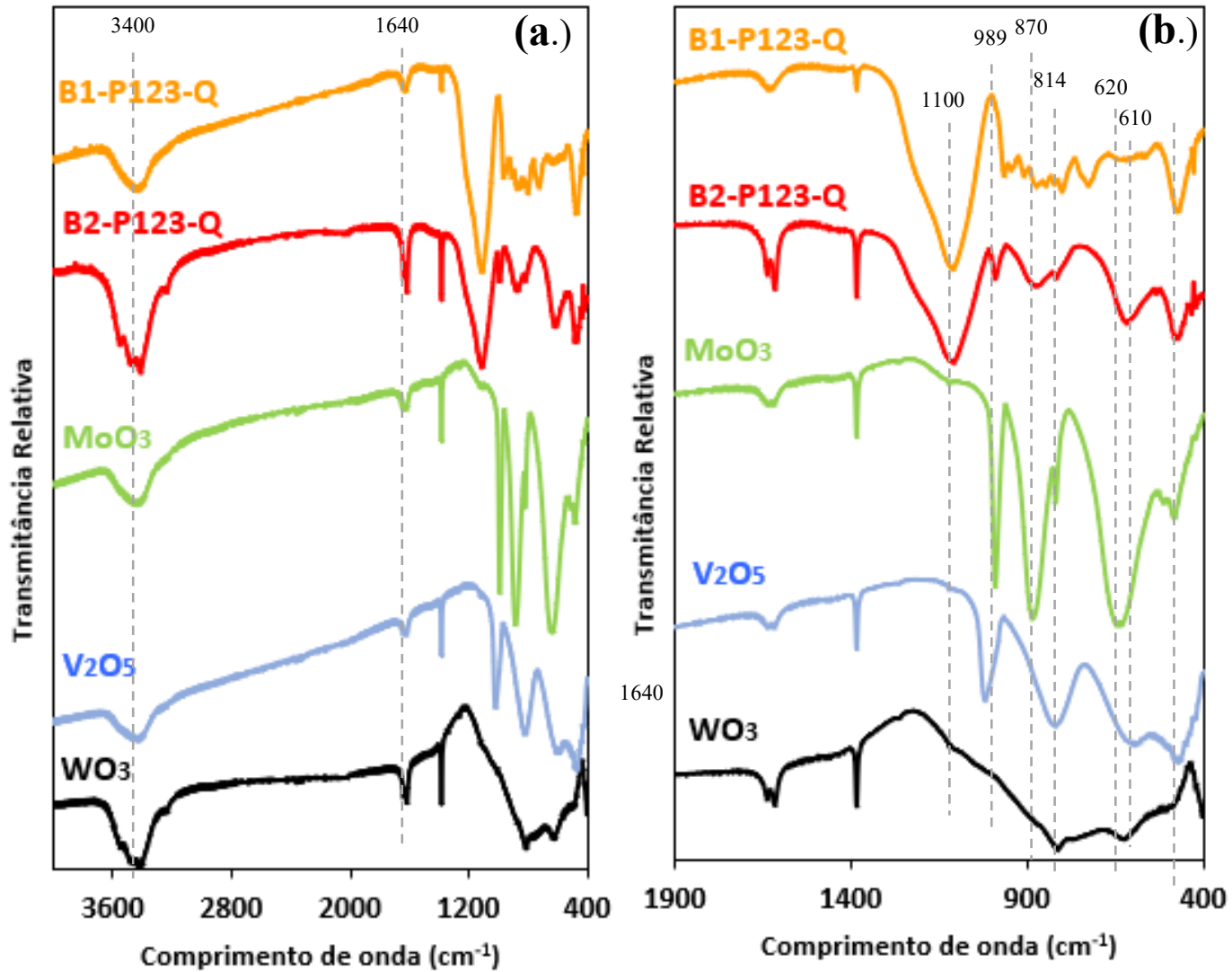

Fonte: Autor 
Quando analisados os espectros das amostras B2 e B3 foi possível identificar a similaridades entre as curvas devido a semelhança da composição. Ambos possuem como fase ativa principalmente os elementos molibdênio e vanádio com relação semelhante, diferenciando na presença de tungstênio na amostra B2. Os espectros obtidos para as duas amostras apresentam bandas características da fase ortorrômbica $\alpha-\mathrm{MoO}_{3}$, relacionadas a vibração da ligação molibenil $v(\mathrm{M}=\mathrm{O})$ em $989 \mathrm{~cm}^{-1}$. Os estiramentos na região de 870 e $814 \mathrm{~cm}^{-1}$ também foram identificados por Chithambararaj e Bose (2011) para materiais que apresentaram como fase cristalina $\alpha-\mathrm{MoO}_{3}$ (ortorrômbica). Outra banda característica ao estiramento (Mo-O) foi identificada na região próxima a $620 \mathrm{~cm}^{-1}$ (CHITHAMBARARAJ, BOSE, 2012).

Os espectros correspondentes as amostras B2 e B3 preparadas na presença de copolímero tanto a frio quando a quente foram os que apresentaram maior semelhança ao espectro do $\mathrm{MoO}_{3}$ puro padrão, mostrado na Figura 32, indicando que a principal fase formada nessas amostras foi a $\alpha-\mathrm{MoO}_{3}$ ortorrômbica. Já as amostras preparadas por tratamento hidrotérmico sem a presença do copolímero, apresentaram bandas correspondentes a mesma fase em $989 \mathrm{~cm}^{-1}$, porém em menor intensidade. Tais amostras apresentam também bandas características aos estiramentos (V-O) em 450, 610 em $814 \mathrm{~cm}^{-1}$ observados também na amostra padrão de $\mathrm{V}_{2} \mathrm{O}_{5}$. (WU, GAO, WU, 2015). Na análise das amostras B2 não foram identificadas bandas características as ligações (W-O), que podem estar sobrepostas as bandas (V-O) já que o espectro da amostra padrão de WO3 apresenta bandas na região de 610 e $814 \mathrm{~cm}^{-1}$.

As amostras com composição B1 apresentaram espectros diferentes em relação as amostras anteriores. A região compreendida entre 700 e $970 \mathrm{~cm}^{-1}$ apresentou uma série de bandas que vão além aos estiramentos Mo-O e V-O identificados nas amostras anteriores, indicando uma maior complexidade da composição superficial dos materiais obtidos. Tal complexidade foi observada também por Liu et al. (2014) em estudos utilizando catalisadores a base de Cu e Mo. Clark e Doyle (1965) apresentaram em seu trabalho as principais bandas características de molibdatos e tungstato de diferentes metais (disponíveis para consulta no Anexo I). Materiais contendo molibdato de cobre $\left(\mathrm{CuMoO}_{4}\right)$ em sua composição apresentam bandas fortes na região de 950 e $725 \mathrm{~cm}^{-1}$, e outras mais fracas em 905, 880, 845, $790 \mathrm{~cm}^{-1}$, tais bandas foram identificadas nos espectros das amostras B1 na Figura 31, e a presença desse composto justifica a grande quantidade de bandas observadas entre $700-970 \mathrm{~cm}^{-1}$.

Em uma comparação feita com o espectro da amostra padrão de $\mathrm{WO}_{3}$ foi possível identificar a banda referente ao estiramento $\mathrm{W}-\mathrm{O}-\mathrm{W}$ na região entre $800-804 \mathrm{~cm}^{-1}$, banda observada também para o tungstato de cobre $\left(\mathrm{CuWO}_{4}\right)$ e uma banda forte $\mathrm{em} 910 \mathrm{~cm}^{-1}$ referente ao mesmo composto (CLARK, DOYLE, 1965). 
A utilização do Pluronic ${ }^{\circledR P 123}$ durante a preparação das amostras B1 não afetou a composição superficial das amostras, já que seus espectros apresentaram bandas semelhantes às das amostras $\mathrm{B} 1$ preparadas apenas por $\mathrm{TH}$, diferenciando apenas a intensidade entre elas. Outro ponto interessante é a ausências das bandas em 2996-2952 $\mathrm{cm}^{-1}$ referentes aos estiramentos das ligações $(-\mathrm{C}-\mathrm{H})$ presentes no grupo metil das macromoléculas do polímero, indicando sua total remoção quando as amostras são tratadas a temperaturas próximas a $500{ }^{\circ} \mathrm{C}$.

\subsubsection{Análises por difratometria de raios-X (DRX)}

A segunda e principal caracterização realizada foi por difratometria de raios-X para a determinação das fases cristalinas e componentes presentes em cada amostra. Para isso, os espectros obtidos foram comparados a espectros de substâncias padrões do banco de dados do International Centre for Diffraction Data (ICDD). A Figura 33 apresenta os difratogramas das amostras B1 (a), B2 (b), B3 (c) nos cinco métodos de preparação propostos e uma comparação com os difratogramas de padrões de $\mathrm{MoO}_{3}, \mathrm{~V}_{2} \mathrm{O}_{5}$ e $\mathrm{WO}_{3}(\mathrm{~d})$.

Analisandos os difratogramas obtidos como um todo, foi possível observar que para uma mesma composição, a metodologia proposta de preparo não trouxe muitas variações para a formação das fases cristalinas, já que os difratogramas apresentaram picos semelhantes para todas as amostras, com variações de intensidades, que sugere uma alteração de cristalinidade.

A amostra B1 apresentou como principal fase cristalina o molibdato de cobre $\left(\mathrm{CuMoO}_{4}\right)$, com picos característicos em $2 \theta$ igual a $24,3^{\circ} ; 27,3^{\circ} ; 29^{\circ}$ e $30^{\circ}$ (CARD: 00-0220242), apresentados também por Chigrin, Lebukhova e Ustinov (2013) em estudos sobre transformações estruturais do $\mathrm{CuMoO}_{4}$. A amostra mostrou também a presença do $\mathrm{W}_{0,4} \mathrm{Mo}_{0,6} \mathrm{O}_{3}$ com picos característicos em $2 \theta$ igual a $27,3^{\circ}, 26,3^{\circ}, 33,4^{\circ}, 43^{\circ}$ e $54^{\circ}(00-032-1391)$.

As amostras B2 e B3 apresentaram em seus difratogramas picos comuns, indicando que a adição de tungstênio proposta na amostra B2 pode não ter atuado na formação das fases cristalinas das amostras finais. Assim o elemento pode ter sido depositado na forma de óxido $\left(\mathrm{WO}_{3}\right)$ em porções amorfas do material ou ainda ter ocorrido uma substituição isomórfica na estrutura do $\alpha-\mathrm{MoO}_{3}$. Outro ponto possível é os picos relativos aos compostos com tungstênio serem menos intensos e se sobrepuseram as fases cristalinas predominantes. 
Figura 33 - Difração de raios-X das amostras B1 (a.), B2 (b.) e B3 (c.) preparadas na etapa 1 e comparação com padrões (d.)
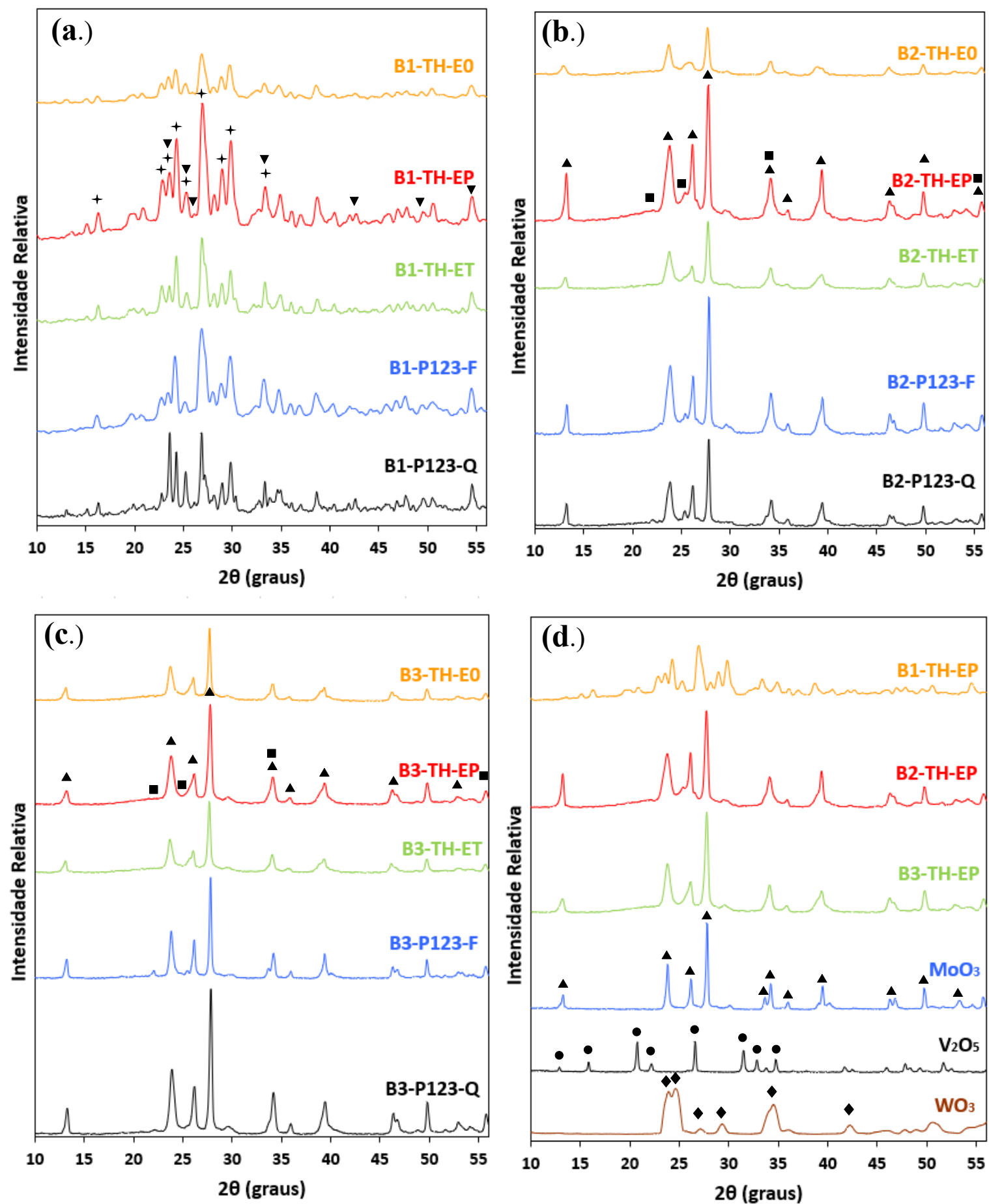

Fonte: Autor

Legenda:

$$
\begin{aligned}
& \boldsymbol{\Delta}-\alpha-\mathrm{MoO}_{3} \\
& \text { - }-\mathrm{V}_{2} \mathrm{O}_{5} \\
& \text { - }-\mathrm{WO}_{3} \\
& +-\mathrm{CuMoO}_{4} \\
& \text { - }-\mathrm{W}_{0,4} \mathrm{Mo}_{0,6} \mathrm{O}_{3} \\
& \text { - }-\mathrm{MoV}_{2} \mathrm{O}_{8}
\end{aligned}
$$


A principal fase cristalina formada nas amostras $\mathrm{B} 2$ e $\mathrm{B} 3$ foi a $\alpha-\mathrm{MoO}_{3}$ ortorrômbico, conforme identificado na Figura 33. Além da identificação dos principais picos utilizando o banco de dados do IDCC, os difratogramas obtidos foram comparados também a difratogramas de amostras padrão de $\mathrm{MoO}_{3}, \mathrm{~V}_{2} \mathrm{O}_{5}$ e $\mathrm{WO}_{3}$, obtidas pela calcinação a $500{ }^{\circ} \mathrm{C}$ de seus precursores, heptamolibdato, metavanadato e tungstato de amônio. Analisando a Figura 33(d.) é possível observar que as principais diferenças entre a curva padrão de $\mathrm{MoO}_{3}$ e as experimentais (B2 e B3) é elevação da linha de base, que corresponde a porção amorfa do material provavelmente relacionada ao suporte. Tais amostras apresentam também picos com pequena intensidade referentes ao $\mathrm{MoV}_{2} \mathrm{O}_{8}$ em $2 \theta$ igual a 21,5 e $25^{\circ}$ (Card: 00-018-0851).

As amostras sintetizadas na presença do copolímero P123 apresentaram difratogramas semelhantes as amostras sintetizadas via tratamento hidrotérmico para as três diferentes composições, indicando que sua utilização não alterou a composição dos materiais formados ou estrutura cristalina, e sim suas propriedades morfológicas e cristalinidade.

\subsubsection{Análise de fisissorção de $\mathrm{N}_{2}$ para determinação de área específica e porosidade}

A Tabela 9 apresenta os dados de área específica, volume e diâmetro de poros para as amostras B1, B2 e B3 sintetizadas. Analisando os resultados obtidos para as amostras preparadas por tratamento hidrotérmico $(\mathrm{Bx}-\mathrm{TH}-\mathrm{ET} / \mathrm{EP} / \mathrm{E} 0)$, foi possível observar que as diferentes metodologias propostas apresentaram comportamento semelhante em relação a conformação de poros e área específica para as amostras de mesma composição. Já que os resultados apresentaram a mesma ordem de grandeza: área específica entre $37,9-55,0 \mathrm{~m}^{2} / \mathrm{g}$, volume de poro $0,293-0,436 \mathrm{~cm}^{3} / \mathrm{g}$ e diâmetro de poros de $29,3-37,0 \mathrm{~nm}$.

$\mathrm{Na}$ literatura, amostras padrões de $\mathrm{MoO}_{3}$ e $\mathrm{V}_{2} \mathrm{O}_{5}$ apresentam uma área específica de 0,5 e $7,6 \mathrm{~m}^{2} / \mathrm{g}$, respectivamente. O que indica que a realização do tratamento hidrotérmico contribuiu para um aumento significativo de área. Em estudos desenvolvidos por RASTEIRO et al. (2017), catalisadores mássicos compostos por molibdênio e vanádio apresentaram áreas entre 11,4 e 12,8 $\mathrm{m}^{2} / \mathrm{g}$ também utilizando o método de tratamento hidrotérmico, porém não há a utilização de um suporte, cuja a principal função é o aumento da área específica. Assim é possível observar os efeitos da combinação suporte+TH na preparação de catalisadores.

Para as amostras B2 e B3, a preparação com evaporação parcial (-EP) foi a que apresentou os maiores valores de diâmetro de poros, mas não necessariamente de área específica. Já para a amostra B1 ela apresentou um valor intermediário em relação as outras 
duas. Os diâmetros de poro das amostras sintetizadas são correspondentes a materiais mesoporosos.

Tabela 9 - Resultados de área específica e porosidade obtidos por fisissorção com $\mathrm{N}_{2}$ para as amostras preliminares B1, B2 e B3 sintetizadas por tratamento hidrotérmico

\begin{tabular}{lccc}
\hline \multicolumn{1}{c}{ Amostra } & $\begin{array}{c}\text { Área BET } \\
\left(\mathrm{m}^{2} / \mathrm{g}\right)\end{array}$ & $\begin{array}{c}\text { Volume de poro } \\
\left(\mathrm{cm}^{3} / \mathrm{g}\right)\end{array}$ & $\begin{array}{c}\text { Diâmetro de poro } \\
(\mathrm{nm})\end{array}$ \\
\hline B1-TH-ET (Evap. total) & 38,0 & 0,346 & 35,7 \\
B1-TH-EP (Evap. parcial) & 38,0 & 0,329 & 34,7 \\
B1-TH-E0 (Sem evap.) & 39,6 & 0,331 & 33,5 \\
B1-P123-Q & 11,3 & 0,033 & 11,6 \\
B1-P123-F & 57,3 & 0,459 & 32,0 \\
\hline B2-TH-ET (Evap. total) & 43,2 & 0,394 & 35,6 \\
B2-TH-EP (Evap. parcial) & 37,9 & 0,344 & 36,5 \\
B2-TH-E0 (Sem evap.) & 44,5 & 0,293 & 29,3 \\
B2-P123-Q & 26,0 & 0,066 & 10,2 \\
B2-P123-F & 55,7 & 0,440 & 31,6 \\
\hline B3-TH-ET (Evap. total) & 55,0 & 0,436 & 31,0 \\
B3-TH-EP (Evap. parcial) & 43,9 & 0,406 & 37,0 \\
B3-TH-E0 (Sem evap.) & 50,2 & 0,434 & 34,6 \\
B3-P123-Q & 29,5 & 0,112 & 15,2 \\
B3-P123-F & 49,6 & 0,313 & 24,6 \\
\hline Fon Aur & & & \\
\hline & & & \\
\hline
\end{tabular}

Fonte: Autor

As amostras sintetizadas na presença do copolímero apresentaram maior valor de área específica e volume de poros para as composições B1 e B2, utilizando o método a frio. $\mathrm{O}$ aumento observado foi aproximadamente de $10 \mathrm{~m}^{2} / \mathrm{g}$ para a área em ambos os casos. Já a amostras B3 não seguiu o mesmo perfil, a maior área superficial foi apresentada pela amostra B3-TH-ET. A Figura 34 apresenta as isotermas de adsorção-dessorção de nitrogênio para as amostras de composição B2 para as cinco metodologias propostas. 
Figura 34 - Isotermas de adsorção-dessorção de nitrogênio das amostras B2. (•)-Curva obtida durante a adsorção do $\mathrm{N}_{2}$ e ( $\boldsymbol{\Delta}$ )-Curva obtida durante a dessorção
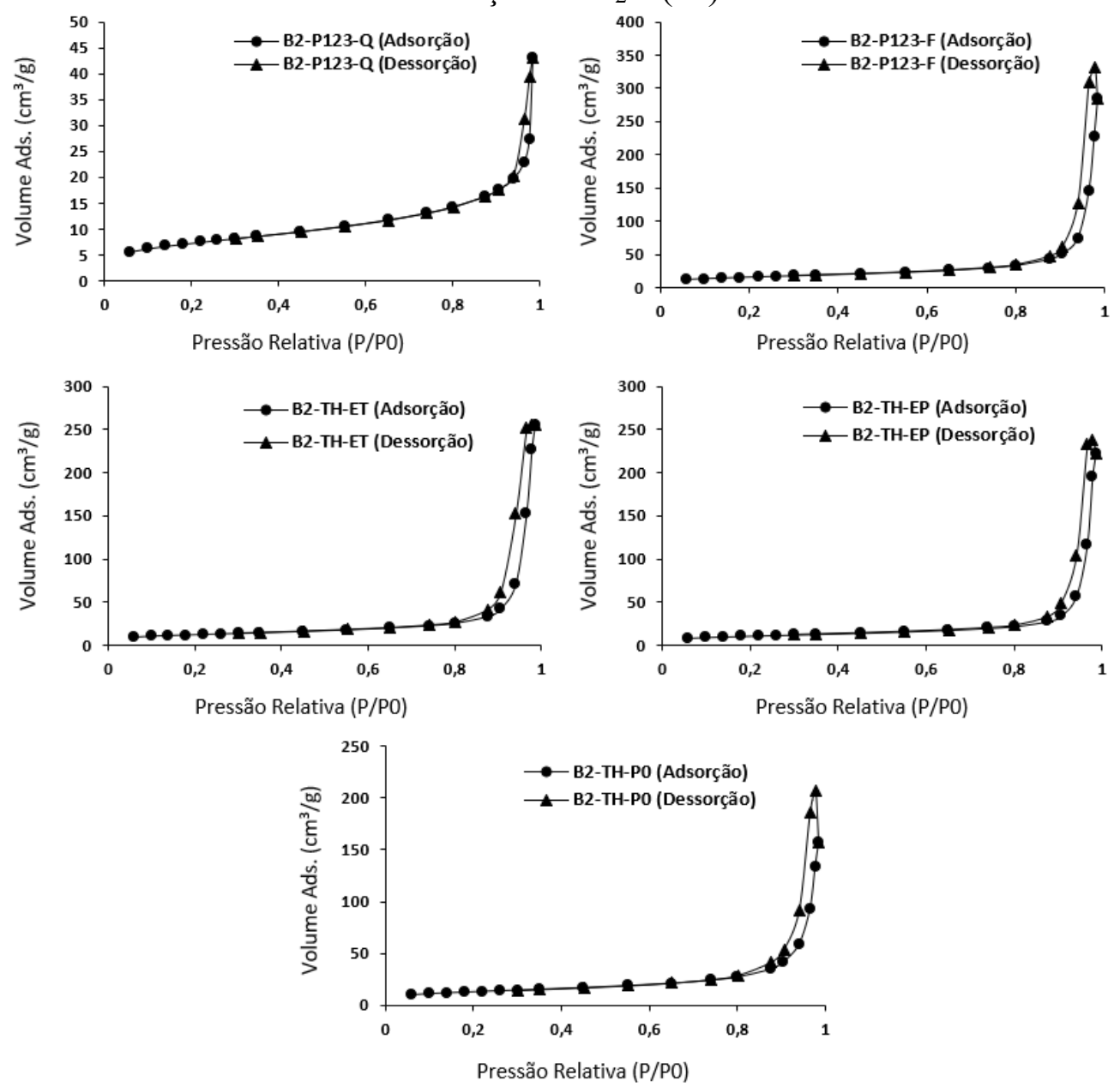

Fonte: Autor

\subsubsection{Microscopia eletrônica de varredura (MEV)}

A Figura 35 apresenta as imagens obtidas por microscopia eletrônica de varredura (MEV) para as amostras com composição B2 obtidas via tratamento hidrotérmico com evaporação total da água (a), na presença de Pluronic ${ }^{\circledR}$ P123 a frio (b) e utilizando o P123 a quente (c). As imagens são mostradas com uma ampliação de 15000x e 50000x e foram realizadas medidas dos diâmetros de poros visíveis. 
Figura 35 - Imagens obtidas por MEV das amostras (a.) B2 preparadas por TH-ET, (b.) com polímero a frio e (c.) polímero a quente com ampliação de x 15.000 e x 50.000

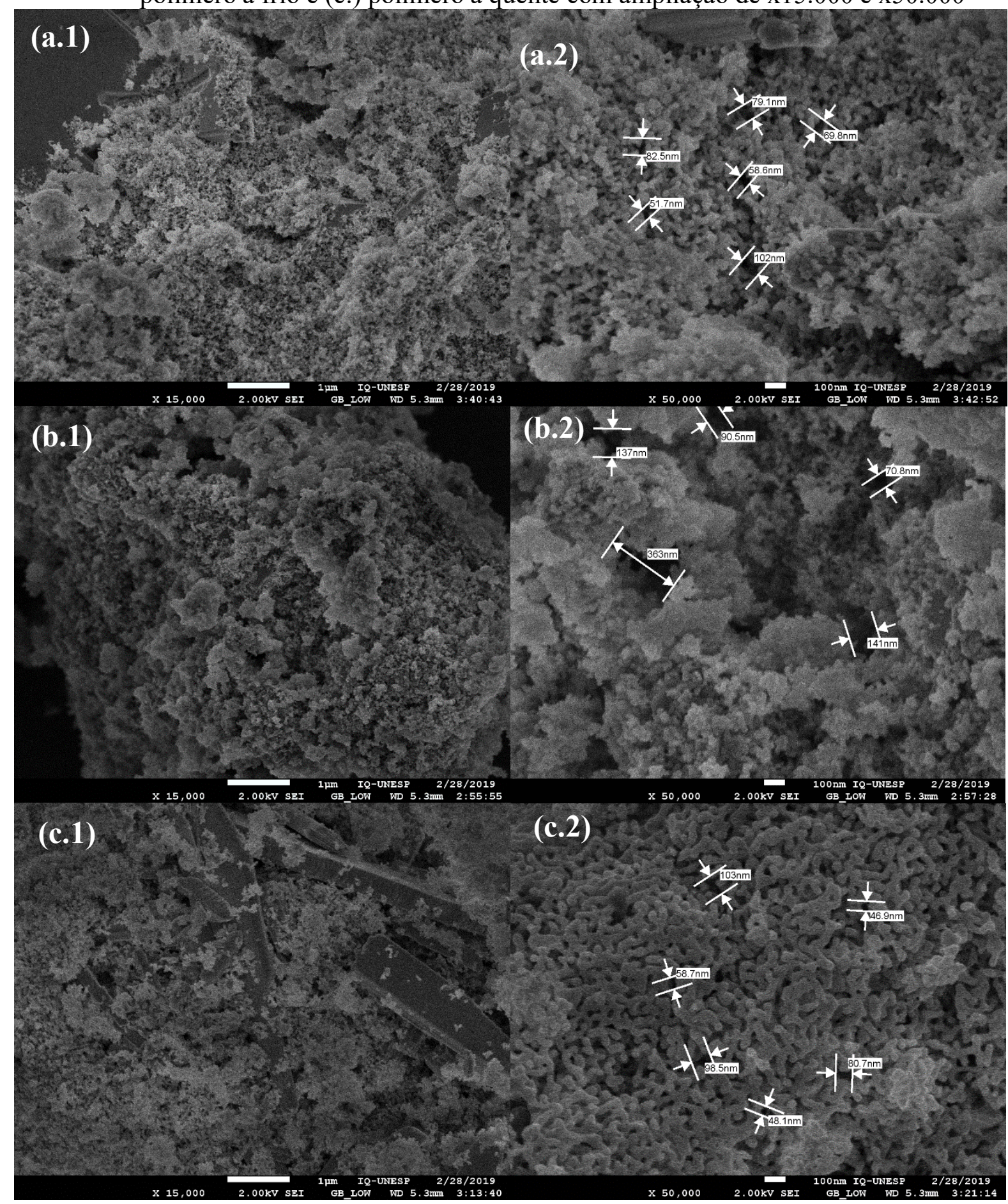

Fonte: Autor

$\mathrm{Na}$ microscopia da amostra obtida por tratamento hidrotérmico (B2-TH-ET - a.1) é possível identificar os cristais de $\alpha-\mathrm{MoO}_{3}$ envoltos por uma porção amorfa, provavelmente correspondente a sílica Aerosil utilizada como suporte. O mesmo é observado nas amostras preparadas na presença do copolímero P123 tanto a quente quanto a frio. 
Schuh et al. (2015) realizaram um estudo sobre a influência da morfologia do $\alpha-\mathrm{MoO}_{3}$ na reação de oxidação do propeno. Os materiais preparados por eles eram mássicos formados apenas pelos óxidos puros, sem a utilização de um suporte. Nas imagens obtidas é possível a visualização de estruturas em formato de barras retangulares, estruturas semelhantes às observadas na imagem (c.1) principalmente.

Quando analisados os diâmetros de poros obtidos para as três amostras, eles condizem com os valores obtidos por fisissorção com $\mathrm{N}_{2}$. Apesar dos valores não coincidirem, nas duas análises a amostra que apresentou maiores diâmetros foi a B2-P123-F preparada na presença do P123 a frio, pela medida realizada por MEV, os poros identificados apresentam um diâmetro médio próximo a $100 \mathrm{~nm}$.

\subsubsection{Discussão dos resultados da primeira etapa}

Dados os resultados obtidos na primeira etapa do projeto, foram selecionadas duas amostras para os testes em reator para avaliação catalítica na obtenção do ácido acrílico, uma amostra preparada via tratamento hidrotérmico e outra sintetizada na presença de copolímero P123.

As amostras preparadas utilizando o copolímero apresentaram resultados similares em relação a composição e cristalinidade conforme discutido nas análises de FTIR e DRX, nas quais ambas mostraram composições e fases semelhantes. A principal diferença observada entre elas foi o tamanho de poro obtido nas análises por fisissorção de $\mathrm{N}_{2}$. Nesse caso a amostra "a quente" (Bx-P123-Q) apresentou um diâmetro muito inferior a amostra sintetizada "a frio". Como o propósito da utilização do copolímero é obter um material mesoporoso com maior dimensão de poros, foram escolhidas para o teste em reator as amostras preparadas a frio $(\mathrm{Bx}-$ P123-F).

As amostras de mesma composição sintetizadas via tratamento hidrotérmico não apresentaram variações de fase cristalina quando preparadas pelos diferentes métodos. As amostras B1 apresentaram como fase cristalina principal o $\mathrm{CuMoO}_{4}$ enquanto as amostras B2 e $\mathrm{B} 3$ apresentaram em sua estrutura $\mathrm{o} \mathrm{MoO}_{3}$ ortorrômbico, observando apenas a alteração da cristalinidade, sendo ela maior nas amostras preparadas com evaporação parcial do solvente (Bx-TH-EP) com picos mais finos e intensos (DRX). Tais amostras apresentaram também maior diâmetro de poros analisados por fisissorção de $\mathrm{N}_{2}$, principal fator que levou a escolha desse método de síntese para o preparo das amostras por tratamento hidrotérmico na segunda etapa do projeto. 


\subsection{ETAPA II - AMOSTRAS SINTETIZADAS PELOS DIFERENTES MÉTODOS DE PREPARO PARA A AVALIAÇÃO CATALÍTICA}

$\mathrm{Na}$ segunda etapa do projeto, os catalisadores com composições B1, B2 e B3 foram sintetizados utilizando quatro metodologias de preparação diferentes para a avaliação em reator na produção do ácido acrílico. A primeira técnica foi por evaporação (Bx-EV), a segunda por tratamento hidrotérmico $(\mathrm{Bx}-\mathrm{TH})$, a terceira por evaporação seguido por tratamento hidrotérmico $(\mathrm{Bx}-\mathrm{EV}+\mathrm{TH})$ e por fim, utilizando um copolímero de blocos (B1-P123), conforme descrito na metodologia. O procedimento seguido para a síntese das amostras por tratamento hidrotérmico foi aquele que apresentou melhores resultados na primeira etapa do projeto, ou seja, por evaporação parcial do solvente. Foi preparada também a amostra B1 na presença do copolímero para avaliar o comportamento das amostras nos resultados de conversão e seletividade.

Os resultados de composição, cristalinidade, morfologia e avaliação catalítica na obtenção do ácido acrílico são apresentados e discutidos nos itens a seguir.

\subsubsection{Fluorescência de raios-X (FRX)}

As análises de fluorescência de raios $\mathrm{X}$ foram realizadas no Instituto Oceanográfico da USP para a determinação quantitativa da composição das amostras sintetizadas. As análises foram realizadas nos materiais sólidos finais obtidos e nos líquidos remanescentes do tratamento hidrotérmico, quando aplicável, para avaliar a quantidade de materiais ativos que foram solubilizados durante o tratamento hidrotérmico.

As tabelas a seguir apresentam os resultados de composição para as fases sólida e líquida para as amostras B1, B2, B3 e as variações da amostra B1. Os resultados indicam a presença de elementos como $\mathrm{Fe}$ e $\mathrm{Cr}$ que não foram utilizados nas preparações, esses valores correspondem a análise de picos secundários do molibdênio e vanádio que aparecem nas mesmas posições características desses elementos e por isso podem ser desconsiderados.

A Tabela 10 apresenta os resultados de composição obtidos para as amostras do tipo B1. É possível observar que a amostra preparada por evaporação (EV) apresentou uma composição semelhante à composição teórica esperada. Tal composição foi calculada com base na quantidade de reagentes utilizados e considerando a formação de óxido simples de $\mathrm{MoO}_{3}$, $\mathrm{V}_{2} \mathrm{O}_{5}, \mathrm{WO}_{3}, \mathrm{CuO}$ e $\mathrm{SiO}_{2}$. Esses resultados indicam que, no método por evaporação, todo o reagente utilizado é convertido nos catalisadores finais, ocorrendo apenas a eliminação dos 
$\mathrm{NH}_{4}{ }^{+} \mathrm{e} \mathrm{NO}_{3}{ }^{-}$formados durante a dissolução dos sais, não havendo perda de fase ativa. O mesmo não foi observado para as amostras sintetizadas por tratamento hidrotérmico. Tanto a amostra $\mathrm{B} 1-\mathrm{EV}+\mathrm{TH}$ quanto a amostra $\mathrm{B} 1-\mathrm{TH}$ apresentaram em comum um aumento no teor de $\mathrm{SiO}_{2}$ quando realizado TH e uma diminuição das composições referentes as fases ativas de Mo e W. Isso indica que durante a realização do tratamento hidrotérmico uma parte dos materiais ativos da amostra foi solubilizado e permaneceu na fase líquida mesmo após o resfriamento em banho de gelo. A análise de composição da fase líquida indicou um teor de 5,54\% em massa de Mo no líquido do TH da amostra B1-EV+TH e 2,84\% da amostra B1-TH. Esse é um dos principais fatores que colaboram para os baixos resultados de rendimento calculados para o processo de preparação das amostras sintetizadas por TH na primeira etapa do projeto. Como foi mostrado no item 5.1, o maior rendimento de preparo obtido foi de 28,30\% para a amostra B1-TH-E0.

Quando o tratamento hidrotérmico foi realizado durante a preparação das amostras B1, foi observada uma diminuição no teor de vanádio de 11,480 para 10,153\% e um aumento significativo no teor de cobre de 6,236\% para 16,873\%. Quando o TH foi realizado na amostra já calcinada (B1-EV+TH), foi observado o inverso, um aumento no teor de vanádio e diminuição no teor de cobre.

Tabela 10 - Composições em \%massa das amostras B1

\begin{tabular}{ccccccc}
\hline & B1-EV & $\begin{array}{c}\text { B1- } \\
\text { EV+TH }\end{array}$ & $\begin{array}{c}\text { B1- } \\
\text { EV+TH* }\end{array}$ & B1-TH & B1-TH* & $\begin{array}{c}\text { B1-teo } \\
\text { (esperado) }\end{array}$ \\
\hline $\mathrm{SiO}_{2} / \mathrm{Si}^{*}$ & 12,220 & 24,706 & 0,333 & 30,123 & 0,168 & $\mathbf{1 4 , 8 5}$ \\
$\mathrm{V}_{2} \mathrm{O}_{5} / \mathrm{V}^{*}$ & 11,480 & 20,438 & 0,438 & 10,153 & 0,401 & $\mathbf{1 2 , 4 6}$ \\
$\mathrm{Cr}_{2} \mathrm{O}_{3} / \mathrm{Cr}^{*}$ & 0,442 & - & - & 0,032 & - & - \\
$\mathrm{Fe}_{2} \mathrm{O}_{3} / \mathrm{Fe}^{*}$ & 0,042 & - & - & - & - & - \\
$\mathrm{CuO} / \mathrm{Cu}^{*}$ & 6,236 & 3,545 & 0,963 & 16,873 & - & $\mathbf{5 , 3 6}$ \\
$\mathrm{MoO}_{3} / \mathrm{Mo}^{*}$ & 53,360 & 38,876 & 5,919 & 35,640 & 2,841 & $\mathbf{5 0 , 8 7}$ \\
$\mathrm{WO}_{3} / \mathrm{W}^{*}$ & 16,220 & 12,436 & 2,188 & 7,179 & 1,224 & $\mathbf{1 6 , 4 6}$ \\
$-/ \mathrm{H}_{2} \mathrm{O}^{*}$ & - & - & 90,159 & & 95,366 & - \\
\hline
\end{tabular}

*Resultados para os líquidos. Fonte: Autor

As composições em porcentagem em massa das amostras B2 são mostradas na Tabela 11. Semelhante ao comportamento apresentado pela amostra B1, as amostras B2-EV e B3- EV (Tabela 12) também apresentaram composições semelhantes às teóricas esperadas, 
concordando com a discussão anterior de que a perda de fase ativa durante a preparação é menor quando utilizado o método por evaporação.

Tabela 11 - Composições em \%massa para as amostras B2

\begin{tabular}{ccccccc}
\hline & B2-EV & $\begin{array}{c}\text { B2- } \\
\text { EV+TH }\end{array}$ & $\begin{array}{c}\text { B2- } \\
\text { EV+TH* }\end{array}$ & B2-TH & B2-TH* & $\begin{array}{c}\text { B2-teo } \\
\text { (esperado) }\end{array}$ \\
\hline $\mathrm{SiO}_{2} / \mathrm{Si}^{*}$ & 12,145 & 20,744 & 0,175 & 29,714 & 0,088 & $\mathbf{1 5 , 5 6}$ \\
$\mathrm{V}_{2} \mathrm{O}_{5} / \mathrm{V}^{*}$ & 6,609 & 9,660 & 0,228 & 6,380 & 0,200 & $\mathbf{7 , 6 0}$ \\
$\mathrm{Cr}_{2} \mathrm{O}_{3} / \mathrm{Cr}^{*}$ & - & - & - & - & - & - \\
$\mathrm{Fe}_{2} \mathrm{O}_{3} / \mathrm{Fe}^{*}$ & 0,043 & - & - & - & - & - \\
$\mathrm{CuO} / \mathrm{Cu}^{*}$ & 0,027 & - & - & 0,023 & - & - \\
$\mathrm{MoO}_{3} / \mathrm{Mo}^{*}$ & 76,016 & 66,892 & 2,418 & 58,911 & 5,851 & $\mathbf{7 1 , 4 9}$ \\
$\mathrm{WO}_{3} / \mathrm{W}^{*}$ & 5,159 & 2,704 & 0,670 & 4,972 & 0,297 & $\mathbf{5 , 3 5}$ \\
$-/ \mathrm{H}_{2} \mathrm{O}^{*}$ & - & - & 96,509 & - & 93,563 & - \\
\hline
\end{tabular}

*Resultados para os líquidos. Fonte: Autor

Nas amostras B2 preparadas por tratamento hidrotérmico foi possível observar uma diminuição do teor de molibdênio e tungstênio, de 76,016\% e 5,159\% para 58,911\% e 4,972\% para a amostra B2-TH e para $66,892 \%$ e $2,704 \%$ para a amostra B2-EV+TH. Por outro lado, o teor de vanádio se manteve praticamente constante para a amostra B2-TH e apresentou um leve aumento para a amostra B2-EV+TH.

Tabela 12 - Composições em \%massa para as amostras B3

\begin{tabular}{ccccccc}
\hline & B3-EV & $\begin{array}{c}\text { B3- } \\
\mathbf{E V + T H}\end{array}$ & $\begin{array}{c}\text { B3- } \\
\mathbf{E V + T H *}\end{array}$ & B3-TH & B3-TH* & $\begin{array}{c}\text { B3-teo } \\
\text { (esperado) }\end{array}$ \\
\hline $\mathrm{SiO}_{2} / \mathrm{Si}^{*}$ & 10,006 & 12,567 & 0,125 & 31,984 & 0,154 & $\mathbf{1 6 , 4 9}$ \\
$\mathrm{V}_{2} \mathrm{O}_{5} / \mathrm{V}^{*}$ & 11,515 & 11,809 & 0,175 & 6,657 & 0,578 & $\mathbf{1 0 , 3 0}$ \\
$\mathrm{Cr}_{2} \mathrm{O}_{3} / \mathrm{Cr}^{*}$ & - & - & - & - & - & - \\
$\mathrm{Fe}_{2} \mathrm{O}_{3} / \mathrm{Fe}^{*}$ & - & - & 0,006 & - & - & - \\
$\mathrm{CuO} / \mathrm{Cu}^{*}$ & 0,036 & 0,026 & - & - & - & - \\
$\mathrm{MoO}_{3} / \mathrm{Mo}^{*}$ & 78,444 & 75,598 & 1,854 & 61,298 & 4,572 & $\mathbf{7 3 , 2 0}$ \\
$\mathrm{WO}_{3} / \mathrm{W}^{*}$ & - & - & - & - & - & - \\
$-/ \mathrm{H}_{2} \mathrm{O}^{*}$ & - & - & 97,795 & - & 94,696 & - \\
\hline
\end{tabular}

*Resultados para os líquidos. Fonte: Autor

A amostra B3 apresentou comportamento diferente em relação ao tratamento hidrotérmico. Quando realizado durante a preparação (B3-TH), foi observado uma diminuição nos teores de óxidos de molibdênio e vanádio, indicando a solubilização de material ativo durante sua preparação, confirmado pela análise do líquido remanescente, que apresentou um teor de 4,572\% em massa para o molibdênio. Já quando o tratamento foi realizado na amostra 
calcinada $(\mathrm{B} 3-\mathrm{EV}+\mathrm{TH})$, não foram observadas mudanças significativas de composição, confirmada pela análise do líquido mão do TH que 97,795\% era formada por água, mostrando a pequena presença dos materiais ativos.

As Tabelas 13 e 14 mostram os resultados para as variações da amostra B1 sintetizadas sem a presença de cobre no caso B1.2 e sem Cu e W no caso B1.3, sintetizadas por evaporação (EV) e evaporação seguida de tratamento hidrotérmico $(\mathrm{EV}+\mathrm{TH})$. Após o tratamento hidrotérmico, a amostra B1.2-EV+TH apresentou um aumento no teor de óxidos de vanádio e diminuição no teor de tungstênio, mantendo o mesmo teor de óxidos de molibdênio. Os resultados foram condizentes com a composição do líquido obtida, indicando que uma maior quantidade de óxido de tungstênio foi dissolvida durante o tratamento hidrotérmico.

Tabela 13 - Composições em \%massa para as amostras B1.2

\begin{tabular}{ccccc}
\hline & B1.2-EV & B1.2-EV+TH & B1.2-EV+TH* & $\begin{array}{c}\text { B1.2-teo } \\
\text { (esperado) }\end{array}$ \\
\hline $\mathrm{SiO}_{2} / \mathrm{Si}^{*}$ & 12,671 & 12,437 & 0,184 & 15,69 \\
$\mathrm{~V}_{2} \mathrm{O}_{5} / \mathrm{V}^{*}$ & 13,277 & 18,317 & 0,217 & 13,16 \\
$\mathrm{Cr}_{2} \mathrm{O}_{3} / \mathrm{Cr}^{*}$ & - & - & - & - \\
$\mathrm{Fe}_{2} \mathrm{O}_{3} / \mathrm{Fe}^{*}$ & 0,042 & - & - & - \\
$\mathrm{CuO} / \mathrm{Cu}^{*}$ & 0,038 & 0,049 & - & - \\
$\mathrm{MoO}_{3} / \mathrm{Mo}^{*}$ & 56,587 & 55,825 & 2,805 & 53,75 \\
$\mathrm{WO}_{3} / \mathrm{W}^{*}$ & 17,385 & 13,372 & 1,176 & 17,40 \\
$-/ \mathrm{H}_{2} \mathrm{O}^{*}$ & - & - & 95,619 & - \\
\hline
\end{tabular}

*Resultados para os líquidos. Fonte: Autor

A amostra B1.3 apresentou uma diminuição do teor de $\mathrm{MoO}_{3}$ de $66,361 \%$ para $64,225 \%$ e um aumento do teor de vanádio para 20,354\%, mantendo o mesmo teor de suporte.

Tabela 14 - Composições em \%massa para as amostras B1.3

\begin{tabular}{ccccc}
\hline & B1.3-EV & B1.3-EV+TH & B1.3-EV+TH* & $\begin{array}{c}\text { B1.3-teo } \\
\text { (esperado) }\end{array}$ \\
\hline $\mathrm{SiO}_{2} / \mathrm{Si}^{*}$ & 17,367 & 15,376 & 0,199 & 18,99 \\
$\mathrm{~V}_{2} \mathrm{O}_{5} / \mathrm{V}^{*}$ & 16,241 & 20,354 & 0,245 & 15,93 \\
$\mathrm{Cr}_{2} \mathrm{O}_{3} / \mathrm{Cr}^{*}$ & - & - & - & - \\
$\mathrm{Fe}_{2} \mathrm{O}_{3} / \mathrm{Fe}^{*}$ & - & 0,045 & - & - \\
$\mathrm{CuO} / \mathrm{Cu}^{*}$ & 0,033 & - & - & - \\
$\mathrm{MoO}_{3} / \mathrm{Mo}^{*}$ & 66,361 & 64,225 & 2,797 & 65,07 \\
$\mathrm{WO}_{3} / \mathrm{W}^{*}$ & - & - & - & - \\
$-/ \mathrm{H}_{2} \mathrm{O}^{*}$ & - & - & 96,759 & - \\
\hline
\end{tabular}

Fonte: Autor 
A Tabela 15 apresenta a composição real da amostra B1-P123, sintetizada na presença do copolímero. Analisando os resultados foi possível notar que a perda de fase ativa foi menor nesse caso que no método por tratamento hidrotérmico, mesmo a amostra B1-P123 permanecendo 96 horas em tratamento.

Tabela 15 - Composições em \%massa para a amostra B1 com P123

\begin{tabular}{ccccc}
\hline & $\mathbf{B 1 - P 1 2 3}$ & $\mathbf{B 1 - P 1 2 3}$ & $\begin{array}{c}\text { B1-teo } \\
\text { (esperado) }\end{array}$ & B1-TH \\
\hline $\mathrm{SiO}_{2} / \mathrm{Si}^{*}$ & 20,169 & 0,112 & $\mathbf{1 4 , 8 5}$ & 30,123 \\
$\mathrm{~V}_{2} \mathrm{O}_{5} / \mathrm{V}^{*}$ & 9,123 & 0,512 & $\mathbf{1 2 , 4 6}$ & 10,153 \\
$\mathrm{Cr}_{2} \mathrm{O}_{3} / \mathrm{Cr}^{*}$ & - & - & - & 0,032 \\
$\mathrm{Fe}_{2} \mathrm{O}_{3} / \mathrm{Fe}^{*}$ & 0,030 & - & - & - \\
$\mathrm{CuO} / \mathrm{Cu}^{*}$ & 9,717 & - & $\mathbf{5 , 3 6}$ & 16,873 \\
$\mathrm{MoO}_{3} / \mathrm{Mo}^{*}$ & 46,615 & 2,313 & $\mathbf{5 0 , 8 7}$ & 35,640 \\
$\mathrm{WO}_{3} / \mathrm{W}^{*}$ & 14,346 & 0,965 & $\mathbf{1 6 , 4 6}$ & 7,179 \\
$-/ \mathrm{H}_{2} \mathrm{O}^{*}$ & - & 96,098 & - & \\
\hline
\end{tabular}

Fonte: Autor

\subsubsection{Análises por transformada de Fourier na região da infravermelho (FTIR)}

As amostras sintetizadas na segunda etapa do projeto foram analisadas por FTIR e os resultados são mostrados na Figura 36 a seguir. As amostras B1, B2 e B3 sintetizadas por TH apresentaram espectros com as mesmas bandas características identificadas nas análises de suas respectivas amostras preliminares, discutidas no item 5.1.1. Os espectros das amostras B2-TH e B3-TH possuem bandas características aos estiramentos da ligação metal-oxigênio Mo-O em 620,814 e $870 \mathrm{~cm}^{-1}$ comuns em materiais compostos por $\alpha-\mathrm{MoO}_{3}$. Já os espectros da amostra B1-TH, sugerem a presença de compostos $\mathrm{CuMoO}_{4}$, com bandas características em 950, 905, $725 \mathrm{~cm}^{-1}$ (CHITHAMBARARAJ, BOSE, 2012; CHITHAMBARARAJ, BOSE, 2011).

Todos os espectros apresentam em comum uma banda em $1640 \mathrm{~cm}^{-1}$ referente ao estiramento H-O-H das moléculas de água devido a umidade residual presente nas amostras e outra em $1100 \mathrm{~cm}^{-1}$ referente a ligação Si-O-Si da sílica usada como suporte (MUSIC, FILIPOVIC-VINCEKOVIC, SEKOVANIC, 2011).

Analisando os espectros obtidos para as amostras B1, as diferentes bandas encontradas indicam que a metodologia empregada na síntese influenciou a composição superficial das amostras obtidas. A amostra sintetizada por evaporação B1-EV apresentou uma banda forte na região de $800 \mathrm{~cm}^{-1}$, o que indicou a possível preesença de ligações $\mathrm{W}-\mathrm{O}$ no material. A associação dessa banda forte com outras de menor intensidade na mesma região levou ao seu 
alargamento, formando uma grande banda entre 400 e $950 \mathrm{~cm}^{-1}$, que dificultou a análise de outras possíveis bandas que pssam estar sobrepostas.

Figura 36 - Espectrogramas na região do infravermelho das amostras B1 (a.), B2 (b.) e B3 (c.) e variações da amostra B1 (d.) testadas em reator
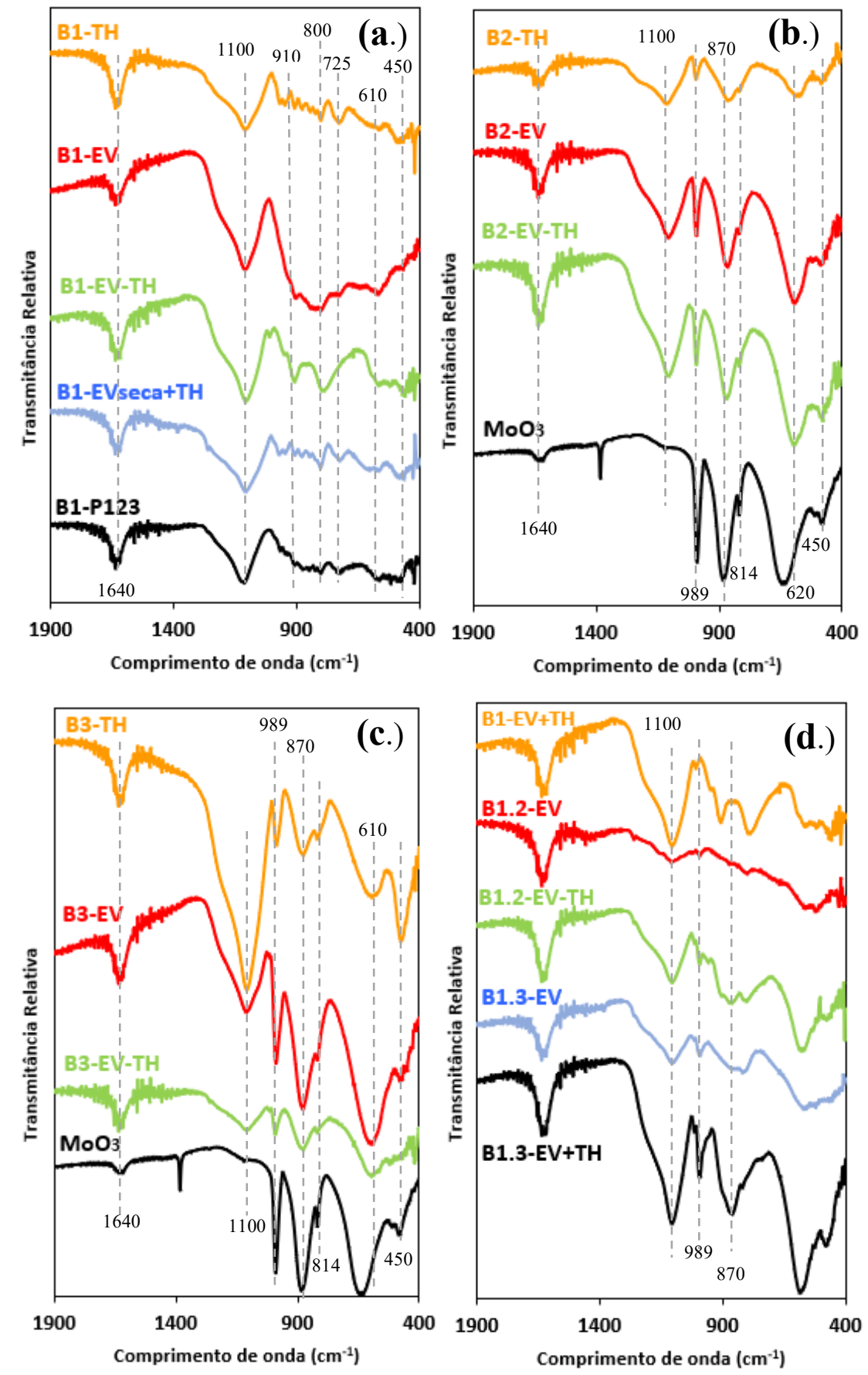

Fonte: Autor

A amostra B1-EV+TH não apresentou a mesma série de bandas de pequena intensidade entre 800 e $950 \mathrm{~cm}^{-1}$, identificadas na amostra B1-TH. O que indica uma mudança na 
composição da superfície do material não sendo mais formado predominantemente por compostos com grande quantidade de $\mathrm{Cu}-\mathrm{O}$. O que condiz com os resultados de composição obtidos por FRX, que mostraram $16,87 \%$ em massa de $\mathrm{Cu}$ na amostra $\mathrm{B} 1-\mathrm{TH}$, enquanto a amostra B1-EV+TH apresentou apenas 3,54\%.

As amostras B2 e B3 sintetizadas pelos três diferentes métodos propostos (EV, TH e $\mathrm{EV}+\mathrm{TH})$ apresentaram espectros semelhantes, com bandas características dos estiramentos Mo$\mathrm{O}$ relacionadas ao composto $\alpha-\mathrm{MoO}_{3}$ (ortorrômbico) identificadas também nas amostras $\mathrm{B} 2 \mathrm{e}$ B3 sintetizadas na primeira etapa do projeto. O mesmo foi observado para a amostra B1.3, variação da amostra B1 contendo apenas Mo e V.

\subsubsection{Análises por difratometria de raios-X (DRX)}

As fases cristalinas presentes nos materiais sintetizados foram determinadas por difração de raios-X e são apresentadas na Figura 37. Analisando os espectros foi possível observar que para as amostras do tipo B1, a estrutura cristalina formada no material final foi totalmente dependente do tipo de preparação utilizada, apresentando picos de difração característicos de diferentes fases, identificadas nos difratogramas da imagem (a.). A amostra sintetizada por tratamento hidrotérmico (B1-TH) apresentou como principal fase cristalina o $\mathrm{CuMoO}_{4}$, com picos em $2 \theta=24,3^{\circ}, 27,3^{\circ}, 29^{\circ}$ e $30^{\circ}$, e houve também a formação da fase $\mathrm{W}_{0,4} \mathrm{Mo}_{0,6} \mathrm{O}_{3}$, apresentando picos com menor intensidade, mesmas fases identificadas para tal preparação na primeira etapa do projeto. A formação de tais fases pode ser associada a maior composição de óxidos de cobre presentes no sólido formado, com uma composição em massa de $16,87 \%$ para o cobre determinadas por FRX. Deste modo, a formação do composto $\mathrm{CuMoO}_{4}$ durante a etapa do tratamento hidrotérmico contribuiu para maior incorporação do cobre no sólido formado, diminuindo sua concentração na fase líquida a um nível indetectável na análise realizada.

Já a amostra sintetizada por evaporação (B1-EV) apresentou como fase predominante o $\mathrm{W}_{0,5} \mathrm{Mo}_{0,5} \mathrm{O}_{3}$, com picos de difração característicos em $2 \theta=23,3^{\circ}, 24,8^{\circ}, 26,5^{\circ} 34,1^{\circ} 54,1^{\circ}$ (Card: 00-028-0667) e a fase $\mathrm{CuMoO}_{4}$ em menor quantidade, isso se deve a maior composição em massa de tungstênio incorporadas a amostra (composição de 16,22\% de tungstênio e 6,236\% de cobre determinados por FRX). 
Figura 37 - Análise de difração de raios-X das amostras B1 (a.), B2 (b.) e B3 (c.) e variações da amostra B1 (d.) testadas em reator
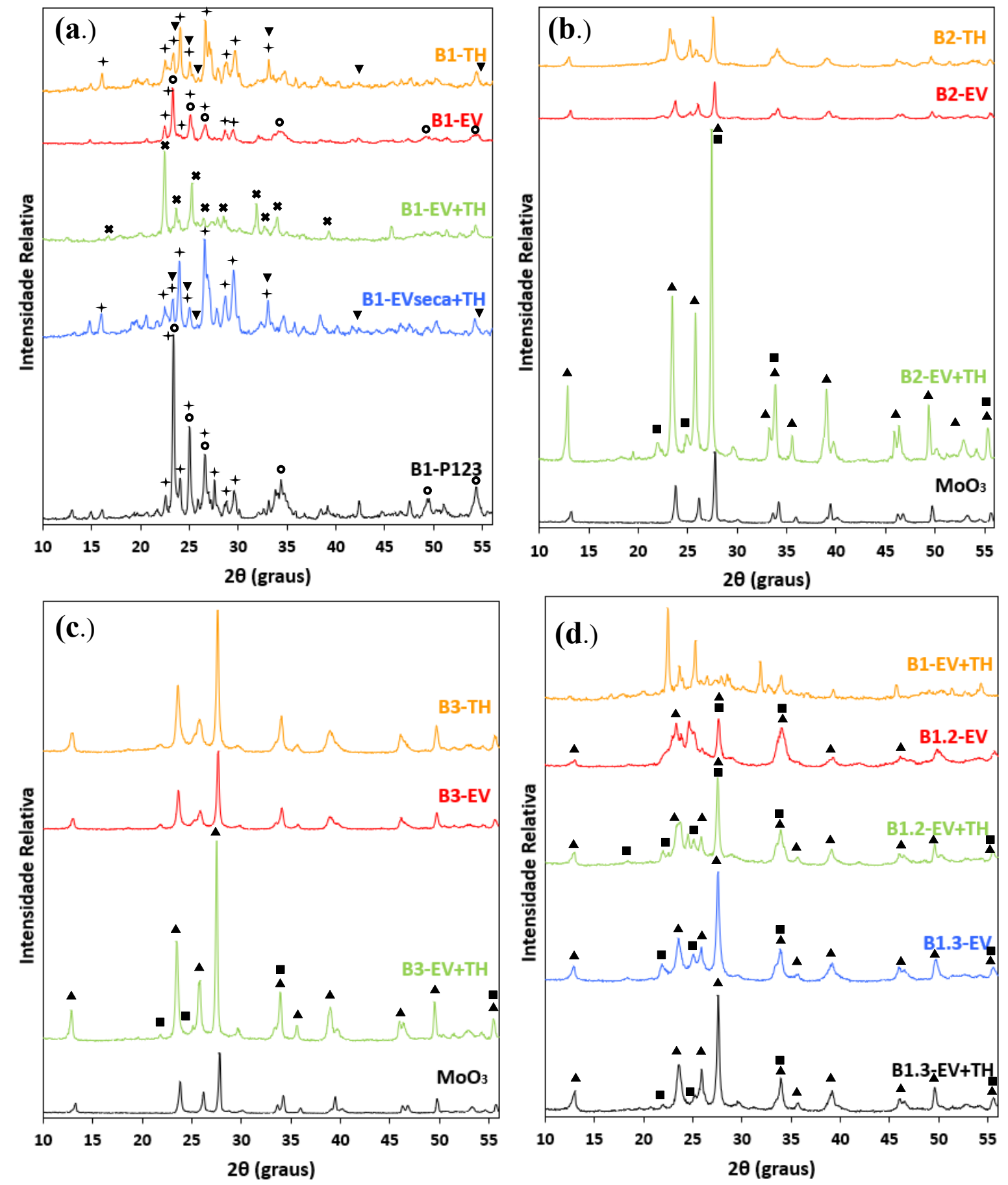

Fonte: Autor

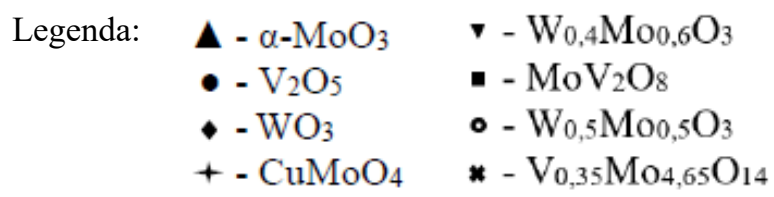


Quando realizado o tratamento hidrotérmico na amostra B1-EV para a obtenção da amostra nomeada B1-EV+TH, foi observado uma grande transformação de fases, com a formação principal do $\mathrm{V}_{0,35} \mathrm{Mo}_{4,65} \mathrm{O}_{14}$, identificado por picos em $2 \theta=22,5^{\circ}, 23,65^{\circ}, 25,5^{\circ}, 31,5^{\circ}$ e $37^{\circ}$, como indicado no difratograma (a.). Simultaneamente foi observado um aumento no teor de óxidos associados ao vanádio, de 11,48\% na amostra evaporada para 20,44\% em massa na amostra após o tratamento hidrotérmico. Tais resultados indicam que a formação das fases cristalinas está diretamente relacionada a composição em massa final dos catalisadores.

As amostras do tipo B2 e B3 não apresentaram o mesmo comportamento em relação as mudanças de fases mostradas pela amostra B1 quando sintetizadas por diferentes métodos de preparo. As amostras apresentaram como fase cristalina principal a fase ortorrômbica do trióxido de molibdênio $\left(\alpha-\mathrm{MoO}_{3}\right)$ atribuindo ao molibdênio um estado de oxidação +6 , geralmente presente em amostras tratadas a altas temperaturas devido a sua maior estabilidade. Os difratogramas apresentaram também picos com pouca intensidade referentes a fase $\mathrm{MoV}_{2} \mathrm{O}$, que também apresenta uma estrutura ortorrômbica, o que facilita a troca isoestrutural dos elementos (POSSATO et al., 2017; SILVA, SILVA, MATOS, 2018).

As variações das amostras B1 sintetizadas (as amostras B1.2 e B1.3 (d.)) apresentaram difratogramas que indicam a formação de uma estrutura com maior presença de componentes amorfos, com picos largos e poucos definidos com a elevação da linha de base, o que dificultou a identificação exata das fases cristalinas presentes. Os principais picos identificados também são referentes os componentes $\alpha-\mathrm{MoO}_{3}$ e $\mathrm{MoV}_{2} \mathrm{O}$, com as mesmas características apresentadas para as amostras B2 e B3. Isso indica que, a adição do nitrato de cobre durante as preparações, auxiliou para a formação das diferentes fases formadas para a amostra B1, mesmo ele não estando presente na estrutura cristalina de fases como o $\mathrm{V}_{0,35} \mathrm{Mo}_{4,65} \mathrm{O}_{14}$ e $\mathrm{W}_{0,5} \mathrm{Mo}_{0,5} \mathrm{O}_{3}$.

\subsubsection{Análise de fisissorção de $\mathrm{N}_{2}$ para determinação de área específica e porosidade}

A Error! Reference source not found. apresenta os resultados de área específica, volume e diâmetro de poros para as amostras B1, B2 e B3 sintetizadas pelas diferentes técnicas de preparação. É possível observar que as amostras sintetizadas por evaporação, independentemente da composição, foram as que apresentaram menores valores de área específica e diâmetro de poros, de 10,4 a $25,1 \mathrm{~m}^{2} / \mathrm{g}$, valores um pouco maiores que aos encontrados para os óxidos de molibdênio e vanádio puros, que correspondem a 0,5 e 7,6 m²/g, respectivamente (RASTEIRO et al., 2017). 
Quando as amostras são sintetizadas via tratamento hidrotérmico, observa-se um aumento significativo da área específica e volume de poros em todos os casos, e também gera um aumento no diâmetro médios de poros.

Tabela 16 - Resultados de área específica e porosidade obtidos por fisissorção com $\mathrm{N}_{2}$ para as amostras testadas em reator

\begin{tabular}{lccc}
\hline \multicolumn{1}{c}{ Amostra } & $\begin{array}{c}\text { Área BET } \\
\left(\mathrm{m}^{2} / \mathrm{g}\right)\end{array}$ & $\begin{array}{c}\text { Volume de poro } \\
\left(\mathrm{cm}^{3} / \mathrm{g}\right)\end{array}$ & $\begin{array}{c}\text { Diâmetro de poro } \\
(\mathrm{nm})\end{array}$ \\
\hline B1-TH & 52,0 & 0,409 & 30,0 \\
B1-EV & 15,4 & 0,108 & 27,5 \\
B1.2-EV & 16,2 & 0,092 & 22,0 \\
B1.3-EV & 25,1 & 0,183 & 20,8 \\
B1-EV+TH & 45,5 & 0,296 & 25,1 \\
B1.2-EV+TH & 27,0 & 0,159 & 23,2 \\
B1.3-EV+TH & 37,9 & 0,232 & 24,5 \\
\hline B2-TH & 27,4 & 0,202 & 28,4 \\
B2-EV & 19,4 & 0,120 & 23,7 \\
B2-EV+TH & 31,8 & 0,205 & 24,8 \\
\hline B3-TH & 37,9 & 0,326 & 32,8 \\
B3-EV & 10,4 & 0,066 & 25,4 \\
B3-EV+TH & 32,5 & 0,183 & 22,6 \\
\hline
\end{tabular}

Fonte: Autor

\subsubsection{Avaliação catalítica dos materiais na obtenção do ácido acrílico}

As amostras sintetizadas na segunda etapa do projeto foram avaliadas na obtenção do ácido acrílico partindo-se de dois reagentes diferentes: a acroleína e o glicerol. Primeiramente elas foram avaliadas na reação de oxidação da acroleína, o principal intermediário na reação de oxidesidratação do glicerol, para avaliar os efeitos dos diferentes métodos de preparação nos resultados de conversão e seletividade. Por fim, os materiais foram avaliados também na reação de obtenção do ácido acrílico a partir do glicerol em uma única etapa.

A reação de oxidação da acroleína foi realizada a $308{ }^{\circ} \mathrm{C}$ e com uma relação $\mathrm{O}_{2} /$ reagente igual a 3, mesmas condições utilizadas no processo com o glicerol. Assim foi possível relacionar os dois processos. A reação de oxidação é exotérmica e libera grandes quantidades 
de energia $(\Delta \mathrm{H}=-298,3 \mathrm{~kJ} / \mathrm{mol})$, principalmente nos primeiros minutos de reação, nos quais a superfície da amostra está mais ativa devido ao tratamento térmico realizado. A Figura 38 apresenta o perfil de temperatura, teor de $\mathrm{O}_{2}$ na saída do processo e a massa de produto líquido recolhido, apresentados nos testes de oxidação da acroleína (OMATA et al., 2015).

Figura 38 - Comportamento da reação de oxidação da acroleína em função do tempo acompanhando parâmetros de temperatura, conversão de $\mathrm{O} 2$ e massa de produto recolhido

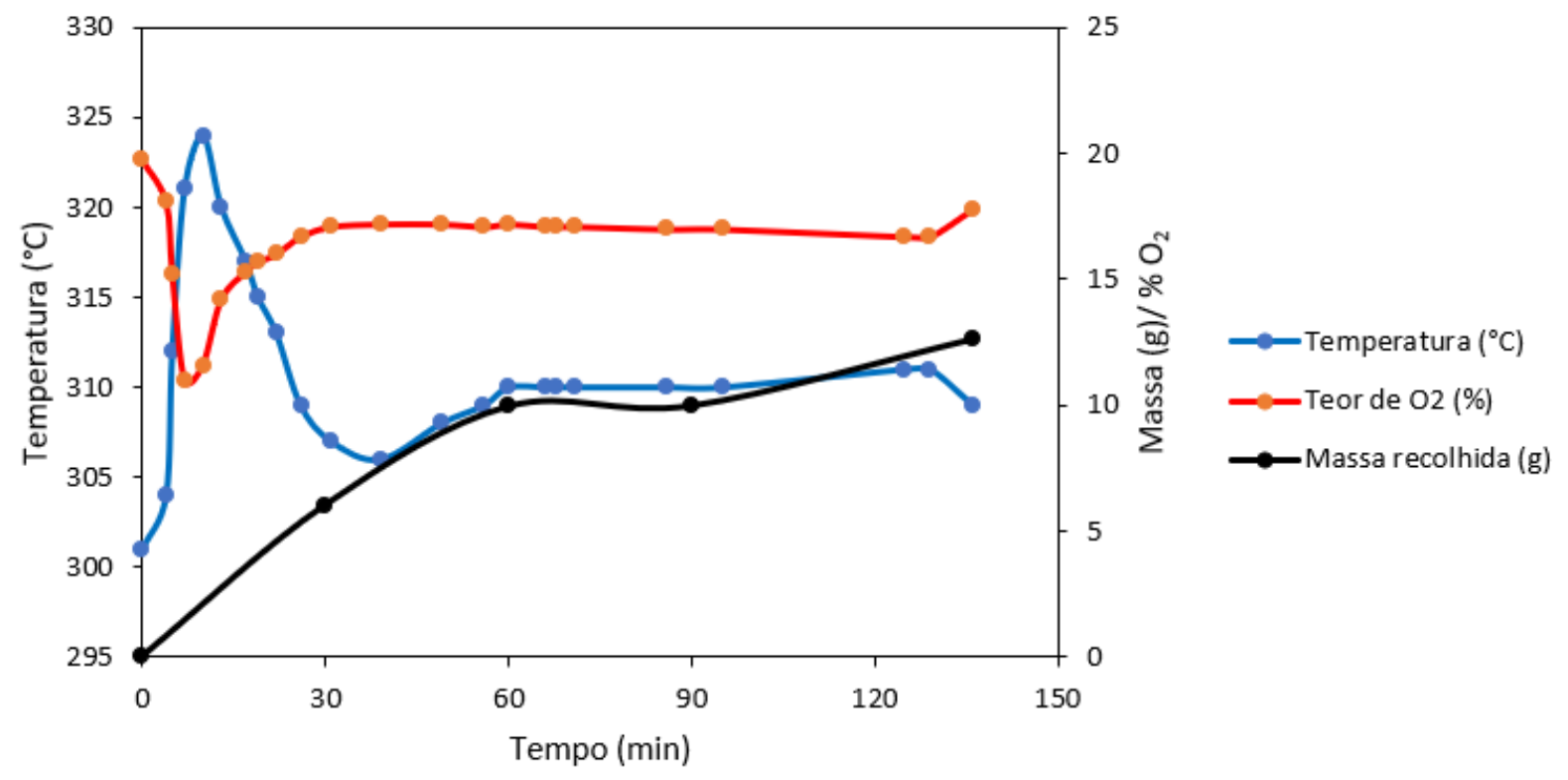

Fonte: Autor

O início do fluxo da solução de acroleína foi realizado com o reator a aproximadamente $300{ }^{\circ} \mathrm{C}$ e teor de $20 \%$ de $\mathrm{O}_{2}$ nos gases de saída. No momento em que ocorre o início da reação (aproximadamente aos 5 minutos, tempo necessário para a solução chegar no evaporador), foi observado um aumento brusco de temperatura até $324{ }^{\circ} \mathrm{C}$ e redução do teor de $\mathrm{O}_{2}$, devido ao seu maior consumo na reação. Em seguida o controlador de temperatura no forno do reator atuou para se atingir a temperatura desejada de $308{ }^{\circ} \mathrm{C}$ e o regime do sistema foi atingido após a primeira hora de reação.

A seguir são apresentados os resultados de conversão e seletividade para as amostras B1, B2 e B3 preparadas na segunda etapa do projeto utilizadas na reação de oxidação da acroleína. Antes de iniciar as discussões sobre os resultados e composição vale ressaltar a importância do $\mathrm{O}_{2}$ nos ciclos redox. Para acontecer a oxidação da acroleína é necessário a redução de um átomo de vanádio da superfície do catalisador, liberando uma vacância de oxigênio, e depois o oxigênio molecular alimentado no reator é o responsável por restaurar essa 
vacância livre, seguindo mecanismo Mars-van Krevelen (MVK), por isso é necessário a alimentação em excesso de $\mathrm{O}_{2}$ na reação (RASTEIRO et al., 2017).

A Figura 39 apresenta os resultados catalíticos para as amostras do tipo B1. A amostra B1-EV e B1-EV+TH apresentaram conversões próximas a 50\% na primeira hora de reação e seletividades entre 9,03 e 15,89\% para o $\mathrm{CO}_{2}$. Quanto a amostra B1-TH, ela apresentou uma conversão de $25,68 \%$ e uma maior seletividade para a formação de $\mathrm{CO}$ e $\mathrm{CO}_{2}$. entre os produtos obtidos.

Figura 39 - Resultados de conversão e seletividade para as amostras B1 preparadas por EV, TH e EV+TH avaliadas na oxidação da acroleína

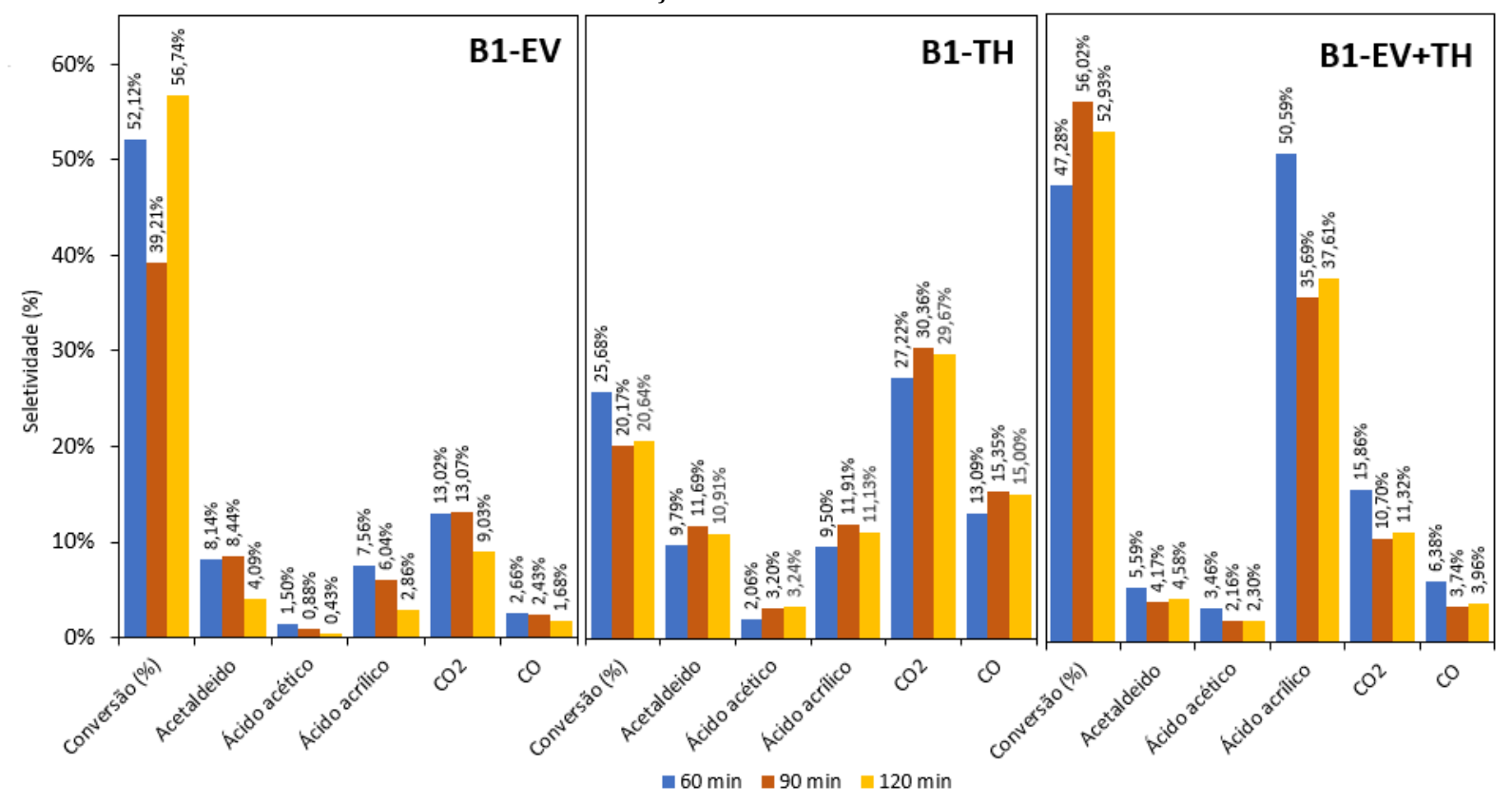

Fonte: Autor

A maior seletividade obtida para o ácido acrílico foi apresentada pela a amostra B1$\mathrm{EV}+\mathrm{TH}$ e está relacionada principalmente a fase cristalina formada, o $\mathrm{V}_{0,35} \mathrm{Mo}_{4,65} \mathrm{O}_{14}$, que já foi identificada em outros trabalhos como a mais ativa na oxidação da acroleína. Em estruturas contendo óxidos mistos desse tipo, o estado de oxidação $\mathrm{Mo}^{+6}$ não é variante, mas devido à similaridade de seu diâmetro com o do $\mathrm{V}^{4+}$, ele é capaz de acomodar o $\mathrm{V}^{4+}$ na rede cristalina e facilitar as mudanças dos estados de oxidação e criação das vacâncias durante a reação (LIU et al., 2015).

A Figura 40 mostra os resultados catalíticos para as amostras do tipo B2. Ambas as amostras apresentaram uma conversão próxima a 50\% para a acroleína e uma seletividade de ácido acrílico máxima de 2,36\% para a preparação por TH e 5,82\% para a preparação EV+TH, 
foi observada também uma maior formação de $\mathrm{CO}_{2}$ e $\mathrm{CO}$ para a amostra preparada por EV+TH. Tais resultados podem ser relacionados a composição das amostras formadas, apesar de ambas apresentarem como principal fase cristalina o $\alpha-\mathrm{MoO}_{3}$, a composição da amostra $\mathrm{B} 2-\mathrm{EV}+\mathrm{TH}$ foi de $66,892 \%$ de óxidos de molibdênio e $9,660 \%$ de óxidos compostos por vanádio, enquanto para a amostra B2-TH foi de 58,911\% e 6,380\%, uma maior composição de fase ativa permitiu uma maior oxidação de acroleína.

Figura 40 - Resultados de conversão e seletividade para as amostras B2 preparadas TH e EV+TH avaliadas na oxidação da acroleína

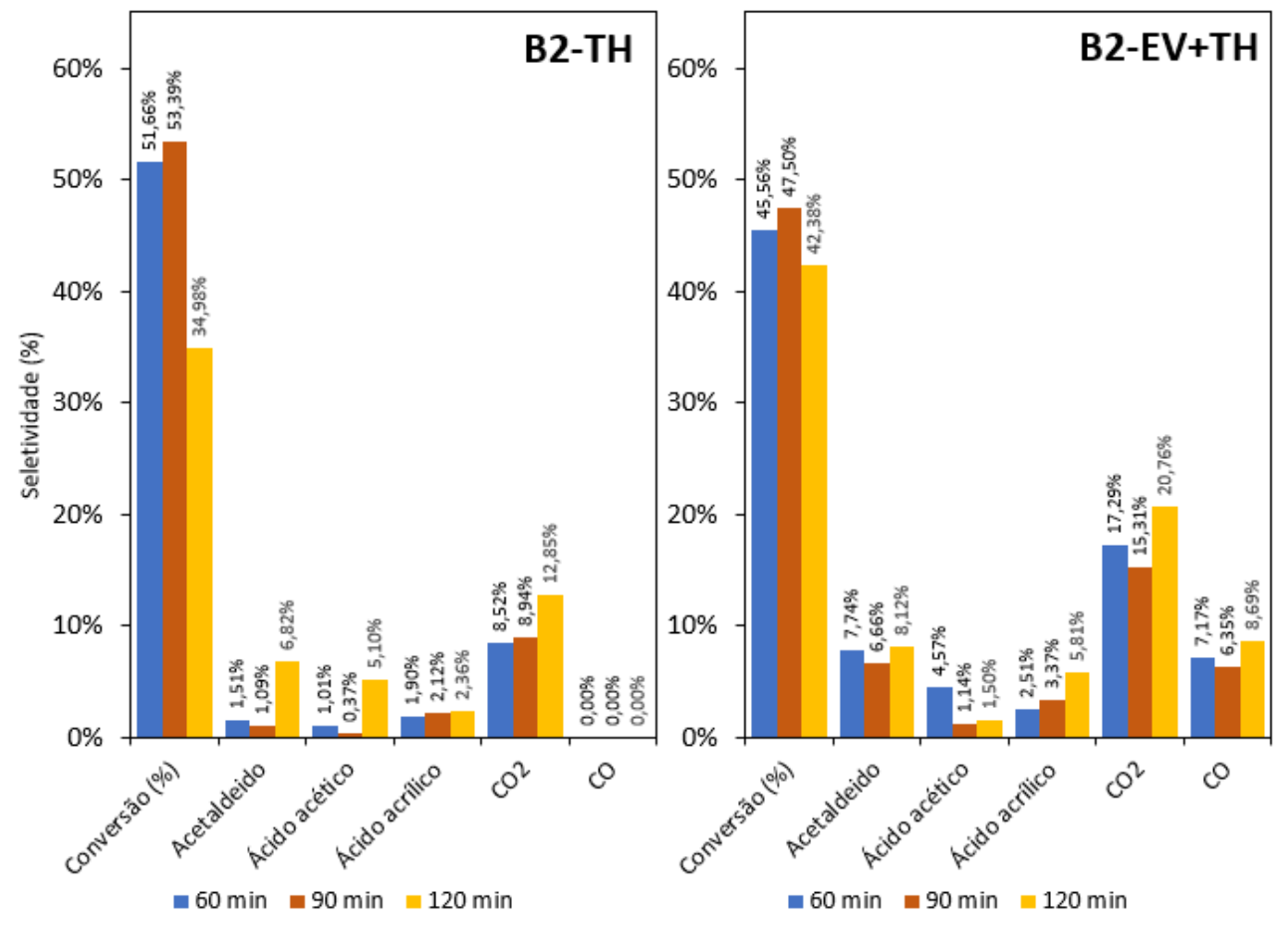

Fonte: Autor

Enquanto as amostras do tipo B2 apresentaram comportamentos semelhantes na oxidação da acroleína, as amostras do tipo B3 apresentaram algumas diferenças em relação à metodologia de preparação utilizada, e os resultados são apresentados na Figura 41. O teste realizado utilizando a amostra B3-TH apresentou uma conversão de 28,21\% para a acroleína na primeira hora de reação diminuindo para $21,05 \%$ ao fim, seletividade máxima de 1,32\% para o ácido acrílico e grande formação de subprodutos, 12,06\% de seletividade para o acetaldeído, e valores superiores a $30 \%$ para o $\mathrm{CO}_{2}$. Já a amostra sintetizada por EV+TH apresentou uma maior conversão, $51,61 \%$ quando atingido o regime da reação, com seletividade de 2,50\% para o ácido acrílico e menores seletividades, 4,01\% para o acetaldeído e 5,65\% para o $\mathrm{CO}_{2}$ não observando a formação de $\mathrm{CO}$. A grande formação de $\mathrm{CO}_{2}$ está relacionada a maior presença 
da fase $\alpha-\mathrm{MoO}_{3}$ que leva a completa oxidação do acetaldeído, acroleína e até mesmo o ácido acrílico (RESSLER, 2008).

Figura 41 - Resultados de conversão e seletividade para as amostras B3 preparadas TH e $\mathrm{EV}+\mathrm{TH}$ avaliadas na oxidação da acroleína

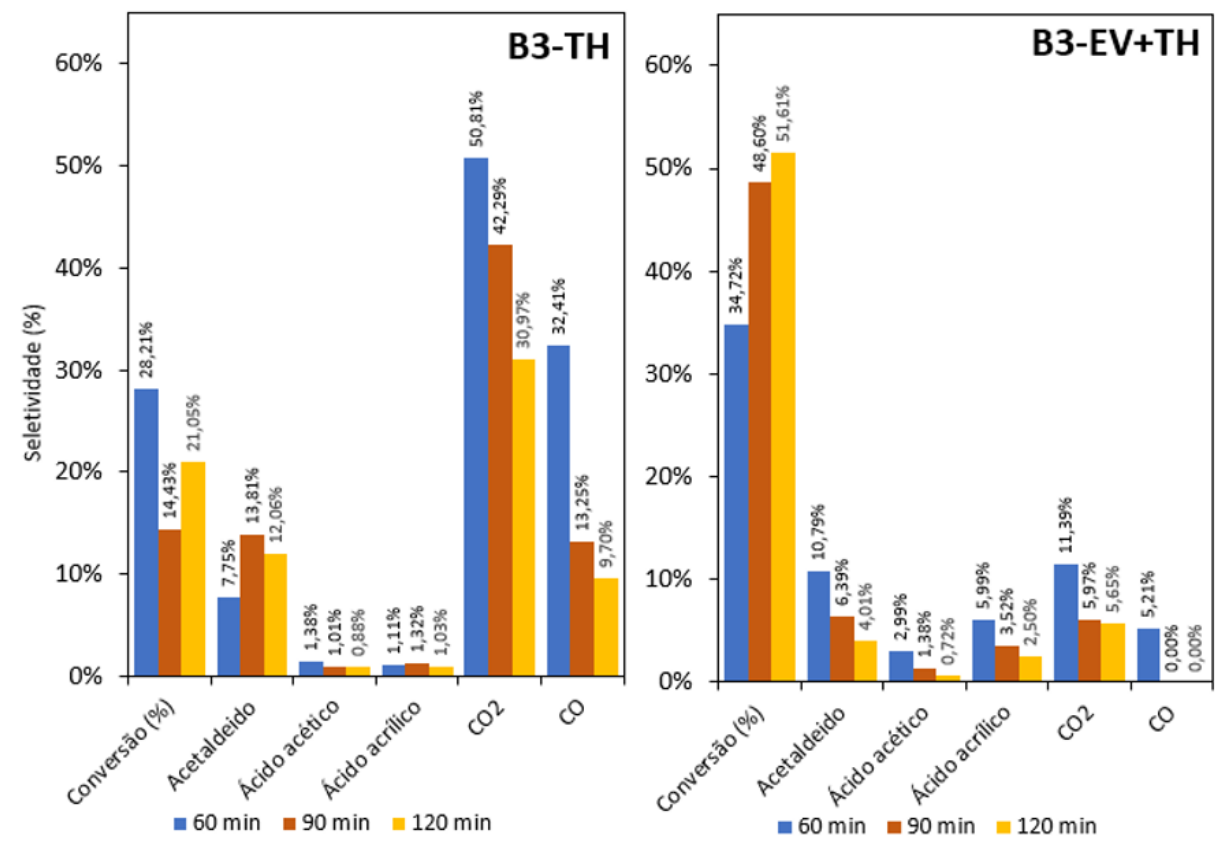

Fonte: Autor

Visto que as amostras do tipo B1 foram as que apresentaram melhores resultados no processo de obtenção do ácido acrílico, foram propostas algumas alterações em sua composição para avaliar como a adição do cobre e do tungstênio afetam na atividade dos catalisadores. Para isso foram sintetizadas as amostras B1.2, sem a adição do nitrato de cobre, mantendo as mesmas quantidades dos outros reagentes e a B1.3, sem a adição de $\mathrm{Cu}$ e W, apresentando apenas Mo e V em sua composição, com teores diferentes aos apresentados pelas amostras do tipo B3. Os resultados de conversão e seletividades são mostrados na Figura 42.

A amostra B1.2-EV apresentou durante os testes uma baixa conversão de acroleína, com valores entre $11,65 \%$ e $26,52 \%$ quando a atingido o equilíbrio da reação e altas seletividades para a formação dos subprodutos como acetaldeído (43-45\%) e $\mathrm{CO}_{2}(38-56,41 \%)$, o que pode estar relacionada a maior presença de material amorfo na amostra, que sugere que a formação de fases cristalina é de extrema importância nas reações de oxidação. Após a realização do tratamento hidrotérmico $(\mathrm{B} 1.2-\mathrm{EV}+\mathrm{TH})$, observou-se a formação de uma estrutura mais cristalina com maior teor de vanádio $(18,317 \%)$ que sugere a formação de óxidos mistos contendo o elemento. O teste catalítico apresentou conversões superiores a 50\% para acroleína 
e a formação do ácido acrílico como produto principal, com seletividade de 26,54\% quando atingindo o regime. Nesse caso observou-se também a menor formação de $\mathrm{CO}_{2}$ e acetaldeído.

Figura 42 - Resultados catalíticos para as variações do catalisador B1 (B1.2 e B1.3) avaliados na oxidação da acroleína em fase gasosa

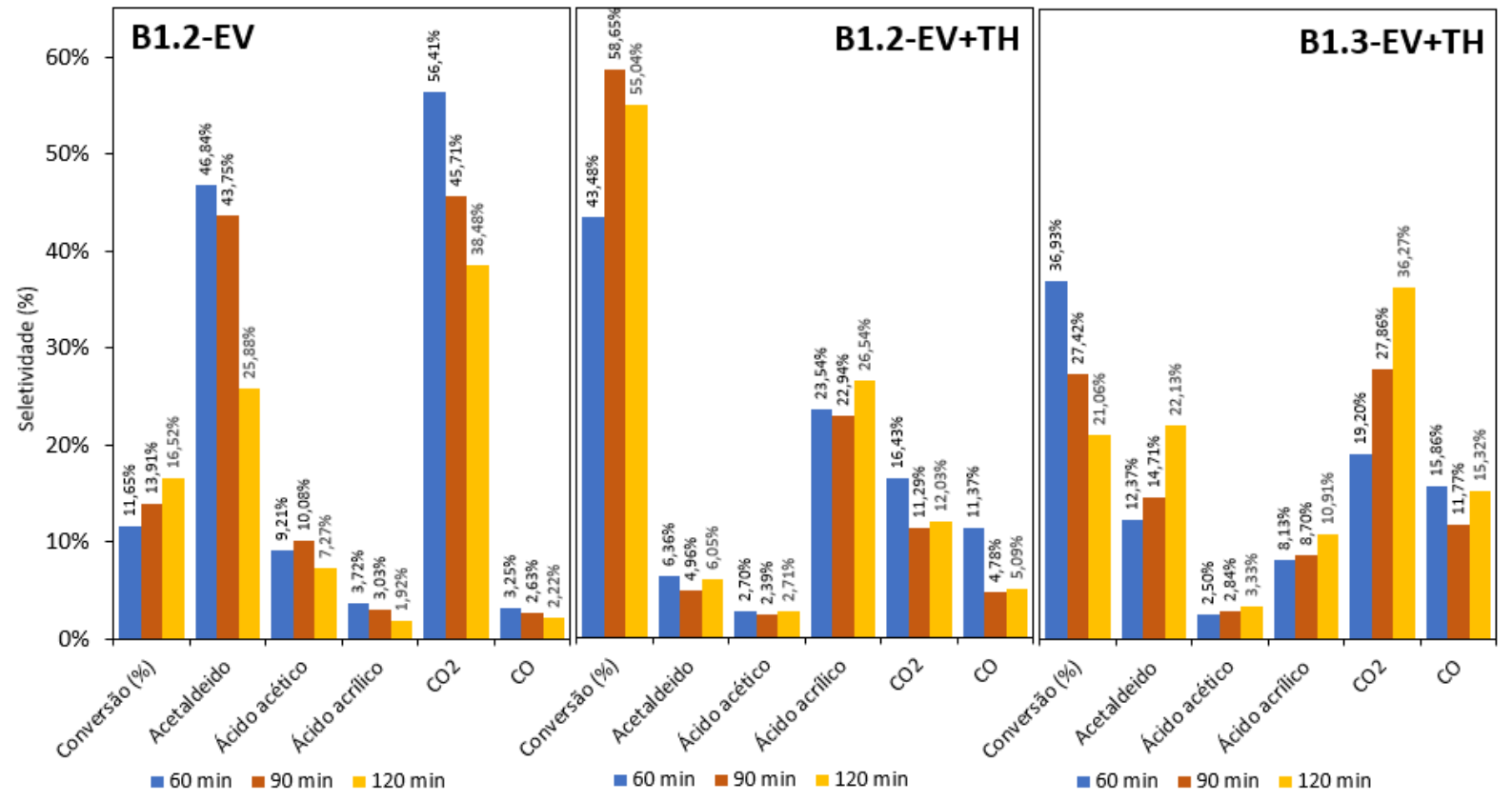

Fonte: Autor

A amostra B1.3-EV+TH, contendo apenas Mo e V em sua composição, apresentou uma conversão da acroleína de 36,93\% na primeira hora de reação, reduzindo para $21,06 \%$ ao fim do teste. Tal comportamento pode estar relacionado a maior atividade do catalisador nos primeiros minutos de reação devido etapa de ativação realizada antes do início do teste. A amostra apresentou uma seletividade para o ácido acrílico de $10,91 \%$, relativamente alta quando comparada a amostra B3-EV+TH formada também por MoVO, com diferentes proporções, porém apresentou maior formação de acetaldeído, com seletividades superiores a $12 \%$, indicando que o aumento do teor de vanádio na forma de óxidos simples leva a uma maior formação de subprodutos.

A amostra B1-P123-F sintetizada na presença do copolímero bloco P123 apresentou uma seletividade máxima de 2,89\% para o ácido acrílico, conforme identificado na Figura 43. Das amostras com composição B1, esta foi a que obteve menor seletividade para o ácido acrílico, indicando que a adição do copolímero neste caso não melhorou o desempenho da amostra. 
Figura 43 - Resultados Catalíticos para a amostra sintetizada na presença de Pluronic ${ }^{\circledR}$ P123

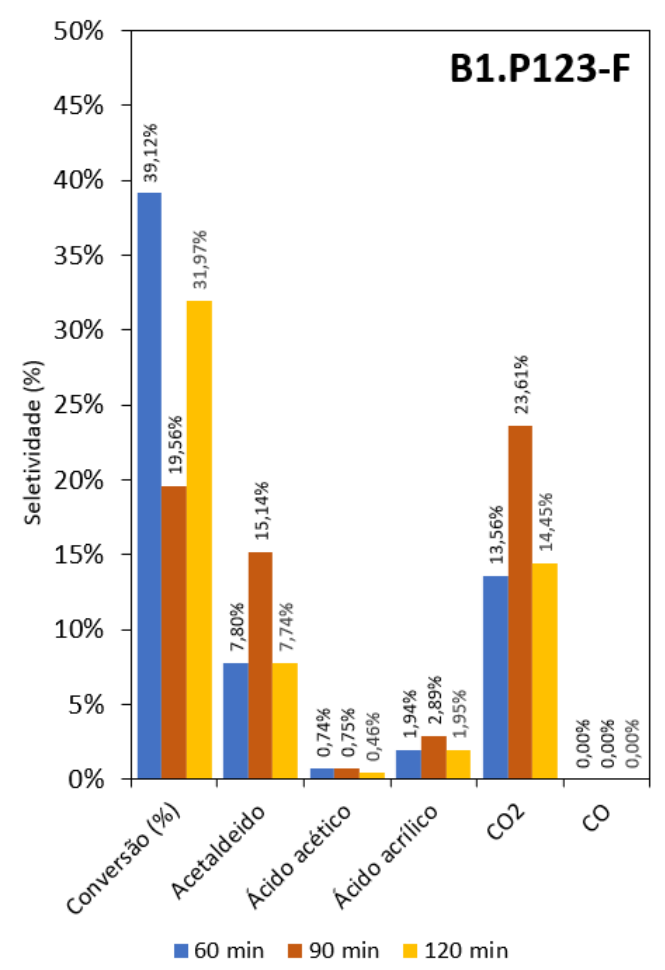

Fonte: Autor

Realizando uma breve discussão sobre os resultados obtidos nos testes de oxidação da acroleína, é possível dizer que a formação de óxidos mistos, principalmente de vanádio e molibdênio, é de extrema importância para se alcançar bons resultados de seletividade para os produtos desejados. A formação da fase cristalina $\mathrm{V}_{0,35} \mathrm{Mo}_{4,65} \mathrm{O}_{14}$ na amostra $\mathrm{B} 1-\mathrm{EV}+\mathrm{TH}$, levou a uma seletividade para o ácido acrílico $66 \%$ maior que quando a principal fase é o $\alpha-\mathrm{MoO}_{3}$. Isso se deve a incorporação dos íons $\mathrm{V}^{4+}$ na rede cristalina do óxido de molibdênio, o que pode facilitar as mudanças dos estados de oxidação do vanádio $\left(\mathrm{de}^{4+} / \mathrm{V}^{5+} \mathrm{e} \mathrm{V}^{5+} / \mathrm{V}^{4+}\right)$ e restabelecer as vacâncias $\mathrm{O}_{2}$ durante a reação, processos essenciais no mecanismo de Mars-Van Krevelen para reações de oxidação seletiva (RASTEIRO, 2017).

Outro ponto observado foi que as amostras sintetizadas por $\mathrm{EV}+\mathrm{TH}$ apresentaram melhores resultados de seletividade para o ácido acrílico que as sintetizadas apenas por EV ou $\mathrm{TH}$, ocorrendo para todos os tipos de amostras (B1, B2 e B3), o que sugere que a realização do tratamento hidrotérmico após o processo de calcinação altera propriedades nos catalisadores que melhoram seu desempenho e pode estar relacionado ao estimulo do crescimento epitaxial das fases formadas necessárias para o bom funcionamento do catalisador, o que merece atenção 
em trabalhos futuros, já que atualmente a maioria das pesquisas estão voltadas para a síntese via tratamento hidrotérmico apenas (POSSATO et al., 2017; OMATA et al., 2013).

Terminados os testes com a acroleína, os catalisadores foram testados também na desidratação oxidativa do glicerol em uma única etapa e os resultados são mostrados na Figura 44. Nos testes catalíticos de todas as amostras sintetizadas na segunda etapa do projeto foram obtidas conversões de 100\% para o glicerol, não identificando picos relacionados a sua presença nos produtos de saída analisados por cromatografia gasosa.

Figura 44 - Seletividade da reação de oxirredução do glicerol em fase gasosa na presença dos catalisadores propostos no trabalho
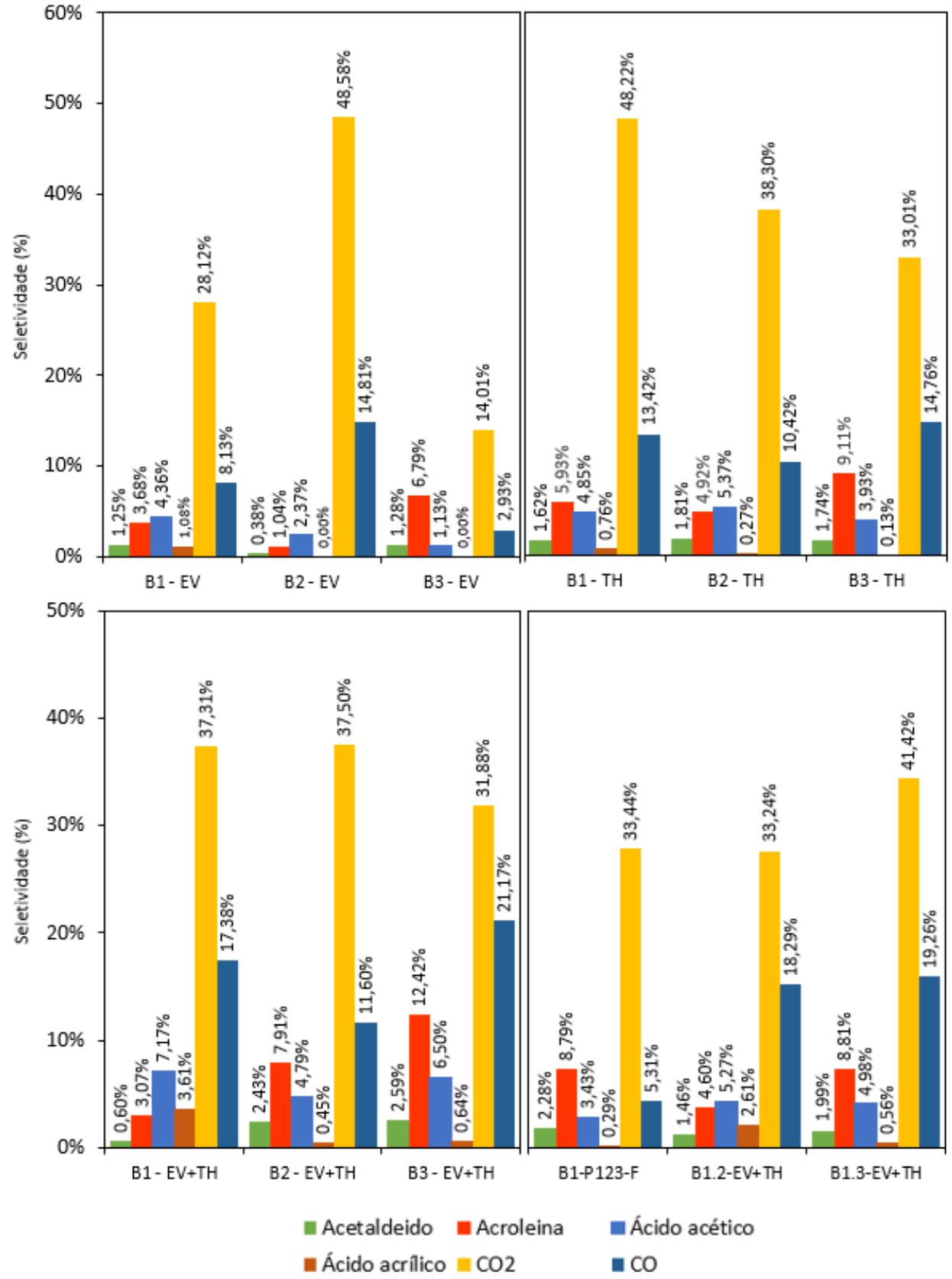

Fonte: Autor 
De maneira geral, foi observado que as amostras que apresentaram melhores resultados de seletividade para o ácido acrílico nas reações de oxidação da acroleína foram os que se destacaram no processo utilizando o glicerol, com seletividade de 3,61\% para a amostra B1$\mathrm{EV}+\mathrm{TH}$ e 2,61\% para a amostra B1.2-EV+TH. Todos os ensaios apresentaram também grande formação de $\mathrm{CO}$ e $\mathrm{CO}_{2}$, com valores de seletividade médios superiores a $15 \%$ para o $\mathrm{CO}$ e $35 \%$ para o $\mathrm{CO}_{2}$, condizentes a valores encontrados na literatura (LIU et al., 2015; POSSATO et al., 2015).

Apesar dos resultados apresentados pelas amostras sintetizadas no trabalho serem relativamente inferiores às apresentadas na literatura, que mostram seletividades de até 33,5\% na produção de ácido acrílico partindo-se do glicerol usando catalisadores MoV em estudos realizados por Rasteiro et al. (2017) e outros trabalhos apresentados na Tabela 17, vale ressaltar que geralmente os testes catalíticos são realizados em microescala, utilizando uma quantidade de $0,1-0,2 \mathrm{~g}$ de catalisador e vazões de reagentes na faixa de $0,05 \mathrm{~mL} / \mathrm{min}$, em condições reacionais amplamente estudadas e otimizadas em inúmeros trabalhos relacionados ao tema, visando uma maior seletividade para o ácido acrílico. No presente trabalho foi utilizado um reator fabricado em aço com um volume de leito maior, o que permite a troca de calor entre os reagentes na sua entrada e saída, simulando um teste em maior escala, utilizando quantidades maiores de catalisador, em condições próximas as reais de operação, esse foi um dos principais motivos para tal discrepância de valores.

Tabela 17 - Resultados da literatura para a reação de desidratação oxidativa do glicerol

\begin{tabular}{lccc}
\hline \multicolumn{1}{c}{ Catalisador } & $\begin{array}{c}\text { Conversão do } \\
\text { glicerol (\%) }\end{array}$ & $\begin{array}{c}\text { Seletividade para } \\
\text { ácido acrílico (\%) }\end{array}$ & Ref. \\
\hline $\mathrm{MoV} / \mathrm{SiW} / \mathrm{Al}_{2} \mathrm{O}_{3}$ & 100 & 12 & (LIU et al., 2015) \\
$\mathrm{W}_{2,2} \mathrm{~V}_{0,4} \mathrm{Nb}_{2,4} \mathrm{O}_{14}$ & 100 & 59,2 & (OMATA et al., 2015) \\
$\mathrm{V}_{2} \mathrm{O}_{5}-\mathrm{MFI}$ & 100 & 17 & (POSSATO et al., 2015) \\
$\mathrm{Mo}-\mathrm{V}-\mathrm{O}$ & 100 & 26,3 & (DELEPLANQUE, 2010) \\
$\mathrm{W}-\mathrm{V}-\mathrm{O}$ & 100 & 23,7 & (DELEPLANQUE, 2010) \\
\hline Fonte: Autor & & &
\end{tabular}

Outro fator que também influenciou nos resultados foi a atividade apresentada pelo sistema. Os equipamentos utilizados no processo (vaporizador, tubulações e reator), quando atuando a altas temperaturas, mostraram alta atividade catalítica na reação com o glicerol, o que foi prejudicial ao estudo. O sistema apresentou conversões superiores a $70 \%$ na ausência dos catalisadores, como mostrado nos resultados da Tabela 18. O teste em branco foi realizado também usando a acroleína como reagente, que apresentou uma menor conversão. 
Tabela 18 - Resultados de conversão e seletividades para os ensaios sem catalisador

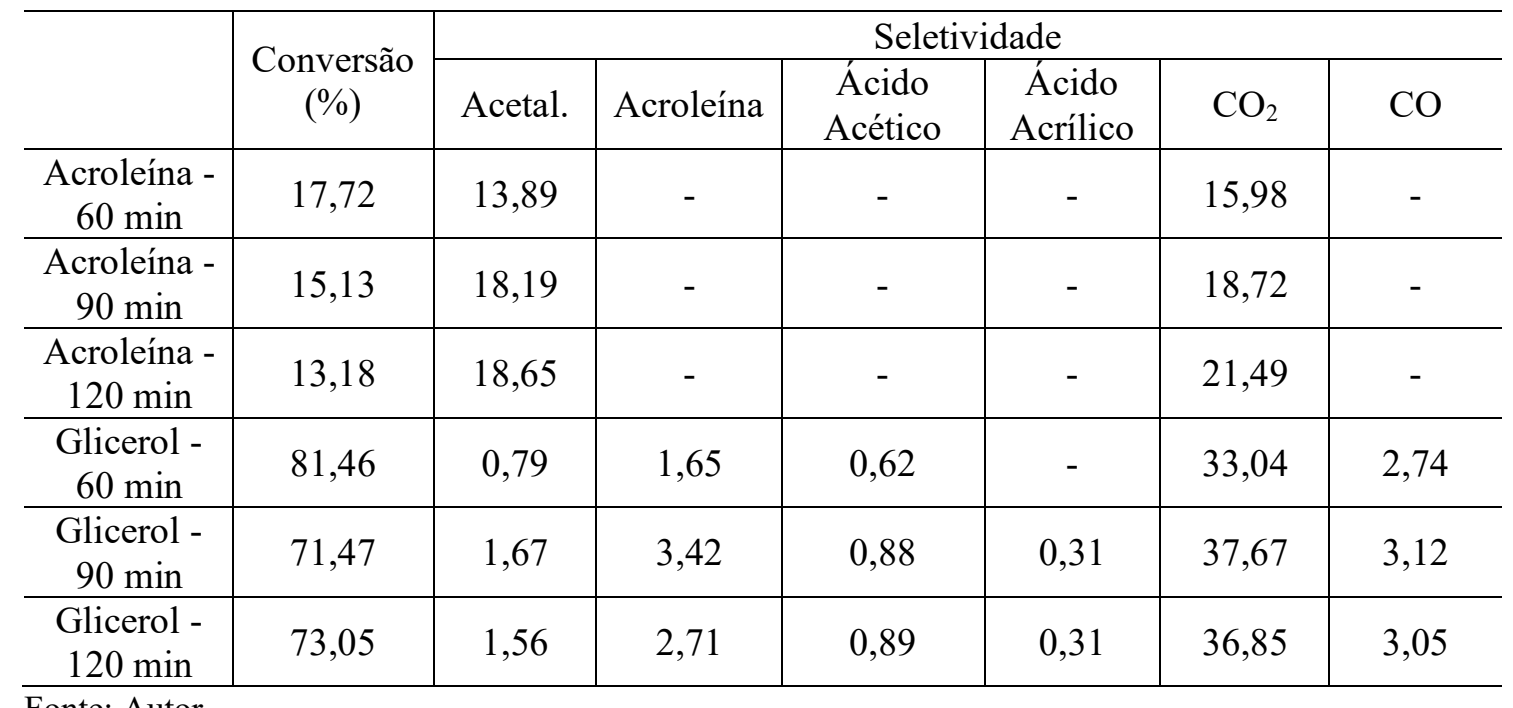

Além dos testes em branco, realizados na ausência de uma amostra de catalisador, que indicaram uma alta atividade catalítica do sistema reacional, foi feito também o cálculo do balanço de carbono nos ensaios com o glicerol seguindo a Equação 11 descrita no item 4,3,1 da metodologia. Os erros no balanço associados a cada valor foram calculados para cada ensaio avaliando os diferentes tipos de catalisadores sintetizados e os resultados são apresentados na Tabela 19. É possível notar erros superiores a 30\% na maioria dos testes catalíticos com os catalisadores sintetizados na reação de conversão do glicerol. Tal resultados indica que uma parte dos compostos formados contendo carbono não foi detectada com exatidão na saída do processo, que pode corresponder a um excesso de $\mathrm{CO}$ e $\mathrm{CO}_{2}$ produzidos pela oxidação total do glicerol e intermediários.

Tabela 19 - Erros no balanço de carbono (\%)

\begin{tabular}{l|c}
\multicolumn{2}{c}{ para testes com o glicerol } \\
\hline \multirow{2}{*}{ Amostra } & Balanço de C (\%) - Glicerol \\
\cline { 2 - 2 } & 60 min \\
\hline B1-EV & 53,39 \\
B1-TH & 25,21 \\
B2-TH & 38,91 \\
B3-TH & 37,31 \\
B1 - EV+TH & 30,87 \\
B2-EV-TH & 31,78 \\
B3-EV+TH & 24,81 \\
B1-P123-F & 46,47 \\
B1.2-EV+TH & 34,47 \\
B1.3-EV+TH & 22,98 \\
\hline
\end{tabular}

Fonte: Autor 


\section{CONCLUSÕES}

Na primeira etapa do projeto, conclui-se que a variação da quantidade de água utilizada durante a realização do tratamento hidrotérmico após a mistura dos sais precursores não influencia a composição das fases cristalinas formadas ou na quantidade de material formado. Ao contrário, a cristalinidade, o volume de poros e área superficial sofrem influência dessa variável. Nesse tipo de síntese, a adição do copolímero auxilia para obtenção de um material com maior volume de poros.

Já na segunda etapa, as fases cristalinas formadas das amostras do tipo B1 $\mathrm{Mo}_{12} \mathrm{~V}_{4,8} \mathrm{~W}_{2,4} \mathrm{Cu}_{2,2} \mathrm{Si}_{8,4}$ são fortemente influenciadas pelo método de síntese utilizado. A adição de novos elementos facilita a formação de óxidos mistos de $\mathrm{Mo}-\mathrm{V}$ e $\mathrm{Mo}-\mathrm{Cu}$, com fases cristalinas principais de $\mathrm{CuMoO}_{4}$ para a amostra sintetizada por tratamento hidrotérmico, $\mathrm{W}_{0,4} \mathrm{Mo}_{0,6} \mathrm{O}_{3}$ para a amostra sintetizada por evaporação e $\mathrm{V}_{0,35} \mathrm{Mo}_{4,65} \mathrm{O}_{14}$ para a amostra sintetizada por evaporação seguida por tratamento hidrotérmico. Os elementos que constituem a fase cristalina principal da amostra sofrem menor perda durante o tratamento hidrotérmico, aqueles que não se associam, continuam dissolvidos no líquido mãe e se apresentam em menor quantidade nos materiais sólidos formados. Esse comportamento não é observado para as amostras do tipo B2- $\mathrm{Mo}_{12} \mathrm{~V}_{2} \mathrm{~W}_{0,5} \mathrm{Si}_{6,2}$ e B3- $\mathrm{Mo}_{12} \mathrm{~V}_{2,7} \mathrm{Si}_{6,2}$ que apresentam uma menor formação de óxidos mistos associados ao $\mathrm{MoV}_{2} \mathrm{O}_{8}$, o que pode estar relacionado a grande estabilidade da estrutura ortorrômbica do $\alpha-\mathrm{MoO}_{3}$.

As amostras que apresentam como fase cristalina algum tipo de óxido misto são as que apresentam maior atividade catalítica na oxidação da acroleína e consequentemente, na obtenção do ácido acrílico partindo-se do glicerol.

A amostra B1 sintetizada por evaporação seguida por tratamento hidrotérmico, com fase cristalina predominante $\mathrm{V}_{0,35} \mathrm{Mo}_{4,65} \mathrm{O}_{14}$, apresenta a maior seletividade para o ácido acrílico de $50,59 \%$ na reação com acroleína e 3,61\% partindo-se do glicerol, melhor resultado entre os materiais estudados.

As amostras B2 e B3, que apresentaram como principal fase cristalina o óxido simples de $\alpha-\mathrm{MoO}_{3}$, apresentam baixa atividade, com seletividade máxima próxima a $6 \%$ quando usada a acroleína como reagente e seletividades inferiores a 1\% partindo-se do glicerol. Uma possível explicação é a ausência de vanádio ligado a estrutura cristalina principal, cuja a principal fase formada foi o $\alpha-\mathrm{MoO}_{3}$, que impossibilitou a redução do elemento de $\mathrm{V}^{5+} / \mathrm{V}^{4+}$ que leva a oxidação seletiva da acroleína. 
Apesar de serem obtidos valores inferiores de conversão e seletividades em relação a literatura, foi possível concluir que bons catalisadores para oxidação devem apresentar óxidos mistos em sua estrutura cristalina. Ou seja, principalmente contendo vanádio, que provavelmente realiza a oxidação da acroleína devido aos vários estados de oxidação.

O método de preparação por evaporação seguido de tratamento hidrotérmico é o que apresentou melhores resultados de seletividade para o ácido acrílico, se sobressaindo ao método de TH. Isso indica que a realização do tratamento térmico antes do hidrotérmico pode estimular em cada amostra o crescimento epitaxial das fases formadas necessárias para o bom funcionamento do catalisador e que favorecem as reações de oxidação, por isso merecem uma maior atenção em trabalhos futuros. 


\section{REFERÊNCIAS}

AGÊNCIA NACIONAL DO PETROLEO, GAS NATURAL E BIOCOMBUSTIVEIS, Biodiesel, 2017. Disponível em: www.anp.gov.br/biocombustiveis/biodiesel. Data de acesso, 07 de maio de 2018.

ALABA, P. A., LEE, C. S., ABNISA, F., AROUA, M. K., COGNRT, P., PERES, Y., DAUD, W. M. A. W. A review of recent progress on electrocatalysts toward efficient glycerol electrooxidation. Rev Chemical Eng., v. x, p. 1-34, 2019.

ALAYAT, A., ECHEVERRIA, E., MCLLROY, D. N., MCDONALD, A. Enhancement of the catalytic performance of silica nanosprings (NS)- supported iron catalyst with copper, molybdenum, cobalt and ruthenium promoters for Fischer-Tropsch synthesis. Fuel

Processing Technology, v. 177, pg. 89-100, 2018.

ALLEN, G. C. Celanese . Oxidation of unsaturated aldehydes to the corresponding acids. US n. US3644509, 22 fev. 1972.

ANDRUSHKEVICH, T.V. Heterogeneous Catalytic Oxidation of Acrolein to Acrylic Acid: Mechanism and Catalysts. Catalysis Reviews - Sci. and Eng. v. 35, n. 2, p. 213-259, 1993.

BEATRIZ, A., ARAUJO, Y. J., LIMA, D. P., Glycerol: a brief history and application in stereoselective syntheses. Química Nova. v. 34, n. 2, pg. 306-319, 2011.

BEZERRA, F. A., ALTINO, H. O. N., SOARES, R. S. Oxidative dehydration of glycerol over Molybdenum- and vanadium-based catalysts. J. Braz. Chem. Soc., v. 00, pg. 1-9, 2019.

BRUNEUER, S., EMMET, P. H., TELLER, E. Adsorption of gases in multimolecular layer. Journal of the American Chemical Society, 60, 1938, 309 - 318.

CALLAHAN, J.L., FOREMAN, R. W., VEATCH, F. Process for the oxidation of olefins. US Patent 2941007, 1960.

CALLAHAN, J. L.; GRASSELLI, R. K. A selectivity factor in vapor-phase hydrocarbon oxidation catalysis. AIChE Journal, v. 9, n. 6, p. 755-760, 1963.

CETESB, Ficha de Informação de Produto Químico. Disponível em: < http://sistemasinter.cetesb.sp.gov.br/produtos/ficha_completa1.asp?consulta $=\% \mathrm{C} 1 \mathrm{CIDO} \% 20$ ACR\%CDLICO> . Data de acesso: 07 mai. 2018.

CHAI, S. H., WANG, H. P., LIANG, Y., XU, B. Q. Sustainable production of acrolein: investigation of solid acid-base catalysts for gas-phase dehydration of glycerol. Green Chemistry, v. 9, n. 10, p. 1130-1136, 2007.

CHAI, S. H., TAO, L. Z., YAN, B. VEDRINE, J. C., XU, B. Q.. Sustainable production of acrolein: effects of reaction variables, modifiers doping and $\mathrm{ZrO} 2$ origin on the performance of WO3/ZrO2 catalyst for the gas-phase dehydration of glycerol. RSC Adv, v. 4, pg. 4619, 2014. 
CHIGRIN, P. G., LEBUKHOVA, N. V., USTINOV, A. Yu., Structural transformations of $\mathrm{CuMoO} 4$ in the catalytic oxidation of carbon. Kinects and Catalysis, 54-1, pg. 76-80, 2013 CHITHAMBARARAJ, A., BOSE, A. C., Hydrothermal synthesis of hexagonal and orthorhombic MoO3 nanoparticles. Journal of Alloys and Compounds. v. 509, pg. 8105$8110,2011$.

CHITHAMBARAJ, A., BOSE, A. C., Microwave assisted ultra fast synthesis of 1-D molybdenum oxide nanocrystals: structural and electrical studies. Advanced Material Research, v. 488-489, pg 940-944, 2012.

CLARK, G. M, DOYLE, W. P. Infra-red spectra of anhydrous molybdates and tungstates. In: Spectrochimica Acta, 1066, v. 22, pg 1441-1447, Pergamen Press Ltd, Irland, 1965.

DABDOUB, M. J., BRANZEL, J. L. Biodiesel: visão crítica do status e perspectivas na academia e na indústria. Química Nova, v. 32, n. 2, pg. 776-792, 2009.

DELEPLANQUE, J., DUBOIS, J. L., DEVAUX, J. F., UEDA, W. Production of acrolein and acrylic acid through dehydration and oxydehydration of glycerol with mixed oxide catalysts. Catalysis Today, v. 157, pg. 351-358, 2010.

DOLHYJ, S., G., MILBERGER, E. C. Standard Oil Co. Catalyst compositions especially useful for preparation of unsaturated acids. GB n. GB1477029, 22 jun. 1977.

DROCHNER, A., KAMPE, P., MENNING, N., BLICKHAN, N., JEKEWITZ, T., VOGEL, $\mathrm{H}$. Acrolein Oxidation to Acrylic Acid on Mo/V/W-Mixed Oxide Catalysts. Chemical Engineering Tecnology, v. 37, n. 3, pg 398 - 408, 2014.

DUMESIC, J. A.; HUBER, G. W.; BOUDART, M. Principles of Heterogeneous Catalysis. In: ERTL, GERHARD et al. Handbook of Heterogeneous Catalysis (2nd Edition) v.1, p114. Wiley-VCH Verlag GmbH \& Co. KGaA, Weinheim, Germany, 2008.

EMPRESA DE PESQUISA ENERGETICA, Análise de Conjunturas dos Biocombustíveis - Ano 2018. Rio de Janeiro, 2019.

FANTIM, W. F., VIEIRA, L. H., MARTINS, L., CONDOTTA, R., POÇO, J. G. R., Estudo da reação de oxidação seletiva de aldeídos insaturados. Etapa I: Preparação de catalisadores, In: Congresso Brasileiro de Iniciação Científica, 12, 2017, São Carlos. Anais... São Carlos: 2017 , pg. $3078-3083$.

FANTIM, W. M., CABRAL, C. P., CONDOTTA, R., POÇO, J. G. R. Estudo das propriedades físico-químicas de catalisadores heterogêneos baseados em óxidos mistos para a oxidação seletiva de aldeídos insaturados. In: Congresso Brasileiro de Catalise, 20, 2019, São Paulo. Anais... São Paulo, 2019.

FERLAZZO, N., BUZZI, G. F., GHIRGA, M. Sir Soc Italiana Resine Spa. Method of preparing acrylic acid. US n. US3997600, 14 dez. 1976.

FOGLER, S. H. Elementos de engenharia das reações químicas. 4. Ed. Rio de Janeiro, RJ LTC, 2009. 
GRASSELLI, R.K.; BURRINGTON, J.D. Oxidation of low-molecular-weight hydrocarbons. In: Ertl, Gerhard. Handbook of Heterogeneous Catalysis ( $2^{\text {nd }}$ Edition) $V 7$ p3479-3489. Wiley-VCH Verlag GmbH \& Co. KGaA, Weinheim, Germany 2008.

GRASSELLI, R. K, TENHOVER, M.A. Ammoxidation. In: Ertl, G. Handbook of Heterogeneous Catalysis ( $2^{\text {nd }}$ Edition), V7 p 3489-3517, Wiley-VCH Verlag GmbH \& Co. KGaA, Weinheim, Germany, 2008.

GRASSELLI, R. K., TRIFIRO, F. Acrolein and acrylic acid from biomass. CrossMark. V. 28 , p. $59-67,2017$.

GRASSELLI, R. K. Fundamental principles of selective heterogeneous oxidation catalysis. Topics in Catalysis Vol. 21, Nos. 1-3, October 2002.

GRASSELLI, R., SURESH. D. Standard Oil Co. Process for the conversion of unsaturated aldehydes to acid. US n. US3840595, 08 out. 1974.

GREGG, S. J., SING, K. W. S. Adsorption, Surface Area and Porosity. 2. Auflage, Academic press, London, 1982.

HENSEL, J., LUSSLING, T., NOLL, E., SCHAEFER, H., WEIGERT, W. Degussa. Catalysts for the oxidation of alpha, beta-unsaturated aldehydes to alpha, betaunsaturated carboxylic acids and process for their preparation. US n. US3773692, 20 nov. 1973.

IHS MARKIT, Acrylic Acid and Esters. Chemical Economics Handbook, 2017.

KADOWAKI, K., KOSHIKAWA, T. Mitsubishi Petro.Co. Production of acrylic acid. US n. US3773828, 20 nov. 1973.

KRABETZ, R., ENGELBACH, H. BASF Company. Production of acrylic acid by oxidation of acrolein. US n. US3845120, 29 out. 1974.

KAMER, P. C. J., VOGT, D., THYBAUT, J. Contemporary Catalysis: Science, Technology and Applications. The Royal Society of Chemistry, 2017.

KRUK, M. Access to Ultralarge-pore ordered mesoporous materials through selection of surfactant/ swelling-agent micellar template. Accounts of Chemical Research, v. 45, n. 10, pg. 1678-1687, 2012.

LIN, M. M. Selective oxidation of propane to acrylic acid with molecular oxygen. Applied Catalysis A: General, v. 207, n. 1/2, p. 1-16, 2001.

LIU, H., YIN, C., LI, H., LIU, B., LI, X., CHAI, Y., LI, Y., LIU, C. Synthesis, characterization and hydrodesulfurization properties of nickel-copper-molybdenum catalysts for the production of ultra-low sulfur diesel. Fuel, v. 129, pg. 138-146, 2014.

LIU, L., WANG, B., DU, Y., ZHONG, Z., BORGNA, A. Bifunctional Mo3VOx/H4SiW12O40/ $\mathrm{Al}_{2} \mathrm{O}_{3}$ catalysts for one-step conversion of glycerol to acrylic acid: catalyst structural evolution and reaction pathways. Applied Catalysis B: Environmental, v. 174/175, p. 1-12, 2015. 
LIU, L., WANG, T., JIN, Y. Catalytic dehydration of glycerol to acrolein over HPW supported on Cs+ modified SBA-15. Catalysis Today, v. 233, pg. 127-132, 2014.

MA, T., DING, J., SHAO, R., XU, W., YUN, Z. Dehydration of glycerol to acrolein over Wells-Dawson and Keggin type phosphotungstic acids supported on MCM-41 catalysts. Chemical Engineering Journal, v. 316 (2010), pg. 797-806, 2017.

MARS, P.; VAN KREVELEN, D. W. Oxidations carried out by means of vanadium oxide catalysts. Chemical Engineering Science, v. 3, p. 41-59, 1954.

MARTIN LUTHER KING, disponível em: https://www.pensador.com/frase/MjIyODg3Mw/, [19_?].

MCNAIR, H. M., BONELLI, E. J., Basic Gas Chromatography. 4ª ed., Varian, 1968.

MORO-OKA, Y., UEDA, W., Multicomponent bismuth molybdate catalyst: A high functionalized catalyst system for the selective oxydation of olefin. Advances in Catalysis, v. 40, p. 233-273, 1994.

MOTA, C. J. A., SILVA, C. X. A., GONCALVES, V. L. C, Gliceroquimica: Novos produtos e processos a partir do glicerol de produção de biodiesel. Química Nova, v. 32, n. 3, p. 639 $648,2009$.

MOTA, C. J. A, PINTO, B. P.; Transformações Catalíticas do Glicerol para Inovação na Indústria Química. Revista Virtual de Química, v. 9 (1), p. 135-149, 2017.

MUSIC, S., FILIPOVIC-VINCEKOVIC, L., SEKOVANIC, L. Precipitation of amorphous $\mathrm{SiO} 2$ particles and their properties. J. Chem. Eng, v. 28, pg. 89-94, 2011.

OGAWA, M., TAKENAKA, S., SHIMIZU, H. Nippon Kayaku Company. Oxidation catalyst. US n. US3857796, 31 dez. 1974.

OHARA, T. Avanços recentes dos catalisadores oxidantes de olefinas C3-C4 sob o ponto de vista de patente. Shokubai, v.19, n3, p.157-63, 1977.

OHARA, T., SATO, T., SHIMIZU, N., PRESCHER, G., SCHWIND, H., WEIBERG, O., MARTEN, K., GREEIM, H. Acrylic acid and derivatives. In: Ullmann's Encyclopedia of Industrial Chemistry, $6^{\mathrm{a}}$ ed, Weinheim, Wiley-VCH, 1998.

OMATA, K., MATSUMOTO, K., MURAYAMA, T., UEDA, W. Direct oxidative transformation of glycerol to acrylic acid over $\mathrm{Nb}$-based complex metal oxide catalysts. Catalysis Today, v. 259, p. 205-212, 2015.

OMATA, K., IZUMI, S., MURAYAMA, T., UEDA, W. Hydrothermal synthesis of W-Nb complex metal and their application to catalytic dehydration of glycerol to acrolein. Catalysis Today, v. 201, p. 7-11, 2013.

OLIVEIRA, F. C., COELHO, S. T., History, evolution, and environmental impact of biodiesel in Brazil: A review. Renewable and Sustainable Energy Reviews, v. 75, pg. 168$179,2017$. 
OYAMA, S. T., WENT, G. T., LEWIS, K. B, BELL, A. T., SOMORJAI, G. A. Oxygen chemisorption and laser raman spectroscopy of unsupported and silica-supported vanadium oxide catalysts. J. Phys. Chem., v. 93, pg. 6786-6790, 1989.

PINTO, B. P., LYRA, J. T., NASCIMENTO, J. A. C., MOTA, C. J A. Ethers of glycerol and ethanol as bio additives for biodiesel. Fuel, v. 168, pg. 76-80, 2016.

POSSATO, L. G., CASSINELLI, W. H., MEYER, C. I., GARETTO, T., PULCINELLI, S. H., SANTILLI, C. V., MARTINS, L. Thermal treatments of precursors of molybdenum and vanadium oxides and the formed $\mathrm{Mox} \mathrm{VyOz}$ phases active in the oxydehydration of glycerol. Applied Catalysis A: General. V 532,pg. 1-11, 2017.

POSSATO, L. G., CASSINELLI, W. H., GARETTO, T., PULCINELLI, S. H., SANTILLI, C. V., MARTINS, L. One-step glycerol oxidehydration to acrylic acid on multifunctional zeolite catalysts. Applied Catalysis A: General, v. 492, p. 243-251, 2015.

RASTEIRO, L. F., VIEIRA, L. H., POSSATO, L. G., PULCINELLI, S. H., SANTILLI, C. V., MARTINS, L. Hydrothermal synthesis of Mo-V mixed oxides possessing several crystalline phases and their performance in the catalytic oxydehydration of glycerol to acrylic acid. Catalysis Today, 2017, pg. 10 - 18, 2017.

RESSLER, T., WALTER, A., HUANG, Z. D., BENSCH, W. Structure and properties of a supported $\mathrm{MoO}_{3}-\mathrm{SBA}-15$ catalyst for selective oxidation of propene. Journal of Catalysis, $\mathrm{v}$. 254, p. 170-179, 2008.

SCHLOGL, R., TRUNSCHKE, A. Hoffmann Eithe. Novel mesopourous mixed metal oxide catalyst and method for the preparation thereof. EP n. EP1930074 A1. 11 jun. 2006.

SCHMAL, M. Catálise Heterogênea. Rio de Janeiro: Synergia, 2011. Páginas consultadas: $125-175$.

SCHUH, K., KLEIST, W., HOJ, M., JENSEN, A., D., BEATO, P., PATZKE, G. R., GRUNWALDT, J. D. Systematic study on the influence of the morphology of $\alpha-\mathrm{MoO} 3$ in the selective oxidation of propylene. Journal of Solid State Chemistry, v. 228, pg. 42-52, 2015.

SIGMA-ALDRICH, Poly(ethylene glycol)-block-poly(propylene glycol)-block-poly(ethylene glycol), 2018. Disponível em:

https://www.sigmaaldrich.com/catalog/product/aldrich/435465?lang=pt\&region=BR\&gclid= EAIaIQobChMIo9fb0-HL5QIVDYiRCh2I2QTIEAAYAiAAEgKI4_D_BwE. Data de acesso: 10 set. 2019.

SHIRAISHI, T., HONMARU, S., NAGAOKA, Y., KISHIWADA, S., SHIMIZU, S., ZINPO, K. Sumitomo Chemical Co. Process for the preparation of acrylic acid. US n. US3766265, 16 out. 1973.

SILVA, C. A. A., SILVA, C. F., MATOS, J. M. E. Síntese, caracterização e aplicação do trióxido de molibdênio na fotocatálise de efluente têxtil sintético. Cerâmica, v. 64, pg. 454$465,2018$. 
STOŠIĆ, D., BENNICI, S., SIROTIN, S., STELMACHOWSKI, P., COUTURIER, J. L., DUBOIS, J. L., TRAVERT, A., AUROUX, A. Examination of acid-base properties of solid catalysts for gas phase dehydration of glycerol: FTIR and adsorption microcalorimetry studies. Catalysis Today, v. 226, pg. 167-175, 2014.

TALEBIAN-KIAKALAIEH, A., AMIN, N. A. S., HEZAVEH, H. Glycerol for renewable acrolein production by catalytic dehydration. Renewable and Sustainable Energy Reviews, v. 40, pg. 28-59, 2014.

UEDA, W. Catalytic functions of Bi-Mo-O complex metal oxides in allylic oxidation. Shokubai 45(1), 23-25, 2003.

VENDRINE, J. C. Heterogeneous catalysis on metal oxides. Catalysts, v. 7(11), pg 341, 2017.

WADA, M., YANAGISAWA, I., NINOMIYA, M., OHARA, T. Nippon Shokubai Kagaku Kogyo Co. Ltda. Process for preparing acrylic acid. US n. US3954855, 04 mar. 1976.

WADA, M., OHARA, T., YANAGISAWA, I., NINOMIYA, M. Nippon Catalytic Chem Ind. Process for producing unsaturated carboxylic acids. US n. US3833649, 03 set. 1974.

WASILEWAKI, J., PERKOWSKI, J. Technologia wytwarzania kwasu akrylowego i akroleiny z propylenu. Przemysl Chemiczny, 68, 5, p197-200, 1989.

WU, Y., GAO, G., WU, G. Self-assembled three-dimensional hierarchical porous V2O5/graphene hybrid aerogels for supercapacitors with high energy density and long cycle life. Journal of Materials Chemistry A, v. 5, 2015.

YANAGITA, M., KITAHARA, M. Toa Gasei e Rikagaku Kenkyusho. Process for the production of acrylic acid. US n. US3567772, 02 mar. 1971.

YAMAGUCHI, G., TAKENATA, S., Nippon Kayaku Company. Production of unsaturated aliphatic acids. US n. US3567773, 02 mar. 1971. 


\section{APÊNDICE A- EQUIPAMENTOS UTILIZADOS NOS TESTES CATALÍTICOS}

A identificação e descrição dos equipamentos utilizados durante os testes catalíticos estão descritos na metodologia no item 4.3, esse apêndice apresenta informações adicionais relacionados a eles assim como as curvas de calibração dos controladores de fluxo.

Figura 45 - Cromatógrafo utilizado para análise dos produtos formados

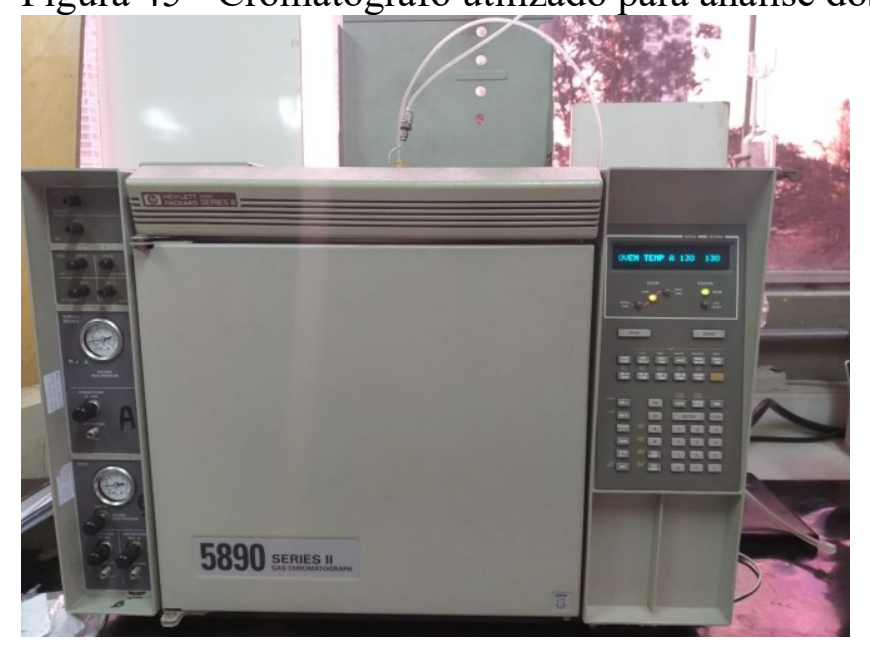

Fonte: Autor

Figura 46 - Esquematização do Condensador

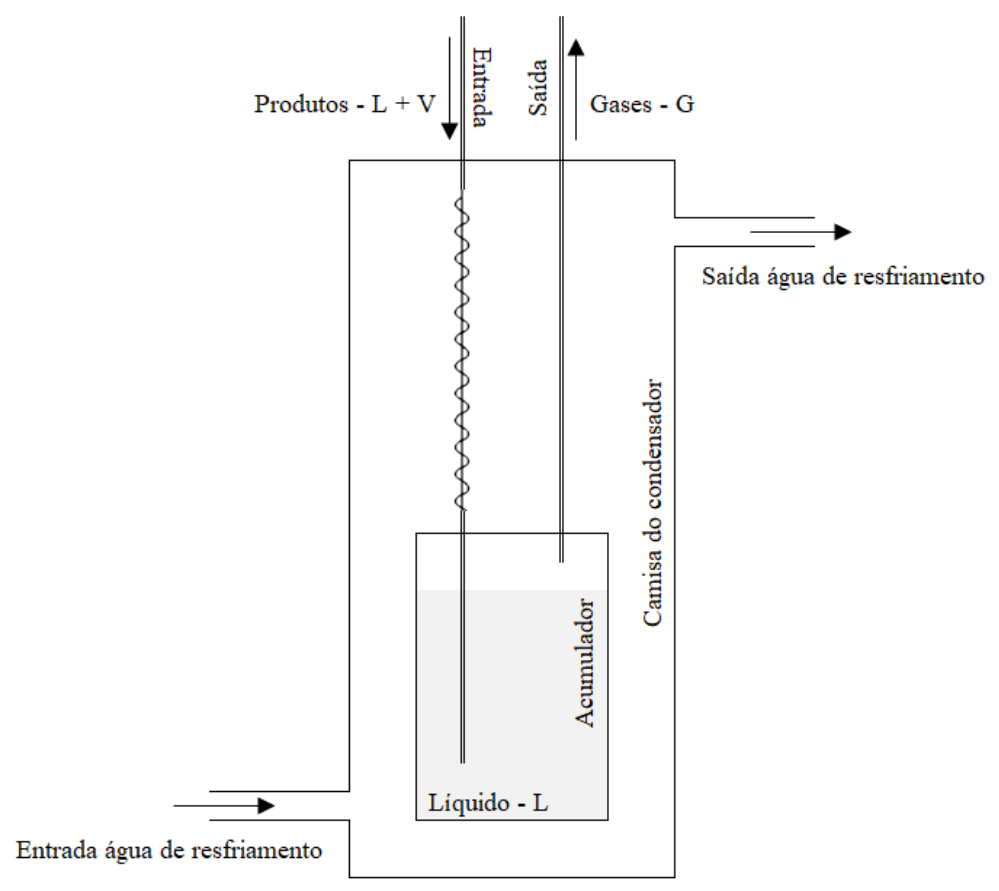

Fonte: Autor 
Tabela 20 - Dados para a calibração do controlador para o ar sintético

\begin{tabular}{c|c|c|c}
\hline $\begin{array}{c}\text { Vazão } \\
\text { painel }\end{array}$ & $\begin{array}{c}\mathrm{V} 1 \\
(\mathrm{~mL})\end{array}$ & $\mathrm{t} 1(\mathrm{~s})$ & $\begin{array}{c}\mathrm{W} \\
(\mathrm{mL} / \mathrm{min})\end{array}$ \\
\hline 10 & 9 & 4,70 & 114,89 \\
\hline 10 & 9 & 4,78 & 112,97 \\
\hline 10 & 9 & 4,78 & 112,97 \\
\hline 9 & 9 & 5,04 & 107,14 \\
\hline 9 & 9 & 4,98 & 108,43 \\
\hline 9 & 9 & 4,96 & 108,87 \\
\hline 11 & 9 & 4,58 & 117,90 \\
\hline 11 & 9 & 4,59 & 117,65 \\
\hline 11 & 9 & 4,53 & 119,21 \\
\hline 12 & 9 & 4,33 & 124,71 \\
\hline 12 & 9 & 4,32 & 125,00 \\
\hline 14 & 9 & 3,87 & 139,53 \\
\hline 14 & 9 & 3,86 & 139,90 \\
\hline 16 & 9 & 3,50 & 154,29 \\
\hline 16 & 9 & 3,49 & 154,73 \\
\hline 18 & 9 & 3,28 & 164,63 \\
\hline 18 & 9 & 3,23 & 167,18 \\
\hline
\end{tabular}

Tabela 21 - Dados para a calibração do controlador de gás nitrogênio

\begin{tabular}{c|c|c|c}
\hline $\begin{array}{c}\text { Vazão } \\
\text { teórica }\end{array}$ & $\begin{array}{c}\mathrm{V} 1 \\
(\mathrm{~mL})\end{array}$ & $\mathrm{t} 1(\mathrm{~s})$ & $\begin{array}{c}\mathrm{W} \\
(\mathrm{mL} / \mathrm{min})\end{array}$ \\
\hline 18 & 10 & 17,40 & 34,48 \\
\hline 18 & 100 & 170,41 & 35,21 \\
\hline 33 & 9 & 6,79 & 79,53 \\
\hline 33 & 99 & 74,70 & 79,52 \\
\hline 47 & 9 & 4,55 & 118,68 \\
\hline 47 & 99 & 49,92 & 118,99 \\
\hline 80 & 9 & 2,51 & 215,14 \\
\hline 80 & 99 & 27,60 & 215,22 \\
\hline
\end{tabular}

Figura 47 - Curva para calibração do controlador para o ar sintético

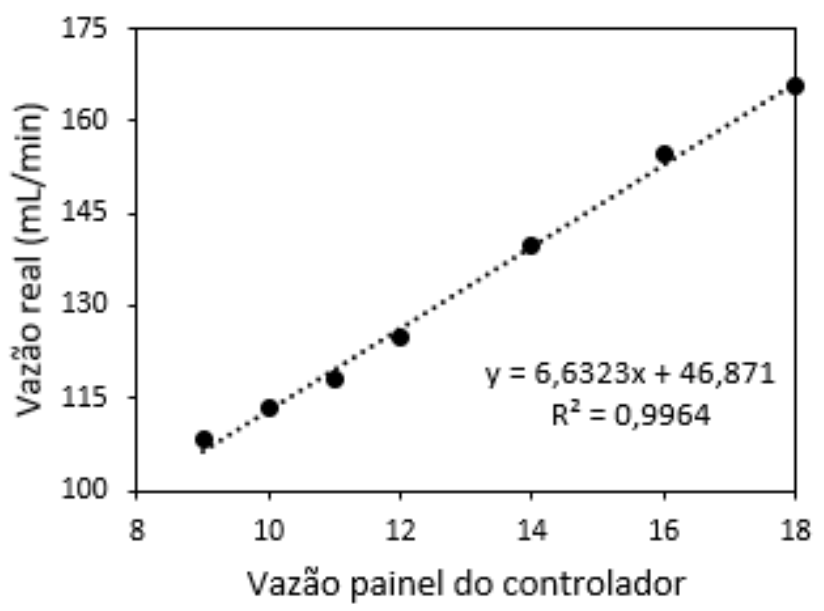

Figura 48 - Curva para calibração do controlador para o nitrogênio

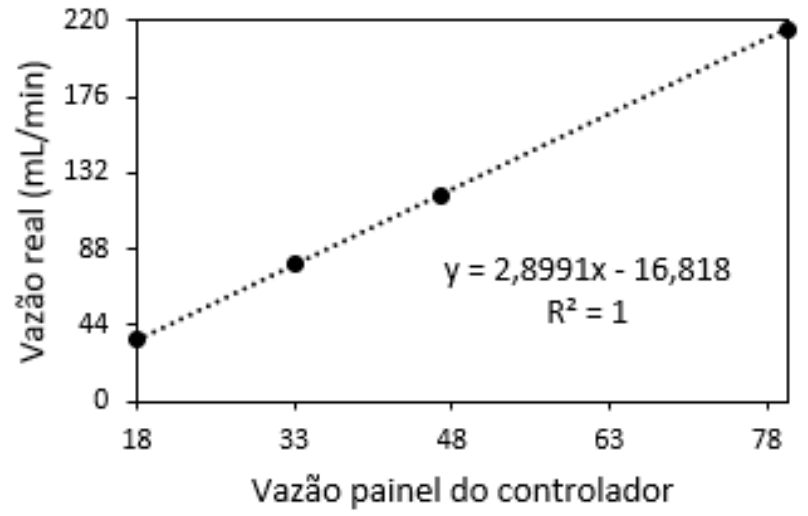




\section{APÊNDICE B- DADOS AUXILIARES PARA A CROMATOGRAFIA GASOSA}

\section{- Procedimento para quantificação dos produtos líquidos na saída do processo}

(FID-líquido)

Os produtos condensáveis obtidos no processo foram identificados e quantificados por cromatografia gasosa utilizando um cromatógrafo HP 5890 series II equipado com uma coluna cromatográfica DB-225 (30 m; 0,530 mm; 1,00 $\mu \mathrm{m})$ e detector FID. Para identificação dos compostos, os tempos de retenção de cada pico obtido nas injeções dos ensaios experimentais foram comparados os tempos de retenção de compostos puros.

Para a quantificação dos componentes presentes nas amostras, foi utilizado etilenoglicol como padrão interno. Para isso, as alíquotas correspondentes a cada amostra do efluente líquido coletada na saída do reator foram pesadas e em seguida adicionado 2\% em massa de etilenoglicol, a mistura então foi injetada no CG para análise no FID e obtenção dos cromatogramas.

Os cálculos para quantificação dos produtos presentes nas amostras foram realizados com base em curvas de calibração obtidas a partir dos resultados dos cromatogramas de soluções com composições conhecidas de cada componente contendo etilenoglicol como padrão interno. As curvas correlacionam as áreas dos picos do componente e do padrão com a massa do componente e do padrão conforme descrito na Equação 13, na qual $x_{i}=\frac{m_{\text {componente } i}}{m_{\text {padrão }}}$ e $y_{i}=\frac{A_{\text {componente } i}}{A_{\text {padrão }}}$ e estão representadas na Figura 49

$x_{i}=\propto * y_{i}$

Nas análises das amostras do processo, as áreas de cada componente e da substância padrão são obtidas pela integração do pico correspondente no cromatograma e a massa de padrão adicionada é conhecia, assim é possível determinar a quantidade de cada componente da amostra e suas concentrações para determinação da conversão e seletividade. A Figura 50 apresenta um exemplo de cromatograma obtido na injeção de uma amostra padrão identificando o tempo de retenção de cada componente da amostra. 
Figura 49 - Curva dos padrões para quantificação dos componentes condensáveis na saída do processo por CG no detector FID.
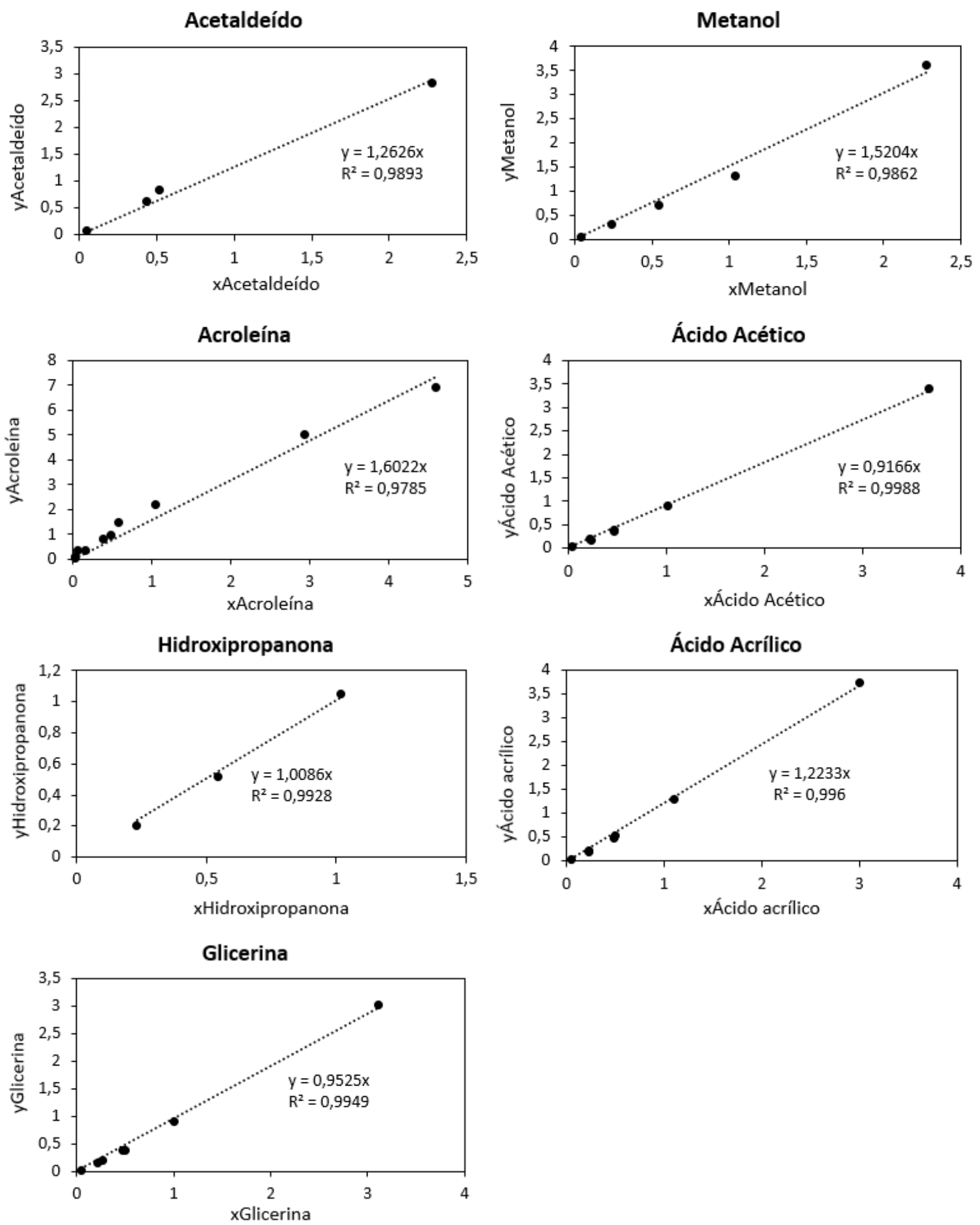

Fonte: Autor 
Figura 50 - Cromatograma obtido na injeção de uma amostra padrão contendo os principais componentes dos produtos de saída do processo

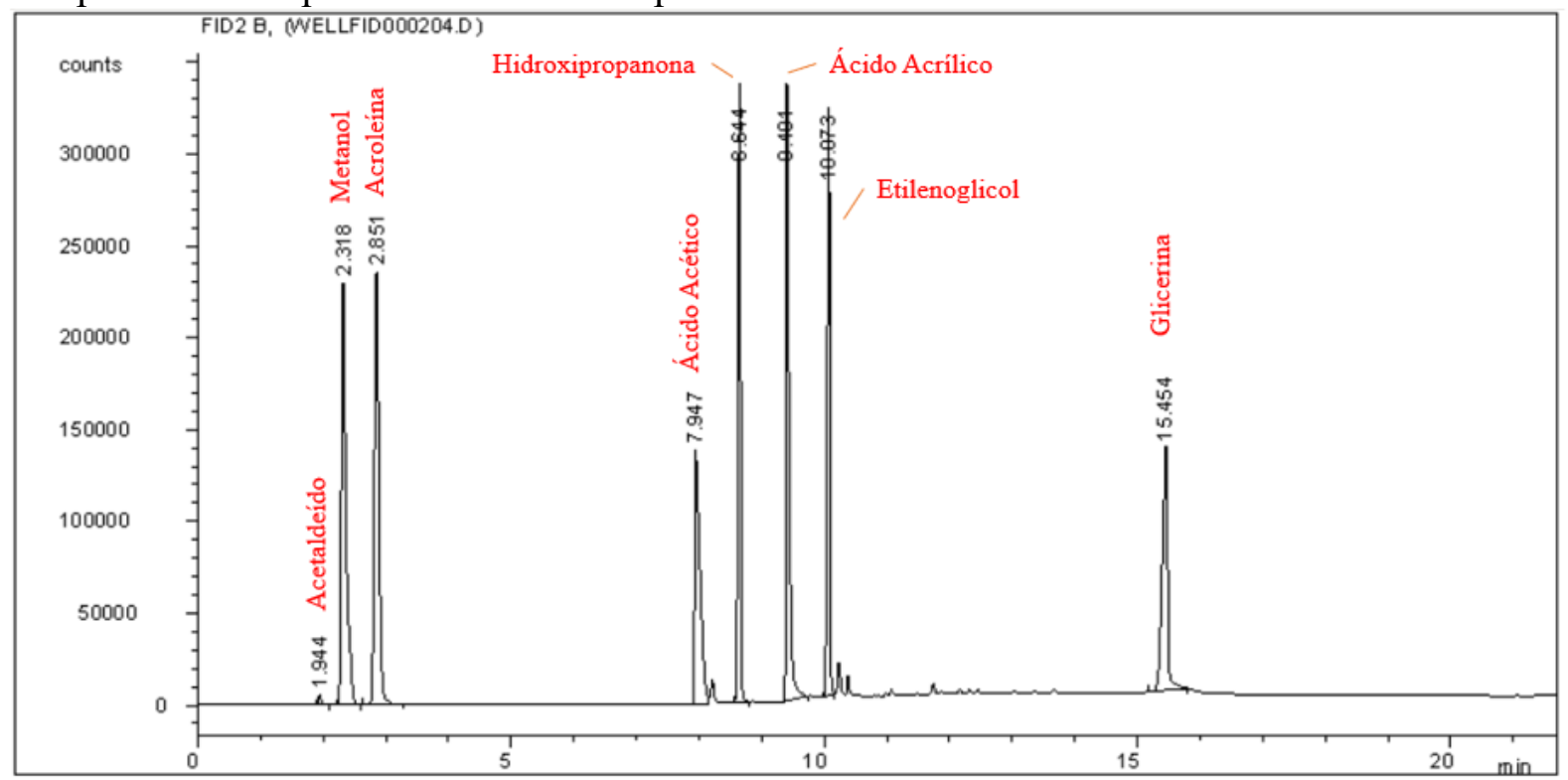

Fonte: Autor

- Procedimento para quantificação da acroleína não condensável na saída do processo (FID-gasoso)

Os produtos obtidos tanto na reação de oxidação da acroleína quanto da oxidesidratação do glicerol são condensáveis a $1{ }^{\circ} \mathrm{C}$, temperatura utilizada no condensador, por isso uma maior quantidade dos componentes formados foi identificada em injeções dos líquidos da saída do processo no detector FID. Porém, um teor residual de acroleína que não condensou foi detectado quando injetada uma amostra do gás de saída no FID, um exemplo de cromatograma é mostrado na Figura 51. Para a quantificação dessa acroleína residual foi utilizada também uma curva de padrão com quantidades conhecidas de acroleína no gás. A fim de cálculos, a acroleína foi considerada um gás ideal.

Para a construção da curva padrão, foram injetadas amostras de gás de um recipiente contendo acroleína pura a 297,6 K variando-se o volume injetado no $\mathrm{CG}(0,5 ; 0,4 ; 0,3 ; 0,2$ e 0,1 mL). A quantidade de mol de acroleína presente na amostra injetada foi calculada considerando a pressão de vapor da acroleína na temperatura do experimento pela equação de estado do gás ideal (Equação 14), na qual $\mathrm{P}_{\mathrm{ACR}}$ é a pressão de vapor da acroleína, $\mathrm{V}$ é o volume de gás injetado no $\mathrm{CG}$, $\mathrm{n}$ é o número de mols de acroleína, $\mathrm{R}=62,3637 \mathrm{mmHg} \mathrm{L} \cdot \mathrm{K}^{-1} \cdot \mathrm{mol}^{-1}$

$\mathrm{P}_{\mathrm{ACR}} * \mathrm{~V}=\mathrm{n} * \mathrm{R} * \mathrm{~T}$ 
Figura 51 - Cromatograma obtido na injeção do gás da saída do processo

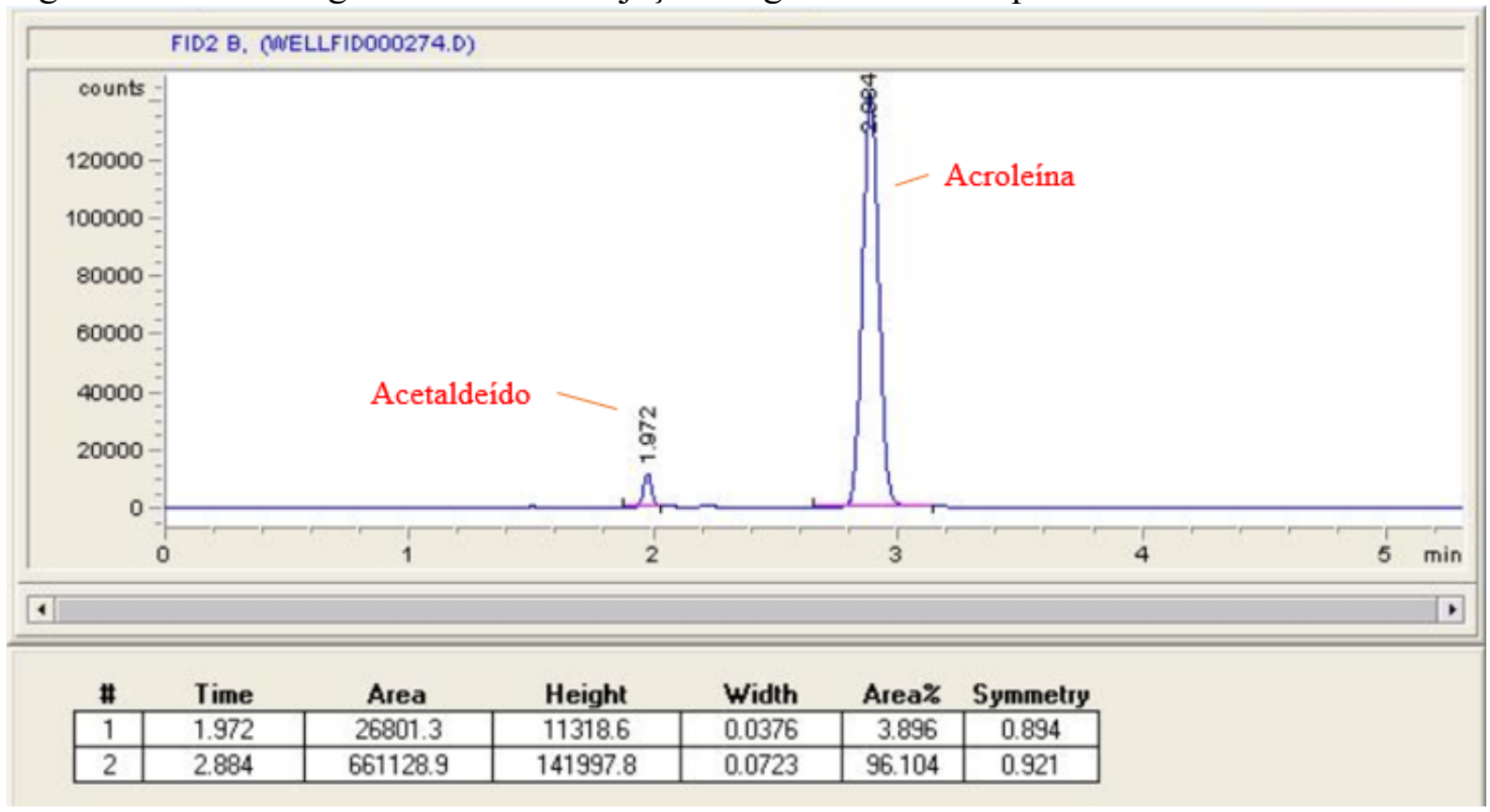

Fonte: Autor

A Figura 52 apresenta a curva padrão para a quantificação da acroleína na fase gasosa na saída do processo. O número de mol de acroleína na amostra injetada é diretamente proporcional ao valor da área do pico do cromatograma. Assim é possível estimar a quantidade de acroleína no gás.

Figura 52 - Curva de calibração para a quantificação da acroleína residual no gás na saída do processo

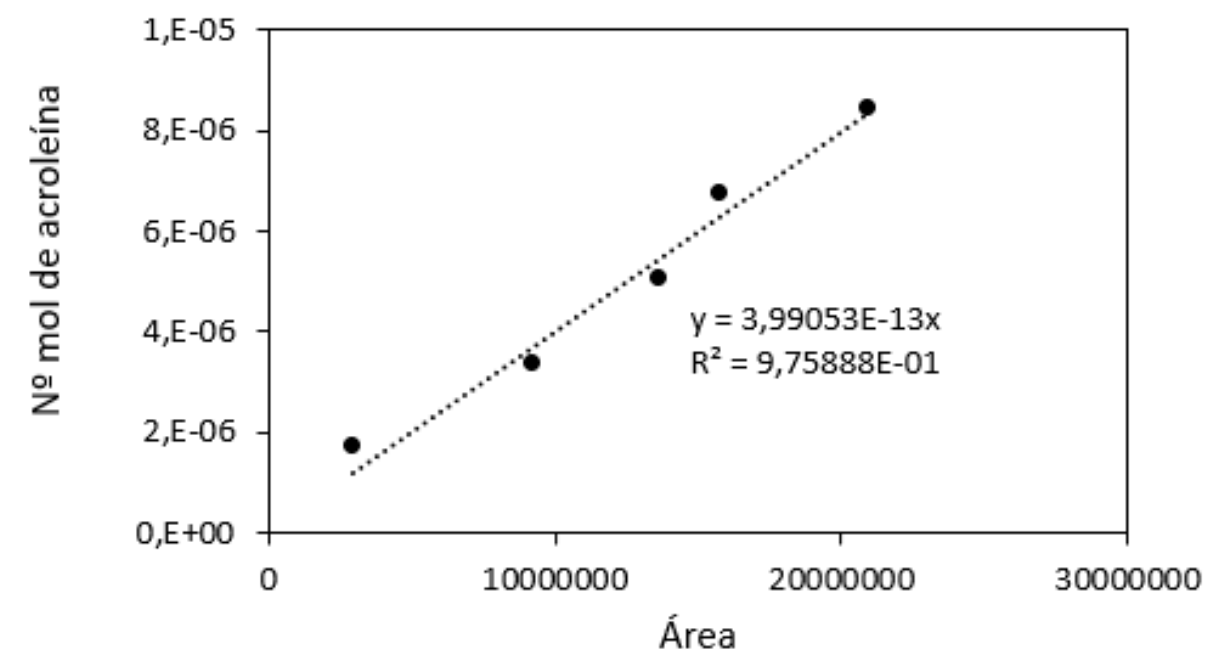

Fonte: Autor 


\section{- Procedimento para a quantificação dos gases da saída do processo por TCD}

A identificação e quantificação dos gases gerados no processo foi feita por cromatografia gasosa no detector TCD, utilizando uma coluna de separação do tipo Select Permanent Gases para a separação de $\mathrm{O}_{2}, \mathrm{~N}_{2}, \mathrm{CO}_{2}$ e $\mathrm{CO}$.

Os fatores de resposta (FR) no TCD foram assumidos da literatura e normalizados com os dados de resposta obtidos pela curva de calibração feita para cada componente. Os valores citados na literatura são mostrados na Tabela 22 e as curvas de calibração foram obtidas utilizando padrões com diferentes concentrações conhecidas de ar sintético, gás nitrogênio e gás carbônico e são mostradas na Figura 53.

Tabela 22 - Fatores de resposta no detector TCD

\begin{tabular}{c|c}
\hline Componente & Fator de Resposta \\
\hline $\mathrm{O}_{2}$ & 0,80 \\
\hline $\mathrm{N}_{2}$ & 0,67 \\
\hline $\mathrm{CO}_{2}$ & 0,915 \\
\hline $\mathrm{CO}$ & 0,67 \\
\hline
\end{tabular}

Fonte: MCNAIR, BONELLI, 1968

A normalização e validação dos fatores de resposta foram feitas pela comparação entre os valores encontrados na literatura e os valores obtidos experimentalmente. Para o cálculo do FR foi selecionada a injeção de uma amostra padrão, cujas as áreas dos picos referente a cada componente e toda a linha de cálculo são mostradas na Tabela 23. Primeiramente foi calculada a concentração teórica de cada componente utilizando as relações concentração/área obtidas graficamente. Em seguida, foi utilizada ferramenta de cálculo de atingir metas para igualar a concentração teórica à calculada, variando-se o fator de resposta. No cálculo foi utilizada a Equação 15 , na qual $c_{\text {teo }} i$ é a concentração teórica, $c_{i}$ é a concentração calculada pelo fator de resposta, Area $_{i}$ é a área do pico do cromatograma referente ao componente i e $F R_{i}$ é o fator de resposta do componente $\mathrm{i}$.

$$
c_{\text {teo } i} \cong c_{i}=\frac{\text { Area }_{i} * F R_{i}}{\sum A r e a_{i} * F R_{i}}
$$


Tabela 23 - Determinação do fator de resposta para análises no TCD

\begin{tabular}{c|c|c|c|c|c}
\hline Componente & Área & $\begin{array}{c}\text { Concentração } \\
\text { teórica } \\
\text { (\%molar) }\end{array}$ & $\begin{array}{c}\text { Fator de } \\
\text { resposta }\end{array}$ & $\begin{array}{c}\text { Concentração } \\
\text { calculada pelo } \\
\text { FR (\%molar) }\end{array}$ & \%Erro \\
\hline $\mathrm{O}_{2}$ & 131061 & 0,1813 & $\mathbf{1 , 1 8 5 3}$ & 0,1806 & 0,000499610 \\
\hline $\mathrm{N}_{2}$ & 925517,9 & 0,7215 & $\mathbf{0 , 6 7 0 0}$ & 0,7207 & 0,000540481 \\
\hline $\mathrm{CO}_{2}$ & 90560,2 & 0,0994 & $\mathbf{0 , 9 3 8 3}$ & 0,0988 & 0,000453967 \\
\hline $\mathrm{CO}$ & & & $\mathbf{0 , 6 7 0 0}$ & & \\
\hline
\end{tabular}

Fonte: Autor.

O fator de resposta do monóxido de carbono foi considerado o da literatura, pois não havia o gás disponível para uma injeção de amostra padrão.

Figura 53 - Curva dos padrões para a quantificação dos gases na saída do processo por CG no detector TCD.
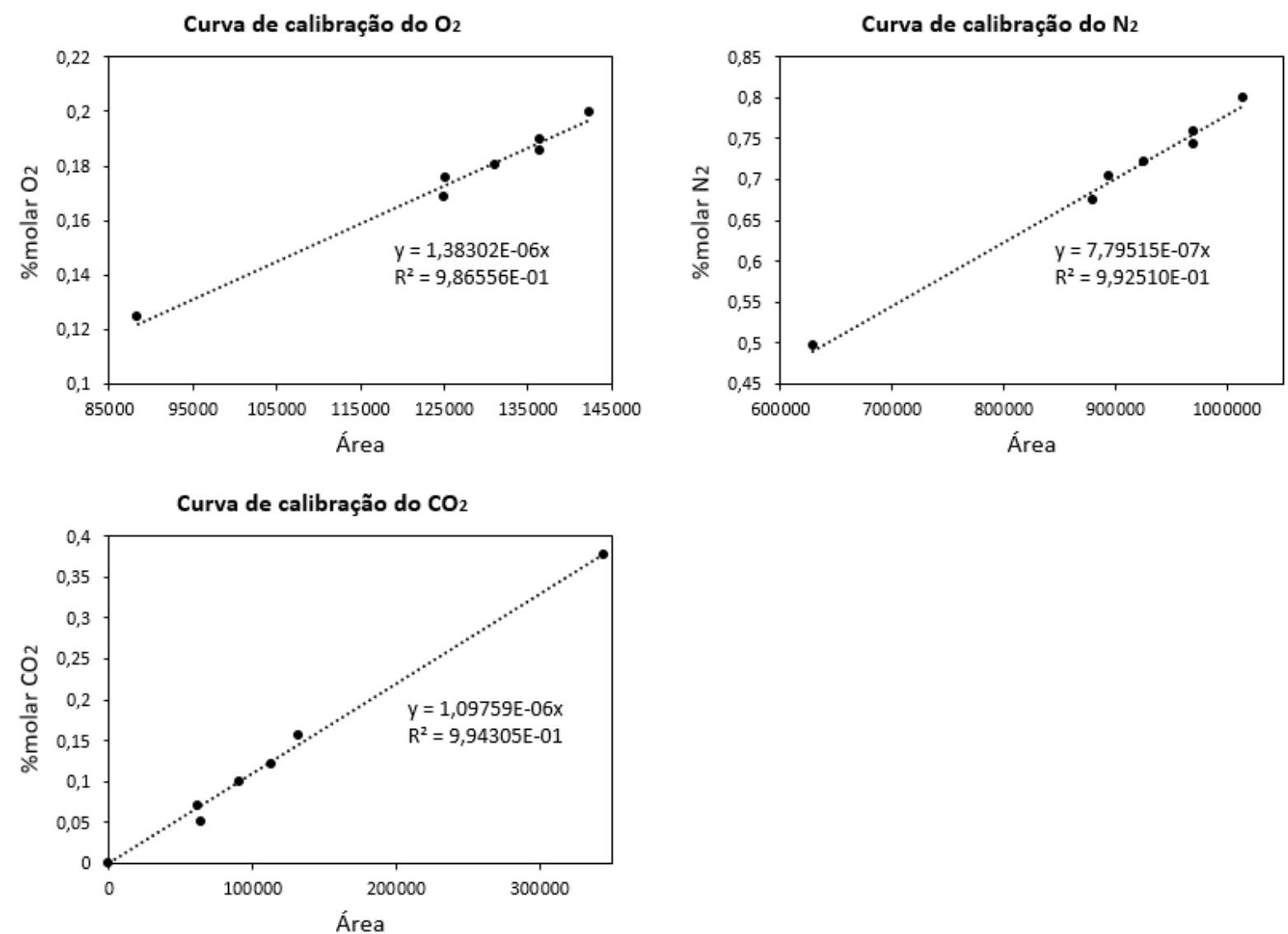

Fonte: Autor.

A Figura 54 apresenta um exemplo de cromatograma obtido para as análises dos gases no TCD identificando o pico e tempo de retenção correspondente de cada componente. 
Figura 54 - Exemplo de cromatograma obtido nas análises no TCD

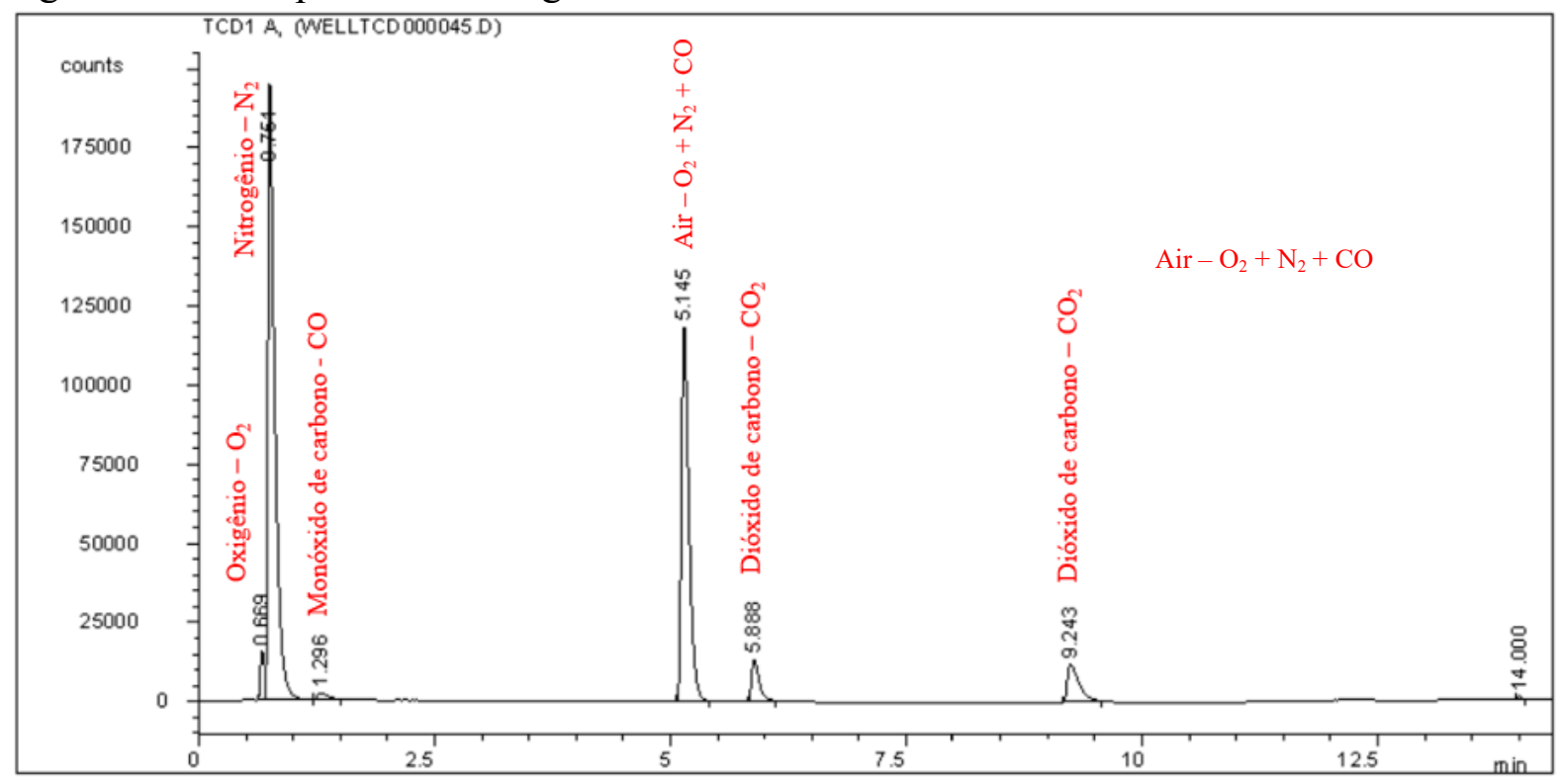

Fonte: Autor 


\section{APÊNDICE C- CÁLCULOS DE CONVERSÃO E SELETIVIDADE}

Tabela 24 - Cálculos de conversão e seletividade amostrar B1-EV e B1-TH

\begin{tabular}{|c|c|c|c|c|c|c|}
\hline \multicolumn{7}{|l|}{ Dados gerais do ensaio } \\
\hline $\begin{array}{c}\text { Catalisador } \\
\text { Reagente } \\
\text { Amostra }\end{array}$ & $\begin{array}{l}\text { B1-EV } \\
\text { Acroleína } \\
60 \mathrm{~min}\end{array}$ & $\begin{array}{c}\text { B1-EV } \\
\text { Acroleína } \\
90 \mathrm{~min}\end{array}$ & $\begin{array}{c}\text { B1-EV } \\
\text { Acroleína } \\
120 \mathrm{~min}\end{array}$ & $\begin{array}{l}\text { B1-TH } \\
\text { Acroleína } \\
60 \mathrm{~min}\end{array}$ & $\begin{array}{c}\text { B1-TH } \\
\text { Acroleína } \\
90 \mathrm{~min}\end{array}$ & $\begin{array}{c}\text { B1-TH } \\
\text { Acroleína } \\
120 \text { min }\end{array}$ \\
\hline \multicolumn{7}{|l|}{ Áreas Obtidas no CG } \\
\hline \multicolumn{7}{|l|}{ FID - líquido } \\
\hline Acetaldeído - 2,011 & 186149,1 & 172853,5 & 124317,4 & 104572,2 & 97564,3 & 93427,1 \\
\hline Metanol - 2,318 & 105886,3 & 112342,5 & 74179,3 & 136344,6 & 146234 & 156743 \\
\hline Acroleína- 2,851 & 2219744,2 & 2339771,3 & 1388940,6 & 3234873,3 & 3457261,1 & 3445613,9 \\
\hline Ac. Acético - 7,947 & 34052,5 & 17810,5 & 12982,9 & 21755,3 & 26437,4 & 27469,3 \\
\hline Desconhecido - 8,726 & 0 & 0 & 0 & 0 & 0 & 0 \\
\hline Ac. Acrílico - 9,450 & 182635,8 & 130702,8 & 91678,3 & 107269,5 & 104973,5 & 100649,2 \\
\hline Etilenoglicol - 10,073 & 857244,2 & 1101982,5 & 965528,9 & 2379257,5 & 2356417,3 & 2467952 \\
\hline \multicolumn{7}{|l|}{ FID - gás } \\
\hline Desconhecido - 1,5 & 0 & 536 & 536 & 0 & 0 & 0 \\
\hline Desconhecido - 1,5 & 0 & 679,3 & 679,3 & 2066,5 & 3124,2 & 3124,2 \\
\hline Acetaldeído - 2,010 & 1435 & 24784,5 & 24784,5 & 3161,4 & 2971 & 2971 \\
\hline Desconhecido - 2,280 & 0 & 2816,6 & 2816,6 & 0 & 0 & 0 \\
\hline Acroleína - 2,856 & 33699,3 & 743066,3 & 743066,3 & 186060 & 192034 & 192034 \\
\hline \multicolumn{7}{|l|}{ TCD - gás } \\
\hline $\mathrm{O}_{2}-0,667$ & 132413,1 & 137250,9 & 137250,9 & 113467,1 & 121476,3 & 121476,3 \\
\hline$N_{2}-0,748$ & 966646,1 & 978151,6 & 978151,6 & 968252,2 & 978352,4 & 978352,4 \\
\hline $\mathrm{CO}-1,326$ & 4020,6 & 2872,9 & 2872,9 & 22957 & 21369 & 21369 \\
\hline $\mathrm{N}_{2}+\mathrm{O}_{2}-5,151$ & 692583,6 & 700531,1 & 700531,1 & 681047 & 679143 & 679143 \\
\hline $\mathrm{CO}_{2} 1-5,894$ & 14072,8 & 11013,5 & 11013,5 & 34091,6 & 30176,4 & 30176,4 \\
\hline $\mathrm{CO}_{2} 2-9,312$ & 20252,9 & 13940 & 13940 & 69593,6 & 64714,2 & 64714,2 \\
\hline Desconhecido - 14,001 & 15485,8 & 20277,9 & 20277,9 & 0 & 0 & 0 \\
\hline \multicolumn{7}{|l|}{ Cálculos } \\
\hline \multicolumn{7}{|l|}{ Conversão (\%) } \\
\hline Conversão Acroleína (\%) & $52,12 \%$ & $39,21 \%$ & $56,74 \%$ & $25,68 \%$ & $20,17 \%$ & $20,64 \%$ \\
\hline Conversão $\mathrm{O}_{2}(\%)$ & $4,36 \%$ & $2,03 \%$ & $2,03 \%$ & $19,04 \%$ & $14,51 \%$ & $14,51 \%$ \\
\hline \multicolumn{7}{|l|}{ Rendimento (\%) } \\
\hline Acetaldeído & $12,21 \%$ & $12,66 \%$ & $6,14 \%$ & $14,68 \%$ & $17,54 \%$ & $16,37 \%$ \\
\hline Metanol & $0,00 \%$ & $0,00 \%$ & $0,00 \%$ & $0,00 \%$ & $0,00 \%$ & $0,00 \%$ \\
\hline Acroleína & $0,00 \%$ & $0,00 \%$ & $0,00 \%$ & $0,00 \%$ & $0,00 \%$ & $0,00 \%$ \\
\hline Ácido acético & $2,26 \%$ & $1,32 \%$ & $0,65 \%$ & $3,09 \%$ & $4,80 \%$ & $4,86 \%$ \\
\hline Ácido acrílico & $7,56 \%$ & $6,04 \%$ & $2,86 \%$ & $9,50 \%$ & $11,91 \%$ & $11,13 \%$ \\
\hline $\mathrm{CO}_{2}$ & $39,05 \%$ & $39,20 \%$ & $27,09 \%$ & $81,66 \%$ & $91,07 \%$ & $89,00 \%$ \\
\hline $\mathrm{CO}$ & $7,97 \%$ & $7,30 \%$ & $5,05 \%$ & $39,27 \%$ & $46,05 \%$ & $45,00 \%$ \\
\hline \multicolumn{7}{|l|}{ Seletividade (\%) } \\
\hline \multicolumn{7}{|l|}{$\begin{array}{l}\text { Metanol } \\
\text { Acroleína }\end{array}$} \\
\hline Ácido acético & $1,50 \%$ & $0,88 \%$ & $0,43 \%$ & $2,06 \%$ & $3,20 \%$ & $3,24 \%$ \\
\hline Ácido acrílico & $7,56 \%$ & $6,04 \%$ & $2,86 \%$ & $9,50 \%$ & $11,91 \%$ & $11,13 \%$ \\
\hline $\mathrm{CO}_{2}$ & $13,02 \%$ & $13,07 \%$ & $9,03 \%$ & $27,22 \%$ & $30,36 \%$ & $29,67 \%$ \\
\hline CO & $2,66 \%$ & $2,43 \%$ & $1,68 \%$ & $13,09 \%$ & $15,35 \%$ & $15,00 \%$ \\
\hline \multicolumn{7}{|l|}{ BALANÇO DE C, H N e O } \\
\hline $\mathrm{C}(\%)$ & $34,98 \%$ & $27,11 \%$ & $46,47 \%$ & $9,85 \%$ & $5,55 \%$ & $6,20 \%$ \\
\hline H (\%) & $1,52 \%$ & $8,50 \%$ & $17,44 \%$ & $-4,81 \%$ & $3,64 \%$ & $2,76 \%$ \\
\hline $\mathbf{N}(\%)$ & $1,33 \%$ & $1,34 \%$ & $1,34 \%$ & $2,37 \%$ & $2,70 \%$ & $2,70 \%$ \\
\hline $\mathrm{O}(\%)$ & $0,08 \%$ & $6,75 \%$ & $14,64 \%$ & $-5,36 \%$ & $2,92 \%$ & $2,06 \%$ \\
\hline \multicolumn{7}{|l|}{ Balanço de massa (\%) } \\
\hline & $97,63 \%$ & $89,83 \%$ & $80,61 \%$ & $104,29 \%$ & $96,18 \%$ & $97,03 \%$ \\
\hline
\end{tabular}

Fonte: Autor 
Tabela 25 - Cálculos de conversão e seletividade para as amostras B2-TH e B3-TH

\begin{tabular}{|c|c|c|c|c|c|c|}
\hline $\begin{array}{l}\text { Catalisador } \\
\text { Reagente } \\
\text { Amostra }\end{array}$ & $\begin{array}{l}\text { B2-TH } \\
\text { Acroleína } \\
60 \mathrm{~min}\end{array}$ & $\begin{array}{l}\text { B2-TH } \\
\text { Acroleína } \\
90 \mathrm{~min}\end{array}$ & $\begin{array}{l}\text { B2-TH } \\
\text { Acroleína } \\
120 \mathrm{~min}\end{array}$ & $\begin{array}{l}\text { B3-TH } \\
\text { Acroleína } \\
60 \mathrm{~min}\end{array}$ & $\begin{array}{l}\text { B3-TH } \\
\text { Acroleína } \\
90 \mathrm{~min}\end{array}$ & $\begin{array}{l}\text { B3-TH } \\
\text { Acroleína } \\
120 \mathrm{~min}\end{array}$ \\
\hline \multicolumn{7}{|l|}{ Áreas Obtidas no CG } \\
\hline \multicolumn{7}{|l|}{ FID - líquido } \\
\hline Acetaldeído - 2,011 & 229734,5 & 149345,2 & 97946,3 & 100806,6 & 78512 & 104651,3 \\
\hline Metanol - 2,318 & 310028,2 & 118495,3 & 117624,7 & 114800 & 18763,9 & 14562 \\
\hline Acroleína - 2,851 & 5269794 & 3691700 & 1487332 & 2475424,3 & 2358782,3 & 2387137,1 \\
\hline Ac. Acético - 7,947 & 152582,5 & 49814,8 & 72498,4 & 17812,9 & 5661,6 & 7523,4 \\
\hline Desconhecido - 8,726 & 0 & 0 & 0 & 0 & 0 & 0 \\
\hline Ac. Acrílico - 9,450 & 305198,8 & 307550 & 35749,1 & 15188,2 & 7955,4 & 9465 \\
\hline Etilenoglicol - 10,073 & 6560091,5 & 4999080,5 & 812746,2 & 947328,1 & 828248,9 & 814946,7 \\
\hline \multicolumn{7}{|l|}{ FID - gás } \\
\hline Desconhecido - 1,5 & 0 & 0 & 0 & 0 & 0 & 0 \\
\hline Desconhecido - 1,5 & 0 & 0 & 0 & 992,7 & 992,7 & 992,7 \\
\hline Acetaldeído - 2,010 & 23492 & 23492 & 23492 & 17225,8 & 17225,8 & 17225,8 \\
\hline Desconhecido - 2,280 & 0 & 0 & 0 & 0 & 0 & 0 \\
\hline Acroleína - 2,856 & 1215382,9 & 1215382,9 & 1215382,9 & 855337,9 & 855337,9 & 855337,9 \\
\hline \multicolumn{7}{|l|}{ TCD - gás } \\
\hline $\mathrm{O}_{2}-0,667$ & 133829 & 142040,1 & 142040,1 & 119561,1 & 125898,2 & 125898,2 \\
\hline$N_{2}-0,748$ & 987553,1 & 996361,1 & 996361,1 & 995151,8 & 1000344,2 & 1000344,2 \\
\hline $\mathrm{CO}-1,326$ & 0 & 0 & 0 & 28644,1 & 5421 & 5421 \\
\hline $\mathrm{N}_{2}+\mathrm{O}_{2}-5,151$ & 701887,6 & 712867,3 & 712867,3 & 711176,3 & 717869,1 & 717869,1 \\
\hline $\mathrm{CO}_{2} 1-5,894$ & 9338,7 & 9838,8 & 9838,8 & 32064,3 & 12359 & 12359 \\
\hline $\mathrm{CO}_{2} 2-9,312$ & 11892,4 & 11522,4 & 11522,4 & 46629,6 & 14801,5 & 14801,5 \\
\hline Desconhecido - 14,001 & 21578,9 & 22489,9 & 22489,9 & 0 & 22321 & 22321 \\
\hline \multicolumn{7}{|l|}{ Cálculos } \\
\hline \multicolumn{7}{|l|}{ Conversão (\%) } \\
\hline Conversão Acroleína (\%) & $51,66 \%$ & $53,39 \%$ & $34,98 \%$ & $28,21 \%$ & $15,42 \%$ & $21,05 \%$ \\
\hline Conversão $\mathrm{O}_{2}(\%)$ & $4,33 \%$ & $0,39 \%$ & $0,39 \%$ & $17,39 \%$ & $10,61 \%$ & $10,61 \%$ \\
\hline \multicolumn{7}{|l|}{ Rendimento (\%) } \\
\hline Acetaldeído & $2,27 \%$ & $1,63 \%$ & $10,23 \%$ & $11,63 \%$ & $20,72 \%$ & $18,09 \%$ \\
\hline Metanol & $0,00 \%$ & $0,00 \%$ & $0,00 \%$ & $0,00 \%$ & $0,00 \%$ & $0,00 \%$ \\
\hline Acroleína & $0,00 \%$ & $0,00 \%$ & $0,00 \%$ & $0,00 \%$ & $0,00 \%$ & $0,00 \%$ \\
\hline Ácido acético & $1,52 \%$ & $0,55 \%$ & $7,65 \%$ & $2,08 \%$ & $1,51 \%$ & $1,31 \%$ \\
\hline Ácido acrílico & $1,90 \%$ & $2,12 \%$ & $2,36 \%$ & $1,11 \%$ & $1,32 \%$ & $1,03 \%$ \\
\hline $\mathrm{CO}_{2}$ & $25,55 \%$ & $26,83 \%$ & $38,56 \%$ & $152,44 \%$ & $126,88 \%$ & $92,91 \%$ \\
\hline $\mathrm{CO}$ & $0,00 \%$ & $0,00 \%$ & $0,00 \%$ & $97,24 \%$ & $39,74 \%$ & $29,10 \%$ \\
\hline \multicolumn{7}{|l|}{ Seletividade (\%) } \\
\hline $\begin{array}{c}\text { Acetaldeído } \\
\text { Metanol } \\
\text { Acroleína }\end{array}$ & $1,51 \%$ & $1,09 \%$ & $6,82 \%$ & $7,75 \%$ & $13,81 \%$ & $12,06 \%$ \\
\hline Ácido acético & $1,01 \%$ & $0,37 \%$ & $5,10 \%$ & $1,38 \%$ & $1,01 \%$ & $0,88 \%$ \\
\hline Ácido acrílico & $1,90 \%$ & $2,12 \%$ & $2,36 \%$ & $1,11 \%$ & $1,32 \%$ & $1,03 \%$ \\
\hline $\mathrm{CO}_{2}$ & $8,52 \%$ & $8,94 \%$ & $12,85 \%$ & $50,81 \%$ & $42,29 \%$ & $30,97 \%$ \\
\hline CO & $0,00 \%$ & $0,00 \%$ & $0,00 \%$ & $32,41 \%$ & $13,25 \%$ & $9,70 \%$ \\
\hline \multicolumn{7}{|l|}{ BALANÇO DE C, H N e O } \\
\hline C (\%) & $44,97 \%$ & $46,71 \%$ & $25,49 \%$ & $1,84 \%$ & $4,36 \%$ & $9,55 \%$ \\
\hline H (\%) & $9,43 \%$ & $0,52 \%$ & $1,46 \%$ & $12,22 \%$ & $-5,10 \%$ & $8,74 \%$ \\
\hline N (\%) & $0,24 \%$ & $1,27 \%$ & $1,27 \%$ & $2,83 \%$ & $-0,37 \%$ & $-0,37 \%$ \\
\hline $\mathrm{O}(\%)$ & $7,65 \%$ & $-1,04 \%$ & $0,27 \%$ & $10,28 \%$ & $-4,61 \%$ & $7,92 \%$ \\
\hline \multicolumn{7}{|l|}{ Balanço de massa (\%) } \\
\hline
\end{tabular}

Fonte: Autor 
Tabela 26 - Cálculos de conversão e seletividade para as amostras B1-EV+TH e B2-EV+TH

\begin{tabular}{|c|c|c|c|c|c|c|}
\hline \multicolumn{7}{|l|}{ Dados gerais do ensaio } \\
\hline Catalisador & B1-EV+TH & $\mathrm{B} 1-\mathrm{EV}+\mathrm{TH}$ & B1-EV+TH & $\mathrm{B} 2-\mathrm{EV}+\mathrm{TH}$ & $\mathrm{B} 2-\mathrm{EV}+\mathrm{TH}$ & $\mathrm{B} 2-\mathrm{EV}+\mathrm{TH}$ \\
\hline Reagente & Acroleína & Acroleína & Acroleína & Acroleína & Acroleína & Acroleína \\
\hline Amostra & $60 \mathrm{~min}$ & $90 \mathrm{~min}$ & $120 \min$ & $60 \mathrm{~min}$ & $90 \mathrm{~min}$ & $120 \mathrm{~min}$ \\
\hline \multicolumn{7}{|l|}{ Áreas Obtidas no CG } \\
\hline \multicolumn{7}{|l|}{ FID - líquido } \\
\hline Acetaldeído - 2,011 & 130312,6 & 120029,8 & 127416,5 & 168390,6 & 164846,5 & 193516,1 \\
\hline Metanol - 2,318 & 94863,3 & 119569,2 & 85532,2 & 112592,3 & 69713,7 & 106385,5 \\
\hline Acroleína - 2,851 & 1895502 & 1755899,4 & 1974160,4 & 2056871,6 & 1949299,9 & 2334292,5 \\
\hline Ac. Acético - 7,947 & 79820 & 61483,1 & 63387 & 98468,8 & 27828,3 & 35323,6 \\
\hline Desconhecido - 8,726 & 0 & 0 & 0 & 0 & 0 & 0 \\
\hline Ac. Acrílico - 9,450 & 1246595,6 & 1084566,1 & 1106213,3 & 57779,6 & 88277,1 & 146347 \\
\hline Etilenoglicol - 10,073 & 1020015,2 & 1337825 & 1155959,7 & 1526437 & 966216,9 & 1125901,5 \\
\hline \multicolumn{7}{|l|}{ FID - gás } \\
\hline Desconhecido - 1,5 & 686,3 & 596,4 & 596,4 & 0 & 536 & 536 \\
\hline Desconhecido - 1,5 & 1719,2 & 1549 & 1549 & 0 & 679,3 & 679,3 \\
\hline Acetaldeído - 2,010 & 20155,1 & 16247,7 & 16247,7 & 4562,7 & 24784,5 & 24784,5 \\
\hline Desconhecido - 2,280 & 0 & 0 & 0 & 0 & 2816,6 & 2816,6 \\
\hline Acroleína - 2,856 & 635727,3 & 465721,2 & 465721,2 & 556913,7 & 743066,3 & 743066,3 \\
\hline \multicolumn{7}{|l|}{ TCD - gás } \\
\hline $02-0,667$ & 135322,8 & 146550,1 & 146550,1 & 204015,1 & 204015,1 & 193166,5 \\
\hline $\mathrm{N}_{2}-0,748$ & 1000823,9 & 1026182,1 & 1026182,1 & 1441846,9 & 1441846,9 & 1461538,5 \\
\hline $\mathrm{CO}-1,326$ & 8977 & 6574,7 & 6574,7 & 14656,1 & 14656,1 & 16723,4 \\
\hline $\mathrm{N}_{2}+\mathrm{O}_{2}-5,151$ & 715739,9 & 729901,9 & 729901,9 & 1046458,9 & 1046458,9 & 1040864,6 \\
\hline $\mathrm{CO}_{2} 1-5,894$ & 15931 & 13411,4 & 13411,4 & 25241,4 & 25241,4 & 28536,3 \\
\hline $\mathrm{CO}_{2} 2-9,312$ & 20089,5 & 19558,9 & 19558,9 & 37868,2 & 37868,2 & 41461 \\
\hline Desconhecido - 14,001 & 3183 & 15066,2 & 15066,2 & 26929,7 & 26929,7 & 23049 \\
\hline \multicolumn{7}{|l|}{ Cálculos } \\
\hline \multicolumn{7}{|l|}{ Conversão (\%) } \\
\hline Conversão Acroleína (\%) & $47,28 \%$ & $56,02 \%$ & $52,93 \%$ & $45,56 \%$ & $47,50 \%$ & $42,38 \%$ \\
\hline Conversão $\mathrm{O}_{2}(\%)$ & $5,86 \%$ & $1,10 \%$ & $1,10 \%$ & $2,60 \%$ & $2,60 \%$ & $8,13 \%$ \\
\hline \multicolumn{7}{|l|}{ Rendimento (\%) } \\
\hline Acetaldeído & $8,38 \%$ & $6,26 \%$ & $6,87 \%$ & $11,61 \%$ & $9,99 \%$ & $12,18 \%$ \\
\hline Metanol & $0,00 \%$ & $0,00 \%$ & $0,00 \%$ & $0,00 \%$ & $0,00 \%$ & $0,00 \%$ \\
\hline Acroleína & $0,00 \%$ & $0,00 \%$ & $0,00 \%$ & $0,00 \%$ & $0,00 \%$ & $0,00 \%$ \\
\hline Ácido acético & $5,19 \%$ & $3,24 \%$ & $3,45 \%$ & $6,86 \%$ & $1,70 \%$ & $2,25 \%$ \\
\hline Ácido acrílico & $50,59 \%$ & $35,69 \%$ & $37,61 \%$ & $2,51 \%$ & $3,37 \%$ & $5,81 \%$ \\
\hline $\mathrm{CO} 2$ & $47,57 \%$ & $32,09 \%$ & $33,97 \%$ & $51,88 \%$ & $45,94 \%$ & $62,29 \%$ \\
\hline CO & $19,14 \%$ & $11,23 \%$ & $11,89 \%$ & $21,51 \%$ & $19,05 \%$ & $26,06 \%$ \\
\hline \multicolumn{7}{|l|}{ Seletividade (\%) } \\
\hline Acetaldeído & $5,59 \%$ & $4,17 \%$ & $4,58 \%$ & $7,74 \%$ & $6,66 \%$ & $8,12 \%$ \\
\hline \multicolumn{7}{|l|}{$\begin{array}{l}\text { Metanol } \\
\text { Acroleína }\end{array}$} \\
\hline Ácido acético & $3,46 \%$ & $2,16 \%$ & $2,30 \%$ & $4,57 \%$ & $1,14 \%$ & $1,50 \%$ \\
\hline Ácido acrílico & $50,59 \%$ & $35,69 \%$ & $37,61 \%$ & $2,51 \%$ & $3,37 \%$ & $5,81 \%$ \\
\hline $\mathrm{CO}_{2}$ & $15,86 \%$ & $10,70 \%$ & $11,32 \%$ & $17,29 \%$ & $15,31 \%$ & $20,76 \%$ \\
\hline $\mathrm{CO}$ & $6,38 \%$ & $3,74 \%$ & $3,96 \%$ & $7,17 \%$ & $6,35 \%$ & $8,69 \%$ \\
\hline \multicolumn{7}{|l|}{ BALANÇO DE C, H N e O } \\
\hline $\mathrm{C}(\%)$ & $8,57 \%$ & $24,39 \%$ & $21,29 \%$ & $27,66 \%$ & $31,91 \%$ & $23,36 \%$ \\
\hline$H(\%)$ & $4,10 \%$ & $5,97 \%$ & $9,58 \%$ & $0,03 \%$ & $22,78 \%$ & $2,66 \%$ \\
\hline $\mathrm{N}(\%)$ & $1,61 \%$ & $2,14 \%$ & $2,14 \%$ & $2,72 \%$ & $2,72 \%$ & $1,78 \%$ \\
\hline $\mathrm{O}(\%)$ & $2,48 \%$ & $3,80 \%$ & $7,19 \%$ & $-1,59 \%$ & $19,59 \%$ & $1,28 \%$ \\
\hline \multicolumn{7}{|l|}{ Balanço de massa (\%) } \\
\hline & $94,99 \%$ & $93,12 \%$ & $89,61 \%$ & $98,30 \%$ & $75,71 \%$ & $95,48 \%$ \\
\hline
\end{tabular}

Fonte: Autor 
Tabela 30 - Cálculos de conversão e seletividade para as reações com glicerol (1)

\begin{tabular}{|c|c|c|c|c|c|c|}
\hline \multicolumn{7}{|l|}{ Dados gerais do ensaio } \\
\hline $\begin{array}{c}\text { Catalisador } \\
\text { Reagente } \\
\text { Amostra }\end{array}$ & $\begin{array}{l}\text { B1-EV } \\
\text { Glicerol } \\
60 \text { min }\end{array}$ & $\begin{array}{l}\text { B2-EV } \\
\text { Glicerol } \\
60 \text { min }\end{array}$ & $\begin{array}{l}\text { B3-EV } \\
\text { Glicerol } \\
60 \text { min }\end{array}$ & $\begin{array}{l}\text { B1-TH } \\
\text { Glicerol } \\
60 \text { min }\end{array}$ & $\begin{array}{l}\text { B2-TH } \\
\text { Glicerol } \\
60 \text { min }\end{array}$ & $\begin{array}{l}\text { B3-TH } \\
\text { Glicerol } \\
60 \text { min }\end{array}$ \\
\hline Áreas Obtidas no CG & 0 & 0 & 0 & 0 & 0 & 0 \\
\hline FID - líquido & 0 & 0 & 0 & 0 & 0 & 0 \\
\hline Acetaldeído - 2,011 & 57085,4 & 19232,2 & 54727,9 & 62967,8 & 61234,2 & 76117,2 \\
\hline Metanol - 2,318 & 116570,1 & 14264,9 & 114775,1 & 106957,5 & 53497,3 & 124763 \\
\hline Acroleína - 2,851 & 92517,2 & 22646,1 & 311431,9 & 132888 & 121437,2 & 211001,3 \\
\hline Ac. Acético - 7,947 & 196190,9 & 117908,4 & 47755,9 & 186132,6 & 179643,9 & 169742,4 \\
\hline Desconhecido - 8,726 & 0 & 0 & 3334,7 & 0 & 0 & 0 \\
\hline Ac. Acrílico - 9,450 & 51784 & 0 & 0 & 30974,4 & 9764,7 & 6140,2 \\
\hline Etilenoglicol - 10,073 & 1301282,1 & 1868240,8 & 2395334 & 938138,7 & 794138,2 & 923190,7 \\
\hline FID - gás & 0 & 0 & 0 & 0 & 0 & 0 \\
\hline Desconhecido - 1,5 & 816,9 & 0 & 0 & 1255,8 & 0 & 851,5 \\
\hline Desconhecido - 1,5 & 1622,1 & 3887,3 & 0 & 800,8 & 2915,7 & 1701,9 \\
\hline Acetaldeído - 2,010 & 8825 & 8658,7 & 83,7 & 14701,6 & 14413,4 & 9739,9 \\
\hline Desconhecido - 2,280 & 0 & 0 & 0 & 0 & 0 & 0 \\
\hline Acroleína - 2,856 & 64499,1 & 21297,6 & 552,1 & 73374,1 & 58602 & 166665,9 \\
\hline TCD - gás & 0 & 0 & 0 & 0 & 0 & 0 \\
\hline $02-0,667$ & 85918,3 & 43805,8 & 47009,8 & 45283,2 & 55289 & 67486 \\
\hline N2 - 0,748 & 989345,2 & 977651,1 & 988882,3 & 1041347,2 & 976083,8 & 1008976,3 \\
\hline $\mathrm{CO}-1,326$ & 22876,3 & 38478 & 23818,2 & 28073,6 & 29349,7 & 42242,9 \\
\hline $\mathrm{N} 2+\mathrm{O} 2-5,151$ & 686272,8 & 694126,1 & 654256,1 & 697597,4 & 660487,6 & 688405 \\
\hline CO2 $1-5,894$ & 56477,4 & 90135,5 & 81433,7 & 72039,7 & 76991,1 & 67459,1 \\
\hline CO2 2 - 9,312 & 83463,7 & 87104,6 & 113469,8 & 94412,1 & 115501,9 & 101076,1 \\
\hline Desconhecido - 14,001 & 1485,8 & 0 & 4548,2 & 0 & 0 & 0 \\
\hline Cálculos & $\mathbf{0}$ & $\mathbf{0}$ & $\mathbf{0}$ & $\mathbf{0}$ & $\mathbf{0}$ & $\mathbf{0}$ \\
\hline \multicolumn{7}{|l|}{ Conversão (\%) } \\
\hline Conversão Acroleína (\%) & $100,00 \%$ & $100,00 \%$ & $100,00 \%$ & $100,00 \%$ & $100,00 \%$ & $100,00 \%$ \\
\hline Conversão $\mathrm{O} 2$ (\%) & $38,87 \%$ & $68,23 \%$ & $65,63 \%$ & $67,97 \%$ & $59,62 \%$ & $52,81 \%$ \\
\hline \multicolumn{7}{|l|}{ Rendimento (\%) } \\
\hline Acetaldeído & $1,88 \%$ & $0,57 \%$ & $1,93 \%$ & $2,43 \%$ & $2,72 \%$ & $2,62 \%$ \\
\hline Metanol & $0,00 \%$ & $0,00 \%$ & $0,00 \%$ & $0,00 \%$ & $0,00 \%$ & $0,00 \%$ \\
\hline Acroleína & $3,68 \%$ & $1,04 \%$ & $6,79 \%$ & $5,93 \%$ & $4,92 \%$ & $9,11 \%$ \\
\hline Ácido acético & $6,53 \%$ & $3,55 \%$ & $1,70 \%$ & $7,27 \%$ & $8,05 \%$ & $5,90 \%$ \\
\hline Ácido acrílico & $1,08 \%$ & $0,00 \%$ & $0,00 \%$ & $0,76 \%$ & $0,27 \%$ & $0,13 \%$ \\
\hline $\mathrm{CO} 2$ & $84,35 \%$ & $145,74 \%$ & $42,04 \%$ & $144,65 \%$ & $114,89 \%$ & $99,03 \%$ \\
\hline CO & $24,40 \%$ & $44,43 \%$ & $8,78 \%$ & $40,25 \%$ & $31,27 \%$ & $44,28 \%$ \\
\hline \multicolumn{7}{|l|}{ Seletividade (\%) } \\
\hline $\begin{array}{l}\text { Acetaldeído } \\
\text { Metanol }\end{array}$ & $1,25 \%$ & $0,38 \%$ & $1,28 \%$ & $1,62 \%$ & $1,81 \%$ & $1,74 \%$ \\
\hline Acroleína & $3,68 \%$ & $1,04 \%$ & $6,79 \%$ & $5,93 \%$ & $4,92 \%$ & $9,11 \%$ \\
\hline Ácido acético & $4,36 \%$ & $2,37 \%$ & $1,13 \%$ & $4,85 \%$ & $5,37 \%$ & $3,93 \%$ \\
\hline Ácido acrílico & $1,08 \%$ & $0,00 \%$ & $0,00 \%$ & $0,76 \%$ & $0,27 \%$ & $0,13 \%$ \\
\hline $\mathrm{CO} 2$ & $28,12 \%$ & $48,58 \%$ & $14,01 \%$ & $48,22 \%$ & $38,30 \%$ & $33,01 \%$ \\
\hline CO & $8,13 \%$ & $14,81 \%$ & $2,93 \%$ & $13,42 \%$ & $10,42 \%$ & $14,76 \%$ \\
\hline BALANÇO DE C, H N e O & 0 & 0 & 0 & 0 & 0 & 0 \\
\hline $\mathrm{C}(\%)$ & $53,39 \%$ & $32,82 \%$ & $73,86 \%$ & $25,21 \%$ & $38,91 \%$ & $37,31 \%$ \\
\hline H (\%) & $-5,12 \%$ & $31,55 \%$ & $-0,10 \%$ & $0,94 \%$ & $0,52 \%$ & $13,59 \%$ \\
\hline N (\%) & $0,53 \%$ & $-0,18 \%$ & $-2,16 \%$ & $-4,10 \%$ & $-0,75 \%$ & $0,31 \%$ \\
\hline $\mathrm{O}(\%)$ & $-6,21 \%$ & $27,96 \%$ & $-1,41 \%$ & $1,99 \%$ & $-0,36 \%$ & $11,59 \%$ \\
\hline \multirow{2}{*}{\multicolumn{7}{|c|}{ Balanço de massa (\%) }} \\
\hline & $103,14 \%$ & $67,03 \%$ & $98,24 \%$ & $97,27 \%$ & $97,61 \%$ & $84,75 \%$ \\
\hline
\end{tabular}

Fonte: Autor 
Tabela 31 - Cálculos de conversão e seletividade para as reações com glicerol (2)

\begin{tabular}{|c|c|c|c|c|c|c|}
\hline \multicolumn{7}{|l|}{ Dados gerais do ensaio } \\
\hline $\begin{array}{l}\text { Catalisador } \\
\text { Reagente } \\
\text { Amostra }\end{array}$ & $\begin{array}{c}\text { B1-EV+TH } \\
\text { Glicerol } \\
60 \text { min }\end{array}$ & $\begin{array}{c}\text { B2-EV+TH } \\
\text { Glicerol } \\
60 \text { min }\end{array}$ & $\begin{array}{c}\text { B3-EV+TH } \\
\text { Glicerol } \\
60 \text { min }\end{array}$ & $\begin{array}{l}\text { B1-P123-F } \\
\text { Glicerol } \\
60 \mathrm{~min}\end{array}$ & $\begin{array}{c}\text { B1.2-EV+TH } \\
\text { Glicerol } \\
60 \mathrm{~min}\end{array}$ & $\begin{array}{c}\text { B1.3-EV+TH } \\
\text { Glicerol } \\
60 \text { min }\end{array}$ \\
\hline Áreas Obtidas no CG & $\mathbf{0}$ & $\mathbf{0}$ & $\mathbf{0}$ & 0 & $\mathbf{0}$ & $\mathbf{0}$ \\
\hline FID - líquido & 0 & 0 & 0 & 0 & 0 & 0 \\
\hline Acetaldeído - 2,011 & 23199,1 & 108033,7 & 97653,9 & 64576,4 & 55138,3 & 79849,8 \\
\hline Metanol - 2,318 & 123133 & 56499,9 & 108798,8 & 132553,1 & 86841,9 & 99848,4 \\
\hline Acroleína - 2,851 & 106244,3 & 241583,5 & 390050,8 & 186511,3 & 173478 & 211355 \\
\hline Ac. Acético - 7,947 & 275456 & 179426,6 & 242788,6 & 96276 & 196754,7 & 198166,7 \\
\hline Desconhecido - 8,726 & 0 & 0 & 0 & 0 & 0 & 0 \\
\hline Ac. Acrílico - 9,450 & 148195,2 & 17806,9 & 25521,9 & 8561,6 & 103977,5 & 23995,3 \\
\hline Etilenoglicol - 10,073 & 905410,9 & 1164391,5 & 1004260 & 603390,1 & 917102,8 & 944923,7 \\
\hline FID - gás & 0 & 0 & 0 & 0 & 0 & 0 \\
\hline Desconhecido - 1,5 & 1289,3 & 2607,6 & 1250 & 947,8 & 415,4 & 11088,4 \\
\hline Desconhecido - 1,5 & 1634,7 & 3947,3 & 1191,9 & 0 & 101,6 & 0 \\
\hline Acetaldeído - 2,010 & 5381 & 25541,4 & 13726,1 & 10788 & 1606,3 & 21082,7 \\
\hline Desconhecido - 2,280 & 1494,2 & 1985,5 & 0 & 0 & 254,2 & 844,7 \\
\hline Acroleína - 2,856 & 18232,5 & 146826,7 & 96138,3 & 75812,1 & 11210,9 & 126480 \\
\hline TCD - gás & 0 & 0 & 0 & 0 & 0 & 0 \\
\hline $02-0,667$ & 58950,6 & 67241,6 & 49504,9 & 87176 & 51829,3 & 42830,9 \\
\hline N2 - 0,748 & 990319,4 & 1423237,5 & 1009691 & 1033101,6 & 1078725,5 & 994735,8 \\
\hline $\mathrm{CO}-1,326$ & 47082,1 & 50580,8 & 55798,1 & 11962,4 & 51431,6 & 47390,7 \\
\hline $\mathrm{N} 2+\mathrm{O} 2-5,151$ & 681976,7 & 966312,9 & 692423,1 & 698282,5 & 729129,9 & 665086,8 \\
\hline CO2 $1-5,894$ & 72155,2 & 116729,3 & 59987,5 & 53777,4 & 66744,5 & 72788,8 \\
\hline CO2 2 - 9,312 & 103083,3 & 179418 & 78844,8 & 69456,3 & 88185,3 & 89004,5 \\
\hline Desconhecido - 14,001 & 0 & 0 & 0 & 0 & 0 & 0 \\
\hline Cálculos & $\mathbf{0}$ & $\mathbf{0}$ & $\mathbf{0}$ & $\mathbf{0}$ & 0 & $\mathbf{0}$ \\
\hline \multicolumn{7}{|l|}{ Conversão (\%) } \\
\hline Conversão Acroleína (\%) & $100,00 \%$ & $100,00 \%$ & $100,00 \%$ & $100,00 \%$ & $99,86 \%$ & $99,99 \%$ \\
\hline Conversão O2 (\%) & $58,04 \%$ & $66,13 \%$ & $64,60 \%$ & $39,50 \%$ & $65,14 \%$ & $68,94 \%$ \\
\hline \multicolumn{7}{|l|}{ Rendimento (\%) } \\
\hline Acetaldeído & $0,90 \%$ & $3,61 \%$ & $3,88 \%$ & $3,41 \%$ & $2,19 \%$ & $2,98 \%$ \\
\hline Metanol & $0,00 \%$ & $0,00 \%$ & $0,00 \%$ & $0,00 \%$ & $0,00 \%$ & $0,00 \%$ \\
\hline Acroleína & $3,07 \%$ & $8,96 \%$ & $12,42 \%$ & $8,79 \%$ & $4,60 \%$ & $8,81 \%$ \\
\hline Ácido acético & $10,75 \%$ & $6,06 \%$ & $9,75 \%$ & $5,14 \%$ & $7,91 \%$ & $7,47 \%$ \\
\hline Ácido acrílico & $3,61 \%$ & $0,38 \%$ & $0,64 \%$ & $0,29 \%$ & $2,61 \%$ & $0,56 \%$ \\
\hline $\mathrm{CO} 2$ & $111,93 \%$ & $120,12 \%$ & $95,63 \%$ & $100,32 \%$ & $99,73 \%$ & $124,27 \%$ \\
\hline CO & $52,15 \%$ & $37,17 \%$ & $63,51 \%$ & $15,93 \%$ & $54,87 \%$ & $57,77 \%$ \\
\hline \multicolumn{7}{|l|}{ Seletividade (\%) } \\
\hline $\begin{array}{c}\text { Acetaldeído } \\
\text { Metanol }\end{array}$ & $0,60 \%$ & $2,41 \%$ & $2,59 \%$ & $2,28 \%$ & $1,46 \%$ & $1,99 \%$ \\
\hline Acroleína & $3,07 \%$ & $8,96 \%$ & $12,42 \%$ & $8,79 \%$ & $4,60 \%$ & $8,81 \%$ \\
\hline Ácido acético & $7,17 \%$ & $4,04 \%$ & $6,50 \%$ & $3,43 \%$ & $5,27 \%$ & $4,98 \%$ \\
\hline Ácido acrílico & $3,61 \%$ & $0,38 \%$ & $0,64 \%$ & $0,29 \%$ & $2,61 \%$ & $0,56 \%$ \\
\hline $\mathrm{CO} 2$ & $37,31 \%$ & $40,04 \%$ & $31,88 \%$ & $33,44 \%$ & $33,24 \%$ & $41,42 \%$ \\
\hline $\mathrm{CO}$ & $17,38 \%$ & $12,39 \%$ & $21,17 \%$ & $5,31 \%$ & $18,29 \%$ & $19,26 \%$ \\
\hline BALANÇO DE C, H N e O & 0 & 0 & 0 & $\mathbf{0}$ & 0 & 0 \\
\hline $\mathrm{C}(\%)$ & $30,87 \%$ & $31,78 \%$ & $24,81 \%$ & $46,47 \%$ & $34,47 \%$ & $22,98 \%$ \\
\hline$H(\%)$ & $0,29 \%$ & $1,24 \%$ & $2,17 \%$ & $-1,21 \%$ & $2,68 \%$ & $-2,48 \%$ \\
\hline $\mathrm{N}(\%)$ & $0,39 \%$ & $-1,30 \%$ & $-2,02 \%$ & $-1,32 \%$ & $-2,52 \%$ & $-1,93 \%$ \\
\hline 0 (\%) & $-0,69 \%$ & $0,72 \%$ & $2,45 \%$ & $-1,72 \%$ & $2,79 \%$ & $-1,99 \%$ \\
\hline \multicolumn{7}{|l|}{ Balanço de massa (\%) } \\
\hline & $98,14 \%$ & $96,79 \%$ & $96,24 \%$ & $99,48 \%$ & $95,74 \%$ & $100,59 \%$ \\
\hline
\end{tabular}

Fonte: Autor 
Tabela 32 - Dados de conversão e seletividade para os testes com acroleína sem catalisador

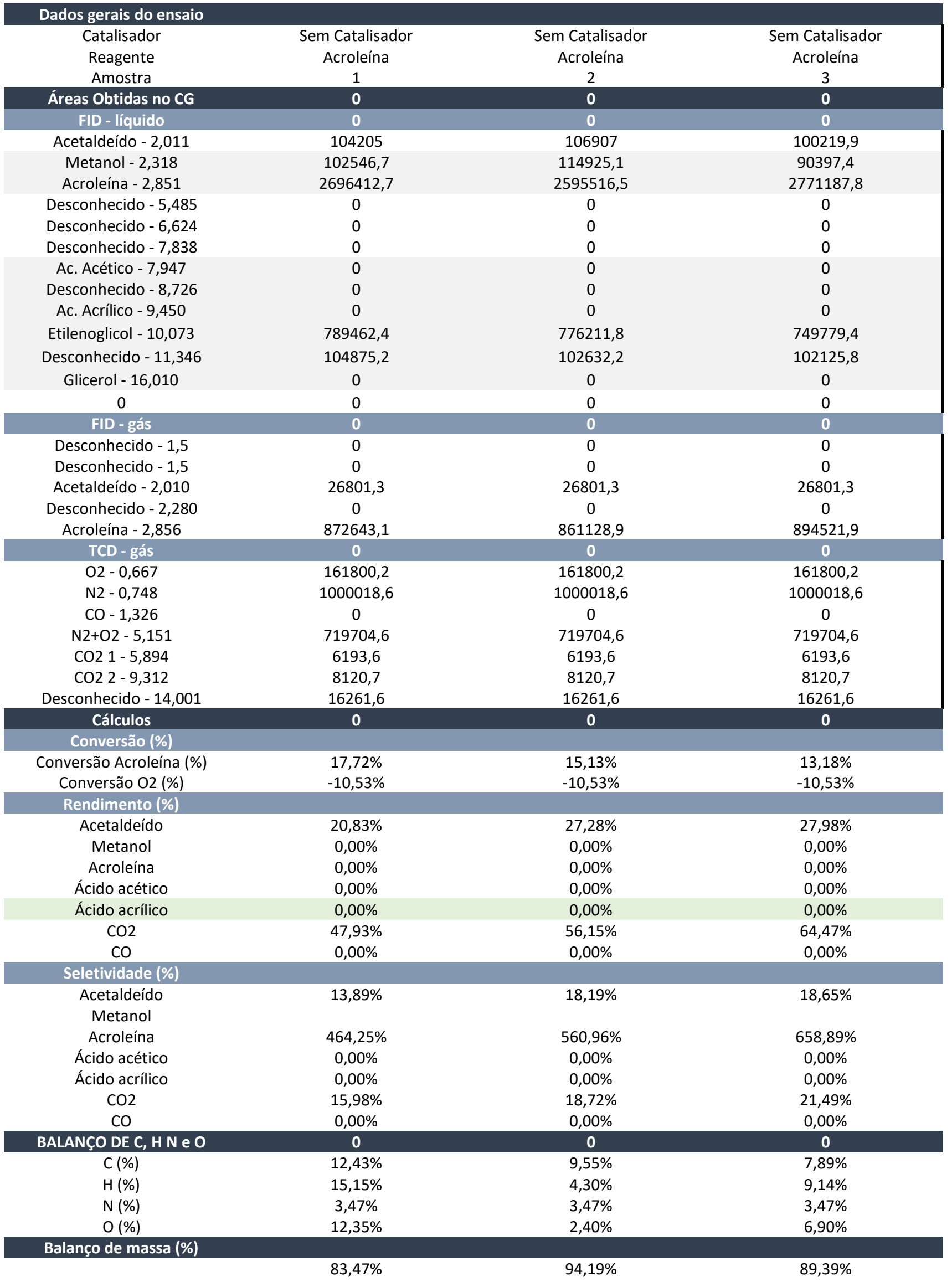

Fonte: Autor 
Tabela 33 - Dados de conversão e seletividade para os testes com glicerol sem catalisador

\begin{tabular}{|c|c|c|c|}
\hline \multicolumn{4}{|l|}{ Dados gerais do ensaio } \\
\hline Catalisador & Sem Catalisador & Sem Catalisador & Sem Catalisador \\
\hline Reagente & Glicerol & Glicerol & Glicerol \\
\hline Amostra & 2 & 3 & 4 \\
\hline Áreas Obtidas no CG & 0 & 0 & 0 \\
\hline FID - líquido & 0 & 0 & 0 \\
\hline Acetaldeído - 2,011 & 28205,1 & 48032,8 & 38291 \\
\hline Metanol - 2,318 & 93180,9 & 132452,3 & 31384 \\
\hline Acroleína - 2,851 & 33653,5 & 78974 & 48670,4 \\
\hline Desconhecido - 5,485 & 14488,4 & 17365,9 & 14868,5 \\
\hline Desconhecido - 6,624 & 6011,3 & 6905 & 0 \\
\hline Desconhecido - 7,838 & 30481,8 & 28819,7 & 27724 \\
\hline Ac. Acético - 7,947 & 21929,1 & 25199,8 & 21738,6 \\
\hline Desconhecido - 8,726 & 10166,4 & 10406,6 & 8452,6 \\
\hline Ac. Acrílico - 9,450 & 0 & 9551,4 & 8080,4 \\
\hline Etilenoglicol - 10,073 & 1152476,4 & 980190,3 & 752018,4 \\
\hline Desconhecido - 11,346 & 44128,6 & 40933,5 & 36447,9 \\
\hline Glicerol - 16,010 & 857413,5 & 1216494,5 & 952447 \\
\hline 0 & 0 & 0 & 0 \\
\hline FID - gás & 0 & 0 & 0 \\
\hline Desconhecido - 1,5 & 0 & 0 & 0 \\
\hline Desconhecido - 1,5 & 657,1 & 657,1 & 657,1 \\
\hline Acetaldeído - 2,010 & 6923 & 6923 & 6923 \\
\hline Desconhecido - 2,280 & 0 & 0 & 0 \\
\hline Acroleína - 2,856 & 21961,1 & 21961,1 & 21961,1 \\
\hline TCD - gás & 0 & 0 & 0 \\
\hline $02-0,667$ & 95250,2 & 95250,2 & 95250,2 \\
\hline$N 2-0,748$ & 1028377,3 & 1028377,3 & 1028377,3 \\
\hline $\mathrm{CO}-1,326$ & 6185,3 & 6185,3 & 6185,3 \\
\hline $\mathrm{N} 2+\mathrm{O} 2-5,151$ & 700580,8 & 700580,8 & 700580,8 \\
\hline CO2 $1-5,894$ & 53276,2 & 53276,2 & 53276,2 \\
\hline $\operatorname{co} 22-9,312$ & 63426,6 & 63426,6 & 63426,6 \\
\hline Desconhecido - 14,001 & 0 & 0 & 0 \\
\hline Cálculos & 0 & 0 & 0 \\
\hline \multicolumn{4}{|l|}{ Conversão (\%) } \\
\hline Conversão Acroleína (\%) & $81,46 \%$ & $71,47 \%$ & $73,05 \%$ \\
\hline Conversão O2 (\%) & $34,06 \%$ & $34,06 \%$ & $34,06 \%$ \\
\hline \multicolumn{4}{|l|}{ Rendimento (\%) } \\
\hline Acetaldeído & $1,18 \%$ & $2,49 \%$ & $2,34 \%$ \\
\hline Metanol & $0,00 \%$ & $0,00 \%$ & $0,00 \%$ \\
\hline Acroleína & $1,65 \%$ & $3,42 \%$ & $2,71 \%$ \\
\hline Ácido acético & $0,93 \%$ & $1,32 \%$ & $1,34 \%$ \\
\hline Ácido acrílico & $0,00 \%$ & $0,31 \%$ & $0,31 \%$ \\
\hline $\mathrm{CO} 2$ & $99,13 \%$ & $113,00 \%$ & $110,55 \%$ \\
\hline $\mathrm{CO}$ & $8,22 \%$ & $9,37 \%$ & $9,16 \%$ \\
\hline \multicolumn{4}{|l|}{ Seletividade (\%) } \\
\hline $\begin{array}{c}\text { Acetaldeído } \\
\text { Metanol }\end{array}$ & $0,79 \%$ & $1,66 \%$ & $1,56 \%$ \\
\hline Acroleína & $1,65 \%$ & $3,42 \%$ & $2,71 \%$ \\
\hline Ácido acético & $0,62 \%$ & $0,88 \%$ & $0,89 \%$ \\
\hline Ácido acrílico & $0,00 \%$ & $0,31 \%$ & $0,31 \%$ \\
\hline $\mathrm{CO} 2$ & $33,04 \%$ & $37,67 \%$ & $36,85 \%$ \\
\hline $\mathrm{CO}$ & $2,74 \%$ & $3,12 \%$ & $3,05 \%$ \\
\hline BALANÇO DE C, H N e O & 0 & 0 & 0 \\
\hline$C(\%)$ & $49,82 \%$ & $37,84 \%$ & $39,90 \%$ \\
\hline $\mathrm{H}(\%)$ & $7,37 \%$ & $-2,18 \%$ & $-8,36 \%$ \\
\hline $\mathrm{N}(\%)$ & $-0,61 \%$ & $-0,61 \%$ & $-0,61 \%$ \\
\hline $\mathrm{O}(\%)$ & $5,69 \%$ & $-2,86 \%$ & $-8,57 \%$ \\
\hline \multicolumn{4}{|l|}{ Balanço de massa (\%) } \\
\hline & $91,12 \%$ & $100,79 \%$ & $106,66 \%$ \\
\hline
\end{tabular}

Fonte: Autor 


\section{ANEXO A - REFERÊNCIAS DE APOIO PARA ANALISES DE FTIR E DRX}

Figura 55 - Bandas características de diferentes molibdatos metálicos

\begin{tabular}{|c|c|c|c|c|c|c|c|c|}
\hline $\mathrm{K}_{2} \mathrm{MoO}_{4}$ & $\mathrm{Rb}_{2} \mathrm{MoO}_{4}$ & $\mathrm{Cs}_{2} \mathrm{MoO}_{4}$ & $\mathrm{Zr}\left(\mathrm{MoO}_{4}\right)_{2}$ & $\mathrm{Hf}\left(\mathrm{MoO}_{4}\right)_{2}$ & $\mathrm{VMoO}_{5}$ & $\mathrm{Cr}_{2}\left(\mathrm{MoO}_{4}\right)_{3}$ & $\mathrm{CuMoO}_{4}$ & $\mathrm{ZnMoO}_{4}$ \\
\hline $\begin{array}{l}1765 \mathrm{vw} \\
1705 \mathrm{vw} \\
1650 \mathrm{vw}, \mathrm{sh} \\
1110 \mathrm{vw}, \mathrm{sp}\end{array}$ & $1640 \mathrm{vw}$ & $\begin{array}{l}1110 \mathrm{~m}, \mathrm{sp} \\
1090 \mathrm{~m}, \mathrm{sp} \\
1085 \mathrm{~m}, \mathrm{sp}\end{array}$ & & & & & & \\
\hline & & & & $\begin{array}{c}1020 \mathrm{w} \\
925 \mathrm{~s}\end{array}$ & $970 \mathrm{~s}$ & $\begin{array}{l}970 \mathrm{~s} \\
930 \mathrm{~s}\end{array}$ & $\begin{array}{l}990 \mathrm{w}, \mathrm{sh} \\
950 \mathrm{~s} \\
905 \mathrm{~m}\end{array}$ & $\begin{array}{l}985 \mathrm{w}, \mathrm{sh} \\
950 \mathrm{~s}\end{array}$ \\
\hline 830 is & $825 \mathrm{~s}$ & $\begin{array}{l}870 \mathrm{~s} \\
820 \mathrm{~s}\end{array}$ & $c a .800 \mathrm{~g}, \mathrm{vb}$ & $815 \mathrm{~s}$ & $840 \mathrm{~s}$ & $850 \mathrm{~s}, \mathrm{~b}$ & $\begin{array}{l}880 \mathrm{~m} \\
845 \mathrm{~m} \\
825 \mathrm{~m}\end{array}$ & $\begin{array}{l}890 \mathrm{~m} \\
865 \mathrm{~m}\end{array}$ \\
\hline & & & & $610 \mathrm{vw}$ & & $\begin{array}{l}770 \mathrm{~s} \\
610 \mathrm{w}\end{array}$ & $\begin{array}{l}790 \mathrm{~m} \\
725 \mathrm{~s}\end{array}$ & $750 \mathrm{~s}$ \\
\hline $485 \mathrm{vw}$ & $\begin{array}{l}335 \mathrm{~m}, \mathrm{sh} \\
315 \mathrm{~s}, \mathrm{~b}\end{array}$ & $\begin{array}{l}335 \mathrm{~m} \\
312 \mathrm{~s}\end{array}$ & $345 \mathrm{~s}, \mathrm{~b}$ & $\begin{array}{l}515 \mathrm{w} \\
325 \mathrm{~m}\end{array}$ & $\begin{array}{l}540 \mathrm{w} \\
390 \mathrm{~s} \\
350 \mathrm{~m}\end{array}$ & $\begin{array}{l}555 \mathrm{w} \\
380 \mathrm{~m}, \mathrm{vb}\end{array}$ & $485 \mathrm{w}$ & $\begin{array}{l}435 \mathrm{~m} \\
335 \mathrm{~m}\end{array}$ \\
\hline $310 \mathrm{w}$ & & $303 \mathrm{~m}, \mathrm{sh}$ & $\begin{array}{l}290 \mathrm{~m} \\
280 \mathrm{~m} \\
250 \mathrm{~s}\end{array}$ & $\begin{array}{l}290 \mathrm{~s} \\
275 \mathrm{~m}\end{array}$ & $\begin{array}{l}300 \mathrm{~m} \\
275 \mathrm{~m}\end{array}$ & $\begin{array}{l}310 \mathrm{~m} \\
250 \mathrm{~m}\end{array}$ & $\begin{array}{l}290 \mathrm{vw} \\
260 \mathrm{vw}\end{array}$ & $\begin{array}{l}310 \mathrm{~m}, \mathrm{~b} \\
290 \mathrm{w}\end{array}$ \\
\hline
\end{tabular}

Fonte, CLARK, DOYLE, 1965.

Figura 56 - Bandas características de diferentes tungstatos metálicos

\begin{tabular}{|c|c|c|c|c|c|c|}
\hline $\mathrm{K}_{\mathrm{a}} \mathrm{WO}_{4}$ & $\mathrm{Rb}_{2} \mathrm{WO}_{4}$ & $\mathrm{Cs}_{2} \mathrm{WO}_{4}$ & $\mathrm{Cr}_{2} \mathrm{WO}_{6}$ & $\mathrm{CuWO}_{4}$ & $\mathrm{Ag}_{8} \mathrm{WO}_{4}$ & $\mathrm{CdWO}_{4}$ \\
\hline $\begin{array}{l}1800 \mathrm{w} \\
1745 \mathrm{w} \\
1650 \mathrm{w} \\
1110 \mathrm{w}, \mathrm{sp} \\
1095 \mathrm{w}, \mathrm{sp}\end{array}$ & $\begin{array}{l}1790 \mathrm{w} \\
1740 \mathrm{w} \\
1640 \mathrm{w} \\
1105 \mathrm{w}, \mathrm{sp} \\
1090 \mathrm{ww}, \mathrm{sp}\end{array}$ & $\begin{array}{l}1740 \mathrm{vw} \\
1640 \mathrm{vw} \\
1110 \mathrm{w}, \mathrm{sp} \\
1095 \mathrm{w}, \mathrm{sp} \\
1090 \mathrm{w}, \mathrm{sp}\end{array}$ & & & & \\
\hline & & & $\begin{array}{l}975 \mathrm{w} \\
940 \mathrm{w} \\
020 \mathrm{w} \\
895 \mathrm{vw}\end{array}$ & $910 \mathrm{~s}$ & $\begin{array}{l}975 \mathrm{w} \\
020 \mathrm{w} \\
900 \mathrm{w} \\
870 \mathrm{~m}\end{array}$ & $885 \mathrm{~s}$ \\
\hline $830 \mathrm{~s}$ & 835 a & $830 \mathrm{a}$ & $\begin{array}{r}770 \mathrm{~m}, \mathrm{sh} \\
c a .600 \mathrm{~s}, \mathrm{vb}\end{array}$ & $\begin{array}{l}800 \mathrm{a} \\
740 \mathrm{~s} \\
605 \mathrm{~m}\end{array}$ & $\begin{array}{l}800 \mathrm{a} \\
740 \mathrm{~m} \\
680 \mathrm{w} \\
630 \mathrm{w}\end{array}$ & $\begin{array}{l}835 \mathrm{~s} \\
700 \mathrm{~g}\end{array}$ \\
\hline & & & $535 \mathrm{w}$ & $550 \mathrm{~m}$ & $570 \mathrm{~m}$ & $\begin{array}{l}560 \mathrm{~m} \\
505 \mathrm{~m} \\
455 \mathrm{~m} \\
410 \mathrm{~m}\end{array}$ \\
\hline $315 \mathrm{~s}$ & & $340 \mathrm{w}$ & $365 \mathrm{~s}, \mathrm{~b}$ & $\begin{array}{l}375 \mathrm{~m} \\
340 \mathrm{~g}\end{array}$ & $\begin{array}{l}380 \mathrm{~m} \\
335 \mathrm{~m}\end{array}$ & $\begin{array}{l}355 \mathrm{~s} \\
310 \mathrm{~s}, \mathrm{vb}\end{array}$ \\
\hline $295 \mathrm{~m}$ & $290 \mathrm{~s}, \mathrm{vb}$ & $290 \mathrm{~m}$ & $295 \mathrm{~s}, \mathrm{~b}$ & $\begin{array}{l}290 \mathrm{~m} \\
270 \mathrm{~m}\end{array}$ & & \\
\hline
\end{tabular}

Fonte: CLARK, DOYLE, 1965 